\title{
High-sensitivity cardiac troponin assays : laboratory and clinical aspects
}

Citation for published version (APA):

Mingels, A. M. A. (2012). High-sensitivity cardiac troponin assays : laboratory and clinical aspects. [Doctoral Thesis, Maastricht University]. Datawyse / Universitaire Pers Maastricht. https://doi.org/10.26481/dis.20120203am

Document status and date:

Published: 01/01/2012

DOI:

10.26481/dis.20120203am

Document Version:

Publisher's PDF, also known as Version of record

\section{Please check the document version of this publication:}

- A submitted manuscript is the version of the article upon submission and before peer-review. There can be important differences between the submitted version and the official published version of record.

People interested in the research are advised to contact the author for the final version of the publication, or visit the DOI to the publisher's website.

- The final author version and the galley proof are versions of the publication after peer review.

- The final published version features the final layout of the paper including the volume, issue and page numbers.

Link to publication

\footnotetext{
General rights rights.

- You may freely distribute the URL identifying the publication in the public portal. please follow below link for the End User Agreement:

www.umlib.nl/taverne-license

Take down policy

If you believe that this document breaches copyright please contact us at:

repository@maastrichtuniversity.nl

providing details and we will investigate your claim.
}

Copyright and moral rights for the publications made accessible in the public portal are retained by the authors and/or other copyright owners and it is a condition of accessing publications that users recognise and abide by the legal requirements associated with these

- Users may download and print one copy of any publication from the public portal for the purpose of private study or research.

- You may not further distribute the material or use it for any profit-making activity or commercial gain

If the publication is distributed under the terms of Article $25 \mathrm{fa}$ of the Dutch Copyright Act, indicated by the "Taverne" license above, 


\section{High-sensitivity \\ cardiac troponin assays}

Laboratory and clinical aspects 
Cover design: Omayra Mingels, Image: Gunther von Hagens' BODY WORLDS, Institute for Plastination, Heidelberg, Germany, www.bodyworlds.com

Printed by Datawyse | Universitaire Pers Maastricht

ISBN: 9789461591098

(C) Alma M.A. Mingels, Maastricht 2012 


\title{
High-sensitivity \\ cardiac troponin assays
}

\section{Laboratory and clinical aspects}

\author{
PROEFSCHRIFT \\ ter verkrijging van de graad van doctor \\ aan de Universiteit Maastricht,
}

op gezag van de Rector Magnificus prof. mr. G.P.M.F. Mols,

volgens het besluit van het College van Decanen,

in het openbaar te verdedigen

op vrijdag 3 februari 2012 om 12.00 uur

\section{Alma Maria Alfred Mingels}

geboren op 14 november 1981 te Veldhoven

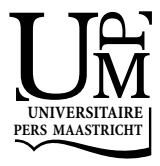




\section{Promotor}

Prof. dr. M.P. van Dieijen-Visser

\section{Copromotor}

Dr. W.K.W.H. Wodzig

\section{Beoordelingscommissie}

Prof. dr. L.J.C. van Loon (voorzitter/chair)

Prof. dr. H.-P. Brunner-La Rocca

Dr. P.O. Collinson (St George's Hospital, London, United Kingdom)

Prof. dr. H.A. Katus (Universitätsklinikum Heidelberg, Heidelberg, Germany)

Prof. dr. C.P.M. Reutelingsperger

Financial support by the Dutch Heart Foundation and the E.C. Noyons Stichting "Stichting ter bevordering van de Klinische Chemie in Nederland" for the publication of this thesis is gratefully acknowledged.

Also Abbott Diagnostics, AKSA Medical, and Roche Diagnostics are gratefully acknowledged for their financial support. 


\section{Contents}

page

List of abbreviations $\quad 6$

$\begin{array}{lll}\text { Chapter } 1 \quad \text { General introduction } & 9\end{array}$

Chapter 2 A comprehensive review of upper reference limits reported for (high-) 23 sensitivity cardiac troponin assays and the challenges that lie ahead

Chapter 3 Reference population and marathon runner sera assessed by highsensitivity cardiac troponin $\mathrm{T}$ and commercial cardiac troponin $\mathrm{T}$ and I assays

Chapter 4 Cardiac troponin T elevations, using highly sensitive assay, in recreational running depend on running distance

Chapter 5 Cystatin C, a marker for renal function after exercise

Chapter 6 Haemodialysis patients longitudinally assessed by high-sensitivity cardiac troponin $\mathrm{T}$ and commercial cardiac troponin $\mathrm{T}$ and cardiac troponin I assays

Chapter 7 The extent of coronary atherosclerosis is associated with increasing circulating levels of high-sensitivity cardiac troponin T

Chapter 8 High-sensitivity cardiac troponin T: risk stratification tool in patients with stable chest-pain

Chapter 9 Time- and temperature-dependent stability of NIST standard reference material 2921 in serum and plasma

Chapter 10 Circulating cardiac troponin T is degraded after acute myocardial infarction

Chapter 11 General discussion

Samenvatting

Summary

Dankwoord / Acknowledgment

Curriculum vitae 


\section{List of abbreviations}

a.a.r.

AKI

AMI

ACS

AUC

BMI

BNP

$B P$

CABG

CAD

CCS

CCTA

C-G

$\mathrm{Cl}$

CK

CKD

CKMB

CLSI

CT

cTn

cTnC

cTnl

cTnT

CV

$\mathrm{CV}_{\mathrm{I}}$

$\mathrm{CV}_{\mathrm{G}}$

$\mathrm{CV}_{\mathrm{A}}$

CVD

ECG

EDTA

eGFR

ESRD

EQA

FRS

GFC

GFR

HAPPY

HDL

HPLC amino acid residue

acute kidney injury

acute myocardial infarction

acute coronary syndrome

area-under-curve determined with ROC analysis

body mass index

B-type natriuretic peptide

blood pressure

coronary artery bypass grafting

coronary artery disease

coronary calcium or Agatston score

coronary / cardiac computed tomographic angiography

Cockcroft-Gault equation

confidence interval

creatine kinase

chronic kidney disease

creatine kinase muscle-brain type

clinical and laboratory standards institute

computed tomography

cardiac troponin

cardiac troponin C (similar to slow skeletal muscle)

cardiac troponin I

cardiac troponin $T$

coefficient of variation, SD / mean

within subject variation

between subjects variation

analytical variation

cardiovascular disease

electrocardiogram / electrocardiography

ethylenediaminetetraacetic acid

estimated GFR

end-stage renal disease

external quality assessment

risk score estimated in the Framingham study that predicts the 10-year risk

on cardiovascular disease

gel filtration chromatography

glomular filtration rate

healthy lifestyle program organized by our hospital: www.happyazm.nl

high-density lipoprotein

high performance liquid chromatography 


\begin{tabular}{|c|c|}
\hline HR & hazard ratio \\
\hline hs & high-sensitivity (assay) \\
\hline hsCRP & high sensitivity C-reactive protein \\
\hline hs-cTn & high-sensitivity cardiac troponin (assay) \\
\hline IC & cTn complex consisting of cTnl and cTnC \\
\hline IDI & integrated discrimination improvement \\
\hline IFCC & International Federation of Clinical Chemistry and Laboratory Medicine \\
\hline II & index of individuality \\
\hline IT & cTn complex consisting of cTnl and cTnT \\
\hline IQR & interquartile range \\
\hline LCMS & liquid chromatography online coupled to mass spectrometry \\
\hline LDH & lactate dehydrogenase \\
\hline LDL & low-density lipoprotein \\
\hline LOB & limit of blank \\
\hline LOD & limit of detection \\
\hline MCQE & Mayo Clinic Quadratic Equation \\
\hline MDRD & modification of diet in renal disease equation \\
\hline MI & myocardial infarction \\
\hline MW & molecular weight \\
\hline NACB & National Academy of Clinical Biochemistry \\
\hline NIST & National Institute of Standards and Technology \\
\hline $\mathrm{NRI}$ & net reclassification improvement \\
\hline NT-proBNP & $\mathrm{N}$-terminal pro-BNP \\
\hline PBS & phosphate buffered saline \\
\hline PBST & PBS with $0.1 \%$ Tween-20 \\
\hline $\mathrm{PCl}$ & percutaneous coronary intervention \\
\hline PROCAM & $\begin{array}{l}\text { risk score estimated in the Prospective Cardiovascular Münster study that } \\
\text { predicts the 10-year risk on AMI }\end{array}$ \\
\hline Q4 & fourth quartile \\
\hline RCV & reference change value \\
\hline $\mathrm{ROC}$ & receiver-operating-characteristic curves \\
\hline SD & standard deviation \\
\hline SKML & Dutch foundation for quality assessment in clinical laboratories \\
\hline SPPS & Statistical Package for Social Sciences \\
\hline SRM & standard reference material \\
\hline TIC & cTn complex consisting of cTnT, cTnl, and cTnC \\
\hline URL & upper reference limit \\
\hline $\mathrm{V}_{0}$ & void volume \\
\hline
\end{tabular}





\section{General introduction}

\section{Acute coronary syndrome}

\section{- Incidence of acute coronary syndromes}

A total of 40,868 subjects deceased in 2008 in the Netherlands because of cardiac or vascular disease. This is $30 \%$ of all-cause mortality, ${ }^{1}$ one of the two leading causes of death, and similar to other developed regions. ${ }^{2}$ The highest cardiac mortality rate accounted for ischemic diseases (28\%), like an acute myocardial infarction (AMI), and the relative incidence increased with age. ${ }^{1}$ A total of 345,830 subjects with cardiovascular disease were hospitalized in 2008, which is almost twice as much as in 1980. In the meanwhile, the mean length of hospitalization was drastically reduced, as were the number of subjects suffering from AMI that died while being hospitalized. Despite the impressive increase in hospitalizations, this went along with a decreasing trend in the absolute number of subjects that died from cardiovascular disease. In 2008, it was for the first that mortality rates for cardiovascular disease and malignant carcinoma were in the same order.

\section{- Definition of an acute coronary syndrome}

An acute coronary syndrome (ACS) starts with the slow development of atherosclerotic plaque in the coronary arteries (coronary artery disease, CAD) that suddenly is characterized by the rupture of the plaque and the subsequent formation of thrombus. ${ }^{3,4}$ In case the vessel becomes occluded, either partially or completely, this results in ischemia in the surrounding cardiac muscle and is diagnosed as an acute myocardial infarction (MI). ${ }^{3,5}$ For a successful survival of patients presenting at the emergency department with such lifethreatening signs, it is crucial to recognize this cardiac syndrome from other non-cardiac complications.

The diagnosis for an AMI was recently redefined by international guidelines of clinicians ${ }^{4,6}$ and laboratory scientists ${ }^{7,8}$ in: the detection of a rise and/or fall of preferably 
cardiac troponin (cTn) - (either T, cTnT or I, cTnl) - with at least one value exceeding the upper reference limit $\left(99^{\text {th }}\right.$ percentile) measured in a cardio-healthy group together with clinical (history, physical exam) and imaging (electrocardiogram, echo) findings. Blood should be obtained at hospital presentation and 6-9 hours later, as can be interpreted from the peak profile in Figure 1. If previous measurements were not elevated but the suspicion for AMI is high, serial sampling should be continued. Moreover, the upper reference limit should be measured with optimal precision defined by a coefficient of variation (CV) $<10 \%$.

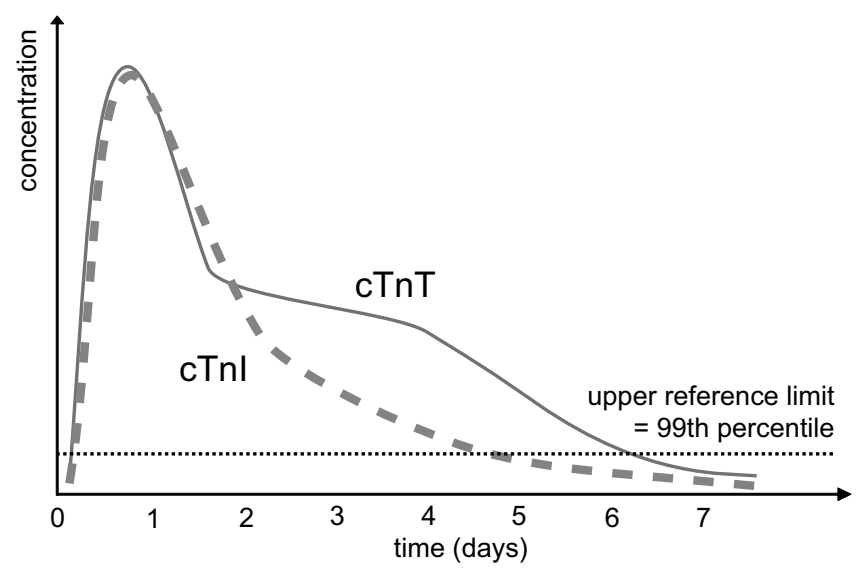

Figure 1: Release curve of cardiac troponin T (cTnT) and I (cTnl) after onset of symptoms of an acute myocardial infarction (AMI). In general, cTnT and cTnl concentrations follow a bi- and monophasic release curve, respectively, although the distinction is often not that obvious.

\section{- Treatment of an acute coronary syndrome}

Treatment of CAD aims to repair the flow in the coronary arteries and is accomplished by percutaneous coronary intervention $(\mathrm{PCI})$ or coronary artery bypass grafting (CABG). Details on revascularization are out of the scope of this thesis and are described elsewhere. ${ }^{9-12}$

\section{Troponin's release in the bloodstream, the hypothesis}

\section{- Troponins: contractile regulatory proteins}

The contractile apparatus of cardiac and skeletal muscle cells consists of thick and thin filaments organized in sarcomeres that slide along each other upon muscle contraction and relaxation, as shown in Figure 2. Thick filaments are built up from myosin, thin filaments 
from a double helix of actin, with tropomyosin wrapped around and at regular sites a troponin complex. The troponin complex is comprised of troponin C (TnC, calcium binding), troponin I (TnI, inhibitory function by blocking the myosin-actin binding site), and troponin T (TnT, location on tropomyosin). Both cTnI and cTnT isoforms are characterized by a cardiac specific N-terminal extension (Swiss-Prot, P19429 and P45379, respectively), while cTnC in cardiac and slow skeletal muscle is similar (Swiss-Prot, P63316). In addition, around $5-10 \%$ of the total cTnT and cTnl content is estimated to be present free and unbound in the cytosol, as indicated in Figure $3 \mathrm{~A}$, though the procedure of estimation ${ }^{13,14}$ has been criticized. ${ }^{6}$

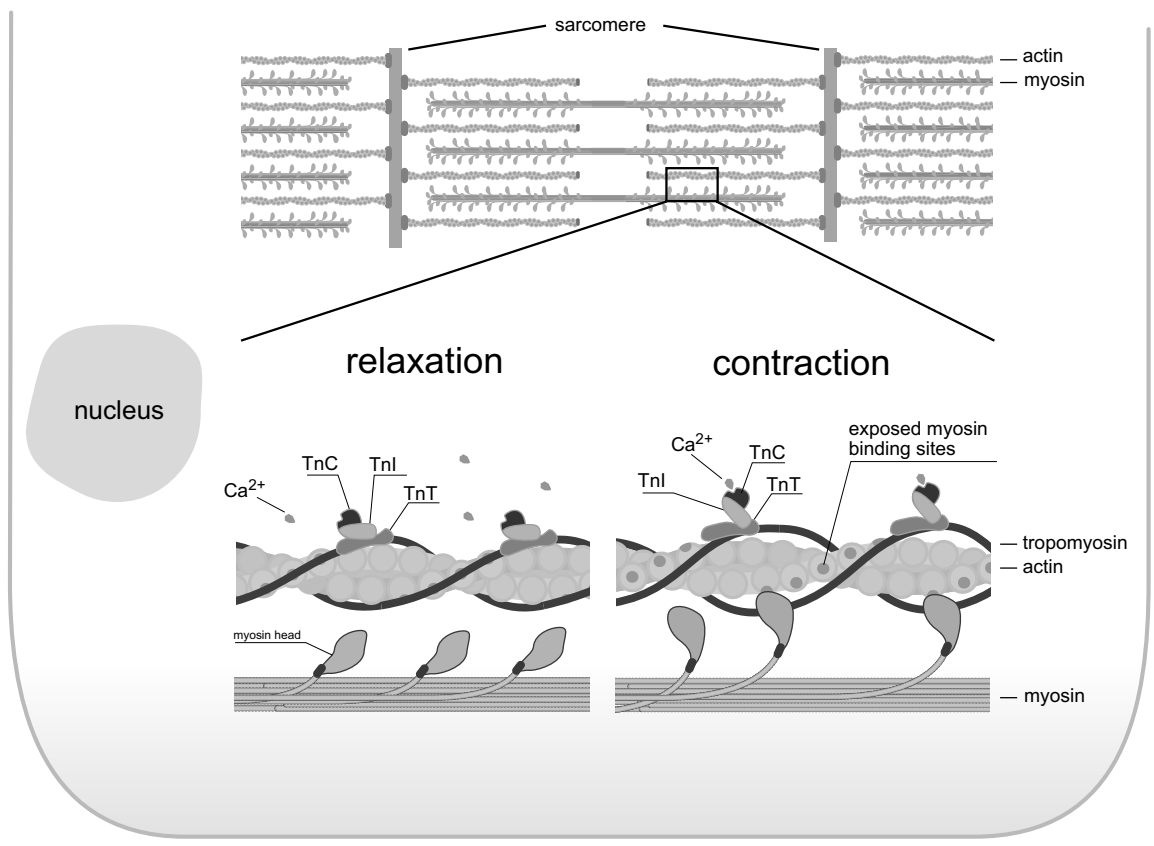

Figure 2: Structural characteristics of human myocytes with a focus on their contractile apparatus (sarcomeres) and the regulatory function of $\mathrm{cTnT}, \mathrm{cTnl}$, and cTnC upon calcium stimulation.

Upon electrical stimulation of the myocytes, a pool of calcium ions is released from mainly the sarcoplasmic reticulum into the cytosol. This change from sub-micromolar to micromolar calcium concentrations results in the adenosine-triphosphate-driven process that is illustrated in Figure 2: calcium binds to cTnC, subsequently there is a conformational change in the cTn complex and the tropomyosin location, resulting in accessible binding sites between actin and myosin, and consequently contraction of the muscles. 
The crystal structure of the core domain of the calcium-saturated human cTn complex (Protein Data Bank, 1JE1) demonstrates two distinct subdomains, the regulatory head and the cTn I-T arm, connected via flexible linkers ${ }^{15}$ as reviewed before. ${ }^{16}$ High resolution data have not been reported for the flexible and cardio-specific N-terminal sites of the cTn and for the complex in the low calcium environment. Nevertheless, experimental hydrogen/deuterium exchange in the cTn complex has added insight in the calciumdependent intra-cTn switch that regulates muscle contraction. ${ }^{17}$

\section{- Irreversible troponin release}

Serum concentrations of cTnT and cTnl in AMI patients typically show a main peak within 1 day after onset of symptoms and remain elevated for approximately 1 week, ${ }^{13,18,19}$ as depicted in Figure 1. Katus et al found that AMI patients with permanent coronary occlusion are characterized by only the second cTnT peak, while AMI patients with early reperfusion show the typical biphasic release. ${ }^{13}$ It was hypothesized that the first peak could be the relatively fast release of cytosolic cTn, while the second broader peak or plateau could be the slower dissociation of cTn from the sarcomeres (Figure $3 C$ ). It is quite remarkable, though, that this hypothesis is not given for cTnl, for which there is consensus that it is mainly present in blood in the cTnl-cTnC complex. ${ }^{19,20}$

Apart from this, we previously showed time-dependent degradation of cTnT in 20 AMI patients with no intact cTnT present anymore 12 hours after onset of symptoms. ${ }^{18}$ Langendorf-reperfusion studies in rat hearts also described the intracellular cTn degradation upon prolonged ischemia. ${ }^{21}$ This would suggest that the biphasic release kinetics might also be attributed to the different half-lives of the cTnT forms. However, since the antibodies from the Roche immunoassay measurements differed from the Western Blots, these results have been criticized and CTnT degradation has been disputed. ${ }^{20,22}$

\section{- Reversible troponin release}

Measurable cTn concentrations have occasionally been noticed without the clear evidence of AMI, among others in subjects with myocarditis or after prolonged strenuous exercise, as summarized before. ${ }^{4,23,24}$ Since the commercial cTn assays appear to be absolutely specific for myocardial tissue, ${ }^{25-27}$ this raises the possibility that cTn can be released from damaged myocytes but without typical myocardial necrosis (Figure 3B). Proposed mechanisms for this 


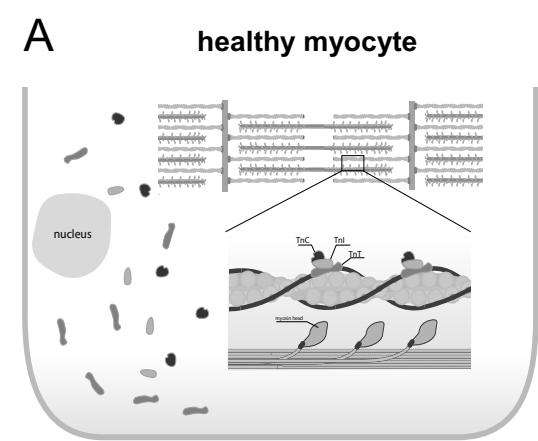

blood vessel

\section{B reversibly damaged myocyte}

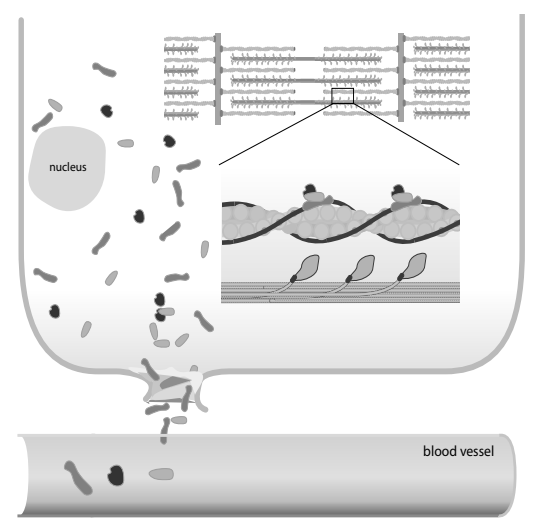

C irreversibly damaged myocyte

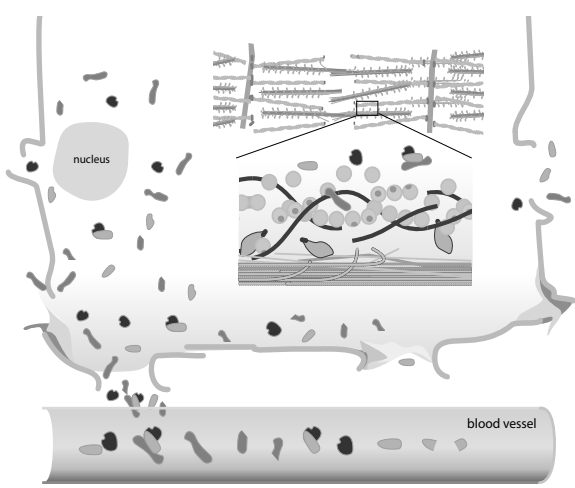

phenomenon of so called reversibly damaged myocytes are the formation of radicals ${ }^{28}$ or blebs (bubbles) $^{29}$ in the plasma membrane, among others, $^{30}$ possibly via a stretch-related mechanism mediated by integrins. ${ }^{31}$

Exercise-induced cTn elevations remain an active topic of discussion, ${ }^{32,33}$ as regular exercise belongs to a healthy life-style but endurance exercise is now and then frightened by a sudden collapse, often due to CAD, hypertrophic cardiomyopathy, or left ventricular hypertrophy. ${ }^{34-36}$ In prolonged strenuous exercise like marathon running or triathlon, cTnT concentrations are elevated in around half of the subjects but in the absence of clinical symptoms. ${ }^{24,37}$ Comparison of cTnl studies is limited, though, as discussed later on in this chapter. More research is therefore required to further understand the pathophysiology of exercise-induced cTn elevations.

Figure 3: Distribution of cTn in myocytes and the blood circulation (A) in healthy condition with cTn present in cytosol and at sarcomeres; (B) after reversible cardiac injury with leakage of cytosolic cTn, as might be after early or minor ischemia as seen post exercise; (C) after irreversible cardiac injury with break down of the whole myocyte, as seen with necrosis in AMI patients. 


\section{The recent introduction of high-sensitivity troponin assays}

Improvements have been advocated for the cTn assays for several reasons. As mentioned before, the diagnostic cut-off concentration for cTn is defined at the $99^{\text {th }}$ percentile measured in a population of cardio-healthy individuals. ${ }^{4,6-8}$ However, at the time this universal definition was published (in the year 2007), most cTn immunoassays that were commercially available were unable to detect cTn concentrations in the blood circulation of healthy individuals (Figure 4A, decision limit ' $b$ '). ${ }^{7}$ If not, these assays lacked analytical performance to measure the $99^{\text {th }}$ percentile concentration with sufficient precision (CV $<10 \%)$, as explained in Figure $4 \mathrm{~B} .{ }^{38}$ Apart from this, more than $20 \mathrm{cTnl}$ immunoassays are commercially available in contrast to the patented cTnT assay. Comparison of cTnl results among different laboratories remains therefore limited. ${ }^{38-40}$
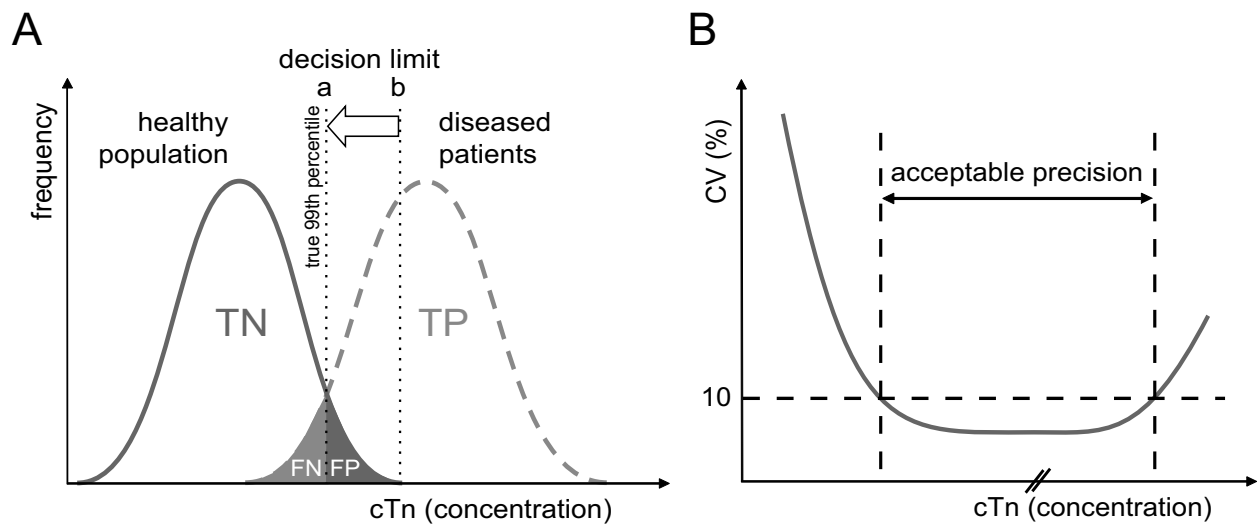

Figure 4: (A) Biomarkers within the blood circulation follow a bell-shaped gaussian distribution within a group of subjects. The diagnostic cut-off concentration for cTn is defined the $99^{\text {th }}$ percentile as measured in a healthy reference control group, so $1 \%$ of these subjects with the highest cTn concentrations are defined unhealthy. ${ }^{4,7}$ At the time of definition, cTn concentrations were undetectable in all healthy individuals, as illustrated by decision limit ' $b$ '. Improvements in the lower measuring range have lately resulted in cTn reference concentrations and thus also a true $99^{\text {th }}$ percentile concentration, as indicated by ' $a$ '. However, this improvement in sensitivity=TP/(TP+FN) goes along with a worsening of the specificity=TN/(TN+FP). TP, number of subjects that were truly assigned positive; $\mathrm{FN}$, number of subjects that were falsely assigned negative; TN, number of subjects that were truly assigned negative; FP, number of subjects that were falsely assigned positive; (B) A typical precision profile of an immunoassay. The diagnostic cutoff concentration should be measured with sufficient precision (coefficient of variation, $\mathrm{CV}=\mathrm{SD} / \mathrm{mean},<10 \%$ ). ${ }^{38}$ 


\section{- Specifications of the high-sensitivity troponin assays}

Lately, improved sensitivity and accuracy in the lower measuring range have been achieved, resulting in a new generation cTn immunoassays. These so-called high-sensitivity (hs) cTn immunoassays are characterized by measurable cTn concentrations in the blood circulation of healthy individuals. They enable the determination of the true upper reference limit $\left(99^{\text {th }}\right.$ percentile), and, as a result, the decision limit lowers from ' $b$ ' to ' $a$ ' (Figure 4A). Cardiologists are quite suspicious about the introduction of the hs assays, as they are afraid to become overloaded by an increasing number of AMI patients as well as for insurance and employment issues. ${ }^{41,42}$

The high-sensitivity assays are characterized by a ratio of the $10 \%$ CV cut-off to the $99^{\text {th }}$ percentile upper reference concentration of $\leq 1.0$ and detection of cTn concentrations in $>50 \%$ of healthy individuals. ${ }^{43,44}$ To date, most assays achieve a $10 \%$ CV cut-off concentration somewhere between the median and $99^{\text {th }}$ percentile concentration measured in healthy individuals. The research Singulex Erenna assay is the only cTnl assay today that achieves CV $<10 \%$ across most of the reference distribution. ${ }^{45-47}$

Apple proposed a scorecard to judge which cTn assays are suitable to use in the clinic and classified them into guideline acceptable, clinically usable, and non-acceptable assays. ${ }^{48}$ Such an objective score system would be of great help to see the wood for the trees, except that his classification system does not include the clinical performance of the assays. ${ }^{49}$

\section{- High-sensitivity troponin assays for diagnostic use}

Improved sensitivity of the cTn immunoassays is expected to facilitate rapid decision making and treatment of patients presenting with symptoms of acute chest pain at the emergency department. Recent results indeed showed that for such patients $(n=718)$ at presentation ( $<3$ hours after onset of symptoms) the diagnostic performance significantly increased from an area under the curve (AUC) of $0.76(95 \% \mathrm{Cl} 0.64-0.88)$ to $0.92(95 \% \mathrm{Cl} 0.87-0.97)$ when using the cTnT as compared to the hs-cTnT assay $(\mathrm{P}=0.01)$, respectively. ${ }^{50}$ Comparable results have been confirmed by others, ${ }^{51}$ also for hs-cTnl assays. ${ }^{52-54}$ Remarkably, the clinical performance of the Abbott Architect-cTnl assay, which does not fulfil the precision requirements of the guidelines, was comparable to the hs-cTnT and Siemens Ultra-cTnl assays. ${ }^{50}$ All of them achieved an AUC $>0.90$, being significantly higher than the current cTnT 
assay $(P<0.05)$ with an AUC of 0.71 and 0.85 within 2 and 10 hours after onset of symptoms, respectively.

An increase in sensitivity goes along with a decrease in specificity, as illustrated in Figure $4 \mathrm{~A}$ by using a lower decision limit ' $a$ ' instead of ' $b$ '. In the clinical example above, the sensitivity increased from $83 \%(95 \% \mathrm{Cl} 76-90)$ to $95 \%(95 \% \mathrm{Cl} 90-98)$, while the specificity decreased from $93 \%(95 \% \mathrm{Cl} 91-95)$ to $80 \%(95 \% \mathrm{Cl} 77-83) .{ }^{50}$ Comparable trends were obtained in the other studies. ${ }^{51-54}$ Still, specificity could be further improved by serial sampling. ${ }^{55,56}$ The guidelines estimated that a delta change in cTn concentration of $20 \%$ could be of clinical value. ${ }^{4,6-8}$ More research is however required to validate the optimal delta cut-off for diagnosis of AMI.

\section{- High-sensitivity troponin assays for prognostic use}

The identification of patients at coronary risk remains an ongoing challenge. Traditional risk factors for cardiac events are among others age, gender, smoking, and the cholesterol concentration. Algorithms of prediction models combine all these factors and estimate the total risk for the occurrence of a cardiac event, like the cardiovascular Munster (PROCAM) risk score that estimates the 10-year risk on $\mathrm{AMI}$ and the Framingham risk score that estimates the 10-year risk on cardiovascular disease in the general population. ${ }^{57,58}$ However, these well known models turn out to perform only moderately well in the clinic.

With the development of the hs-cTn assays, new possibilities seem available to screen patients with a potential cardiovascular risk. A first prognostic hs-cTnT study indeed showed a significant association between increased $\mathrm{CTnT}$ concentrations and the incidence of cardiovascular events in patients with stable chronic heart failure. ${ }^{59}$ As biomarkers are a relatively easy and low-cost screening method, the use of cardiac biomarkers to identify high risk subjects has been proposed before, like for $\mathrm{N}$-terminal pro-B-type natriuretic peptide ${ }^{60}$ and high sensitivity C-reactive protein. ${ }^{61}$ Unfortunately, so far, cardiac markers added only moderately to cardiac risk assessment, even in a multi-marker approach. ${ }^{62,63}$ The next step is now to validate whether hs-cTnT has incremental value on the clinical work-up of mediate or high risk patients. ${ }^{64}$ 


\section{- Harmonization and standardization of troponin assays}

Among the more than $20 \mathrm{cTnl}$ immunoassays available on the market, assay outcome deviates largely, up to 20 -fold. ${ }^{38}$ This is not the case for cTnT, as the cTnT assay is highly patented by the company Roche Diagnostics. ${ }^{65,66}$ Each cTnl assay uses different antibodies, calibrators, and control materials, limiting comparison of laboratory and study results. Especially the $\mathrm{N}$ - and C-terminus of cTnl turned out to be instable and most manufacturers nowadays choose for antibodies against epitopes in the stable region between amino acid $30-110 .^{67,68}$

To validate cTnl assay harmonization, Panteghini emphasized the need for primary and secondary reference material, as depicted in Figure $5 .{ }^{67,69}$ The American Association for Clinical Chemistry in collaboration with the National Institute of Standards and Technology (NIST) formed a cTnl Standardization Committee ${ }^{39,70}$ and, as a result, the NIST standard reference material (SRM) 2921 became recently available as primary reference material. ${ }^{71}$ However, previous stability studies of NIST SRM 2921 spiked in pooled heparin plasma showed time-dependent reduction in assay results. ${ }^{40}$ In addition, instability of purified cTnT (Jart Diris, PhD thesis, Maastricht University, 2003) or recombinant $\mathrm{cTnl}^{72}$ when spiked in serum and incubated at $37^{\circ} \mathrm{C}$ was proven with Western Blot detection. We expect that the reduction in assay outcome could be attributable to the susceptibility of cTn to degradation that hampers the antibody recognition, thereby limiting the application of NIST SRM 2921 for harmonization and standardization purposes.

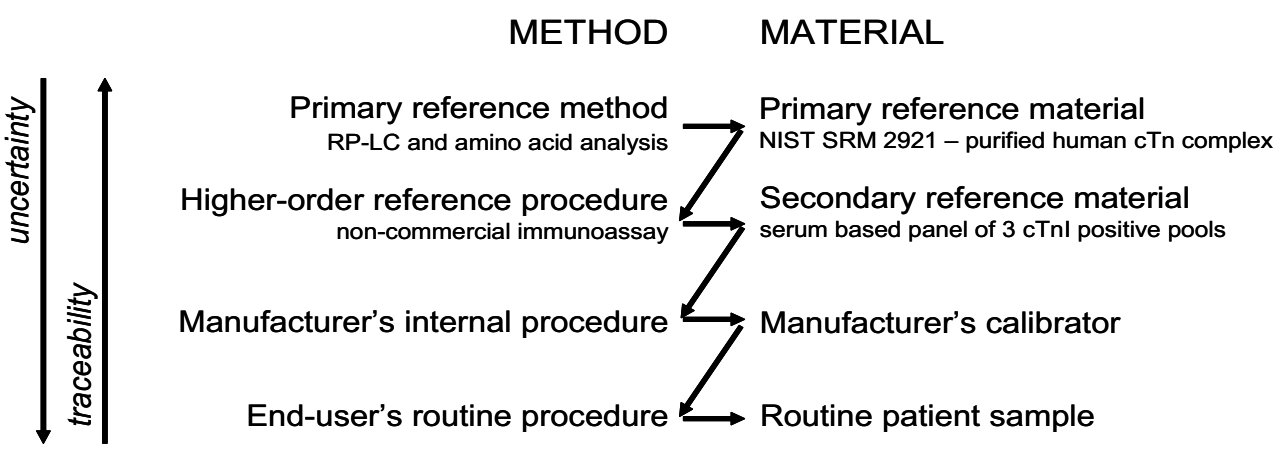

Figure 5: Suggested approach for the standardization of cardiac troponin I (cTnl) measurements. Figure adapted from Panteghini. ${ }^{73}$ 


\section{Outline}

Both cTnT and CTnl are nowadays the golden standard for the diagnosis of a myocardial infarction. Nevertheless, the diagnosis and risk assessment of coronary syndromes are expected to be further improved with the recent development of high-sensitivity cTn immunoassays. This might already be true for subjects that suffer from only minor coronary artery burden. With use of especially the new hs-cTnT assay, we investigated the distribution of cTn concentrations in healthy subjects, in subjects after prolonged strenuous exercise, in renal disease patients, and in patients with stable chest-pain. Moreover, we expected that complete insight in the structural aspects of cTn in the blood circulation might assist in unraveling the pathophysiology of cTn release, but also in cTnl immunoassay harmonization and standardization, and in the clinical interpretation of assay outcome in general.

Chapter 2 reviews the analytical characteristics of the hs-cTnT and hs-cTnl immunoassays currently available. Chapter 3 describes our validation of the hs-cTnT assay and the Architect-cTnl assay in a healthy reference population and in marathon runners. Chapter 4 compares the exercise-induced hs-cTnT elevations in recreational runners among different running distances. Chapter 5 validates whether renal function after marathon running is reduced, as a possible clarification for the exercise-induced cTn elevations. Chapter 6 describes the longitudinal distribution of hs-cTnT and Architect-cTnl concentrations in haemodialysis patients suffering from end-stage renal disease. Chapter 7 investigates the extent of coronary atherosclerosis in stable chest-pain patients in relation to hs-cTnT concentrations in the blood circulation. Chapter 8 shows with survival analysis the incremental value of hs-cTnT as a risk stratification tool in chest-pain patients visiting the cardiology outpatient department. Chapter 9 describes the instability of purified cTn complex NIST SRM 2921 when spiked in serum and questions thereby its application for assay harmonization and standardization. Chapter 10 illustrates the structures and conformation of cTn in the blood circulation of AMI patients. Chapter 11 discusses the results and conclusions from the studies mentioned above with directions for future research. 


\section{References}

1. Vaartjes I, van Dis I, Visseren FL, Bots ML. Hart- en vaatziekten in Nederland. In: Vaartjes I, van Dis I, Visseren FL, Bots ML, eds. Hart- en vaatziekten in Nederland 2009, cijfers over leefstijl- en risicofactoren, ziekte en sterfte. Den Haag: Nederlandse Hartstichting; 2009:7-23.

2. World Health Organization. Available at: http://Infobase.who.int. Accessed 11 June 2011.

3. Lusis AJ. Atherosclerosis. Nature. 2000;407:233-241.

4. Thygesen K, Alpert JS, White HD, et al. Universal definition of myocardial infarction: Kristian Thygesen, Joseph S. Alpert and Harvey D. White on behalf of the Joint ESC/ACCF/AHA/WHF Task Force for the Redefinition of Myocardial Infarction. Eur Heart J. 2007;28:2525-2538.

5. Finn AV, Nakano M, Narula J, Kolodgie FD, Virmani R. Concept of vulnerable/unstable plaque. Arterioscler Thromb Vasc Biol. 2010;30:1282-1292.

6. Thygesen $\mathrm{K}$, Mair J, Katus $\mathrm{H}$, et al. Recommendations for the use of cardiac troponin measurement in acute cardiac care. Eur Heart J. 2010;31:2197-2204.

7. Apple FS, Jesse RL, Newby LK, et al. National Academy of Clinical Biochemistry and IFCC Committee for Standardization of Markers of Cardiac Damage Laboratory Medicine Practice Guidelines: analytical issues for biochemical markers of acute coronary syndromes. Clin Chem. 2007;53:547-551.

8. Morrow DA, Cannon CP, Jesse RL, et al. National Academy of Clinical Biochemistry Laboratory Medicine Practice Guidelines: Clinical characteristics and utilization of biochemical markers in acute coronary syndromes. Circulation. 2007;115:356-375.

9. Vaartjes I, van Dis I, Bots ML, Visseren FL. Ingrepen bij patiënten met hartziekten in Nederland. In: Vaartjes I, van Dis I, Visseren FL, Bots ML, eds. Hart- en vaatziekten in Nederland 2009, cijfers over leefstijl- en risicofactoren, ziekte en sterfte. Den Haag: Nederlandse Hartstichting; 2009:2532.

10. Eagle KA, Guyton RA, Davidoff R, et al. ACC/AHA 2004 guideline update for coronary artery bypass graft surgery: a report of the American College of Cardiology/American Heart Association task force on practice guidelines (committee to update the 1999 guidelines for Coronary Artery Bypass Graft surgery). Circulation. 2004;110:e340-437.

11. Smith SC, Jr., Feldman TE, Hirshfeld JW, Jr., et al. ACC/AHA/SCAI 2005 guideline update for Percutaneous Coronary Intervention-summary article: a report of the American College of Cardiology/American Heart Association task force on practice guidelines (ACC/AHA/SCAl writing committee to update the 2001 guidelines for Percutaneous Coronary Intervention). J Am Coll Cardiol. 2006;47:216-235.

12. Daemen J, Boersma $\mathrm{E}$, Flather $\mathrm{M}$, et al. Long-term safety and efficacy of percutaneous coronary intervention with stenting and coronary artery bypass surgery for multivessel coronary artery disease: a meta-analysis with 5-year patient-level data from the ARTS, ERACI-II, MASS-II, and SoS trials. Circulation. 2008;118:1146-1154.

13. Katus HA, Remppis A, Scheffold T, Diederich KW, Kuebler W. Intracellular compartmentation of cardiac troponin $T$ and its release kinetics in patients with reperfused and nonreperfused myocardial infarction. Am J Cardiol. 1991;67:1360-1367.

14. Bleier J, Vorderwinkler KP, Falkensammer J, et al. Different intracellular compartmentations of cardiac troponins and myosin heavy chains: a causal connection to their different early release after myocardial damage. Clin Chem. 1998;44:1912-1918.

15. Takeda. Structure of the core domain of human cardiac troponin in the $\mathrm{Ca}^{2+}$-saturated form. Nature. 2003;424:35-41.

16. Li MX, Wang X, Sykes BD. Structural based insights into the role of troponin in cardiac muscle pathophysiology. J Muscle Res Cell Motil. 2004;25:559-579.

17. Kowlessur D, Tobacman LS. Troponin regulatory function and dynamics revealed by H/D exchange-mass spectrometry. J Biol Chem. 2010;285:2686-2694. 
18. Michielsen EC, Diris JH, Kleijnen VW, Wodzig WK, Van Dieijen-Visser MP. Investigation of release and degradation of cardiac troponin T in patients with acute myocardial infarction. Clin Biochem. 2007;40:851-855.

19. Katrukha AG, Bereznikova AV, Esakova TV, et al. Troponin I is released in bloodstream of patients with acute myocardial infarction not in free form but as complex. Clin Chem. 1997;43:1379-1385.

20. Bates KJ, Hall EM, Fahie-Wilson MN, et al. Circulating immunoreactive cardiac troponin forms determined by gel filtration chromatography after acute myocardial infarction. Clin Chem. 2010;56:952-958.

21. McDonough JL, Arrell DK, Van Eyk JE. Troponin I degradation and covalent complex formation accompanies myocardial ischemia/reperfusion injury. Circ Res. 1999;84:9-20.

22. Fahie-Wilson MN, Carmichael DJ, Delaney MP, Stevens PE, Hall EM, Lamb EJ. Cardiac troponin T circulates in the free, intact form in patients with kidney failure. Clin Chem. 2006;52:414-420.

23. Kelley WE, Januzzi JL, Christenson RH. Increases of cardiac troponin in conditions other than acute coronary syndrome and heart failure. Clin Chem. 2009;55:2098-2112.

24. Michielsen EC, Wodzig WK, Van Dieijen-Visser MP. Cardiac troponin T release after prolonged strenuous exercise - a review. Sports Med. 2008;38:425-435.

25. Muller-Bardorff M, Hallermayer K, Schroder A, et al. Improved troponin T ELISA specific for cardiac troponin $\mathrm{T}$ isoform: assay development and analytical and clinical validation. Clin Chem. 1997;43:458-466.

26. Davis GK, Labugger R, Van Eyk JE, Apple FS. Cardiac Troponin T is not detected in western blots of diseased renal tissue. Clin Chem. 2001;47:782-783.

27. Ricchiuti V, Voss EM, Ney A, Odland M, Anderson PA, Apple FS. Cardiac troponin T isoforms expressed in renal diseased skeletal muscle will not cause false-positive results by the second generation cardiac troponin T assay by Boehringer Mannheim. Clin Chem. 1998;44:1919-1924.

28. Neumayr G, Pfister R, Mitterbauer G, et al. Effect of the "Race Across The Alps" in elite cyclists on plasma cardiac troponins I and T. Am J Cardiol. 2002;89:484-486.

29. Hickman PE, Potter JM, Aroney C, et al. Cardiac troponin may be released by ischemia alone, without necrosis. Clin Chim Acta. 2010;411:318-323.

30. Rowe WJ. Extraordinary unremitting endurance exercise and permanent injury to normal heart. Lancet. 1992;340:712-714.

31. Hessel MH, Atsma DE, van der Valk EJ, Bax WH, Schalij MJ, van der Laarse A. Release of cardiac troponin I from viable cardiomyocytes is mediated by integrin stimulation. Pflugers Arch. 2008;455:979-986.

32. Shave R, Baggish A, George K, et al. Exercise-induced cardiac troponin elevation: evidence, mechanisms, and implications. J Am Coll Cardiol. 2010;56:169-176.

33. Scharhag J, George K, Shave R, Urhausen A, Kindermann W. Exercise-associated increases in cardiac biomarkers. Med Sci Sports Exerc. 2008;40:1408-1415.

34. Thompson PD, Franklin BA, Balady GJ, et al. Exercise and acute cardiovascular events placing the risks into perspective: a scientific statement from the American Heart Association Council on Nutrition, Physical Activity, and Metabolism and the Council on Clinical Cardiology. Circulation. 2007;115:2358-2368.

35. Tunstall Pedoe DS. Marathon cardiac deaths: the london experience. Sports Med. 2007;37:448450.

36. Roberts WO, Maron BJ. Evidence for decreasing occurrence of sudden cardiac death associated with the marathon. J Am Coll Cardiol. 2005;46:1373-1374.

37. Shave R, George KP, Atkinson G, et al. Exercise-induced cardiac troponin T release: a metaanalysis. Med Sci Sports Exerc. 2007;39:2099-2106.

38. Panteghini M, Pagani F, Yeo KT, et al. Evaluation of imprecision for cardiac troponin assays at low-range concentrations. Clin Chem. 2004;50:327-332.

39. Christenson RH, Duh SH, Apple FS, et al. Toward standardization of cardiac troponin I measurements part II: assessing commutability of candidate reference materials and harmonization of cardiac troponin I assays. Clin Chem. 2006;52:1685-1692. 
40. Cobbaert CM, Weykamp CW, Michielsen EC, Baadenhuijsen H, van Dieijen-Visser MP. Timedependent instability of cardiac troponins in human plasma spiked with NIST reference material 2921. Clin Chem. 2008;54:2078-2079.

41. Morrow DA, Antman EM. Evaluation of high-sensitivity assays for cardiac troponin. Clin Chem. 2009;55:5-8.

42. Hollander JE. Highly sensitive troponins the answer or just more questions? J Am Coll Cardiol. 2009;54:1173-1175.

43. Jaffe AS, Apple FS. High-sensitivity cardiac troponin: hype, help, and reality. Clin Chem. 2010;56:342-344.

44. Apple F. High-sensitivity cardiac troponin assays: what analytical and clinical issues need to be addressed before introduction into clinical practice? Clin Chem. 2010;56:886-891.

45. Apple FS, Simpson PA, Murakami MM. Defining the serum 99th percentile in a normal reference population measured by a high-sensitivity cardiac troponin I assay. Clin Biochem. 2010;43:10341036.

46. Todd J, Freese B, Lu A, et al. Ultrasensitive flow-based immunoassays using single-molecule counting. Clin Chem. 2007;53.

47. Wu AHB, Fukushima N, Puskas R, Todd J, Goix P. Development and preliminary clinical validation of a high sensitivity assay for cardiac troponin using a capillary flow (single molecule) fluorescence detector. Clin Chem. 2006;52:2157-2159.

48. Apple FS. A new season for cardiac troponin assays: it's time to keep a scorecard. Clin Chem. 2009;55:1303-1306.

49. Schneider HG, Tate JR, Hickman PE. What criteria should be used to assess troponin assays? Clin Chem. 2010;56:140-142.

50. Reichlin T, Hochholzer W, Bassetti S, et al. Early diagnosis of myocardial infarction with sensitive cardiac troponin assays. N Engl J Med. 2009;361:858-867.

51. Januzzi JL, Jr., Bamberg F, Lee $\mathrm{H}$, et al. High-sensitivity troponin $\mathrm{T}$ concentrations in acute chest pain patients evaluated with cardiac computed tomography. Circulation. 2010;121:1227-1234.

52. Venge $P$, Johnston $N$, Lindahl B, James $S$. Normal plasma levels of cardiac troponin I measured by the high-sensitivity cardiac troponin I access prototype assay and the impact on the diagnosis of myocardial ischemia. J Am Coll Cardiol. 2009;54:1165-1172.

53. Keller T, Zeller T, Peetz D, et al. Sensitive troponin I assay in early diagnosis of acute myocardial infarction. N Engl J Med. 2009;361:868-877.

54. Kavsak PA, Wang X, Ko DT, MacRae AR, Jaffe AS. Short- and long-term risk stratification using a next-generation, high-sensitivity research cardiac troponin I (hs-cTnl) assay in an emergency department chest pain population. Clin Chem. 2009;55:1809-1815.

55. Giannitsis E, Becker M, Kurz K, Hess G, Zdunek D, Katus HA. High-sensitivity cardiac troponin T for early prediction of evolving non-ST-segment elevation myocardial infarction in patients with suspected acute coronary syndrome and negative troponin results on admission. Clin Chem. 2010;56:642-650.

56. Apple FS, Pearce LA, Smith SW, Kaczmarek JM, Murakami MM. Role of monitoring changes in sensitive cardiac troponin I assay results for early diagnosis of myocardial infarction and prediction of risk of adverse events. Clin Chem. 2009;55:930-937.

57. Assmann G, Cullen P, Schulte H. Simple scoring scheme for calculating the risk of acute coronary events based on the 10-year follow-up of the prospective cardiovascular Munster (PROCAM) study. Circulation. 2002;105:310-315.

58. D'Agostino RB, Sr., Vasan RS, Pencina MJ, et al. General cardiovascular risk profile for use in primary care: the Framingham Heart Study. Circulation. 2008;117:743-753.

59. Latini R, Masson S, Anand IS, et al. Prognostic value of very low plasma concentrations of troponin T in patients with stable chronic heart failure. Circulation. 2007;116:1242-1249.

60. Eurlings LW, van Pol PE, Kok WE, et al. Management of chronic heart failure guided by individual $\mathrm{N}$-terminal pro-B-type natriuretic peptide targets: results of the PRIMA (Can PRo-brain- 
natriuretic peptide guided therapy of chronic heart failure IMprove heart fAilure morbidity and mortality?) study. J Am Coll Cardiol. 2010;56:2090-2100.

61. Ridker PM, Cushman M, Stampfer MJ, Tracy RP, Hennekens CH. Plasma concentration of Creactive protein and risk of developing peripheral vascular disease [see comments]. Circulation. 1998;97:425-428.

62. Wang TJ, Gona P, Larson MG, et al. Multiple biomarkers for the prediction of first major cardiovascular events and death. N Engl J Med. 2006;355:2631-2639.

63. Zethelius B, Berglund L, Sundstrom J, et al. Use of multiple biomarkers to improve the prediction of death from cardiovascular causes. N Engl J Med. 2008;358:2107-2116.

64. Apple FS. High-sensitivity cardiac troponin for screening large populations of healthy people: is there risk? Clin Chem. 2011;54:537-539.

65. Katus HA, Remppis A, Looser S, Hallermeier K, Scheffold T, Kubler W. Enzyme linked immuno assay of cardiac troponin $\mathrm{T}$ for the detection of acute myocardial infarction in patients. Journal of molecular and cellular cardiology. 1989;21:1349-1353.

66. Katus HA. Development of the cardiac troponin T immunoassay. Clin Chem. 2008;54:1576-1577; discussion 1577.

67. Panteghini M. Assay-related issues in the measurement of cardiac troponins. Clin Chim Acta. 2009;402:88-93.

68. International Federation of Clinical Chemistry and Laboratory Medicine (IFCC) Committee on the Standardization of Markers of Cardiac Damage (C-SMCD). Troponin assay analytical characteristics. Available at:

http://www.ifcc.org/PDF/ScientificActivities/IFCC_Troponin_Table_vDec_2010_FINAL_ng_L_28Ja n11.pdf. Accessed 11 June 2011.

69. Panteghini M, Bunk DM, Christenson RH, et al. Standardization of troponin I measurements: an update. Clin Chem Lab Med. 2008;46:1501-1506.

70. Christenson RH, Duh SH, Apple FS, et al. Standardization of cardiac troponin I assays: round Robin of ten candidate reference materials. Clin Chem. 2001;47:431-437.

71. Bunk DM, Welch MJ. Characterization of a new certified reference material for human cardiac troponin I. Clin Chem. 2006;52:212-219.

72. Labugger R, Organ L, Collier C, Atar D, Van Eyk JE. Extensive troponin I and T modification detected in serum from patients with acute myocardial infarction. Circulation. 2000;102:12211226.

73. Panteghini M. Traceability as a unique tool to improve standardization in laboratory medicine. Clin Biochem. 2009;42:236-240. 


\title{
CHAPTER 2
}

\section{A comprehensive review of upper reference limits reported for (high-)sensitivity cardiac troponin assays and the challenges that lie}

\section{ahead}

\begin{abstract}
Cardiac troponins (cTn) are the preferred markers for the diagnosis of acute myocardial infarction (AMI). The guidelines recommend the use of the $99^{\text {th }}$ percentile upper reference concentration of a healthy population as the diagnostic cutoff for AMI. However, a broad range of upper reference limits is still employed, complicating the diagnosis of AMI. This overview is meant to assist laboratory specialists to define an appropriate cutoff value for the diagnosis of AMI. Therefore we provide an overview of the analytical performance and upper reference limits of seven (high-)sensitivity cTn assays: Roche high-sensitivity cTnT and ADVIA Centaur, Stratus CS, Dimension Vista, Vitros ECi, Access and Architect cTnl assays. It is shown that none of the reference populations completely met the guidelines, including those in package inserts. $40 \%$ of the studies collected less than the advised minimum of 300 subjects. Many studies (50\%) did not report their inclusion criteria, while lower $99^{\text {th }}$ percentile limits were observed when more stringent selection criteria were applied. Higher troponin cutoffs were found in men and elderly subjects, suggesting sex- and age-specific cutoffs would be considered. Therefore, there is still need for a large, rigorously screened reference population to more accurately establish cTn upper reference limits.
\end{abstract}


Cardiac troponins (cTn) were generally recommended as the biochemical gold standard for the investigation of patients with acute coronary syndrome (ACS) in 1999 by the National Academy of Clinical Biochemistry (NACB), ${ }^{1}$ and in 2000 by the European Society of Cardiology and the American College of Cardiology (ESC/ACC). ${ }^{2}$ Both clinical ${ }^{3}$ and analytical aspects $^{4,5}$ of these guidelines were revised in 2007, in order to establish a more universal definition of acute myocardial infarction (AMI). According to these guidelines a rise and/or fall of cardiac troponin T (cTnT) or I (cTnl) with at least one value above the $99^{\text {th }}$ percentile of a healthy reference population is the hallmark of myocardial damage. To complete the diagnosis, cTn changes must be accompanied with at least one of the following clinical factors: the presence of ischemic symptoms, electrocardiographic (ECG) alterations (for example ST-T changes, left bundle branch block or development of pathological Q waves), or imaging evidence of either new loss of viable myocardium or new regional wall motion abnormality $^{3,6}$ Importantly, the guidelines recommend a total imprecision (coefficient of variation, $\mathrm{CV}$ ) of $10 \%$ at the $99^{\text {th }}$ percentile reference limit. ${ }^{5}$ In a recent overview, Apple classified the available assays ${ }^{7}$ as "not acceptable" (CV >20\%), "clinically usable" (CV 10-20\%) or "guideline acceptable" (CV $\leq 10 \%)^{8}$ In addition, assays were categorized into 4 levels depending on whether <50\% (level 1), 50-75\% (level 2), 75-95\% (level 3) or >95\% (level 4) of reference concentrations had detectable cTn concentrations below the $99^{\text {th }}$ percentile. Only nine out of twenty-two assays were labeled "guideline acceptable" and nine were defined as "clinically usable". ${ }^{8}$ However, as recently pointed out, the misclassification of patients when using CVs between $10 \%$ and $20 \%$ at the $99^{\text {th }}$ percentile is considered to be insignificant. ${ }^{9}$

Despite the introduction of guideline acceptable assays and the recommendation to use the $99^{\text {th }}$ percentile value of a reference population as cutoff for AMI, a broad range of cutoff concentrations are in use, complicating the diagnosis of AMI for clinicians. A major cause of this heterogeneity is lack of assay harmonization and non-standardized selection of healthy reference populations. ${ }^{10-12}$ This issue will become even more prominent with the ongoing development of increasingly sensitive assays that detect measurable cTn levels in almost everybody. Noteworthy, recent data indicate that even low levels of cTn can predict major adverse cardiac events, pointing out the importance of reliable diagnostic cutoffs. ${ }^{13,14}$

Most laboratories do not have the resources to determine their own $99^{\text {th }}$ percentile cutoff. For appropriate statistical determination of the $99^{\text {th }}$ percentile cutoff a theoretical minimum of 120 reference subjects has been proposed. ${ }^{15}$ In order to reliably assess the $99^{\text {th }}$ 
percentile with an uncertainty $<5 \%$, a sample size of 300 subjects is required. ${ }^{5,6}$ Furthermore, the distribution of sex and age in the reference population should resemble those in a typical group of AMI patients, and should ideally have negative exercise stress tests and normal cardiac function as assessed by non-invasive imaging. The CARMAGUE study pointed out that $\pm 50 \%$ of the laboratories employ cutoff values from the package insert, $15 \%$ adopt values from peer-reviewed studies, ${ }^{16}$ and sometimes arbitrarily chosen values are used. A structured overview of all studies may be a helpful tool that facilitates the diagnostic process and assists laboratories to define appropriate cutoff values.

In the present review, we provide an extensive summary of seven cTn assays, frequently used in clinical practice, that can measure the $99^{\text {th }}$ percentile cutoff with a high precision, including five "guideline acceptable" assays: 1) high sensitivity cTnT (hs-cTnT, Roche Diagnostics), 2) ADVIA Centaur Tnl-Ultra (Siemens Healthcare Diagnostics), 3) Stratus CS Acute Care cTnl (Siemens Healthcare Diagnostics), 4) Dimension Vista cTnl (Siemens Healthcare Diagnostics) and 5) Vitros ECi cTnI ES (Ortho Clinical Diagnostics) assays. We also included two "clinically usable" assays to complete the overview: 6) Access AccuTnl (Beckman Coulter) and 7) Architect cTnl assay (Abbott Diagnostics). Point-of-care tests and research assays were excluded. Between October 2010 and October 2011, we searched the MEDLINE electronic database for publications in English, using the key words "troponin", "troponin assay", and " $99^{\text {th }}$ percentile". We paid special attention to analytical assay characteristics and the $99^{\text {th }}$ percentile cutoffs. We also discuss selection criteria of the reference population, sex/age specific differences in cTn concentrations, and biological variation within or between subjects. These are increasingly prominent subjects of debate since the introduction of the high sensitivity assays.

\section{Hs-cTnT Assay - Roche Diagnostics}

The analytical evaluation of the assay established by the manufacturer (Roche Diagnostics, Mannheim, Germany) described a limit of blank (LOB) of $3 \mathrm{ng} / \mathrm{L}$ and limit of detection (LOD) of $5 \mathrm{ng} / \mathrm{L}$. As depicted in Table 1, other studies reported LODs that ranged from 1 to 5 $\mathrm{ng} / \mathrm{L} .{ }^{17-21}$ According to the package insert a $10 \% \mathrm{CV}$ was measured at $3 \mathrm{ng} / \mathrm{L}$ (version 2010). Most authors found the same value or even lower $10 \% \mathrm{CV}$ cutoffs. ${ }^{18,22-26}$ Only one study reports a noticeable higher $10 \% \mathrm{CV}$ of $18.5 \mathrm{ng} / \mathrm{L}^{27}$ These discrepancies in LOB, LOD, and $10 \%$ $\mathrm{CV}$ can be the result of using various methods of estimation. ${ }^{11}$ 
The reference populations were selected by either health questionnaires, ${ }^{21}$ laboratory tests, ${ }^{17,22}$ or both approaches in combination with echocardiography. ${ }^{25,27}$ In most studies inclusion criteria were not described. ${ }^{18-20,23,24}$ The recommended inclusion of at least 120 cardio-healthy reference subjects, required for reliable estimation of the $99^{\text {th }}$ percentile, was met in most studies, except in Koerbin et al and Vasatova et al using 104 and 73 subjects, respectively. ${ }^{19,25}$

The $99^{\text {th }}$ percentile concentration according to the package insert was $14 \mathrm{ng} / \mathrm{L}$ and calculated from 533 healthy subjects. This value was reproduced in four independent studies. ${ }^{18,20,21,24}$ However, in literature, slightly lower $99^{\text {th }}$ percentile limits $( \pm 12 \mathrm{ng} / \mathrm{L}$ ) were described in a large reference cohort $(n=1061)$ of healthy subjects using EDTA plasma samples $^{17}$ or a small population of 104 subjects, broadly screened by means of questionnaires to exclude possible risk factors, presence of cardiac diseases and cardiovascular medications, followed by stress echocardiography and routine chemistry tests. ${ }^{25}$ In our lab, a cutoff of $16 \mathrm{ng} / \mathrm{L}$ was found ${ }^{22}$ and similar $99^{\text {th }}$ percentile cutoffs were also reported by others, using smaller reference populations, ${ }^{26}$ comprised of $66 \%$ males. ${ }^{19}$

Sex related differences in cTnT levels have been documented using the hs-cTnT assay. ${ }^{18,21,22,24,25,27}$ All studies except one ${ }^{27}$ reported higher cTnT concentrations in males ( $P$ $<0.01$ ). From the reported concentrations in Table 1 , we calculated a mean $99^{\text {th }}$ percentile cutoff of $15.0 \mathrm{ng} / \mathrm{L}$ for males and $9.6 \mathrm{ng} / \mathrm{L}$ for females. ${ }^{21,22,24,25}$ It has been suggested that this could be due to sex specific differences in the pathophysiology of $\mathrm{ACS}^{21}$ or variations in mean heart sizes between men and women. ${ }^{22}$ Several studies indicated higher cTnT levels in elderly. ${ }^{18,22,25}$ Significantly higher cTnT levels were found in people over 60 years, compared to younger subjects, both in the male and female cohort $(P<0.01) .{ }^{25}$ These findings provide an independent replication of a previous report. ${ }^{28}$

Taken together, the $99^{\text {th }}$ percentile cutoff varied between 12 to $17 \mathrm{ng} / \mathrm{L}$. Moreover, in all studies accept for one, this cutoff was measured with an imprecision $\leq 10 \%$.

\section{ADVIA Centaur TnI-Ultra Assay - Siemens Healthcare Diagnostics}

Analytical sensitivity. Four studies with the new generation ADVIA centaur reported a LOD of $6 \mathrm{ng} / \mathrm{L}^{29-32}$ and one study found a slightly higher LOD of $8.5 \mathrm{ng} / \mathrm{L}^{33}$ The package insert (Siemens Healthcare Diagnostics, Frimley, Camberley, UK, version 2009) stated that the LOD of the ADVIA Centaur Tnl-Ultra assay is $6 \mathrm{ng} / \mathrm{L}$ and $30 \mathrm{ng} / \mathrm{L}$ is the minimum concentration 
that could be measured with an analytical imprecision of $<10 \%$. This value was reproduced in four studies, ${ }^{31,32,34,35}$ but higher $10 \% \mathrm{CV}$ cutoffs ranging from 45 to $67 \mathrm{ng} / \mathrm{L}$ were also reported (Table 1B). ${ }^{29,30,33,36,37}$

A cardio-healthy reference population was selected by laboratory tests, ${ }^{29,36}$ sometimes in combination with echocardiography. ${ }^{30,34,37,38}$ Three studies excluded cardiac diseases and their possible risk factors by means of medical history examinations and/or health questionnaires. $^{32,33,35}$ The majority of the studies included an acceptable sample size. Only two studies included less than the recommended 300 subjects $^{33,37}$ from which one study did not meet the minimum inclusion of 120 subjects. ${ }^{37}$

The $99^{\text {th }}$ percentile cutoff measured by the manufacturer is $40 \mathrm{ng} / \mathrm{L}$, for both serum and plasma samples. Similar values were found in two studies ${ }^{30,31}$ but 1.5 to 2 fold higher $99^{\text {th }}$ percentile concentrations have also been reported for lithium heparin plasma and serum samples. ${ }^{29,33-36,38}$ Venge et al attributed their higher $99^{\text {th }}$ percentile cutoff $(80 \mathrm{ng} / \mathrm{L})$ to different inclusion criteria of the reference population, or the use of samples that had been frozen for a substantial length of time. ${ }^{34}$ It should be noted that an older population was used in this study. A majority of the subjects were male and three outliers were excluded with no reported reason. Tate et al included only 108 subjects in the reference population, rigorously screened for cardiovascular risk factors, cardiac diseases, cardiovascular medications, stress echocardiography, blood and urine routine tests and heterophilic antibodies against cTn, which could explain the relatively low $99^{\text {th }}$ percentile concentration of $21 \mathrm{ng} / \mathrm{L}$ found both in plasma and serum samples. ${ }^{37}$ Even lower concentrations for the $99^{\text {th }}$ percentile ( $13 \mathrm{ng} / \mathrm{L}$ and $18 \mathrm{ng} / \mathrm{L}$ for plasma and serum, respectively) were reported in a relatively young reference population with a mean age of 30 years. $^{32}$

Sex dependent differences were also reported, with significantly higher cTnl concentrations in men than in women $(P<0.05) .{ }^{29,32,36,38} A$ statistically significant correlation between age and cTnl concentrations was reported $(R 0.268 ; P<0.0001),{ }^{29,36}$ and in line with this observation older subjects had higher cTnl levels than the younger subjects $(P \leq 0.0002) .{ }^{34,38}$ No significant differences were found among multi-ethnical Asian populations. $^{35}$

In conclusion, $10 \% \mathrm{CV}$ and $99^{\text {th }}$ percentile cutoffs ranged between $30-67 \mathrm{ng} / \mathrm{L}$ and $13-87$ ng/L, respectively. Most, but not all studies ${ }^{30,32,37}$ concluded that the ADVIA Centaur TnIUltra Assay is guideline acceptable. 


\section{Stratus CS Acute Care cTnI Assay - Siemens Healthcare Diagnostics}

The analytical evaluation of the assay established by the manufacturer (Siemens Healthcare Diagnostics) yielded a LOB of $30 \mathrm{ng} / \mathrm{L}$ and a LOD of $60 \mathrm{ng} / \mathrm{L}$, while other studies reported LODs ranging from 10 to $20 \mathrm{ng} / \mathrm{L}^{39-42}$ According to the package insert $60 \mathrm{ng} / \mathrm{L}$ is the minimum concentration that can be measured with an analytical imprecision of $<10 \%$ (version 2001). In literature similar results were found. ${ }^{40-42}$

The inclusion criteria of reference populations were not specified in the majority of the publications, including the package insert and the only study including $>300$ subjects. ${ }^{41}$ Others screened either history of cardiac disease, hematochemical alterations and hyperpyrexia ${ }^{42}$ or by means of history check, ECG, treadmill tests, stress echocardiography or angiogram, ${ }^{39}$ using both sample sizes $<200$ subjects.

The $99^{\text {th }}$ percentile concentration provided by the manufacturer is $70 \mathrm{ng} / \mathrm{L}$. This value was reproduced by Christenson, ${ }^{41}$ but lower cutoff concentrations of $30 \mathrm{ng} / \mathrm{L}^{42}$ and $50 \mathrm{ng} / \mathrm{L}^{40}$ were also reported with an accompanying $10 \% \mathrm{CV}$ to $99^{\text {th }}$ percentile ratio of 2.33 and 1.20 , respectively. These lower estimations may be due to the inclusion of younger subjects, and the small sample size.

In conclusion, only one reference population included a sufficiently large sample size and reported the assay to be guideline acceptable. ${ }^{41}$ More studies are however needed for the Stratus CS assay to make valid conclusions.

\section{Dimension Vista cTnl Assay - Siemens Healthcare Diagnostics}

Analytical validation of the Dimension Vista cTnl assay by the manufacturer (Siemens Healthcare Diagnostics) yielded a LOB of $15 \mathrm{ng} / \mathrm{L}$ and a total imprecision (CV) below $10 \%$ at $40 \mathrm{ng} / \mathrm{L}$ (version 2008). Only one independent study validated the sensitivity of the Dimension Vista cTnl Assay, and reported a LOB, LOD and 10\% CV cutoff of 11, 15, and 36 $\mathrm{ng} / \mathrm{L}$, respectively. ${ }^{43}$

The reference population collected by the manufacturer included 199 people with no clear description of the applied screening methods. Arrabola et al included 350 individuals (73\% male) after examination of the patient's medical history. ${ }^{43}$

The $99^{\text {th }}$ percentile cutoff calculated by the manufacturer is $45 \mathrm{ng} / \mathrm{L}$. Arrabola et al reported a lower cutoff $(22 \mathrm{ng} / \mathrm{L})$, and a $10 \% \mathrm{CV}$ to $99^{\text {th }}$ percentile ratio of 1.64 . No 
significant sex and age related differences in cTnl levels are currently described for this assay. However, caution is required in interpretation of the limited available evidence. ${ }^{43}$

In conclusion. Although more studies are required to confirm these results, the Dimension Vista cTnl Assay is not guideline acceptable according to the current evidence in literature. $^{43}$

\section{Vitros ECi Troponin I ES Assay - Ortho Clinical Diagnostics}

Analytical validation of the Vitros ECi CTnI ES assay by the manufacturer (Ortho Clinical Diagnostics, Buckinghamshire, UK) yielded a LOB of $7 \mathrm{ng} / \mathrm{L}$ and a LOD of $12 \mathrm{ng} / \mathrm{L}$. The package insert (version 3.0) states that the lowest concentration measurable with an imprecision (CV) less than $10 \%$ is $34 \mathrm{ng} / \mathrm{L}$. Tate and colleagues replicated this result, ${ }^{37}$ but other studies reported $10 \% \mathrm{CV}$ cutoffs of $40 \mathrm{ng} / \mathrm{L}^{44}$ and $93 \mathrm{ng} / \mathrm{L} .{ }^{32}$

The reference populations used by Tate et al and La'ulu et al have already been described above (section on the TnI-Ultra assay). ${ }^{32,37}$ Apple and colleagues recruited serum samples of 2992 healthy subjects, without additional specification, as well as lithium heparin plasma samples from 2000 healthy subjects, aged between 18-66 years and of which 75\% were male. $^{45}$

The $99^{\text {th }}$ percentile cutoff calculated by the manufacturer is $34 \mathrm{ng} / \mathrm{L}$, which corresponds exactly to the $10 \% \mathrm{CV}$ cutoff value. Apple et al calculated the $99^{\text {th }}$ percentile in two independent reference populations. ${ }^{45}$ In one cohort with serum samples they replicated the cutoff value from the manufacturer, in the second reference population with heparin plasma samples a $99^{\text {th }}$ percentile concentration of $31 \mathrm{ng} / \mathrm{L}$ was reported. ${ }^{45}$ Other studies by Tate et al, and La'ulu et al calculated much lower $99^{\text {th }}$ percentile concentrations in populations that were extensively screened, ${ }^{37}$ or comprised relatively young subjects. ${ }^{32}$ However, the concentrations reported at an imprecision of $10 \% \mathrm{CV}$ were markedly higher than the $99^{\text {th }}$ percentile concentration in these studies.

In conclusion, various $10 \% \mathrm{CV}$ values and $99^{\text {th }}$ percentile cutoffs were observed. Consequently, all studies but one ${ }^{45}$ reported a $10 \% \mathrm{CV}$ to $99^{\text {th }}$ percentile ratio $>1$. Therefore, it remains controversial whether this assay can measure the $99^{\text {th }}$ percentile with a precision of $10 \%$, as quoted by the package insert. 


\section{Access AccuTnl assay - Beckman Coulter}

Evaluation of the analytical sensitivity by the manufacturer (Beckman Coulter, Woerden, the Netherlands) indicated a LOD of $4 \mathrm{ng} / \mathrm{L}$. The lowest cTnT concentration which can be measured with a $10 \% \mathrm{CV}$ was shown to be $60 \mathrm{ng} / \mathrm{L}$ according to the package insert (version 2006). In several publications a similar value was mentioned ${ }^{46-48}$ although higher concentrations measured with a $10 \% \mathrm{CV}$ were also found: $104,{ }^{37} 101,{ }^{32}$ and $75 \mathrm{ng} / \mathrm{L}^{49}$. Also, $20 \%$ CVs for these publications were reported to be 43,34 , and $15 \mathrm{ng} / \mathrm{L}$, respectively. Recently, the AccuTnl assay was optimized leading to a lower $10 \% \mathrm{CV}$ value of $14 \mathrm{ng} / \mathrm{L} .{ }^{34,50}$

As described previously, the reference populations consisted mostly of apparently healthy subjects, with no details on how the subjects were screened. ${ }^{45,47,48,51-53}$ In the various studies health questionnaires were applied, either alone, ${ }^{32,54}$ or in combination with ECG and routine blood analysis. ${ }^{34,37,49,55,56}$ Eggers et al clearly showed that a lower cutoff was found when screening for cardiovascular diseases $(28 \mathrm{ng} / \mathrm{L})$ in comparison to the unscreened reference population $(44 \mathrm{ng} / \mathrm{L}) .{ }^{50}$

Similar $99^{\text {th }}$ percentile cutoff as indicated by the package insert $(40 \mathrm{ng} / \mathrm{L})$ were mostly described using a wide variety of reference populations. ${ }^{37,45,46,48,52,53,55,56}$. ${ }^{2}$ wer cutoffs were found when less than 300 subjects were included ${ }^{47,51,57}$ or in a relatively young population. ${ }^{32}$ On the other hand, higher $99^{\text {th }}$ percentile concentrations $(60-80 \mathrm{ng} / \mathrm{L})$ were also measured. ${ }^{34,49}$ A sample matrix effect was observed between serum and plasma, ${ }^{49}$ although others opposed this finding. ${ }^{55-57}$

Sex-related differences in the $99^{\text {th }}$ percentile cutoffs were reported to be statistically significant in three studies. ${ }^{50,52,54}$ Ethnicity was also reported to affect the $99^{\text {th }}$ percentile cutoff, ${ }^{54}$ although later on this fact was contradicted. ${ }^{52}$

Conclusion. Wide variations in $10 \% \mathrm{CV}$ values and $99^{\text {th }}$ cutoffs are observed ranging from 14-104 $\mathrm{ng} / \mathrm{L}$ and $13-80 \mathrm{ng} / \mathrm{L}$ respectively. In some but not all studies the $99^{\text {th }}$ percentile was measured with a CV $<10 \%$, indicating guideline acceptance. However, many publications report cutoffs that were not in agreement with the manufacturer's statements.

\section{Architect cTnl assay - Abbott Diagnostics}

The lowest cTn concentration that can be measured with an analytical imprecision of $10 \%$ was reported to be $32 \mathrm{ng} / \mathrm{L}$ by the manufacturer (Abbott Diagnostics, Abbott Park, IL, USA) 
and others. ${ }^{22,56,58,59}$ In the remaining publications, the $10 \% \mathrm{CV}$ values were indicated to be higher, ranging from 40 to $75 \mathrm{ng} / \mathrm{L}^{32,37,60,61}$ Among these studies, two authors described also higher $10 \%$ CV values for Access AccuTnl assay and Vitros ECi Troponin I ES Assay. 32,37

The screening methods for the reference populations were primarily not specified. ${ }^{45,58-60}$ For this assay, only three reference populations were screened by means of medical history check, ECG and blood laboratory tests. ${ }^{32,37,56}$ One study included less than the advised minimum of 300 subjects. ${ }^{37}$ The reference population, used by the manufacturer, consisted of 224 apparently healthy subjects.

For the $99^{\text {th }}$ percentiles cutoff a concentration of $28 \mathrm{ng} / \mathrm{L}$ was found by the manufacturer and many others report similar results. ${ }^{45,58,59,61}$ Six independent studies, report cutoffs lower than $20 \mathrm{ng} / \mathrm{L} .^{22,32,37,45,60}$ Only one study reported noticeably higher $99^{\text {th }}$ percentile cutoffs in a reference population of 442 subjects, screened by means of medical history check, ECG and routine blood analysis. ${ }^{56}$

Age and sex related differences in $99^{\text {th }}$ percentile cutoffs were not statistically significant.

In summary, upper reference limits varied between 13 and $30 \mathrm{ng} / \mathrm{L}$, while for the $10 \%$ $\mathrm{CV}$ cutoff, values between 30 and $76 \mathrm{ng} / \mathrm{L}$ were reported.

Table 1 (next page): Analytical characteristics, $99^{\text {th }}$ percentile cutoffs, and baseline characteristics of the reference study populations of seven cTn assays frequently used in clinical practice. Included are the five high-sensitivity assays: high sensitivity cTnT (hs-cTnT, Roche Diagnostics), ADVIA Centaur TnlUltra (Siemens Healthcare Diagnostics), Stratus CS Acute Care cTnl (Siemens Healthcare Diagnostics), Dimension Vista cTnl (Siemens Healthcare Diagnostics) and Vitros ECi cTnl ES (Ortho Clinical Diagnostics) assays. Also included are two "clinically usable" assays: Access AccuTnl (Beckman Coulter) and Architect cTnl assay (Abbott Diagnostics). Distinction is made between populations with sufficient subjects $(n \geq 300)$ and smaller populations $(n<300) .{ }^{8 *}$ 


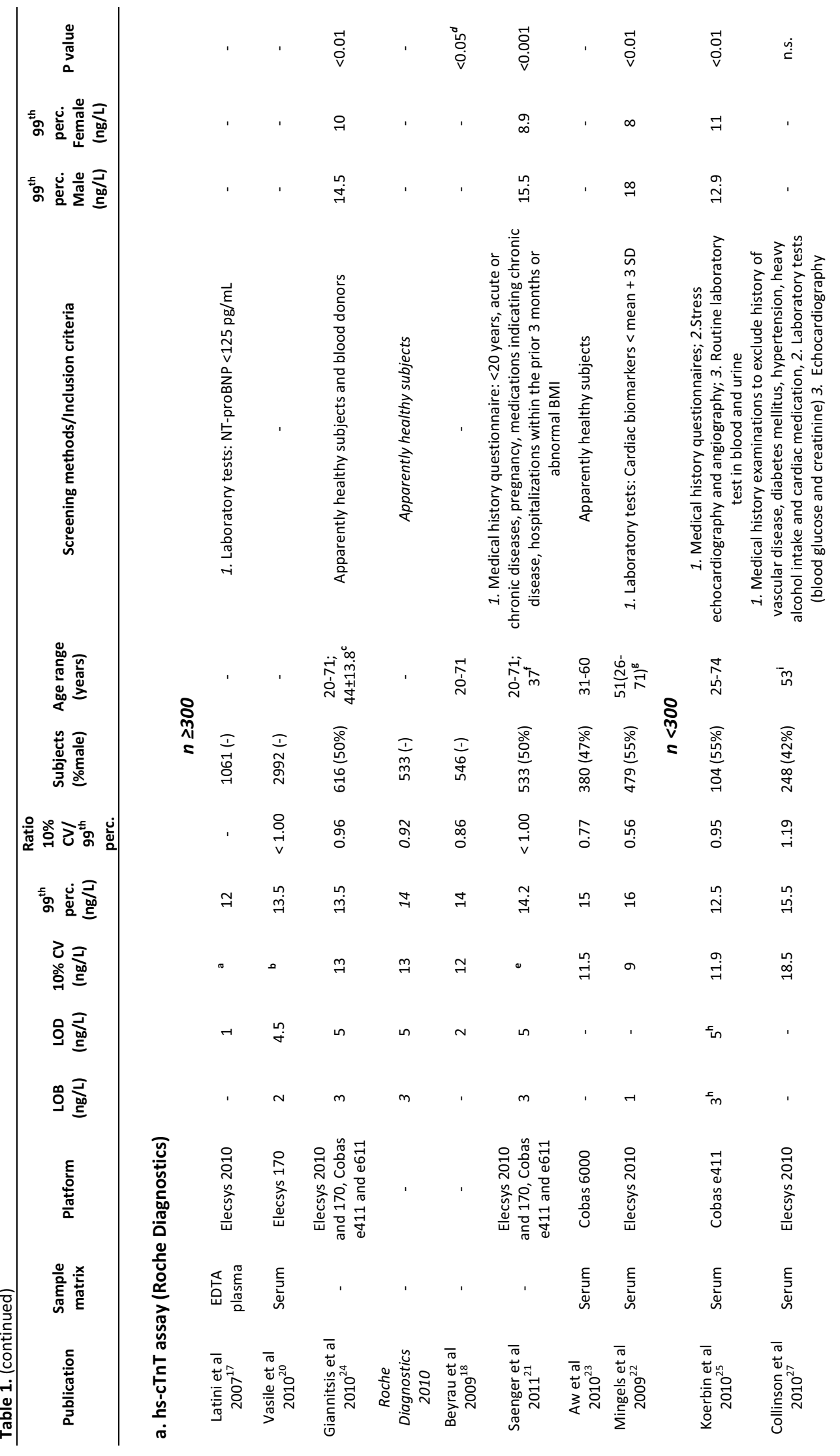




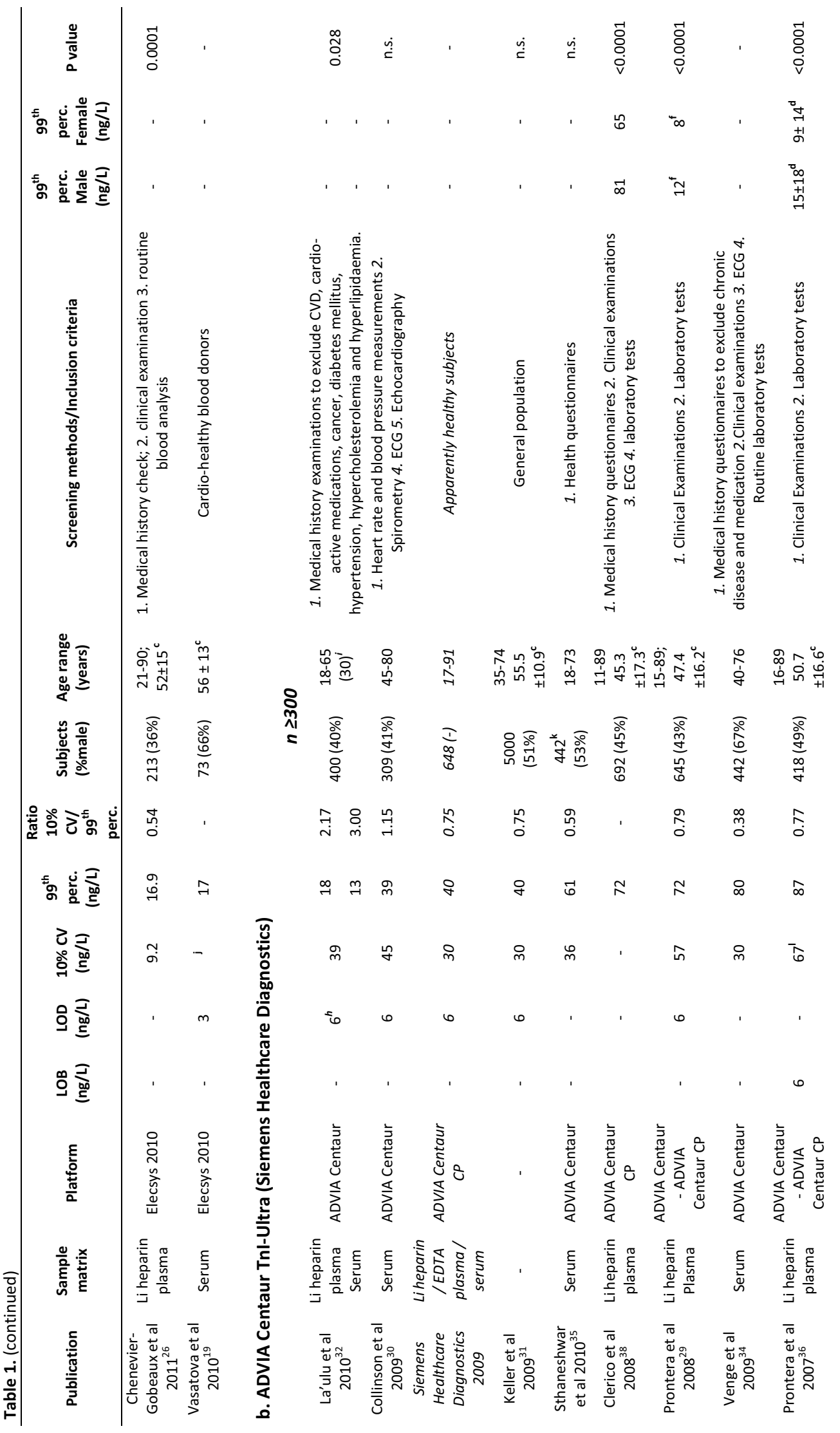




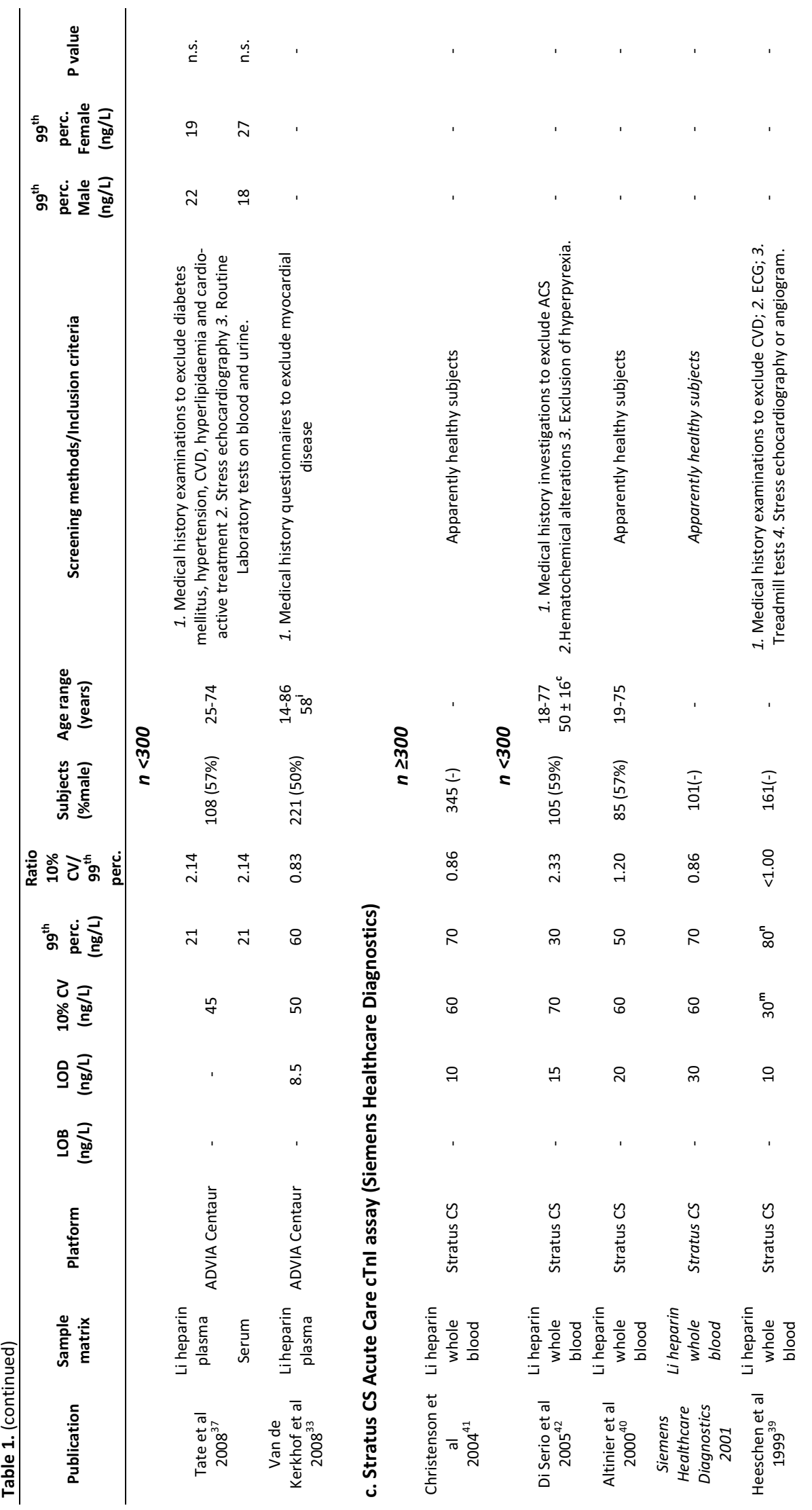




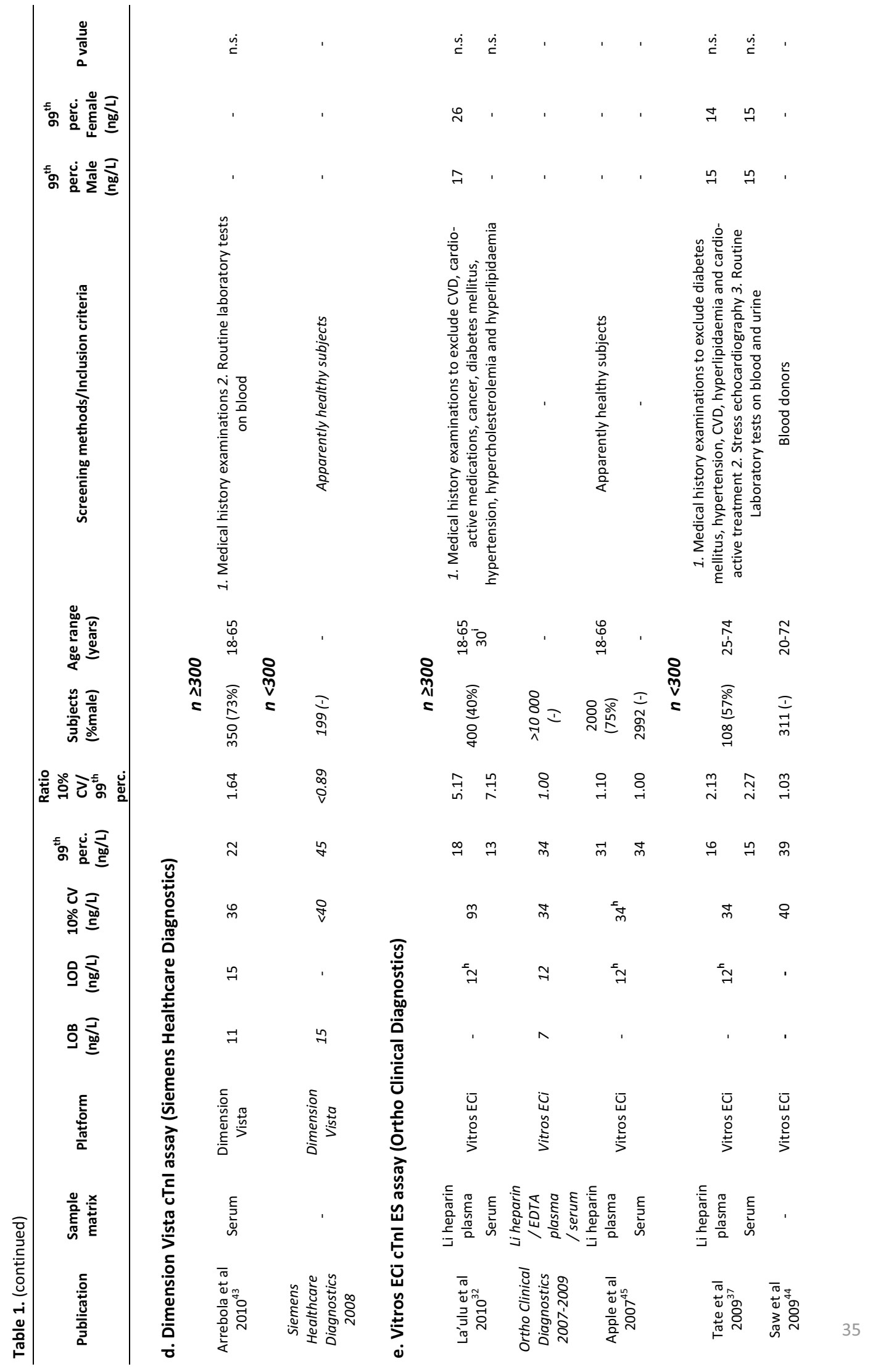




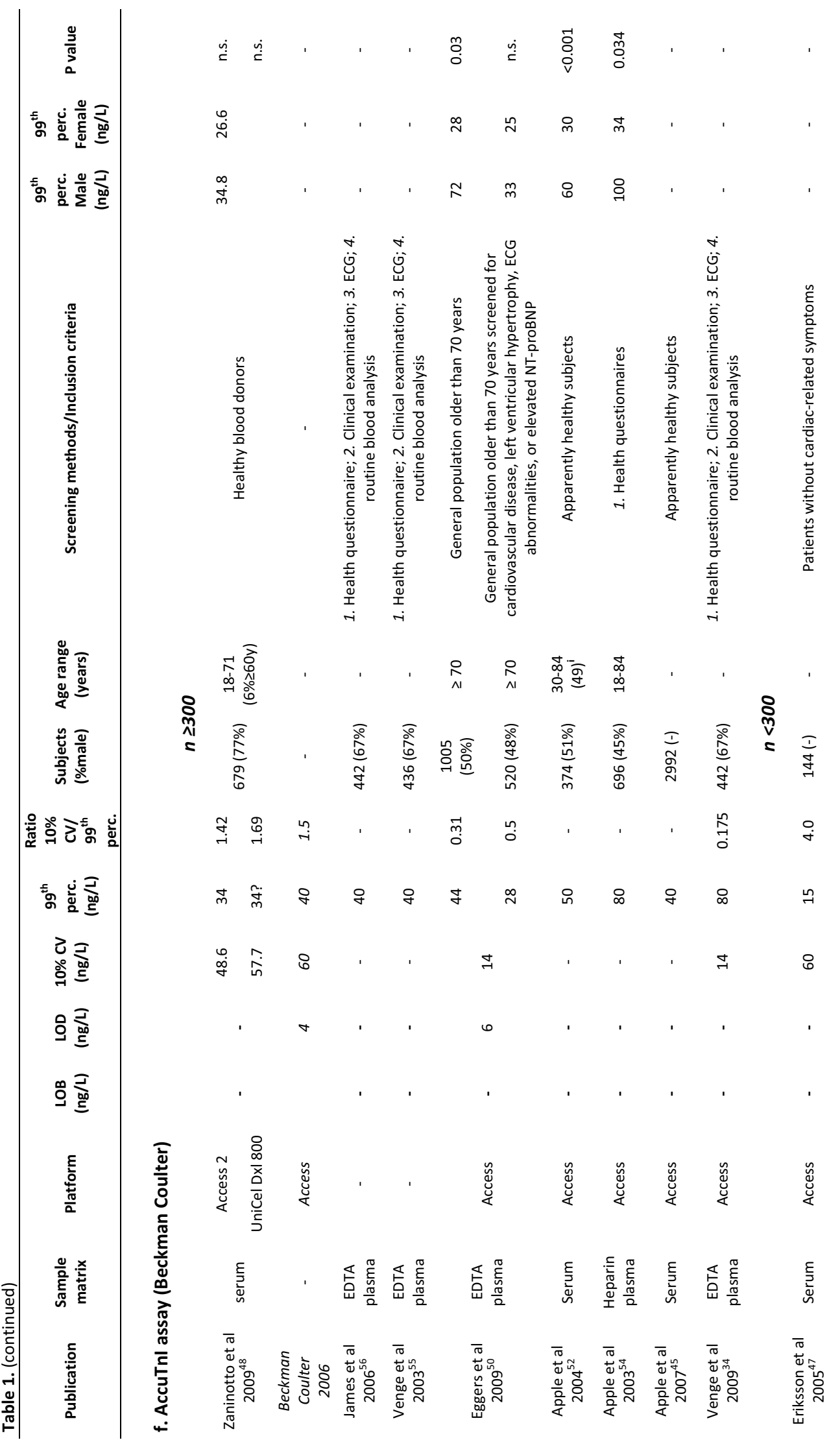




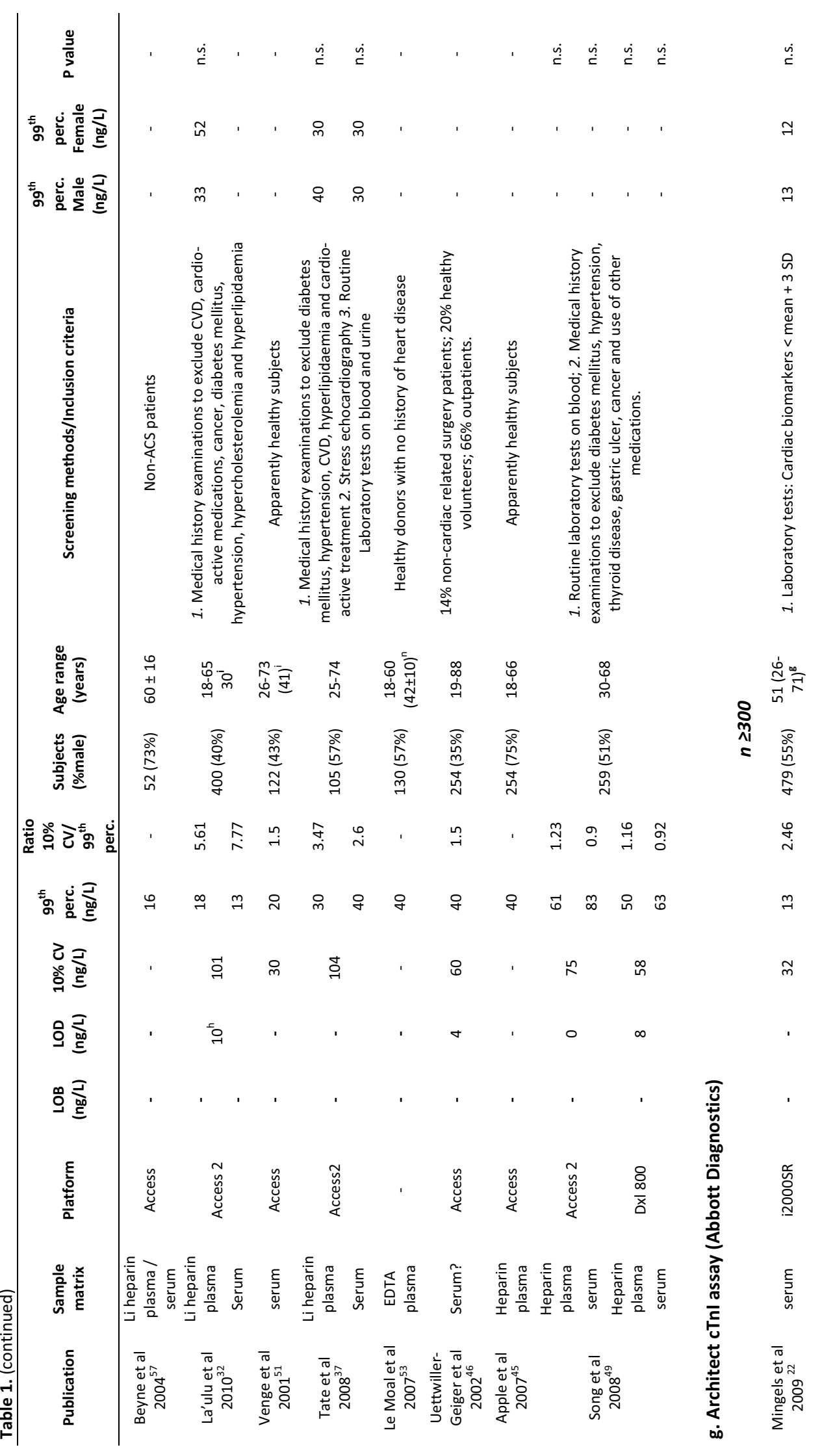




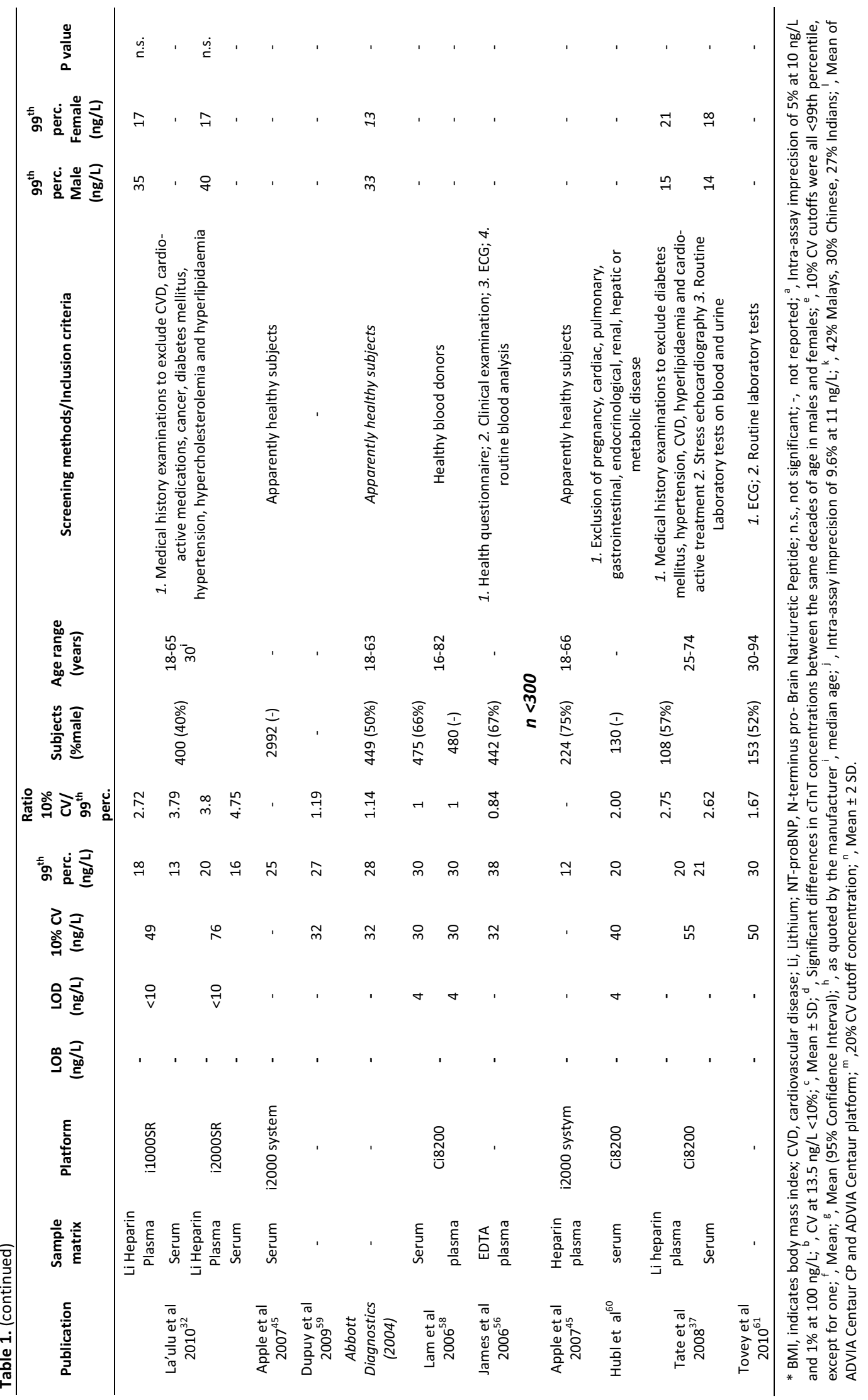




\section{How were reference populations established? A summary}

Despite all efforts, heterogeneity in the functional sensitivity and $99^{\text {th }}$ percentile cutoffs is clearly demonstrated in Table 1 . The reported upper reference limits deviated from the cutoffs described by the manufacturer, due to variations in sample size, health condition, age, sex and ethnicity. In addition, (pre-) analytical factors may have contributed to cutoff discrepancies e.g. serum versus plasma samples ${ }^{11,62}$ or the use of different platforms. Variations in the determination (e.g. using variable number of days, replicates or different platforms) of the functional sensitivity, could explain the range of $10 \%$ or $20 \%$ CV cutoffs that have been reported in literature.

The broad variation is apparent from the reviewed studies (66 studies; 53 publications) with sample sizes from $<100$ to $>10,000$ subjects. Most studies $(40 \%)$ included less than the advised minimum of 300 subjects and $15 \%$ of the studies collected even less than 120 subjects. Notice that with a sample size of 120,300 or 1000 subjects the $99^{\text {th }}$ percentile cutoff can be strongly affected by respectively only 1,3 or 10 subjects.

Another concern is the variation in inclusion criteria among studies. The majority of studies (50\%) reported no inclusion criteria, suspecting that no extensive screening was performed. In $26 \%$ of the studies, the reference populations were screened by means of medical history questionnaires and/or laboratory tests. In $24 \%$ of the cases it was combined with ECG or cardiac imaging techniques such as stress echocardiography or angiography. Herein, no reference population met the selection criteria described in the guidelines ${ }^{6}$ However, four studies are eligible, reporting a reference population comprised of more than 300 individuals and screened by means of non-invasive imaging. ${ }^{30,34,38,56}$ It must be noted that in two of these studies the same reference population was used (SWISCH study) ${ }^{34,56}$ Importantly, studies that most extensively screened their reference population, reported lower $99^{\text {th }}$ percentile cutoff concentrations. ${ }^{25,30,37,50,55,56}$ Evidently, in smaller reference populations more stringent screening methods can be performed, improving the composition of the reference population..$^{25,27,37,42}$ This is counterbalanced by the fact that a small sample size makes the $99^{\text {th }}$ percentile cutoff more prone to outliers.

Ideally, the distribution of sex and age in the reference population resembles those of a typical group of AMI patients. ${ }^{6,15}$ However, age distribution in the reference populations varied widely among studies. A majority chose a broad age distribution (25-75 years), but 
some reference populations were composed of merely younger ${ }^{32,43}$ or older subjects. ${ }^{30,34}$ Only two publications use a group of reference individuals in the same age category as AMI patients (>45 years). ${ }^{30,34}$ Although, we estimate that collecting a younger reference population should be better for prognostic purposes. The $99^{\text {th }}$ percentile cutoff concentration had a tendency to increase with age..$^{22,25,30,34,36}$ This supports recent ROC analysis from Reiter et al who reported that optimal diagnosis for AMI was achieved at higher cutoff concentrations in elderly as compared to younger subjects (cutoff, 70 years). ${ }^{63}$ Moreover, sex specific differences in the $99^{\text {th }}$ percentile cutoff concentration are frequently reported. The cTnT and cTnl assays measured respectively 1.7- and 1.2-fold higher cTn levels in men than women, with mean/median concentrations statistically higher in males. ${ }^{21,22,24,25,29,36-38}$ Also ethnicity was reported to influence the $99^{\text {th }}$ percentile cutoff, ${ }^{54}$ although others contradict this finding. ${ }^{19,52}$ Taken together, these findings add to the existing body of evidence that sex and age influence cTn levels. ${ }^{64}$ Future research should reveal whether sex- and age-specific cutoff values can improve diagnostic or prognostic performance.

\section{Current status on biological variation}

The NACB recommends using the rising and/or falling pattern of cardiac troponin obtained by serial measurements. They propose $a \geq 20 \%$ change in cTn concentration to be suggestive of AMI. ${ }^{4}$ A twenty percent difference exceeds 3 analytical standard deviations, but it neglects the contribution of the biological variation to cardiac troponin levels when measuring in the lower range. ${ }^{65} \mathrm{~A}$ better approach may be the reference change value (RCV). The RCV is established in healthy individuals and calculated as follows: $\mathrm{RCV}=\mathrm{z} \times \sqrt{2} \times \sqrt{\mathrm{CV}_{\mathrm{A}}^{2}+\mathrm{CV}_{1}^{2}}$; where $\mathrm{z}$ is the standard deviation for a certain probability, ${ }^{65}$ and $\mathrm{CV}_{\mathrm{A}}$ and $C V_{1}$ represent the analytical and biological variation respectively. When troponin concentrations are measured at two time points, and the subtraction of both values exceeds a critical value, defined by the RCV, the change is considered significant. Using this approach, $\mathrm{Wu}$ et al established the log-normal RCV for an hs-cTnl assay (Erenna Immunoassays, Singulex). They concluded that an increase of $48 \%$ or a decrease of $32 \%$ over a four hour period (short term), and $+81 \%$ or $-32 \%$ change over an eight week period (long term) is required. ${ }^{66}$ Log-normal RCVs have also been calculated for cTnT using the hs-cTnT assay. ${ }^{20}$ 
For short term changes, the cTnT concentration must rise $85 \%$ to exceed the critical difference, whereas for long term changes a $>3$ fold increase is required.

Another way to express the biological variation is the index of individuality (II). The II can be calculated by the simplified formula: $\mathrm{CV}_{\mathrm{I}} / \mathrm{CV}_{\mathrm{G}}$ (within subject variation/between subject variation). ${ }^{67}$ By definition, reference intervals are more useful for biomarkers with a high II $(>1.4)$ than for markers with a low II $(<0.6) .{ }^{68}$ For $c T n l$, the $\mathrm{CV}_{1}$ is smaller than the $\mathrm{CV}_{\mathrm{G}}$, both for short-term and long-term measurements $(9.7 \%$ versus $57 \%$, and $14 \%$ versus $63 \%$ respectively). ${ }^{66}$ This results in a short-term II of 0.21 and a long term II of 0.39 . When the II is low as for cTnl, it has been proposed to subdivide the reference population into more homogenous reference cohorts, which will improve the II and the usefulness of the marker in clinical practice. ${ }^{67}$ The short- and long-term II for cTnT were higher, 0.84 and 1.4, respectively $\left(\mathrm{CV}_{\mathrm{l}}, 48 \%\right.$ and $94 \% ; \mathrm{CV}_{\mathrm{G}}, 86 \%$ and $94 \%$ for short- and long-term, respectively). ${ }^{20}$ Overall, cTnT seems to be more useful than cTnl, but with only one cTnl and one cTnT study published, more studies are required for a more decisive conclusion.

\section{Conclusion and future perspectives}

In general, large heterogeneity in $99^{\text {th }}$ percentile cutoff values of cTn complicates the diagnosis of myocardial infarction. Major causes are lack of cardiac troponin assay harmonization, and non-standardized selection of individuals in healthy reference populations. We reviewed the literature on reference populations for seven (high-)sensitivity assays used in clinical practice and found that the upper reference limits deviated from the package inserts for all assays, although this was less apparent for the hs-cTnT assay.

As for now, the best way to establish a reference population is still debatable. From all reviewed literature, no reference populations were collected according to the guidelines 5,6 although three nearly met the required standards. ${ }^{30,34,38,56} \mathrm{~A}$ total of $40 \%$ of the studies collected less than the advised minimum of 300 subjects for reliable estimation of the $99^{\text {th }}$ percentile cutoff and $50 \%$ of the studies did not report their inclusion criteria. Moreover, there is important suggestive evidence that substantially lower cutoff values were calculated in studies that applied the most stringent selection criteria to their reference group. The available literature supports the concept that age and sex are important determinants of cardiac cTn levels. Men have on average 1.7- and 1.2-fold higher cTn levels, measured with 
the cTnT and cTnl assays respectively, and the $99^{\text {th }}$ percentile cutoff concentration increases with age. $22,25,30,34,36$

There is thus need for a large and highly screened population of cardio-healthy subjects that are preferably sex-and age-matched for AMI patients, although nowadays the value of sex-and age-specific cutoffs remain unclear. As proposed by the IFCC, multicentre studies can be the answer to heterogeneity in reference populations: a large number of reference subjects, collected at national scale that can be adopted by clinical laboratories to determine the $99^{\text {th }}$ percentile cutoff values. ${ }^{69}$ Alternatively, the optimal cutoff value can be defined by ROC analyses, ${ }^{63}$ reference change values, or the $97.5^{\text {th }}$ percentile can be chosen as diagnostic cutoff, ${ }^{1}$ which would be less sensitive to outliers.

Further research should reveal whether more stringent selection criteria and sex/agespecific cutoffs can optimize the use of cTn for diagnostic and prognostic purposes, or whether alternative approaches such as the use of reference change values have added value.

\section{References}

1. Wu AH, Apple FS, Gibler WB, Jesse RL, Warshaw MM, Valdes R, Jr. National Academy of Clinical Biochemistry Standards of Laboratory Practice: recommendations for the use of cardiac markers in coronary artery diseases. Clin Chem. 1999;45:1104-1121.

2. Alpert JS, Thygesen K, Antman E, Bassand JP. Myocardial infarction redefined--a consensus document of the joint European Society of Cardiology/American College of Cardiology committee for the redefinition of myocardial infarction. J Am Coll Cardiol. 2000;36:959-969.

3. Thygesen K, Alpert JS, White HD, et al. Universal definition of myocardial infarction. Circulation. 2007;116:2634-2653.

4. Morrow DA, Cannon CP, Jesse RL, et al. National Academy of Clinical Biochemistry laboratory medicine practice guidelines: clinical characteristics and utilization of biochemical markers in acute coronary syndromes. Circulation. 2007;115:356-375.

5. Apple FS, Jesse RL, Newby LK, et al. National Academy of Clinical Biochemistry and IFCC committee for standardization of markers of cardiac damage laboratory medicine practice guidelines: analytical issues for biochemical markers of acute coronary syndromes. Clin Chem. 2007;53:547-551.

6. Thygesen K, Mair J, Katus $\mathrm{H}$, et al. Recommendations for the use of cardiac troponin measurement in acute cardiac care. Eur Heart J. 2010;31:2197-2204.

7. International Federation of Clinical Chemistry and Laboratory Medicine (IFCC) committee on the standardization of markers of cardiac samage (C-SMCD). Troponin assay analytical characteristics. Available at:

http://www.ifcc.org/PDF/ScientificActivities/IFCC_Troponin_Table_vDec_2010_FINAL_ng_L_28Ja n11.pdf. Accessed 11 June 2011.

8. Apple FS. A new season for cardiac troponin assays: it's time to keep a scorecard. Clin Chem. 2009;55:1303-1306. 
9. Jaffe AS, Apple FS, Morrow DA, Lindahl B, Katus HA. Being rational about (im)precision: a statement from the biochemistry subcommittee of the joint European Society of Cardiology/American College of Cardiology foundation/American Heart Association/world heart federation task force for the definition of myocardial infarction. Clin Chem. 2010;56:941-943.

10. Morrow DA, Antman EM. Evaluation of high-sensitivity assays for cardiac troponin. Clin Chem. 2009;55:5-8.

11. Panteghini M. A critical appraisal of experimental factors influencing the definition of the 99th percentile limit for cardiac troponins. Clin Chem Lab Med. 2009;47:1179-1182.

12. Panteghini M. Assay-related issues in the measurement of cardiac troponins. Clin Chim Acta. 2009;402:88-93.

13. de Lemos JA, Drazner MH, Omland T, et al. Association of troponin T detected with a highly sensitive assay and cardiac structure and mortality risk in the general population. JAMA. 2010;304:2503-2512.

14. defilippi CR, de Lemos JA, Christenson RH, et al. Association of serial measures of cardiac troponin T using a sensitive assay with incident heart failure and cardiovascular mortality in older adults. JAMA. 2010;304:2494-2502.

15. Solberg HE. Establishment and Use of Reference Values. In: Burtis CA, Ashwood ER, Bruns DE, eds. Tietz textbook of clinical chemistry and molecular diagnostics. 4th ed: Elsevier Saunders; 2006:425-448.

16. Pulkki K, Suvisaari J, Collinson P, et al. A pilot survey of the use and implementation of cardiac markers in acute coronary syndrome and heart failure across Europe. The CARdiac MArker Guideline Uptake in Europe (CARMAGUE) study. Clin Chem Lab Med. 2009;47:227-234.

17. Latini R, Masson S, Anand IS, et al. Prognostic value of very low plasma concentrations of troponin T in patients with stable chronic heart failure. Circulation. 2007;116:1242-1249.

18. Beyrau R, Braun S, Dolci A, et al. Multicentre evaluation of a high sensitive Elecsys troponin $T$ assay [Abstract]. Clin Chem. 2009;55:A70.

19. Vasatova M, Pudil R, Tichy $M$, et al. High-sensitivity troponin $T$ as a marker of myocardial injury after radiofrequency catheter ablation. Ann Clin Biochem. 2010:1-3.

20. Vasile VC, Saenger AK, Kroning JM, Jaffe AS. Biological and analytical variability of a novel highsensitivity cardiac troponin T assay. Clin Chem. 2010;56:1086-1090.

21. Saenger AK, Beyrau R, Braun $S$, et al. Multicenter analytical evaluation of a high-sensitivity troponin T assay. Clin Chim Acta. 2011;412:748-754.

22. Mingels A, Jacobs L, Michielsen E, Swaanenburg J, Wodzig W, van Dieijen-Visser M. Reference population and marathon runner sera assessed by highly sensitive cardiac troponin $T$ and commercial cardiac troponin T and I assays. Clin Chem. 2009;55:101-108.

23. Aw TC, Pua SK, Yew L, Lim WR, Tan SP. Performance of a new rapid automated high-sensitive troponin T (hsTnT) immunoassay [Abstract]. Clinical chemistry. 2010;56:C88.

24. Giannitsis E, Kurz K, Hallermayer K, Jarausch J, Jaffe AS, Katus HA. Analytical validation of a highsensitivity cardiac troponin T assay. Clin Chem. 2010;56:254-261.

25. Koerbin G, Tate JR, Hickman PE. Analytical characteristics of the Roche highly sensitive troponin T assay and its application to a cardio-healthy population. Ann Clin Biochem. 2010:1-5.

26. Chenevier-Gobeaux C, Meune C, Blanc MC, Cynober L, Jaffray P, Lefevre G. Analytical evaluation of a high-sensitivity troponin $\mathrm{T}$ assay and its clinical assessment in acute coronary syndrome. Ann Clin Biochem. 2011;48:452-458.

27. Collinson P, Heung Y, Gaze D, Boa F, Senior R. The assay performance and 99th percentile reference limit for cardiac troponin $\mathrm{T}$ using a new high sensitivity assay in a fully characterised reference population [Abstract]. Clinical Chemistry. 2010;56:C50.

28. Wallace TW, Abdullah SM, Drazner MH, et al. Prevalence and determinants of troponin $\mathrm{T}$ elevation in the general population. Circulation. 2006;113:1958-1965.

29. Prontera C, Fortunato A, Storti S, et al. Evaluation of analytical performance of Advia ${ }^{\circledR} \mathrm{Tnl}$ ultra immunoassay and comparison with Access ${ }^{\circledR}$ AccuTnl(TM) method. Immuno-analyse \& Biologie Spécialisée. 2008;23:311-318. 
30. Collinson PO, Clifford-Mobley O, Gaze D, Boa F, Senior R. Assay imprecision and 99th-percentile reference value of a high-sensitivity cardiac troponin I assay. Clin Chem. 2009;55:1433-1434.

31. Keller T, Zeller T, Peetz D, et al. Sensitive troponin I assay in early diagnosis of acute myocardial infarction. N Engl J Med. 2009;361:868-877.

32. La'ulu SL, Roberts WL. Performance characteristics of five cardiac Troponin I assays. Clin Chim Acta. 2010;411:1095-1101.

33. van de Kerkhof D, Peters B, Scharnhorst V. Performance of the Advia Centaur second-generation troponin assay Tnl-Ultra compared with the first-generation cTnl assay. Ann Clin Biochem. 2008;45:316-317.

34. Venge $P$, James $S$, Jansson $L$, Lindahl B. Clinical performance of two highly sensitive cardiac troponin I assays. Clin Chem. 2009;55:109-116.

35. Sthaneshwar P, Jamaluddin FA, Fan YS. Reference value for cardiac troponin I in a multi-ethnic group. Pathology. 2010;42:454-456.

36. Prontera C, Fortunato A, Storti $S$, et al. Evaluation of analytical performance of the Siemens ADVIA Tnl ultra immunoassay. Clin Chem. 2007;53:1722-1723.

37. Tate JR, Ferguson W, Bais R, Kostner K, Marwick T, Carter A. The determination of the 99th centile level for troponin assays in an Australian reference population. Ann Clin Biochem. 2008;45:275-288.

38. Clerico A, Fortunato A, Ripoli A, Prontera C, Zucchelli GC, Emdin M. Distribution of plasma cardiac troponin I values in healthy subjects: pathophysiological considerations. Clin Chem Lab Med. 2008;46:804-808.

39. Heeschen C, Goldmann BU, Langenbrink L, Matschuck G, Hamm CW. Evaluation of a rapid whole blood ELISA for quantification of troponin I in patients with acute chest pain. Clin Chem. 1999;45:1789-1796.

40. Altinier S, Mion M, Cappelletti A, Zaninotto M, Plebani M. Rapid measurement of cardiac markers on Stratus CS. Clin Chem. 2000;46:991-993.

41. Christenson RH, Cervelli DR, Bauer RS, Gordon M. Stratus CS cardiac troponin I method: performance characteristics including imprecision at low concentrations. Clin Biochem. 2004;37:679-683.

42. Di Serio F, Amodio G, Varraso L, et al. Integration between point-of-care cardiac markers in an emergency/cardiology department and the central laboratory: methodological and preliminary clinical evaluation. Clin Chem Lab Med. 2005;43:202-209.

43. Arrebola MM, Lillo JA, Diez De Los Rios MJ, et al. Analytical performance of a sensitive assay for cardiac troponin I with loci technology. Clin Biochem. 2010;43:998-1002.

44. Saw S, Wang C, Sethi S. Meeting the challenge of the ESC/ACC definition of myocardial infarction of the new troponin I ES on the VITROS $^{\circledR} 5600$ integrated system and VITROS ${ }^{\circledR}$ ECi immunodiagnostic system [Abstract]. Clin Chem. 2009;55:B51.

45. Apple FS, Murakami MM. Serum and plasma cardiac troponin I 99th percentile reference values for 3 2nd-generation assays. Clin Chem. 2007;53:1558-1560.

46. Uettwiller-Geiger D, Wu AH, Apple FS, et al. Multicenter evaluation of an automated assay for troponin I. Clin Chem. 2002;48:869-876.

47. Eriksson S, Ilva T, Becker C, et al. Comparison of cardiac troponin I immunoassays variably affected by circulating autoantibodies. Clin Chem. 2005;51:848-855.

48. Zaninotto M, Mion MM, Novello E, et al. Precision performance at low levels and 99th percentile concentration of the Access AccuTnl assay on two different platforms. Clin Chem Lab Med. 2009;47:367-371.

49. Song S, Suh B, Lee SG, Kim JH, Kwon OH. Comparison of $10 \%$ coefficient of variation and 99th percentile cutoff of troponin I in serum and heparinized plasma using Access 2 and DxI 800. Clin Chim Acta. 2009;399:117-118.

50. Eggers KM, Jaffe AS, Lind L, Venge $P$, Lindahl B. Value of cardiac troponin I cutoff concentrations below the 99th percentile for clinical decision-making. Clin Chem. 2009;55:85-92. 
51. Venge $P$, Lindahl B, Wallentin L. New generation cardiac troponin I assay for the access immunoassay system. Clin Chem. 2001;47:959-961.

52. Apple FS, Murakami MM. Serum 99th percentile reference cutoffs for seven cardiac troponin assays. Clin Chem. 2004;50:1477-1479.

53. Le Moal E, Giuliani I, Bertinchant JP, Polge A, Larue C, Villard-Saussine S. Earlier detection of myocardial infarction by an improved cardiac Tnl assay. Clin Biochem. 2007;40:1065-1073.

54. Apple FS, Quist HE, Doyle PJ, Otto AP, Murakami MM. Plasma 99th percentile reference limits for cardiac troponin and Creatine Kinase MB mass for use with European Society of Cardiology/American College of Cardiology consensus recommendations. Clin Chem. 2003;49:1331-1336.

55. Venge $P$, Johnston $N$, Lagerqvist $B$, Wallentin L, Lindahl B. Clinical and analytical performance of the liaison cardiac troponin I assay in unstable coronary artery disease, and the impact of age on the definition of reference limits. A FRISC-II substudy. Clin Chem. 2003;49:880-886.

56. James S, FLODin M, Johnston N, Lindahl B, Venge $P$. The antibody configurations of cardiac troponin I assays may determine their clinical performance. Clin Chem. 2006;52:832-837.

57. Beyne $P$, Bouvier $E$, Werner $P$, et al. Emergency department triage of patients with acute chest pain: definition of cardiac troponin I decisional value to manage patients without electrocardiographic evidence of ischemia. Clin Chem Lab Med. 2004;42:556-559.

58. Lam Q, Black M, Youdell O, Spilsbury H, Schneider HG. Performance evaluation and subsequent clinical experience with the Abbott Automated Architect STAT Troponin-I assay. Clin Chem. 2006;52:298-300.

59. Dupuy AM, Bouvier S, Bargnoux AS, Badiou S, Cristol JP. Clinical efficacy of two cardiac troponin I assays. Clin Chem Lab Med. 2009;47:1013-1015.

60. Hubl W, Demant T, Gladrow E. Evaluation of the ARCHITECT STAT troponin-I assay. Clin Lab. 2005;51:251-255.

61. Tovey JA, Brain A, Penney MD. Calculation of the 99th percentile upper reference limit and clinical decision concentration of the Abbott STAT Tnl assay. Ann Clin Biochem. 2010;47:576-577.

62. van de Kerkhof D, Peters B, Scharnhorst V. Troponin I concentrations in heparinized plasma and serum differ when measured with the Advia Centaur Tnl-Ultra assay. Scand J Clin Lab Invest. 2008;45:316-317.

63. Reiter $\mathrm{M}$, Twerenbold R, Reichlin $\mathrm{T}$, et al. Early diagnosis of acute myocardial infarction in the elderly using more sensitive cardiac troponin assays. Eur Heart J. 2011;32:1379-1388.

64. Roger VL, Go AS, Lloyd-Jones DM, et al. Heart disease and stroke statistics--2011 update: a report from the American Heart Association. Circulation. 2011;123:e18-e209.

65. Fraser CG, Harris EK. Generation and application of data on biological variation in clinical chemistry. Crit Rev Clin Lab Sci. 1989;27:409-437.

66. Wu AH, Lu QA, Todd J, Moecks J, Wians F. Short- and long-term biological variation in cardiac troponin I measured with a high-sensitivity assay: implications for clinical practice. Clin Chem. 2009;55:52-58.

67. Petersen PH, Fraser CG, Sandberg S, Goldschmidt H. The index of individuality is often a misinterpreted quantity characteristic. Clin Chem Lab Med. 1999;37:655-661.

68. Harris EK. Effects of intra- and interindividual variation on the appropriate use of normal ranges. Clin Chem. 1974;20:1535-1542.

69. Ceriotti F. Common reference intervals: the IFCC position. Clin Biochem. 2009;42:297. 



\section{Reference population and marathon runner sera assessed by high-} sensitivity cardiac troponin $\mathrm{T}^{*}$ and commercial cardiac troponin $\mathrm{T}$ and I assays

Background: Endurance exercise can increase cardiac troponin (cTn) concentrations as high as those seen in cases of minor myocardial infarction. The inability of most cTn assays to reliably quantify cTn at very low concentrations complicates a thorough data analysis, and the clinical implications of such increases remain unclear. The application of recently developed high-sensitivity cTn immunoassays may help resolve these problems.

Methods: We evaluated the pre-commercial high-sensitivity cardiac troponin T (hs-cTnT) assay from Roche Diagnostics and the Architect cardiac troponin I (cTnI) assay from Abbott Diagnostics by testing samples from a reference population of 546 individuals and a cohort of 85 marathon runners. We also measured the samples with the current commercial cTnT assay for comparison.

Results: Although the hs-cTnT and Architect cTnl assays were capable of measuring cTn concentrations at low concentrations $(<0.01 \mu \mathrm{g} / \mathrm{L})$, only the hs-cTnT assay demonstrated a CV of $<10 \%$ at the 99th percentile of the reference population and a near-gaussian distribution of the measurements. After a marathon, $86 \%$ of the runners had cTnT concentrations greater than the 99th percentile with the hs-cTnT assay, whereas only $45 \%$ of the runners showed increased concentrations with the current cTnT assay. cTn concentrations remained significantly increased the day after the marathon. A multiple regression analysis demonstrated marathon experience and age to be significant predictors of post-marathon cTn concentrations $(P<0.05)$.

Conclusions: The hs-cTnT assay was the only assay tested with a performance capability sufficient to detect cTn concentrations in healthy individuals. The number of runners with increased cTn concentrations after a marathon depends highly on an assay's limit of detection. The assay in this study with the lowest detection limit, the hs-cTnT assay, showed that almost all runners had increased cTn concentrations. The clinical implications of these findings require further investigation.

Part of this work has been published in: Mingels A, Jacobs L, Michielsen E, Swaanenburg J, Wodzig W, Van Dieijen-Visser M. Clin Chem 2009;55:101-108 and Jacobs L, Van de Kerkhof J, Mingels A, Kleijnen V, Van der Sande F, Wodzig W, Kooman J, Van Dieijen-Visser M. Ann Clin Biochem 2009;46:283-90.

\footnotetext{
* At the time of investigation, the high-sensitivity cardiac troponin T (hs-cTnT) assay was only precommercially available.
} 
Regular exercise is part of a healthy lifestyle and aids in the prevention of cardiovascular disease. ${ }^{1}$ In endurance exercise such as marathon running, however, physical collapse is frequently observed during and after races, and such collapses are often associated with coronary artery disease or left ventricular hypertrophy. ${ }^{1-3}$ The risk for such a cardiac event has been suggested to be comparable with that encountered in other daily activities and thus seems relatively low. ${ }^{2-4}$ Nevertheless, the concentrations of highly specific cardiac markers such as the cardiac troponins (cTn) are known to increase after prolonged exercise to concentrations similar to those seen after a minor myocardial infarction, ${ }^{5-9}$ as we have recently reviewed for cardiac troponin $\mathrm{T}(\mathrm{cTnT}) .{ }^{10}$ Because the consequences of $\mathrm{cTn}$ release are still unclear, the phenomenon of exercise-induced cTn release is an active topic of discussion and requires further study.

The recent development of more sensitive cTnT and cardiac troponin I (cTnl) immunoassays and their evaluation in different clinical settings ${ }^{11-13}$ have prompted a redefinition of the diagnosis of acute myocardial infarction (AMI) as follows: an increase and/or decrease in the concentrations of cardiac markers, preferably cTnT or cTnl, should be documented by at least one observation above the $99^{\text {th }}$ percentile value of the reference population, and such results should be accompanied by clinical, electrocardiographic, or imaging findings. ${ }^{14,15}$ Until recently, however, most cTn assays lacked an analytical performance sufficient to detect cTn concentrations in a reference population or to distinguish reference values from the analytical noise. The inadequacy of cTn assays can be attributed either to the limit of detection (LOD) of the cTn assay being higher than reference values or to assay imprecision (coefficient of variation, CV) being $>10 \%$ at the $99^{\text {th }}$ percentile value of the reference population. ${ }^{16-18}$

Because of the wide variation in cTn assays, comparisons of previous studies of exerciseinduced cTn release make sense only for studies that have used the same cTn immunoassay. Such comparisons are especially difficult for cTnl studies because, in contrast to the patented cTnT assay, the approximately $20 \mathrm{cTnl}$ immunoassays that have been developed use different antibodies directed against different epitopes. ${ }^{14,16,17,19}$ In addition, the various assays use different calibrator and control materials. We previously demonstrated that the CTnT concentration increases after prolonged exercise by $59 \%$ on average. ${ }^{10}$ In brief, exercise-induced cTn release is characterized by a peak after the event is finished and a return to baseline concentrations within 1 day. ${ }^{10}$ In the presence of clinical symptoms, 
exercise-induced cTn release would be indicative of $\mathrm{AMI}$ and would require further investigation. The use of recently developed high-sensitivity cTn assays may provide new insights into the exercise-induced release of cTn.

We studied the analytical performance of 2 recently introduced cTn assays, the precommercial high-sensitivity cTnT (hs-cTnT) assay from Roche Diagnostics and the Architect cTnl assay from Abbott Diagnostics. cTn concentrations were investigated both in a reference population and in a cohort of marathon runners. We included the current commercially available cTnT assay (fourth generation) in the study for comparison.

\section{Methods}

\section{Reference population}

The reference population consisted of 546 apparently healthy persons from a health-check program at our hospital (www.happyazm.nl), and all individuals provided informed consent. To rule out individuals with cardiac syndromes, we included individuals in the study only when the following cardiac biomarker concentrations were all available: creatine isoenzyme MB, N-terminal pro-B-type natriuretic peptide, CTnT and cTnI. Consequently, we excluded 45 individuals from the reference population. We also excluded 22 individuals because the concentration of one of these 4 biomarkers exceeded the mean $+3 * S D s$ : creatine kinase isoenzyme MB mass (male cutoff, $>10 \mu \mathrm{g} / \mathrm{L}$; female cutoff, $>7.9 \mu \mathrm{g} / \mathrm{L}$; maximum, $13.37 \mu \mathrm{g} / \mathrm{L}$ ) in 10 individuals, $\mathrm{N}$-terminal pro-B-type natriuretic peptide concentration (cutoff, $>41$ $\mathrm{pmol} / \mathrm{L}$; maximum, $166 \mathrm{pmol} / \mathrm{L}$ ) in 8 individuals, and cTn concentration (cTnT maximum, $0.134 \mu \mathrm{g} / \mathrm{L} ; \mathrm{cTnl}$ maximum, $0.217 \mu \mathrm{g} / \mathrm{L}$ ) in 4 individuals.

\section{Marathon population}

Of the 836 runners who participated in the 2007 Maas Marathon (42.2 km), 85 runners were enrolled in the present study. This study was approved by the ethics committee (Maastricht University Medical Center, the Netherlands), and all participants signed informed consent forms. The maximum temperature on the day of the marathon was $23.4^{\circ} \mathrm{C}$ with a south wind $<14 \mathrm{~m} / \mathrm{s}$. We collected serum samples $0-2 \mathrm{~h}$ before the race, $<1 \mathrm{~h}$ after the race, and on the day after the race in a subgroup of 23 runners whom we selected for logistical reasons. 


\section{Biomarker measurement}

The serum samples were clotted, centrifuged, and stored at $-80^{\circ} \mathrm{C}$ until analysis. cTnl was measured with the Architect i2000SR (Abbott Diagnostics), with the LOD of $0.009 \mu \mathrm{g} / \mathrm{L}$, a CV of $\leq 10 \%$ at $0.032 \mu \mathrm{g} / \mathrm{L}$, and the $99^{\text {th }}$ percentile cutoff of $0.012 \mu \mathrm{g} / \mathrm{L}$, as provided by the manufacturer. We measured cTnT on the Elecsys 2010 instrument (Roche Diagnostics) with the current commercially available cTnT immunoassay (fourth generation), with an LOD of $<0.01 \mu \mathrm{g} / \mathrm{L}$, a CV $\leq 10 \%$ at $0.03 \mu \mathrm{g} / \mathrm{L}$, and a $99^{\text {th }}$ percentile cutoff at $<0.01 \mu \mathrm{g} / \mathrm{L}$. cTnT was also measured with the pre-commercial hs-cTnT assay. Complete validation of the hs-cTnT assay (same lot number) was performed in the research and development department of Roche Diagnostics. Intra-assay CVs were 5.7 and $0.5 \%$ at 0.022 and $2.98 \mu \mathrm{g} / \mathrm{L}$, respectively; interassay CVs were 3.0 and $1.4 \%$ at 0.021 and $3.03 \mu \mathrm{g} / \mathrm{L}$, respectively. The linearity of the hscTnT assay was evaluated by serial dilution, from 1 part serum plus 9 parts diluent to 9 parts serum plus 1 part diluent (initial cTnT concentration in serum, $9.5 \mu \mathrm{g} / \mathrm{L}$; Diluent Universal, Roche Diagnostics). The measured CTnT concentrations deviated from the expected concentrations by factors of 0.99 to 1.05 . A comparison of the current cTnT assay and the hscTnT assay (cTnT up to $8 \mu \mathrm{g} / \mathrm{L}, \mathrm{n}=160$ ) yielded the following regression equation: $\mathrm{y}=0.996 \mathrm{x}+$ $0.003 \mu \mathrm{g} / \mathrm{L}$, where $\mathrm{x}$ represents results obtained for the current commercial cTnT assay and $\mathrm{y}$ represents results for the hs-cTnT assay $\left[r=0.9926 ; 95^{\text {th }}\right.$ percentile of the residual distribution from the median is 0.331 (Passing-Bablok regression analysis)]. We also measured creatine kinase and albumin concentrations with the Synchron LX 20 instrument (Beckman Coulter).

\section{Statistical analysis}

Data were analyzed with SPSS, Version 13.0. A nonparametric approach was used to calculate the upper reference limits $\left(97.5^{\text {th }}\right.$ and $99^{\text {th }}$ percentiles), and the KolmogorovSmirnov test was used to evaluate whether biomarker data deviated from a gaussian distribution. The LOD was defined by the sum of the mean of 10 measurements of cTnnegative serum $+3 \mathrm{SDs}$, but, hindsight, more accurate would be to describe this as the LOB. For variables with a gaussian distribution, we used the paired-samples $t$-test to evaluate differences between pre- and post-exercise samples and used the independent-samples $t$ test to test sex differences. Multiple regression analysis was used to evaluate possible associations of sex, age, body mass index, and experience (number of prior completed marathons) with post-marathon cTn concentration. We log-transformed the data with non- 
gaussian distributions and analyzed the data as described above if the transformed data approximated a gaussian distribution. For variables with a non-gaussian distribution, we analyzed the original data with the nonparametric Wilcoxon signed rank test and the MannWhitney U-test. For statistical calculations, CTnT concentrations less than the LOD were set equal to the LOD. Unless otherwise stated, the threshold for statistical significance was set at a P level of 0.05 .

A

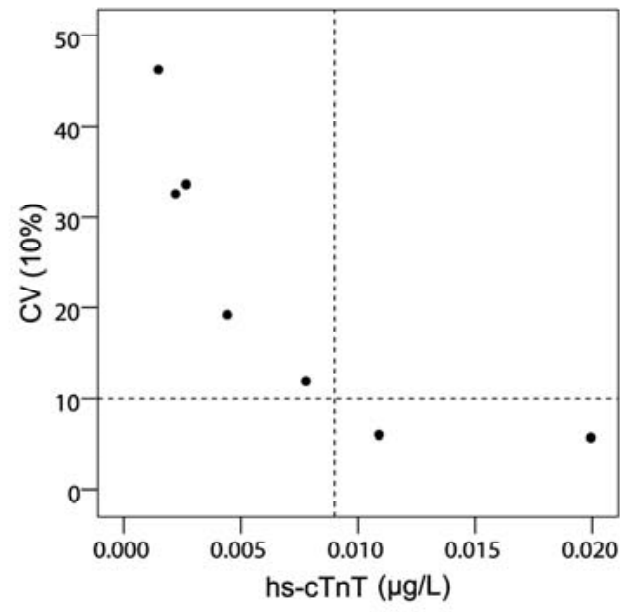

B

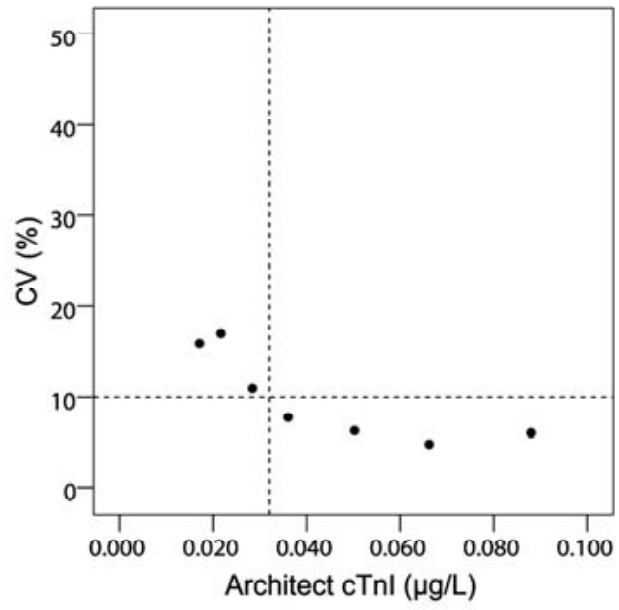

Figure 1: Precision profiles using a panel of serum samples as established for (A) the hs-cTnT assay with $\mathrm{CV}=10 \%$ at $0.009 \mu \mathrm{g} / \mathrm{L}$ and for (B) the Architect cTnl assay with $\mathrm{CV}=10 \%$ at $0.032 \mu \mathrm{g} / \mathrm{L}$.

\section{Results}

We used the NCCLS (now CLSI) EP5 guideline to establish precision profiles for the hs-cTnT and Architect CTnI assays. As shown in Figure 1, the assay profiles produced 10\% CV cutoff concentrations at 0.009 and $0.032 \mu \mathrm{g} / \mathrm{L}$, respectively. We used 10 measurements of cTnnegative serum (mean $+3^{*} \mathrm{SD}$ ) to establish LODs for the hs-cTnT and Architect cTnl assays. The LOD was $<0.001 \mu \mathrm{g} / \mathrm{L}$ for the hs-cTnT assay and $0.009 \mu \mathrm{g} / \mathrm{L}$ for the Architect cTnl assay.

Figure 2 shows cTn concentrations obtained for the reference population. With the Architect cTnl assay, almost all measurements (97\%) were below the LOD. In contrast, the hs-cTnT assay yielded measurable concentrations for most of the samples in the reference population. For the Architect cTnl assay, the $99^{\text {th }}$ percentile value $(0.013 \mu \mathrm{g} / \mathrm{L})$ was less than the $10 \% \mathrm{CV}$ value. In contrast, the hs-cTnT assay had a CV of $<10 \%$ at the $99^{\text {th }}$ percentile 

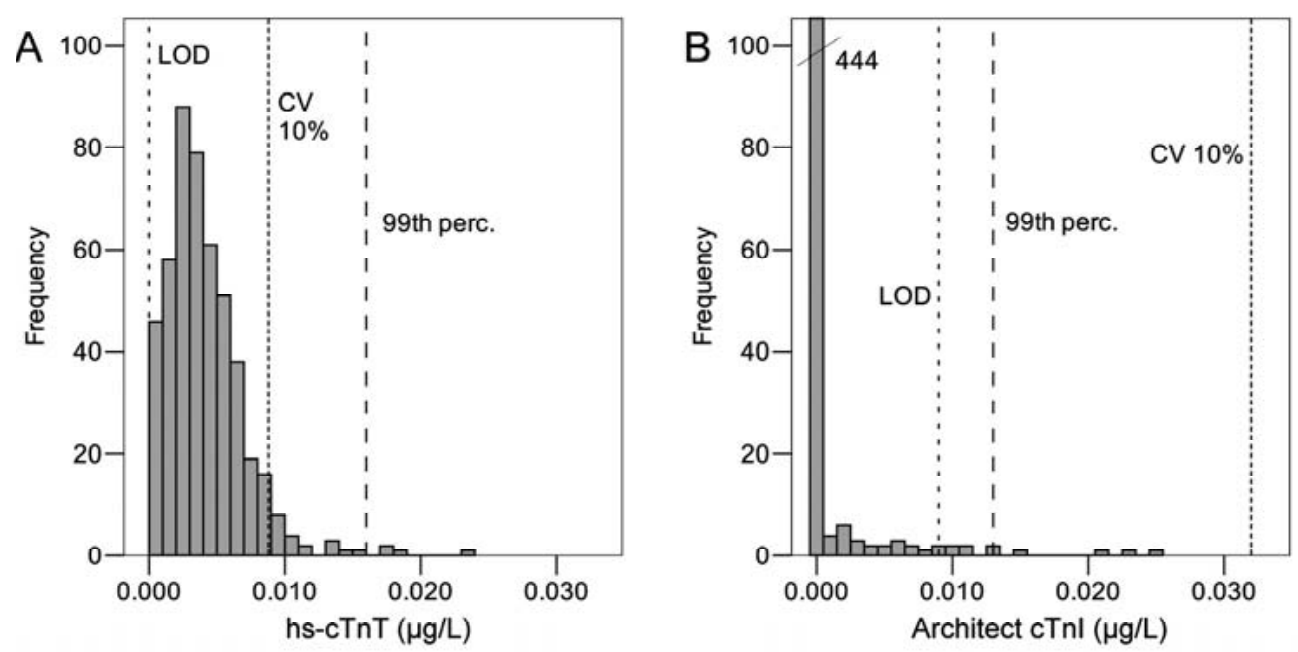

Figure 2: cTn concentrations in the reference population $(n=479)$ as measured with the $(A)$ hs-cTnT and (B) Architect cTnl assay. According to the $4^{\text {th }}$ generation CTnT assay, for all samples the cTn concentration was below LOD $(<0.01 \mu \mathrm{g} / \mathrm{L})$. See also comments in methods section regarding LOD.

Table 1: cTn reference values as measured with the hs-cTnT and Architect cTnl assays. ${ }^{a}$

\begin{tabular}{lcc}
\hline Study population & $\begin{array}{c}\text { hs-cTnT assay } \\
\mu \mathrm{g} / \mathrm{L}\end{array}$ & $\begin{array}{c}\text { Architect cTnl assay } \\
\mu \mathrm{g} / \mathrm{L}^{\mathrm{b}}\end{array}$ \\
\hline $\begin{array}{l}\text { Total } \mathrm{n}=479 \\
\text { mean }\end{array}$ & 0.004 & 0.001 \\
median & 0.004 & $<0.001$ \\
$97.5^{\text {th }}$ percentile & 0.011 & 0.008 \\
$99^{\text {th }}$ percentile & 0.016 & 0.013 \\
Females $\mathrm{n}=215$ & & \\
mean & 0.003 & 0.001 \\
median & 0.003 & 0.000 \\
$97.5^{\text {th }}$ percentile & 0.007 & 0.007 \\
$99^{\text {th }}$ percentile & 0.008 & 0.012 \\
Males $\mathrm{n}=264$ & & \\
mean & 0.005 & 0.001 \\
median & 0.005 & $<0.001$ \\
$97.5^{\text {th }}$ percentile & 0.014 & 0.008 \\
$99^{\text {th }}$ percentile & 0.018 & 0.013 \\
\hline
\end{tabular}

a Data for both assays were not normally distributed $(\mathrm{P}<0.001)$, including after log transformation. Differences between males and females in mean cTn concentration: hs-cTnT assay, $\mathrm{P}<0.001$; Architect cTnl assay, P 0.788 .

${ }^{b}$ Ninety-seven percent of the measurements were below the LOD $(0.009 \mu \mathrm{g} / \mathrm{L})$. 
value $(0.016 \mu \mathrm{g} / \mathrm{L})$. The current commercially available cTnT assay (fourth generation) produced values that were all below the $\operatorname{LOD}(<0.01 \mu \mathrm{g} / \mathrm{L})$. Finally, analysis of the hs-cTnT data revealed cTn reference values that were higher for males than for females $(P<0.001$; Table 1).

Table 2 summarizes the baseline characteristics of the marathon population ( 85 runners). These data are comparable with those of the total marathon population of 836 runners ( $88 \%$ men; mean age, 45 years; mean running time, $3.76 \mathrm{~h}$ ). The participants in our study seem to be highly experienced runners. Fortyfour percent had previously completed 110 marathons, and $36 \%$ had completed $>10$ marathons.

Figure 3 shows that only the hs-cTnT and Architect cTnl assays were able to measure prerace cTn concentrations. All prerace concentrations obtained with the current commercially available cTnT assay were below the assay's LOD. Table 3 shows that prerace concentrations obtained with the hs-cTnT assay were within the reference interval (P 0.282). Pre-race concentrations were significantly higher than the reference values $(P<0.001)$ when the Architect cTnl assay was used; however, pre-exercise concentrations obtained with the Architect cTnl assay should be considered with care, because $82 \%$ were below the LOD of the assay $(<0.009 \mu \mathrm{g} / \mathrm{L})$.

Immediately after the marathon, all runners in the study showed an approximately 10fold increase in cTnT and cTnl concentrations in the hs-cTnT and Architect cTnl assays (Table 3). Albumin concentrations increased only slightly after the marathon; hence, we did not correct cTn concentrations for the effect of dehydration. The hs-cTnT assay showed that the

Table 2: Baseline characteristics of the reference and marathon study population.

\begin{tabular}{|c|c|c|c|c|c|}
\hline & $\begin{array}{l}\text { age }^{a} \\
\text { years }\end{array}$ & $\begin{array}{c}\text { weight }^{a} \\
\text { kg }\end{array}$ & $\begin{array}{c}\text { height }^{\mathrm{a}} \\
\mathrm{m}\end{array}$ & $\begin{array}{c}\text { marathons } \\
\text { completed }^{\mathrm{b}} \\
\mathrm{n}\end{array}$ & $\begin{array}{c}\text { running time }{ }^{\mathrm{a}} \\
\mathrm{h}\end{array}$ \\
\hline \multicolumn{6}{|c|}{ Reference population } \\
\hline Total $(n=479)$ & $51(26-71)$ & & & & \\
\hline Females $(n=215)$ & $49(26-68)$ & & & & \\
\hline Males $(n=264)$ & $53(32-70)$ & & & & \\
\hline \multicolumn{6}{|l|}{ Marathon runners } \\
\hline Total $(n=85)$ & $47(27-67)$ & 70 (53-89) & $1.77(1.58-1.92)$ & 7 (191) & $3.80(2.90-5.00)$ \\
\hline Females $(n=15)$ & $46(27-60)$ & $57(50-65)$ & $1.66(1.58-1.75)$ & $5(57)^{c}$ & $4.18(3.49-5.34)$ \\
\hline Males $(n=70)$ & $47(30-68)$ & $73(61-90)$ & $1.79(1.68-1.93)$ & $8(255)$ & $3.71(2.87-4.69)$ \\
\hline
\end{tabular}


Figure 3: cTn concentrations in the reference and marathon study populations as measured with the current commercially available cTnT assay, the hscTnT assay, and the Architect cTnl assay. Boxes represent the interquartile range (IQR), whiskers represent $1.5 \times$ the IQR values, and horizontal lines represent medians. Extreme values (o) represent values between $1.5 \times I Q R$ and $3 \times I Q R$; outliers $(*)$ represent values $>3 \times$ IQR.

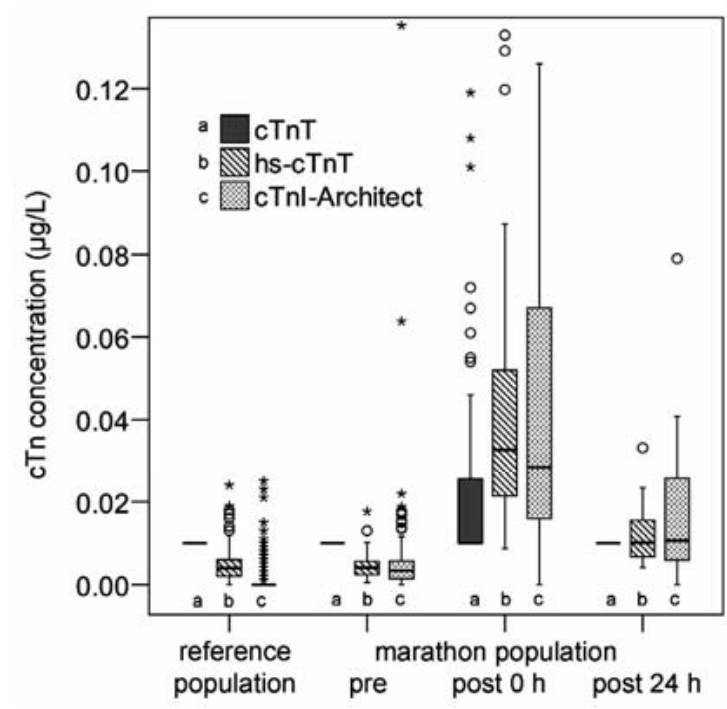

Table 3: Measurement statistics for the marathon study population for serum samples taken before, immediately after, and the day after the race.

\begin{tabular}{|c|c|c|c|c|c|}
\hline & $\begin{array}{l}\mathrm{cTnT} \\
\mu \mathrm{g} / \mathrm{L}\end{array}$ & $\begin{array}{c}\text { hs-cTnT } \\
\mu \mathrm{g} / \mathrm{L}\end{array}$ & $\begin{array}{c}\text { Architect cTnl } \\
\mu \mathrm{g} / \mathrm{L}\end{array}$ & $\begin{array}{l}\mathrm{CK} \\
\mathrm{U} / \mathrm{L} \\
\end{array}$ & $\begin{array}{c}\text { albumin } \\
\mathrm{g} / \mathrm{L}\end{array}$ \\
\hline \multicolumn{6}{|l|}{ Pre-race } \\
\hline mean & $<\mathrm{LOD}$ & 0.004 & 0.007 & 141 & 43.8 \\
\hline median & $<\mathrm{LOD}$ & 0.004 & 0.003 & 117 & 43.8 \\
\hline $97.5^{\text {th }}$ percentile & $<$ LOD & 0.010 & 0.022 & 293 & 48.0 \\
\hline normality test, $\mathrm{P}$ value & $<0.001$ & $0.200^{a, b}$ & $<0.001$ & $0.200^{a, b}$ & $0.200^{b}$ \\
\hline gender difference, $P$ value & 1.000 & $0.008^{\mathrm{a}}$ & 0.021 & $0.002^{\mathrm{a}}$ & 0.136 \\
\hline \multicolumn{6}{|l|}{ Post-race $0 \mathrm{~h}$} \\
\hline mean & 0.026 & 0.042 & 0.057 & 508 & 47.8 \\
\hline median & $<$ LOD & 0.033 & 0.029 & 378 & 48 \\
\hline $97.5^{\text {th }}$ percentile & 0.119 & 0.133 & 0.231 & 2249 & 52.7 \\
\hline normality test, $\mathrm{P}$ value & $<0.001$ & $0.200^{a, b}$ & $0.200^{a, b}$ & $0.021^{\mathrm{a}}$ & $0.200^{b}$ \\
\hline pre/post difference, $\mathrm{P}$ value & $<0.001$ & $<0.001^{a}$ & $<0.001^{a}$ & $<0.001^{\mathrm{a}}$ & $<0.001$ \\
\hline gender difference, $P$ value & 0.411 & $0.451^{a}$ & $0.156^{\mathrm{a}}$ & $0.793^{\mathrm{a}}$ & 0.031 \\
\hline \multicolumn{6}{|l|}{ Post-race $24 \mathrm{~h}$} \\
\hline mean & $<$ LOD & 0.012 & 0.031 & 2183 & 42.6 \\
\hline median & $<L O D$ & 0.010 & 0.011 & 1458 & 42.8 \\
\hline $97.5^{\text {th }}$ percentile & $<\mathrm{LOD}$ & $0.023^{c}$ & $0.145^{c}$ & $6240^{c}$ & $47.0^{c}$ \\
\hline normality test, $\mathrm{P}$ value & $<0.001$ & $0.200^{\mathrm{a}, \mathrm{b}}$ & $0.200^{\mathrm{a}, \mathrm{b}}$ & $0.200^{\mathrm{a}, \mathrm{b}}$ & $0.200^{b}$ \\
\hline pre/post difference, $\mathrm{P}$ value & 1.000 & $<0.001^{\mathrm{a}}$ & $<0.001^{\mathrm{a}}$ & $<0.001^{\mathrm{a}}$ & 0.359 \\
\hline gender difference, $\mathrm{P}$ value & 1.000 & $0.214^{\mathrm{a}}$ & $0.967^{\mathrm{a}}$ & $0.596^{\mathrm{a}}$ & 0.170 \\
\hline
\end{tabular}

${ }^{a}$ Data normalized by log-transformation prior to testing

${ }^{\mathrm{b}}$ Highest possible $\mathrm{P}$ value given by the Kolmogorov-Smirnov test of normality

${ }^{c}$ Because of the small sample size $(n=23)$, values for the $96^{\text {th }}$ percentile are shown 
CTnT concentration had increased to above the $99^{\text {th }}$ percentile $(0.016 \mu \mathrm{g} / \mathrm{L})$ in almost all of the runners (86\%). In contrast, only about half of the runners (45\%) were above the 99thpercentile value $(0.01 \mu \mathrm{g} / \mathrm{L})$ when the current commercially available cTnT assay was used. Results obtained with the hs-cTnT assay were highly correlated with values obtained with the current cTnT assay (Spearman rank correlation coefficient 0.955, for values above the $10 \%$ CV cutoff concentration; $\mathrm{P}<0.001)$. The Architect cTnl assay yielded cTnl concentrations that were increased to greater than the $99^{\text {th }}$ percentile in $81 \%$ of the runners. This percentage appeared comparable to that of the hs-cTnT assay; however, the $10 \%$ CV cutoff $(0.032 \mu \mathrm{g} / \mathrm{L})$ was exceeded in only $47 \%$ of the runners when the Architect cTnl assay was used. For the hs-cTnT assay, nearly all of the post-exercise concentrations (98\%) were greater than the $10 \% \mathrm{CV}$ concentration $(0.009 \mu \mathrm{g} / \mathrm{L})$.

Multiple regression analysis (Table 4) revealed running experience (the number of previously completed marathons) and age to be significant predictors of post-marathon cTn concentration as detected with the hs-cTnT assay (experience, P 0.005; age, P 0.017) and the Architect cTnI assay (experience, P 0.001; age, P 0.008). Indeed, a comparison of the 2 outer quartiles of these cTn results showed that the runners with the lowest cTn concentrations had significantly more experience in marathon running than those with the highest cTn concentrations (hs-cTnT assay, P 0.005; Architect cTnl assay, P 0.036). With respect to age, we found no significant difference between the 2 outer cTn quartiles for either the hs-cTnT assay (P 0.254) or the Architect cTnl assay (P 0.689). We also noted no significant interaction between experience and age in the regression model (hs-cTnT assay, P 0.542; Architect cTnl assay, P 0.696). Furthermore, gender and body mass index showed no significant association with post-exercise cTn concentration (Table 4). A regression analysis of the change in cTn concentration (post-exercise concentration minus pre-exercise concentration) showed experience and age to be significant predictors of the change in cTn concentration (Table 5). Finally, in contrast to pre-exercise cTn concentrations, post-exercise concentrations appeared to be higher in women than in men, but this gender difference was not statistically significant (Table 3).

The day after the marathon, cTn concentrations returned to below the LOD when the current commercially available cTnT assay was used (Figure 3). When hs-cTnT and Architect cTnl assays were used, cTn concentrations measured 1 day after the race remained significantly increased compared with pre-race cTn concentrations $(P<0.001$ for both the hs- 
cTnT and Architect cTnl assays). The cTn concentration was still greater than the $99^{\text {th }}$ percentile value in $17 \%$ of the runners measured with the hs-cTnT assay and in $43 \%$ of the runners measured with the Architect cTnl assay. The selected group of 23 runners who were studied the day after the marathon was compared with the total marathon study population (85 runners). The 2 groups showed no significant differences in pre-race and post-race cTn concentrations $(P>0.1)$ measured with any of the cTn assays used in this study.

\section{Discussion}

cTnT and cTnl immunoassays that have lower LODs, such as the hs-cTnT and cTnl- Architect assays, are better able to delineate the upper reference limits for cTn because of analytical improvements made in the lower portion of measurement interval $(<0.01 \mu \mathrm{g} / \mathrm{L})$. The hs-cTnT assay was the only assay tested in this study that achieved sufficient precision, ${ }^{14,15}$ because the $10 \% \mathrm{CV}$ cutoff concentration $(0.009 \mu \mathrm{g} / \mathrm{L})$ was lower than the $99^{\text {th }}$ percentile value of the reference population $(0.016 \mu \mathrm{g} / \mathrm{L}$, diagnostic cutoff). The hs-cTnT assay had the lowest LOD in this study and in this respect appears superior to the other cTn assays currently available. ${ }^{20}$ Our analytical results for the hs-cTnT assay are in agreement with those of Latini et $\mathrm{al}^{11}$ and Kurz et $\mathrm{al}^{21}$ the only other reports to have described the use of this precommercial assay. Latini et al obtained an LOD of $0.001 \mu \mathrm{g} / \mathrm{L}$, an inter-assay CV of $5 \%$ at 0.01 $\mu \mathrm{g} / \mathrm{L}$, and an inter-assay CV of $8 \%$. In the reference population $(\mathrm{n}=1061$, with a concurrent $\mathrm{N}$ terminal pro-B-type natriuretic peptide concentration of $<125 \mathrm{ng} / \mathrm{L}$ ), these investigators obtained a $99^{\text {th }}$ percentile cTnT cutoff value of $0.012 \mu \mathrm{g} / \mathrm{L}$. We obtained significantly higher cTnT concentrations in males than in females with the hs-cTnT assay, a difference that has not been reported previously. ${ }^{19,22}$ Given that the mean heart size is larger for males than for females, ${ }^{23,24}$ it is reasonable to expect cTn reference values of males and females to differ. More accurate methods are required to study this possible sex difference, because the $10 \%$ CV cutoff value of the hs-cTnT assay $(0.009 \mu \mathrm{g} / \mathrm{L})$ was higher than the mean and median CTnT concentrations in the reference population studied (males, $0.005 \mu \mathrm{g} / \mathrm{L}$; females, $0.003 \mu \mathrm{g} / \mathrm{L}$ ). In addition, it is noteworthy that the $99^{\text {th }}$ percentile value of the reference population is slightly higher with the hs-cTnT assay $(0.016 \mu \mathrm{g} / \mathrm{L})$ than with the current commercially available assay $(<0.01 \mu \mathrm{g} / \mathrm{L})$, but measurements with the current assay are not reliable for concentrations $<0.03 \mu \mathrm{g} / \mathrm{L}$ (with CVs $>10 \%$ ). Recently, it was indeed confirmed that $\mathrm{CTnT}$ concentrations with the current assay at $0.03 \mu \mathrm{g} / \mathrm{L}$ were approximately $75 \%$ higher when 
Table 4: Multiple linear regression models for log-transformed cTn concentrations directly after the race as measured with the (A) hs-cTnT and (B) Architect cTnl assay.

A

\begin{tabular}{llccccc}
\hline & $\log (\mathrm{hs}-\mathrm{cTnT})$ & $\mathrm{B}^{\mathrm{a}}$ & $\mathrm{SE}^{\mathrm{b}}$ & $\mathrm{P}$ value & power & $\mathrm{R}^{\mathrm{c}}$ \\
\hline Model 1 & & & & 0.061 & 0.469 & 0.242 \\
& intercept & 1.63 & 0.07 & $<0.001$ & & \\
& $\log$ (experience) & -0.11 & 0.06 & 0.061 & & \\
Model 2 & & & 0.010 & 0.792 & 0.383 \\
& intercept & 1.20 & 0.19 & $<0.001$ & & \\
& log(experience) & -0.19 & 0.06 & 0.005 & & \\
& age & 0.01 & 0.00 & 0.017 & & \\
Model 3 & & & & 0.025 & 0.730 & 0.387 \\
& intercept & 1.21 & 0.19 & $<0.001$ & & \\
& log(experience) & -0.19 & 0.06 & 0.005 & & \\
& age & 0.01 & 0.00 & 0.021 & & \\
& gender & -0.04 & 0.09 & 0.657 & & \\
Model 4 & & & & 0.055 & 0.669 & 0.387 \\
& intercept & 1.30 & 0.56 & 0.025 & & \\
& log(experience) & -0.19 & 0.06 & 0.005 & & \\
& age & 0.01 & 0.00 & 0.024 & & \\
& gender & -0.05 & 0.11 & 0.641 & & \\
BMl & 0.00 & 0.02 & 0.871 & & \\
\hline
\end{tabular}

B

\begin{tabular}{llccccc}
\hline & $\log ($ Architect cTnl) & $\mathrm{B}^{\mathrm{a}}$ & $\mathrm{SE}^{\mathrm{b}}$ & $\mathrm{P}$ value & power & $\mathrm{R}^{\mathrm{c}}$ \\
\hline Model 1 & & & & 0.023 & 0.629 & 0.290 \\
& intercept & 1.74 & 0.10 & $<0.001$ & & \\
& $\log$ (experience) & -0.20 & 0.09 & 0.023 & & \\
Model 2 & & & 0.002 & 0.907 & 0.437 \\
& intercept & 1.01 & 0.28 & 0.001 & & \\
& log(experience) & -0.33 & 0.09 & 0.001 & & \\
& age & 0.02 & 0.01 & 0.008 & & \\
Model 3 & & & & 0.006 & 0.864 & 0.440 \\
& intercept & 0.98 & 0.29 & 0.001 & & \\
& log(experience) & -0.33 & 0.10 & 0.001 & & \\
& age & 0.02 & 0.01 & 0.007 & & \\
& gender & 0.07 & 0.15 & 0.657 & & \\
Model 4 & & & 0.015 & 0.816 & 0.440 \\
& intercept & 1.12 & 0.82 & 0.178 & & \\
& log(experience) & -0.33 & 0.10 & 0.001 & & \\
& age & 0.02 & 0.01 & 0.009 & & \\
& gender & 0.05 & 0.16 & 0.746 & & \\
BMI & -0.01 & 0.03 & 0.857 & & \\
\hline
\end{tabular}

${ }^{a}$ unstandardized coefficient in regression equation

${ }^{\mathrm{b}}$ Standard Error

'Pearson's correlation coefficient 
Table 5: Multiple linear regression models for log-transformed delta (post- minus pre-race) cTn concentrations as measured with the (A) hs-cTnT and (B) Architect cTnl assay.

A

\begin{tabular}{llccccc}
\hline & log(delta hs-cTnT) & $\mathrm{B}^{\mathrm{a}}$ & $\mathrm{SE}^{\mathrm{b}}$ & $\mathrm{P}$ value & power & $\mathrm{R}^{\mathrm{c}}$ \\
\hline Model 1 & & & & 0.048 & 0.510 & 0.254 \\
& intercept & -1.42 & 0.08 & $<0.001$ & & \\
& $\log ($ experience) & -0.13 & 0.07 & 0.048 & & \\
Model 2 & & & & 0.031 & 0.656 & 0.336 \\
& intercept & -1.78 & 0.22 & $<0.001$ & & \\
& log(experience) & -0.19 & 0.07 & 0.010 & & \\
& age & 0.01 & 0.01 & 0.081 & & \\
Model 3 & & & & 0.070 & 0.587 & 0.340 \\
& intercept & -1.77 & 0.22 & $<0.001$ & & \\
& log(experience) & -0.19 & 0.07 & 0.011 & & \\
& age & 0.01 & 0.01 & 0.091 & & \\
& gender & -0.05 & 0.11 & 0.673 & & \\
Model 4 & & & 0.133 & 0.526 & 0.341 \\
& intercept & -1.64 & 0.65 & 0.014 & & \\
& log(experience) & -0.19 & 0.07 & 0.011 & & \\
& age & 0.01 & 0.01 & 0.103 & & \\
gender & -0.06 & 0.12 & 0.636 & & \\
BMI & -0.01 & 0.03 & 0.826 & & \\
& & & & & \\
& & & & & \\
\hline
\end{tabular}

B

\begin{tabular}{llccccc}
\hline & $\log$ (delta Architect cTnl) & $\mathrm{B}^{\mathrm{a}}$ & $\mathrm{SE}^{\mathrm{b}}$ & $\mathrm{P}$ value & power & $\mathrm{R}^{\mathrm{c}}$ \\
\hline Model 1 & & & & 0.081 & 0.416 & 0.227 \\
& intercept & -1.38 & 0.12 & $<0.001$ & & \\
& log(experience) & -0.19 & 0.10 & 0.081 & & \\
Model 2 & & & 0.013 & 0.765 & 0.376 \\
& intercept & -2.17 & 0.34 & $<0.001$ & & \\
& log(experience) & -0.32 & 0.12 & 0.007 & & \\
& age & 0.02 & 0.01 & 0.018 & & \\
Model 3 & & & & 0.024 & 0.738 & 0.393 \\
& intercept & -2.24 & 0.35 & $<0.001$ & & \\
& log(experience) & -0.34 & 0.02 & 0.005 & & \\
& age & 0.02 & 0.01 & 0.013 & & \\
& gender & 0.17 & 0.18 & 0.356 & & \\
Model 4 & & & 0.050 & 0.682 & 0.395 \\
& intercept & -2.56 & 1.00 & 0.014 & & \\
& log(experience) & -0.33 & 0.12 & 0.006 & & \\
& age & 0.02 & 0.01 & 0.013 & & \\
& gender & 0.19 & 0.20 & 0.331 & & \\
BMI & 0.01 & 0.04 & 0.734 & & \\
\hline
\end{tabular}

${ }^{a}$ unstandardized coefficient in regression equation

${ }^{\mathrm{b}}$ Standard Error

'Pearson's correlation coefficient 
measured with the hs-cTnT assay. ${ }^{25}$ With the Architect cTnl assay, we did not obtain sufficient precision in the lower part of the measurement interval (a CV $>10 \%$ at the $99^{\text {th }}$ percentile value of the reference population). Recently, Tate et al reported a comparison study of 9 cTn assays. ${ }^{26}$ Individuals were excluded from the reference population in cases of diabetes mellitus, hypertension, cardiac disease, hyperlipidemia, and patients taking cardiac medications. The $99^{\text {th }}$ percentile value in this reference population $(n=111)$ with the Architect cTnl assay was $0.021 \mu \mathrm{g} / \mathrm{L}$, which is even higher than the cutoff we reported $(0.013$ $\mu \mathrm{g} / \mathrm{L})$. In addition, Wu et al recently showed that $\mathrm{cTnl}$ concentrations assayed in a reference population with a prototype assay based on single-photon fluorescence detection fit a gaussian distribution. ${ }^{27,28}$ The introduction of more sensitive and accurate cTn assays affects the number of AMI patients who are detected. ${ }^{29}$ Serial cTn testing with the use of highsensitivity assays will be necessary to determine the clinical significance of cTn concentrations at the lower end of the measurement interval. ${ }^{30}$

In most studies that have investigated prolonged exercise, cTn concentrations became detectable immediately after exercise. ${ }^{10,31,32}$ Furthermore, pre-exercise concentrations were below the LOD, ${ }^{16-18}$ as was seen in the present study for the current commercially available cTnT assay. In addition, assay imprecision was too high to differentiate pre-exercise values from noise, ${ }^{16-18}$ an observation that held true for the Architect cTnl assay in our study. The hs-cTnT assay showed increases in CTnT in almost all of the marathon runners (86\%). In contrast, a meta-analysis of 26 studies (1120 individuals) that used second- and thirdgeneration cTnT assays showed cTnT increases in only $47 \%$ of the individuals. ${ }^{33}$ When a third generation cTnT assay was used, about half of the runners (59\%) also showed increased cTnT concentrations. ${ }^{10}$ It is still questionable whether cardiovascular insufficiency is the underlying mechanism of collapse during or after prolonged exercise. With a fourthgeneration cTnT assay, Siegel et al reported that only $18 \%$ of collapsed marathon runners ( $n=99$ ) showed increased cTn concentrations. ${ }^{34}$

The Architect cTnl assay produced a broader cTn distribution than the hs-cTnT assay, both immediately after the race and a day later. This finding might be explained by the higher imprecision of the Architect cTnl assay. Nevertheless, both the hs-cTnT and Architect cTnl assays showed that cTnT and cTnl concentrations remained significantly increased the day after the marathon. This finding is in contrast with the results obtained with the majority of cTn assays, in which cTn seems to return to baseline concentrations within a day. 
The cTn concentrations in runners after a marathon were higher than the cutoff used for diagnosing AMI. ${ }^{14,15}$ The concentration difference was minor, however, and the increases occurred in the absence of any clinical symptoms. Two opposing theories attempt to explain the link between exercise-induced cTn release and (acute) cardiac events. ${ }^{35}$ First, the reversibility concept proposes that exercise increases the number of radicals and thereby membrane permeability, causing cTn leakage from the cytosolic cellular pool. ${ }^{36,37}$ This release has been suggested to be relatively fast and may correspond to the first cTn peak seen in AMI patients ( $<1$ day). ${ }^{31,38,39}$ Subsequently, however, there would be an influx and efflux of cytoplasmic constituents up to toxic levels. The second theory, the irreversibility concept, suggests that the cTn released after prolonged exercise is due to the breakdown of myocytes. This release would require the dissociation of cTn from the cTn complex (on actin molecules) and is thought to be much slower ( $>1$ day). It therefore could correspond to the later cTn release that is seen as a second peak in AMI patients. ${ }^{31,38,39}$ Whether prolonged exercise has any long-term consequences remains to be clarified. To address this issue, Hessel et al studied cTnl release from cultures of rat cardiomyocytes and demonstrated the release of intact cTnl from viable cardiomyocytes, ${ }^{40}$ which would imply that reversible cell damage must take place after prolonged exercise. Further research is required to reveal whether troponin release after AMI is similar to the release occurring after prolonged exercise, both from a structural and from a kinetic point of view.

In the largest marathon population studied thus far (482 runners), less marathon experience and an older age appeared to be associated with increases in cTn, whereas race duration and the presence of traditional cardiovascular risk factors were not. ${ }^{8}$ Neilan et al used both echocardiography and serum biomarkers to study non-elite marathon runners specifically ${ }^{32}$ and found that cTnT concentrations were significantly higher in runners who trained $\leq 56 \mathrm{~km} /$ week than in runners who trained $>72 \mathrm{~km} /$ week. In a meta-analysis of 1120 individuals, Shave et $\mathrm{al}^{33}$ found exercise duration to affect post-exercise cTn concentration but found the effect of age to be non-significant. When we used more sensitive assays, we also found a significant negative correlation between post-marathon cTn concentration and experience and found a non-significant positive relationship with age.

The clinical impact of exercise-induced increases in cTn concentration has not yet been fully clarified. Herrmann et al advised that until the phenomenon is better understood, affected athletes should undergo further cardiologic investigation, including a stress test. ${ }^{41}$ 
Whyte et al suggested that serial measurements should be made after a marathon to evaluate a patient for an AMI. ${ }^{42}$ In the present study, the use of cTn assays with lower LODs showed $86 \%$ of the athletes to have increased cTnT concentrations after a marathon and $81 \%$ to have increased cTnl concentrations. There seems to be no rationale for examining all athletes with positive cTn concentrations in the absence of clinical symptoms. Further research is required to investigate whether a diagnostic cTn cutoff higher than the $99^{\text {th }}$ percentile value is more realistic for well-trained athletes.

\section{References}

1. Thompson PD, Franklin BA, Balady GJ, et al. Exercise and acute cardiovascular events placing the risks into perspective: a scientific statement from the American Heart Association council on nutrition, physical activity, and metabolism and the council on clinical cardiology. Circulation. 2007;115:2358-2368.

2. Tunstall Pedoe DS. Marathon cardiac deaths: the london experience. Sports Med. 2007;37:448450.

3. Roberts WO, Maron BJ. Evidence for decreasing occurrence of sudden cardiac death associated with the marathon. J Am Coll Cardiol. 2005;46:1373-1374.

4. Redelmeier DA, Greenwald JA. Competing risks of mortality with marathons: retrospective analysis. BMJ. 2007;335:1275-1277.

5. Scharhag J, Herrmann M, Urhausen A, Haschke M, Herrmann W, Kindermann W. Independent elevations of $\mathrm{N}$-terminal pro-brain natriuretic peptide and cardiac troponins in endurance athletes after prolonged strenuous exercise. Am Heart J. 2005;150:1128-1134.

6. La Gerche A, Connelly KA, Mooney DJ, Macisaac Al, Prior DL. Biochemical and functional abnormalities of left and right ventricular function following ultra-endurance exercise. Heart. 2007;94:860-866.

7. Kratz A, Lewandrowski KB, Siegel AJ, et al. Effect of marathon running on hematologic and biochemical laboratory parameters, including cardiac markers. Am J Clin Pathol. 2002;118:856863.

8. Fortescue EB, Shin AY, Greenes DS, et al. Cardiac troponin increases among runners in the Boston Marathon. Ann Emerg Med. 2007;49:137-143, 143 e131.

9. Leers MP, Schepers R, Baumgarten R. Effects of a long-distance run on cardiac markers in healthy athletes. Clin Chem Lab Med. 2006;44:999-1003.

10. Michielsen EC, Wodzig WK, Van Dieijen-Visser MP. Cardiac troponin T release after prolonged strenuous exercise - a review. Sports Med. 2008;38:425-435.

11. Latini R, Masson S, Anand IS, et al. Prognostic value of very low plasma concentrations of troponin T in patients with stable chronic heart failure. Circulation. 2007;116:1242-1249.

12. Lam $Q$, Black M, Youdell O, Spilsbury H, Schneider HG. Performance evaluation and subsequent clinical experience with the Abbott Automated Architect STAT Troponin-I assay. Clin Chem. 2006;52:298-300.

13. Hickman PE, Koerbin G, Southcott E, et al. Newer cardiac troponin I assays have similar performance to troponin $\mathrm{T}$ in patients with end-stage renal disease. Ann Clin Biochem. 2007;44:285-289.

14. Apple FS, Jesse RL, Newby LK, et al. National Academy of Clinical Biochemistry and IFCC Committee for Standardization of Markers of Cardiac Damage Laboratory Medicine Practice Guidelines: analytical issues for biochemical markers of acute coronary syndromes. Clin Chem. 2007;53:547-551. 
15. Thygesen K, Alpert JS, White HD, et al. Universal definition of myocardial infarction: Kristian Thygesen, Joseph S. Alpert and Harvey D. White on behalf of the joint ESC/ACCF/AHA/WHF task force for the redefinition of Myocardial Infarction. Eur Heart J. 2007;28:2525-2538.

16. Panteghini M, Pagani F, Yeo KT, et al. Evaluation of imprecision for cardiac troponin assays at low-range concentrations. Clin Chem. 2004;50:327-332.

17. Giannitsis E, Katus HA. Comparison of cardiac troponin T and troponin I assays--implications of analytical and biochemical differences on clinical performance. Clin Lab. 2004;50:521-528.

18. Panteghini $M$. The new definition of myocardial infarction and the impact of troponin determination on clinical practice. Int J Cardiol. 2006;106:298-306.

19. Apple FS, Murakami MM. Serum and plasma cardiac troponin I 99th percentile reference values for 3 2nd-generation assays. Clin Chem. 2007;53:1558-1560.

20. Available at: International Federation of Clinical Chemistry Committee on Standardization of Markers of Cardiac Damage

http://www.ifcc.org/index.php?option=com_remository\&ltemid=120\&func=fileinfo\&id=87.

21. Kurz K, Giannitsis E, Zehelein J, Katus HA. Highly sensitive cardiac troponin T values remain constant after brief exercise- or pharmacologic-induced reversible myocardial ischemia. Clin Chem. 2008;54:1234-1238.

22. Wallace TW, Abdullah SM, Drazner MH, et al. Prevalence and determinants of troponin $\mathrm{T}$ elevation in the general population. Circulation. 2006;113:1958-1965.

23. Olivetti G, Giordano G, Corradi D, et al. Gender differences and aging: effects on the human heart. J Am Coll Cardiol. 1995;26:1068-1079.

24. Salton CJ, Chuang ML, O'Donnell CJ, et al. Gender differences and normal left ventricular anatomy in an adult population free of hypertension. A cardiovascular magnetic resonance study of the Framingham Heart Study Offspring cohort. J Am Coll Cardiol. 2002;39:1055-1060.

25. Giannitsis E, Kurz K, Hallermayer K, Jarausch J, Jaffe AS, Katus HA. Analytical validation of a highsensitivity cardiac troponin T assay. Clin Chem. 2010;56:254-261.

26. Tate JR, Ferguson W, Bais R, Kostner K, Marwick T, Carter A. The determination of the 99th centile level for troponin assays in an Australian reference population. Ann Clin Biochem. 2008;45:275-288.

27. Wu AHB, Fukushima N, Puskas R, Todd J, Goix P. Development and preliminary clinical validation of a high sensitivity assay for cardiac troponin using a capillary flow (single molecule) fluorescence detector. Clin Chem. 2006;52:2157-2159.

28. Todd J, Freese B, Lu A, et al. Ultrasensitive flow-based immunoassays using single-molecule counting. Clin Chem. 2007;53:1990-1995.

29. Melanson SE, Tanasijevic MJ, Jarolim P. Cardiac troponin assays: a view from the clinical chemistry laboratory. Circulation. 2007;116:e501-504.

30. Wu AH, Jaffe AS. The clinical need for high-sensitivity cardiac troponin assays for acute coronary syndromes and the role for serial testing. Am Heart J. 2008;155:208-214.

31. Shave R, George K, Gaze D. The influence of exercise upon cardiac biomarkers: a practical guide for clinicians and scientists. Curr Med Chem. 2007;14:1427-1436.

32. Neilan TG, Januzzi JL, Lee-Lewandrowski E, et al. Myocardial injury and ventricular dysfunction related to training levels among nonelite participants in the Boston marathon. Circulation. 2006;114:2325-2333.

33. Shave R, George KP, Atkinson G, et al. Exercise-induced cardiac troponin T release: a metaanalysis. Med Sci Sports Exerc. 2007;39:2099-2106.

34. Siegel AJ, Januzzi J, Sluss P, et al. Cardiac biomarkers, electrolytes, and other analytes in collapsed marathon runners: implications for the evaluation of runners following competition. Am J Clin Pathol. 2008;129:948-951.

35. Koller A. Exercise-induced increases in cardiac troponins and prothrombotic markers. Med Sci Sports Exerc. 2003;35:444-448.

36. Neumayr G, Gaenzer H, Pfister R, et al. Plasma levels of cardiac troponin I after prolonged strenuous endurance exercise. Am J Cardiol. 2001;87:369-371, A310. 
37. Neumayr G, Pfister R, Mitterbauer G, et al. Effect of the "Race Across The Alps" in elite cyclists on plasma cardiac troponins I and T. Am J Cardiol. 2002;89:484-486.

38. Katus HA, Remppis A, Scheffold T, Diederich KW, Kuebler W. Intracellular compartmentation of cardiac troponin $\mathrm{T}$ and its release kinetics in patients with reperfused and nonreperfused myocardial infarction. Am J Cardiol. 1991;67:1360-1367.

39. Michielsen EC, Diris JH, Kleijnen VW, Wodzig WK, Van Dieijen-Visser MP. Investigation of release and degradation of cardiac troponin T in patients with acute myocardial infarction. Clin Biochem. 2007; 40:851-855.

40. Hessel MH, Atsma DE, van der Valk EJ, Bax WH, Schalij MJ, van der Laarse A. Release of cardiac troponin I from viable cardiomyocytes is mediated by integrin stimulation. Pflugers Arch. 2008;455:979-986.

41. Herrmann M, Scharhag J, Miclea M, Urhausen A, Herrmann W, Kindermann W. Post-race kinetics of cardiac troponin $\mathrm{T}$ and $\mathrm{I}$ and $\mathrm{N}$-terminal pro-brain natriuretic peptide in marathon runners. Clin Chem. 2003;49:831-834.

42. Whyte G, George K, Shave R, et al. Impact of marathon running on cardiac structure and function in recreational runners. Clin Sci (Lond). 2005;108:73-80. 



\section{CHAPTER 4}

\section{Cardiac troponin $\mathbf{T}$ elevations, using highly sensitive assay, in recreational running depend on running distance}

Background: Endurance exercise is frequently associated with cardiac troponin (cTn) concentrations, otherwise corresponding to minor myocardial infarction. However, research on the underlying mechanisms has been limited because of assay restraints in the low concentration range.

Methods and results: Using the pre-commercial, highly sensitive hs-cTnT assay, cTnT concentrations were measured in samples from recreational runners obtained before and after running $5 \mathrm{~km}$ (trained, $n=43$ / untrained, $n=122), 15 \mathrm{~km}(\mathrm{n}=38), 21 \mathrm{~km}(\mathrm{n}=10)$, and 42 $\mathrm{km}(\mathrm{n}=85)$ (all trained). The percentage of runners with elevated hs-cTnT concentrations after the run increased with running distance $(0,11,13,40$, and $86 \%)$, in contrast to NT$\operatorname{proBNP}(2,7,0,0$, and 5\%). Median (IQR) hs-cTnT post-run concentrations were $0.004 \mu \mathrm{g} / \mathrm{L}$ (0.003), $0.006 \mu \mathrm{g} / \mathrm{L}$ (0.008), $0.010 \mu \mathrm{g} / \mathrm{L}$ (0.006), $0.014 \mu \mathrm{g} / \mathrm{L}$ (0.019), and $0.030 \mu \mathrm{g} / \mathrm{L}(0.029)$, respectively.

Conclusions: We found, using a novel hs-cTnT assay, the distance of recreational competitive running to be positively related to asymptomatic increases in cTnT post-run concentrations. In contrast, NT-proBNP showed no increase. In addition, the data indicated that a relatively short running distance of $5 \mathrm{~km}$ resulted in CTnT release of untrained participants, in contrast to trained participants, which underlines the necessity of sufficient training. Further effort is needed to clarify the significance of exercise induced cardiac biomarker elevations.

This work has been published in: Mingels A, Jacobs L, Kleijnen V, Laufer E, Winkens B, Hofstra L, Wodzig W, Van Dieijen-Visser M. Clin Res Cardiol 2010;99:385-391.

* At the time of investigation, the high-sensitivity cardiac troponin T (hs-cTnT) assay was only precommercially available. 
Recreational running and other types of regular exercise are performed by millions of people worldwide and the cardiovascular benefits are commonly accepted. However, prolonged strenuous exercise is often associated with cardiac complications ranging from elevations of cardiac biomarkers ${ }^{1,2}$ to infrequent physical collapse or even sudden death. ${ }^{3,4}$ It is for this reason that the American Heart Association and European Society of Cardiology recommend pre-participation screening protocols for young competitive athletes to check for cardiovascular abnormalities. ${ }^{5,6}$ Nevertheless, it remains an active topic of discussion whether the asymptomatic exercise-induced increases of cardiac troponin (cTn) and Nterminal pro-B-type natriuretic peptide (NT-proBNP), the preferred markers for diagnosing acute myocardial infarction and heart failure, respectively, are associated with cardiac cell death. $^{7,8}$

Research on the underlying mechanisms behind exercise-induced cTn elevations has been limited because of cTn assay restraints. ${ }^{9,10}$ First, comparison of cTnl studies is complicated, as approximately $20 \mathrm{cTnl}$ immunoassays have been developed, each using different antibodies, calibrators and control materials. ${ }^{10,11}$ This is in contrast to the patented cTnT assay, as we previously reviewed. ${ }^{12}$ Moreover, until recently, cTn immunoassays were unable to measure detectable concentrations in healthy individuals or assays lacked analytical performance (coefficient of variation, $C V>10 \%$ at the upper reference limit, URL, of a reference population) to measure these concentrations with sufficient precision. ${ }^{10}$ Table 1 summarizes our literature research in subjects after prolonged strenuous exercise when using the contemporary cTnl assays, to further indicate the difficulty in study comparison.

Lately, analytical improvements have been made in the lower part of the cTn measurement interval. When using the pre-commercial highly sensitive hs-cTnT assay, we recently reported an almost Gaussian distribution in a reference population $(n=479),{ }^{13}$ while Kavsak et $\mathrm{al}^{14}$ showed a similar distribution for hs-cTnl when using the adapted AccuTnl assay from Beckman Coulter. With the new generation hs-cTnT and Architect cTnl assay, we showed that CTn concentrations were elevated after running a marathon race in almost all runners (cTnT, 86\%; cTnl, 80\%), but in the absence of clinical symptoms. ${ }^{13}$ However, the level of release of cTnT in people running shorter than marathon distances and how this relates to the level of preparedness is unknown. 


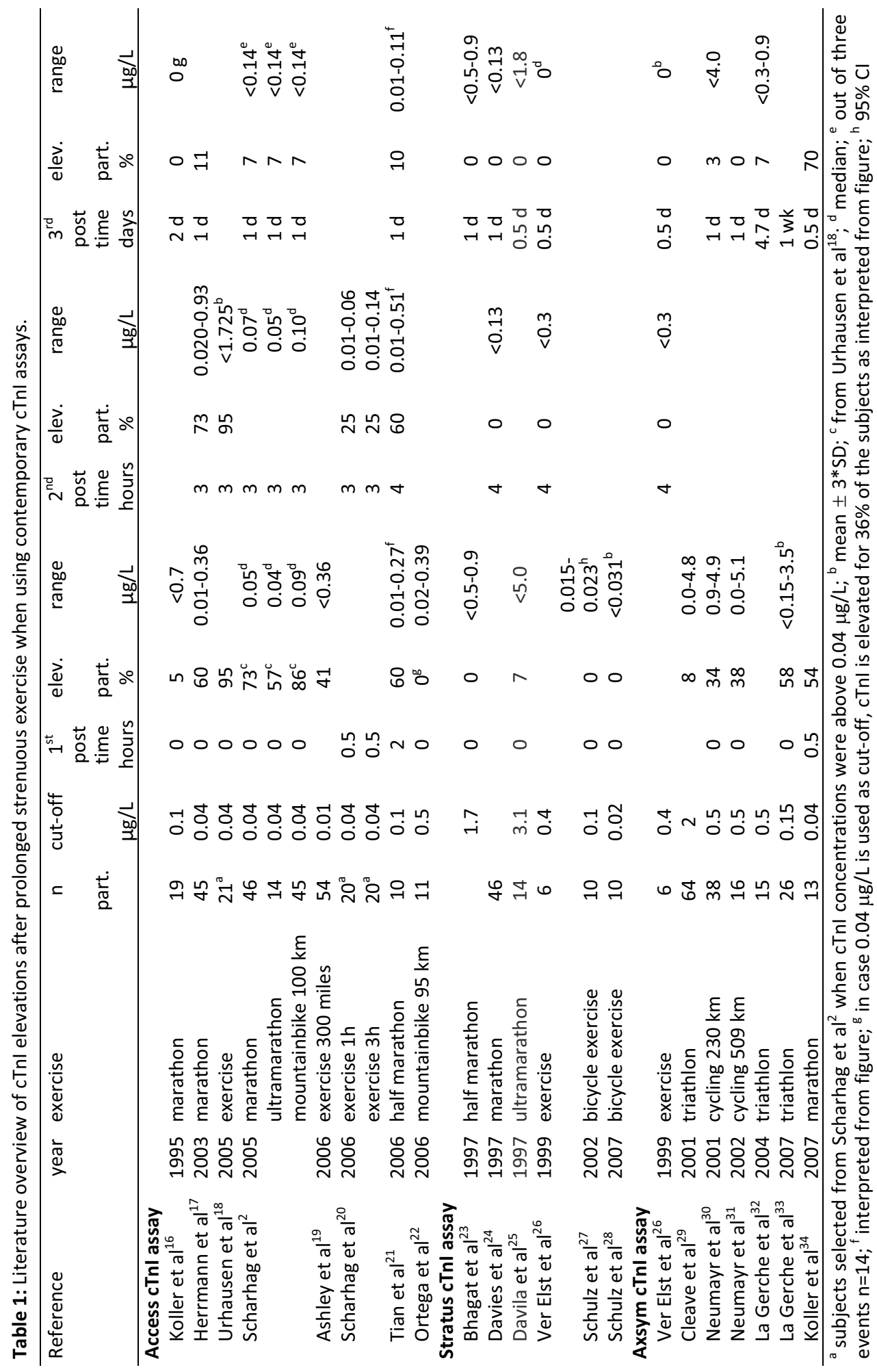




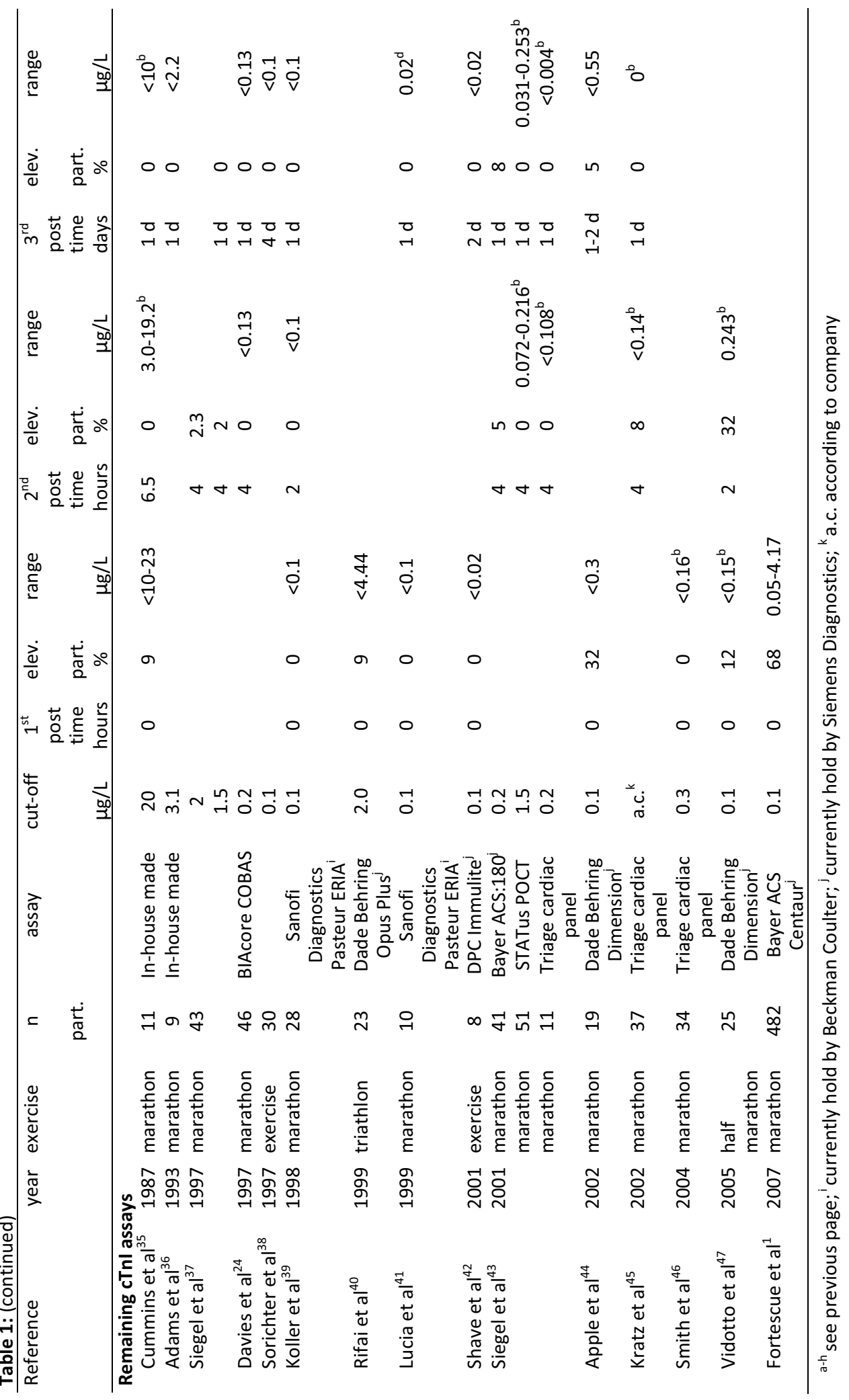


Another evolving cardiac biomarker is NT-proBNP with a release different from cTn, namely a response to increases in ventricular wall stress and the subsequent increase in synthesis of the BNP hormone. ${ }^{15}$ Echocardiographic research in recreational marathon runners indeed indicated that exercise affected systolic and diastolic ventricular functions due to mechanical or volume overload. ${ }^{48}$ Nevertheless, exercise-induced NT-proBNP elevations were shown to be correlated only with a (temporary) reduction in left ventricular early diastolic filling. ${ }^{49}$ For NT-proBNP measurements, the four available immunoassays used antibodies from Roche Diagnostics, simplifying study comparison. ${ }^{50}$ Up till now, with the older generation cTn immunoassays, correlations were not found between exercise-induced elevations of cTn and NT-proBNP. ${ }^{2,47}$

In the present study, we compared cardiac cTnT (using the pre-commercial highly sensitive hs-cTnT immunoassay) and NT-proBNP concentrations in pre- and post-run serum samples of recreational runners participating in different running events $(5,15,21$, and 42 $\mathrm{km})$.

\section{Methods}

\section{Study populations}

The study population consisted of recreational runners who participated in Maastrichts Mooiste 2007 (distance 5 km, n=43; distance 15 km, n=38) or in the Maas Marathon 2007 (distance $21 \mathrm{~km}, \mathrm{n}=10$; distance $42 \mathrm{~km}, \mathrm{n}=85$, see also chapter 3). We also included

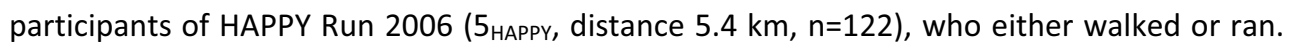
HAPPY is an activity organized by our hospital to promote healthy lifestyle and physical activity in the general population (www.happyazm.nl). For comparison with other studies, we included runner characteristics in Table 2, as gathered from personal communication prior to the running event. The present study was approved by the ethical committee (Maastricht University Medical Center, the Netherlands) and all participants signed informed consent forms. The maximal temperatures were $23^{\circ} \mathrm{C}, 23^{\circ} \mathrm{C}$, and $20^{\circ} \mathrm{C}$ at Maastrichts Mooiste, the Maas Marathon and HAPPY Run, respectively. The wind was $<9 \mathrm{~m} / \mathrm{s}$ from no specific direction, a south wind of $<14 \mathrm{~m} / \mathrm{s}$, and a west wind of $<7 \mathrm{~m} / \mathrm{s}$, respectively. Serum samples were collected $0-2 \mathrm{~h}$ before the run and $<1 \mathrm{~h}$ immediately after the run. After clotting and subsequent centrifugation, serum was stored at $-80^{\circ} \mathrm{C}$ until analysis. Post-run 
concentrations were corrected for the effect of dehydration using the ratio of pre- versus post-run albumin serum concentrations.

\section{Biomarkers}

cTnT was measured on the Elecsys 2010 (Roche Diagnostics) with the pre-commercial, highly sensitive cTnT (hs-cTnT) assay with LOD at $<0.001 \mu \mathrm{g} / \mathrm{L}, \mathrm{CV} \leq 10 \%$ at $0.009 \mu \mathrm{g} / \mathrm{L}$ and the URL $\left(99^{\text {th }}\right.$ percentile) at $0.016 \mu \mathrm{g} / \mathrm{L}$, as validated previously in chapter 3. Recently, Giannitsis et $\mathrm{al}^{51}$ reported $75 \%$ higher values for $\mathrm{cTnT}<0.1 \mu \mathrm{g} / \mathrm{L}$ for the hs-cTnT assay as compared to the fourth generation cTnT assay. Furthermore, intra-assay CVs were 5.7 and $0.5 \%$ at 0.022 and $2.98 \mu \mathrm{g} / \mathrm{L}$, respectively; inter-assay CVs were 3.0 and $1.4 \%$ at 0.021 and $3.03 \mu \mathrm{g} / \mathrm{L}$, respectively. NT-proBNP was also measured on the Elecsys 2010 with LOD at $0.6 \mathrm{pmol} / \mathrm{L}$, intra-assay CV $2.5 \%$ at $8.98 \mathrm{pmol} / \mathrm{L}$ and inter-assay CV $6.8 \%$ at $8.78 \mathrm{pmol} / \mathrm{L}$ as given by the manufacturer. In our reference population defined in chapter 3 , we measured the $99^{\text {th }}$ percentile at $36 \mathrm{pmol} / \mathrm{L}$ and the $97.5^{\text {th }}$ percentile at $28 \mathrm{pmol} / \mathrm{L}$. In addition, albumin (reference range 32.0-47.0 g/L) was measured on the Synchron LX20 (Beckman Coulter).

\section{Statistics}

Data were analyzed with SPSS, Version 15.0. The nonparametric Wilcoxon signed-rank test as used for comparison of post-run with pre-run concentrations within each study population, since the biomarker concentrations were not normally distributed. With the Pearson chi-square test, we tested differences in ratio male/female between the groups. Linear regression analysis was used for comparison of the other variables between the

Table 2: Baseline characteristics of the runner study populations.

\begin{tabular}{|c|c|c|c|c|c|c|}
\hline & $5_{\text {HAPPY }} \mathrm{km}^{a}$ & $5 \mathrm{~km}$ & $15 \mathrm{~km}$ & $21 \mathrm{~km}$ & $42 \mathrm{~km}$ & $P$ value \\
\hline $\mathrm{n}$ & 122 & 43 & 38 & 10 & 85 & \\
\hline sex (male/female) & $59 / 63$ & $24 / 19$ & $31 / 7$ & $8 / 2$ & $70 / 15$ & $<0.001$ \\
\hline age $(\text { years) })^{b}$ & $54(11)$ & $45(9)$ & $47(9)$ & $43(13)$ & $47(9)$ & $<0.001$ \\
\hline $\mathrm{BMI}\left(\mathrm{kg} / \mathrm{m}^{2}\right)^{\mathrm{b}}$ & n.a. ${ }^{c}$ & $24.4(3.5)$ & $23.8(2.1)$ & $24.0(1.3)$ & $22.4(1.7)$ & $<0.001$ \\
\hline Experience $^{d}$ & n.a. & $0.8(2.6)^{\mathrm{e}}$ & $10(31)^{\mathrm{e}}$ & n.a. & $7(21)^{f}$ & n.a. \\
\hline netto run time $(\mathrm{min})^{b}$ & n.a. & $28(4)$ & $78(9)$ & $118(13)$ & $228(30)$ & $<0.001$ \\
\hline velocity $(\mathrm{km} / \mathrm{h})^{\mathrm{b}}$ & n.a. & $10.9(1.3)$ & $11.6(1.3)$ & $10.9(1.1)$ & $11.3(1.5)$ & 0.181 \\
\hline
\end{tabular}


groups. When applied on the hs-cTnT and NT-proBNP concentrations, data were first normalized by log transformation. Regression analysis on the post-run concentrations was corrected for pre-run concentration, age, and sex. Correlations between hs-cTnT and NTproBNP concentrations were calculated using Spearman's correlation coefficient and tested with the one-sample $t$-test for correlations. Runners from different populations were independent to each other. The threshold for statistical significance was set at $\mathrm{P}<0.05$.

\section{Results}

Table 2 summarizes the baseline characteristics of the runner populations in the present study. All individuals were recreational runners participating in a competition, except for the individuals participating in the 2006 HAPPY, an activity of our hospital to promote healthy lifestyle and physical activity, who either walked or ran $5 \mathrm{~km}$ ( $5_{\text {HAPPY }}$ ). For the shortest distances, about half of the participants were male, while for the longer distances most participants were male $(P<0.001)$. As shown in Table 2 , age was higher in the $5_{\text {HAPPY }} \mathrm{km}$ population compared to the other populations ( $P \leq 0.002)$. BMI was lower in the $42 \mathrm{~km}$ population compared to the 5 and $15 \mathrm{~km}$ runners $(P \leq 0.003)$ and marginally lower compared to the $21 \mathrm{~km}$ runners ( $P$ 0.054). The $5_{\text {HAPPY }} \mathrm{km}$ participants had not been stimulated in training, while the $5 \mathrm{~km}$ runners were trained. In the latter population, 26\% runners had experience for only 3 months and participated in the training program 'Start to Run', while $53 \%$ had running experience for $\geq 1$ year. As expected, runners trained on average more kilometers for the $15 \mathrm{~km}$ than for the $5 \mathrm{~km}$ run ( $P$ 0.001). The marathon runners seemed to be highly trained, as $44 \%$ had completed one to ten marathons and $36 \%$ more than 10 marathons previously.

Pre-run concentrations of hs-cTnT and NT-proBNP were within the reference range in most of the runners, as shown in Figure 1. Pre-run hs-cTnT concentrations were significantly higher with increasing running distance $(P<0.001)$. However, these low hs-cTnT concentrations should be considered with care, as they were not measured with adequate precision (91\% of the pre-run concentrations were below $0.009 \mu \mathrm{g} / \mathrm{L}$, the $10 \% \mathrm{CV}$ cutoff value of the hs-cTnT assay). Pre-run NT-proBNP concentrations were only marginally different between the groups (P 0.046). 
After running, hs-cTnT concentrations were significantly elevated $(P \leq 0.005)$, as depicted in Figure $1 \mathrm{~A}$, except in the $5 \mathrm{~km}$ runners ( $\mathrm{P}$ 0.522). Median (IQR) post-run hs-cTnT concentrations were $0.006 \mu \mathrm{g} / \mathrm{L}(0.008)$ in the $5_{\text {HAPPY }} \mathrm{km}$ population and $0.004 \mu \mathrm{g} / \mathrm{L}(0.003)$, $0.010 \mu \mathrm{g} / \mathrm{L}(0.006), 0.014 \mu \mathrm{g} / \mathrm{L}(0.019)$ and $0.030 \mu \mathrm{g} / \mathrm{L}(0.029)$ in the 5, 15, 21, and $42 \mathrm{~km}$ runners, respectively. After correction for the effect of pre-run concentration, age and sex, linear regression analysis showed that hs-cTnT concentrations were significantly higher with increasing running distance $(P<0.001)$, except between the 15 and $21 \mathrm{~km}$ runners $(P 0.347)$. Also, the percentage of runners with elevated hs-cTnT concentrations after the run increased with running distance, as shown in Figure1A.

Figure 1B shows that NT-proBNP post-run concentrations were also significantly elevated compared to the prerun concentrations $(P<0.001)$, while it was marginally elevated in the $21 \mathrm{~km}$ runners (P 0.051). Median (IQR) post-run NT-proBNP concentrations were 8.41 $\mathrm{pmol} / \mathrm{L}$ (11.39) in the $5_{\text {HAPPY }} \mathrm{km}$ population and $7.32 \mathrm{pmol} / \mathrm{L}$ (8.69), $9.14 \mathrm{pmol} / \mathrm{L}$ (10.54), 5.06 $\mathrm{pmol} / \mathrm{L}(7.23)$ and $9.67 \mathrm{pmol} / \mathrm{L}(8.98)$ in the 5, 15, 21, and $42 \mathrm{~km}$ runners, respectively. Regression analysis showed that post-run NT-proBNP concentrations were significantly higher in the 15 and $42 \mathrm{~km}$ runners compared to the other groups $(P<0.001)$ after correction for the pre-run NT-proBNP concentration, sex and age. Furthermore, post-run concentrations in the $5 \mathrm{~km}$ runners were significantly higher than in the $5_{\text {HAPPY }}$ group ( $P$ $<0.001$ ), but not significantly different from the $21 \mathrm{~km}$ runners (P 0.187). Nevertheless, in contrast to the hs-cTnT post-run concentrations, NT-proBNP post-run concentrations mainly remained below the URL (Figure 1B, overall in $96 \%$ of the runners). For comparison, when the URL is defined at the $97.5^{\text {th }}$ percentile as proposed in the National Academy Clinical Biochemistry guideline, ${ }^{1}$ NT-proBNP post-run concentrations were above the URL in $12 \%$ of the $5_{\text {HAPPY }} \mathrm{km}$ population and in $7,0,10$, and $11 \%$ of the runners, respectively.

No clear correlations were identified between pre-run concentrations of hs-cTnT and NT-proBNP ( $r=0.13, P 0.025)$ and the same held true for the post-run concentrations $(r=0.21$, $\mathrm{P}<0.001)$.

\section{Discussion}

\section{Distance effect on hs-cTnT post-run concentrations}

When using the new generation hs-cTnT assay, we found that the distance of competitive running was positively related to the increase in $\mathrm{cTnT}$ post-run concentrations, as shown in 

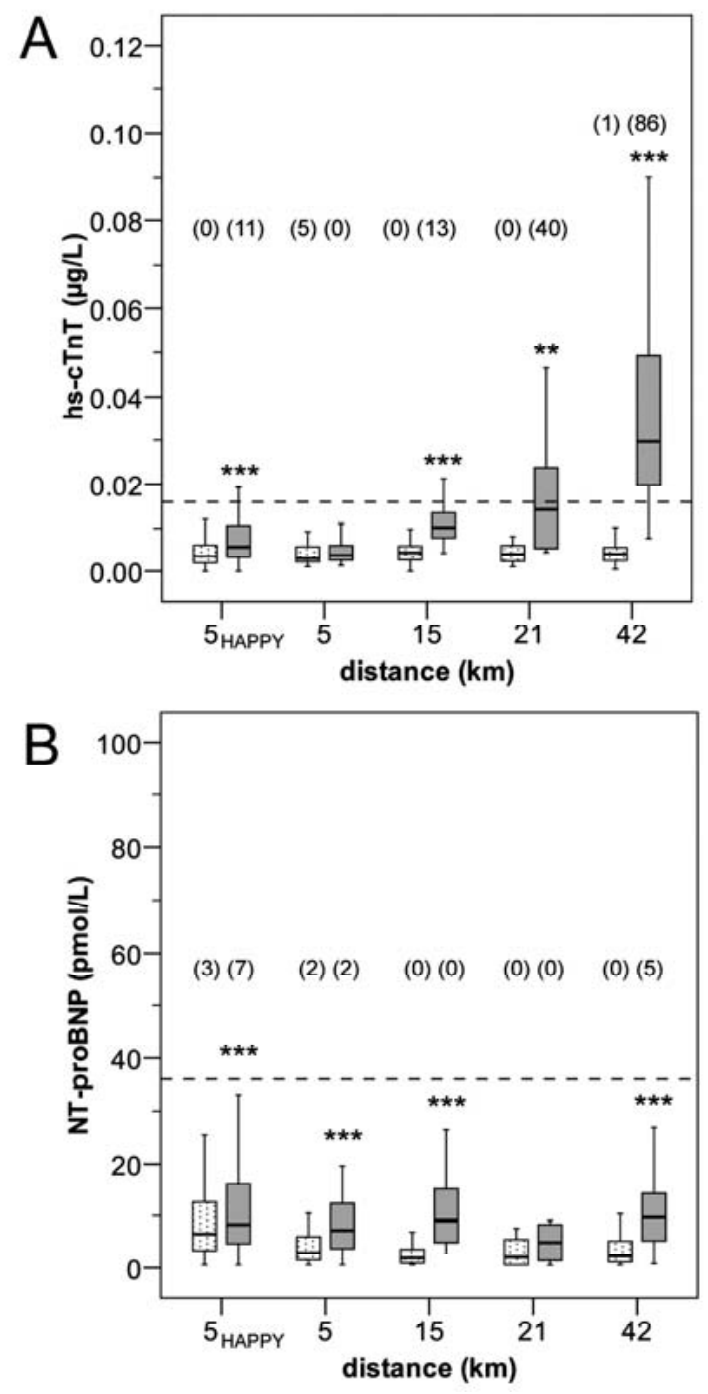

Figure 1: (A) hs-cTnT and (B) NTproBNP concentrations in recreational runners before and after running 5 km, $15 \mathrm{~km}, 21 \mathrm{~km}$, and $42 \mathrm{~km}$. Serum samples were measured pre-run (white boxplot) and immediately after the run (grey boxplot). Post-run concentrations were corrected for the effect of dehydration. All runners participated in a competition, except for the participants of the $5 \mathrm{~km}$ HAPPY ( $\left.5_{\text {HAPPY }}\right)$, who either walked or ran. The dotted lines represent the upper reference limit (URL, 99 ${ }^{\text {th }}$ percentile measured in a reference population as reported previously in chapter 3 ). The boxplots represent the median (line), the interquartile range (IQR, box), and the range $(1.5 \times \mathrm{IQR})$. Outliers are not depicted. Indicated are the comparison of post-run with pre-run concentrations per runner population $(*, P<0.05 ; * *, P<0.01 ; * * *, P<0.001)$ and the percentage of runners above URL (between brackets).

Figure $1 \mathrm{~A}$ for running $5,15,21$, and $42 \mathrm{~km}$. After marathon running for the largest distance studied, hs-cTnT was elevated in most of the runners ( $86 \%$, median $0.030 \mu \mathrm{g} / \mathrm{L}$ ). Also, we showed that post-run hs-cTnT concentrations were significantly increased after $5 \mathrm{~km}$ of exercise in the untrained and non-competitive HAPPY participants $\left(5_{\text {HAPPY }}\right)$, while not in the trained population after $5 \mathrm{~km}$ of competitive running.

Such a distance effect on hs-cTnT post-run concentrations has not been reported so far. As mentioned in the introduction of this chapter, other exercise studies that used older generation cTn assays were restricted because of immunoassay limitations and cTn 
concentrations only became detectable immediately after exercise. ${ }^{8,12}$ For example, when using the third generation cTnT assay (hs-cTnT assay is the fifth generation), Scharhag et al $^{2}$ could not find significantly lower cTnT elevations after marathon running compared to ultramarathon running $(100 \mathrm{~km})$. We showed that in untrained individuals, even running a short distance as $5 \mathrm{~km}$ could lead to significant increases in hs-cTnT concentrations, in contrast to trained runners. In fact, in the marathon runners experience turns out to be a significant predictor of the cTnT post-run concentrations when using the hs-cTnT assay, as previously reported in chapter 3 and as also suggested by the data reported by Fortescue et al. ${ }^{1}$ Neilan et al used both echocardiography and serum biomarkers to study non-elite marathon runners specifically and found that both median CTnT and median NT-proBNP concentrations were significantly higher in runners who trained $\leq 56 \mathrm{~km} /$ week (cTnT, 0.09 $\mu \mathrm{g} / \mathrm{L}$; NT-proBNP $21.5 \mathrm{pmol} / \mathrm{L}$ ) than in those who trained $>72 \mathrm{~km} /$ week (cTnT, $<0.01 \mu \mathrm{g} / \mathrm{L}$; NT-proBNP $12.5 \mathrm{pmol} / \mathrm{L}){ }^{49}$ Others investigated recreational runners, ${ }^{47,52}$ but did not investigate the effect of training and, to the best of our knowledge, no studies have shown cTn elevations in professional runners.

\section{Distance effect absent on NT-proBNP post-run concentrations}

In contrast to hs-cTnT, running distance was not found to be related to post-run NT-proBNP elevations, as shown in Figure 1B. Nevertheless, NT-proBNP concentrations were significantly elevated after running for all studied distances, although the number of individuals with elevated post-run concentrations greatly depended on the URL definition. As suggested in the NACB guideline, ${ }^{50}$ the URL in the present study was defined by the $97.5^{\text {th }}$ percentile value measured in a reference population ( $28 \mathrm{pmol} / \mathrm{L}, \mathrm{n}=479$, chapter 3 ). In literature, though, often $125 \mathrm{pg} / \mathrm{mL}(14.8 \mathrm{pmol} / \mathrm{L})$ is used as the diagnostic cutoff for heart failure $^{53,54}$ as given in the package insert. But even with this lower cut-off, we could not identify increased NT-proBNP post-run elevations with increasing running distances as we did for hs-cTnT (post-run NT-proBNP concentrations were elevated in 29, 14, 26, 10, and $24 \%$ of the runners, respectively). Lippi et al ${ }^{55}$ found that NT-proBNP concentrations did not exceed $14.8 \mathrm{pmol} / \mathrm{L}$ in 17 male runners after running half a marathon. However, in even more intense duration events, Scharhag et $\mathrm{al}^{2}$ did show significant higher post-run NTproBNP concentrations in ultra-marathon runners (median, $28 \mathrm{pmol} / \mathrm{L}$ as interpolated from figure) compared to marathon runners (median, $14 \mathrm{pmol} / \mathrm{L}$ ) and marathon mountain bikers 
(median, $11 \mathrm{pmol} / \mathrm{L}$ ). In addition, Serrano-Ostariz et al ${ }^{56}$ reported in 95 male cyclists (206 $\mathrm{km}$ ) that exercise-induced NT-proBNP elevations were significantly correlated with training status, race time and exercise load (training impulse values), but not with age and exercise intensity.

\section{Effect of exercise intensity on hs-cTnT and NT-proBNP}

We show here that post-run hs-cTnT release increases with running distance and thereby with exercise duration, in contrast to post-run NT-proBNP. However, a meta-analysis of 26 exercise studies (1,120 individuals) that used second and third generation cTnT assays showed a slightly negative relationship with exercise duration (total studies, P 0.022; 15 running studies only, $\mathrm{P}$ 0.016). ${ }^{57}$ It was thought that the shorter endurance exercise events were performed with higher exercise intensities than the longer endurance exercise events. ${ }^{7,57}$ One way to express exercise intensity is to estimate running velocity. ${ }^{58}$ As shown in Table 2, we did not notice different mean running velocities in our populations of competitive running. Next, Jassal et $a^{52}$ reported a modest correlation between post-run cTnT and the time required to complete a marathon race (median cTnT, $0.036 \mu \mathrm{g} / \mathrm{L}$; mean time, $310 \mathrm{~min}$; SD, $30 \mathrm{~min} ; \mathrm{r}=0.40, \mathrm{P}<0.001)$. In the present study, we could not confirm a significant association of running time with the post-run hs-cTnT and NT-proBNP elevations (hs-cTnT, P 0.558; NT-proBNP, P 0.893) by using linear regression analysis with correction for the effect of running distance, pre-run concentration, age and gender.

\section{Clarifications for exercise-induced biomarker increases}

To explain the link between exercise-induced cTn release and (acute) cardiac events, two opposing theories exist, namely the reversibility and irreversibility concept of cardiomyocyte damage, ${ }^{8}$ as discussed previously in chapter 3 . Recently, Sabatine et $\mathrm{al}^{59}$ indicated by using the ultra-sensitive Singulex assay that hs-cTnl was released in patients due to myocyte ischemia without necrosis. Hessel et $\mathrm{al}^{60}$ studied $\mathrm{cTnl}$ release from cultures of rat cardiomyocytes and demonstrated the release of intact cTnl from viable cardiomyocytes. Another clarification was made by Middleton et $\mathrm{al}^{61}$ who proposed that the cTn elevation could be due to an increased turnover of cardiac cTn, as a physiologic response to endurance exercise and the associated increased myocardial demand. Apart from this, a feasible explanation for exercise-induced NT-proBNP elevations is the associated increase in myocardial wall stress. ${ }^{7}$ This would suggest a relation between NT-proBNP and exercise 
duration that we could not confirm in the present study (5-42 km of running), but was found in the more intense exercise events (42-206 km of running and cycling). ${ }^{2,56}$

\section{Study limitations}

Comparison among the considered running distances was limited as different runners were studied for each of the distances. Although the HAPPY population was not completely characterized, we believe that these results are instructive especially when compared to the trained $5 \mathrm{~km}$ runners. Furthermore, training was not given to all the participants and we had to deal with two different definitions for training.

\section{Conclusion}

When using the hs-cTnT assay, we found the distance of recreational, but competitive, running to be positively related to the asymptomatic increases in cTnT post-run concentrations, in contrast to NT-proBNP. Remarkably, a relatively short running distance in an untrained population resulted in significant hs-cTnT release. Greater effort in basic research to investigate the biological and pathological importance of exercise-induced cTn release and the effect of insufficient training on this release is needed.

\section{References}

1. Fortescue EB, Shin AY, Greenes DS, et al. Cardiac troponin increases among runners in the Boston marathon. Ann Emerg Med. 2007;49:137-143, 143 e131.

2. Scharhag J, Herrmann M, Urhausen A, Haschke M, Herrmann W, Kindermann W. Independent elevations of $\mathrm{N}$-terminal pro-brain natriuretic peptide and cardiac troponins in endurance athletes after prolonged strenuous exercise. Am Heart J. 2005;150:1128-1134.

3. Siegel AJ, Januzzi J, Sluss P, et al. Cardiac biomarkers, electrolytes, and other analytes in collapsed marathon runners: implications for the evaluation of runners following competition. Am J Clin Pathol. 2008;129:948-951.

4. Tunstall Pedoe DS. Marathon cardiac deaths: the Iondon experience. Sports Med. 2007;37:448450.

5. Corrado D, Pelliccia A, Bjornstad HH, et al. Cardiovascular pre-participation screening of young competitive athletes for prevention of sudden death: proposal for a common European protocol. Consensus statement of the study group of sport cardiology of the working group of cardiac rehabilitation and exercise physiology and the working group of myocardial and pericardial diseases of the European Society of Cardiology. Eur Heart J. 2005;26:516-524.

6. Maron BJ, Thompson PD, Ackerman MJ, et al. Recommendations and considerations related to preparticipation screening for cardiovascular abnormalities in competitive athletes: 2007 update: a scientific statement from the American Heart Association council on nutrition, physical activity, and metabolism: endorsed by the American College of Cardiology foundation. Circulation. 2007;115:1643-1655. 
7. Scharhag J, George K, Shave R, Urhausen A, Kindermann W. Exercise-associated increases in cardiac biomarkers. Med Sci Sports Exerc. 2008;40:1408-1415.

8. Shave R, George K, Gaze D. The influence of exercise upon cardiac biomarkers: a practical guide for clinicians and scientists. Curr Med Chem. 2007;14:1427-1436.

9. Apple FS, Jesse RL, Newby LK, et al. National Academy of Clinical Biochemistry and IFCC Committee for Standardization of Markers of Cardiac Damage Laboratory Medicine Practice Guidelines: analytical issues for biochemical markers of acute coronary syndromes. Clin Chem. 2007;53:547-551.

10. Panteghini $\mathrm{M}$, Pagani $\mathrm{F}$, Yeo $\mathrm{KT}$, et al. Evaluation of imprecision for cardiac troponin assays at low-range concentrations. Clin Chem. 2004;50:327-332.

11. Tate JR, Ferguson W, Bais R, Kostner K, Marwick T, Carter A. The determination of the 99th centile level for troponin assays in an Australian reference population. Ann Clin Biochem. 2008;45:275-288.

12. Michielsen EC, Wodzig WK, Van Dieijen-Visser MP. Cardiac troponin T release after prolonged strenuous exercise - a review. Sports Med. 2008;38:425-435.

13. Mingels A, Jacobs L, Michielsen E, Swaanenburg J, Wodzig W, van Dieijen-Visser M. Reference population and marathon runner sera assessed by highly sensitive cardiac troponin $T$ and commercial cardiac troponin T and I assays. Clin Chem. 2009;55:101-108.

14. Kavsak PA, MacRae AR, Yerna MJ, Jaffe AS. Analytic and clinical utility of a next-generation, highly sensitive cardiac troponin I assay for early detection of myocardial injury. Clin Chem. 2009;55:573-577.

15. Weber M, Hamm C. Role of B-type natriuretic peptide (BNP) and NT-proBNP in clinical routine. Heart. 2006;92:843-849.

16. Koller A, Mair J, Mayr M, Calzolari C, Larue C, Puschendorf B. Diagnosis of myocardial injury in marathon runners. Ann N Y Acad Sci. 1995;752:234-235.

17. Herrmann M, Scharhag J, Miclea M, Urhausen A, Herrmann W, Kindermann W. Post-race kinetics of cardiac troponin $\mathrm{T}$ and $\mathrm{I}$ and $\mathrm{N}$-terminal pro-brain natriuretic peptide in marathon runners. Clin Chem. 2003;49:831-834.

18. Urhausen A, Scharhag J, Herrmann M, Kindermann W. Clinical significance of increased cardiac troponins T and I in participants of ultra-endurance events. Am J Cardiol. 2004;94:696-698.

19. Ashley EA, Kardos A, Jack ES, et al. Angiotensin-converting enzyme genotype predicts cardiac and autonomic responses to prolonged exercise. J Am Coll Cardiol. 2006;48:523-531.

20. Scharhag J, Urhausen A, Schneider G, et al. Reproducibility and clinical significance of exerciseinduced increases in cardiac troponins and $\mathrm{N}$-terminal pro brain natriuretic peptide in endurance athletes. Eur J Cardiovasc Prev Rehabil. 2006;13:388-397.

21. Tian $\mathrm{Y}$, Nie J, Tong TK, et al. Changes in serum cardiac troponins following a 21-km run in junior male runners. J Sports Med Phys Fitness. 2006;46:481-488.

22. Ortega FB, Ruiz JR, Gutierrez A, Castillo MJ. Extreme mountain bike challenges may induce subclinical myocardial damage. J Sports Med Phys Fitness. 2006;46:489-493.

23. Bhagat $\mathrm{Cl}$, Langton $\mathrm{P}$, Lewer M, Ching S, Beilby JP. Cardiac troponin I should replace CKMB for the diagnosis of acute myocardial infarction. Ann Clin Biochem. 1997;34:511-516.

24. Davies E, Gawad Y, Takahashi M, et al. Analytical performance and clinical utility of a sensitive immunoassay for determination of human cardiac troponin I. Clin Biochem. 1997;30:479-490.

25. Davila-Roman VG, Guest TM, Tuteur PG, Rowe WJ, Ladenson JH, Jaffe AS. Transient right but not left ventricular dysfunction after strenuous exercise at high altitude. I Am Coll Cardiol. 1997;30:468-473.

26. ver Elst KM, Chapelle JP, Boland P, Demolder JS, Gorus FK. Analytic and clinical evaluation of the Abbott AxSYM cardiac troponin I assay. Am J Clin Pathol. 1999;112:745-752.

27. Schulz O, Kromer A. Cardiac troponin I: a potential marker of exercise intolerance in patients with moderate heart failure. Am Heart J. 2002;144:351-358. 
28. Schulz O, Paul-Walter C, Lehmann M, et al. Usefulness of detectable levels of troponin, below the 99th percentile of the normal range, as a clue to the presence of underlying coronary artery disease. Am J Cardiol. 2007;100:764-769.

29. Cleave P, Boswell TD, Speedy DB, Boswell DR. Plasma cardiac troponin concentrations after extreme exercise. Clin Chem. 2001;47:608-610.

30. Neumayr G, Gaenzer H, Pfister R, et al. Plasma levels of cardiac troponin I after prolonged strenuous endurance exercise. Am J Cardiol. 2001;87:369-371, A310.

31. Neumayr G, Pfister R, Mitterbauer G, et al. Effect of the "Race Across The Alps" in elite cyclists on plasma cardiac troponins I and T. Am J Cardiol. 2002;89:484-486.

32. La Gerche A, Boyle A, Wilson AM, Prior DL. No evidence of sustained myocardial injury following an Ironman distance triathlon. Int J Sports Med. 2004;25:45-49.

33. La Gerche A, Connelly KA, Mooney DJ, Macisaac Al, Prior DL. Biochemical and functional abnormalities of left and right ventricular function following ultra-endurance exercise. Heart. 2007;94:860-866.

34. Koller A, Sumann G, Griesmacher A, et al. Cardiac troponins after a downhill marathon. Int J Cardiol. 2008;13:449-452.

35. Cummins B, Auckland ML, Cummins P. Cardiac-specific troponin-I radioimmunoassay in the diagnosis of acute myocardial infarction. Am Heart J. 1987;113:1333-1344.

36. Adams JE, 3rd, Bodor GS, Davila-Roman VG, et al. Cardiac troponin I. A marker with high specificity for cardiac injury. Circulation. 1993;88:101-106.

37. Siegel AJ, Sholar M, Yang J, Dhanak E, Lewandrowski KB. Elevated serum cardiac markers in asymptomatic marathon runners after competition: is the myocardium stunned? Cardiology. 1997;88:487-491.

38. Sorichter S, Mair J, Koller A, et al. Muscular adaptation and strength during the early phase of eccentric training: influence of the training frequency. Med Sci Sports Exerc. 1997;29:1646-1652.

39. Koller A, Mair J, Schobersberger W, et al. Effects of prolonged strenuous endurance exercise on plasma myosin heavy chain fragments and other muscular proteins. Cycling vs running. J Sports Med Phys Fitness. 1998;38:10-17.

40. Rifai N, Douglas PS, O'Toole M, Rimm E, Ginsburg GS. Cardiac troponin T and I, echocardiographic [correction of electrocardiographic] wall motion analyses, and ejection fractions in athletes participating in the Hawaii Ironman Triathlon. Am J Cardiol. 1999;83:1085-1089.

41. Lucia A, Moran M, Perez M, et al. Short-term effects of marathon running in master runners: no evidence of myocardial injury. Int J Sports Med. 1999;20:482-486.

42. Shave R, Dawson E, Whyte G, et al. The cardiospecificity of the third-generation cTnT assay after exercise-induced muscle damage. Med Sci Sports Exerc. 2002;34:651-654.

43. Siegel AJ, Lewandrowski EL, Chun KY, Sholar MB, Fischman AJ, Lewandrowski KB. Changes in cardiac markers including B-natriuretic peptide in runners after the Boston marathon. Am J Cardiol. 2001;88:920-923.

44. Apple FS, Anderson FP, Collinson P, et al. Clinical evaluation of the first medical whole blood, point-of-care testing device for detection of myocardial infarction. Clin Chem. 2000;46:16041609.

45. Kratz A, Lewandrowski KB, Siegel AJ, et al. Effect of marathon running on hematologic and biochemical laboratory parameters, including cardiac markers. Am J Clin Pathol. 2002;118:856863.

46. Smith JE, Garbutt G, Lopes P, Pedoe DT. Effects of prolonged strenuous exercise (marathon running) on biochemical and haematological markers used in the investigation of patients in the emergency department. Br J Sports Med. 2004;38:292-294.

47. Vidotto C, Tschan H, Atamaniuk J, Pokan R, Bachl N, Muller MM. Responses of N-terminal probrain natriuretic peptide (NT-proBNP) and cardiac troponin I (cTnl) to competitive endurance exercise in recreational athletes. Int J Sports Med. 2005;26:645-650.

48. Neilan TG, Yoerger DM, Douglas PS, et al. Persistent and reversible cardiac dysfunction among amateur marathon runners. Eur Heart J. 2006;27:1079-1084. 
49. Neilan TG, Januzzi JL, Lee-Lewandrowski E, et al. Myocardial injury and ventricular dysfunction related to training levels among nonelite participants in the Boston marathon. Circulation. 2006;114:2325-2333.

50. Apple FS, Wu AH, Jaffe AS, et al. National Academy of Clinical Biochemistry and IFCC committee for standardization of markers of cardiac damage laboratory medicine practice guidelines: analytical issues for biomarkers of heart failure. Circulation. 2007;116:e95-98.

51. Giannitsis E, Kurz K, Hallermayer K, Jarausch J, Jaffe AS, Katus HA. Analytical validation of a highsensitivity cardiac troponin T assay. Clin Chem. 2010;56:254-261.

52. Jassal DS, Moffat D, Krahn J, et al. Cardiac injury markers in non-elite marathon runners. Int J Sports Med. 2009;30:75-79.

53. Gustafsson F, Steensgaard-Hansen F, Badskjaer J, Poulsen AH, Corell P, Hildebrandt P. Diagnostic and prognostic performance of $\mathrm{N}$-terminal proBNP in primary care patients with suspected heart failure. J Card Fail. 2005;11:S15-20.

54. Januzzi JL, van Kimmenade R, Lainchbury J, et al. NT-proBNP testing for diagnosis and short-term prognosis in acute destabilized heart failure: an international pooled analysis of 1256 patients: the international collaborative of NT-proBNP study. Eur Heart J. 2006;27:330-337.

55. Lippi G, Schena F, Salvagno GL, et al. Influence of a half-marathon run on NT-proBNP and troponin T. Clin Lab. 2008;54:251-254.

56. Serrano-Ostariz E, Legaz-Arrese A, Terreros-Blanco JL, et al. Cardiac biomarkers and exercise duration and intensity during a cycle-touring event. Clin J Sport Med. 2009;19:293-299.

57. Shave R, George KP, Atkinson G, et al. Exercise-induced cardiac troponin T release: a metaanalysis. Med Sci Sports Exerc. 2007;39:2099-2106.

58. Scharhag J, Shave R, George K, Whyte G, Kindermann W. "Exercise-induced increases in cardiac troponins in endurance athletes: a matter of exercise duration and intensity?". Clin Res Cardiol. 2008;97:62-63; author reply 61.

59. Sabatine MS, Morrow DA, de Lemos JA, Jarolim P, Braunwald E. Detection of acute changes in circulating troponin in the setting of transient stress test-induced myocardial ischaemia using an ultrasensitive assay: results from TIMI 35. Eur Heart J. 2009;30:162-169.

60. Hessel MH, Atsma DE, van der Valk EJ, Bax WH, Schalij MJ, van der Laarse A. Release of cardiac troponin I from viable cardiomyocytes is mediated by integrin stimulation. Pflugers Arch. 2008;455:979-986.

61. Middleton N, George K, Whyte G, Gaze D, Collinson P, Shave R. Cardiac troponin T release is stimulated by endurance exercise in healthy humans. J Am Coll Cardiol. 2008;52:1813-1814. 



\title{
CHAPTER 5
}

\section{Cystatin C, a marker for renal function after exercise}

\begin{abstract}
Renal impairment is common during and after severe exercise. In clinical practice, renal function is evaluated using serum creatinine, urine parameters, and equations to estimate the Glomular Filtration Rate (GFR). However, creatinine levels may be biased by skeletal muscle damage and the GFR equations, requiring age, gender and body weight, are shown to be inadequate in normals. In the present study, we show that serum cystatin $\mathrm{C}$ and creatinine concentrations were elevated after marathon running in 26 and $46 \%$ of the 70 recreational male runners, respectively, possibly because of reduction in renal blood flow. The mean cystatin $C$ increase was twice as low as compared to creatinine ( 21 and $41 \%$, respectively), suggesting that cystatin $C$ is indeed less biased by muscle damage. Future research has to reveal whether training diminishes the elevation in renal markers. Overall, cystatin $\mathrm{C}$ seems a more reliable method to establish renal function during and after extensive exercise.
\end{abstract}


Renal impairment is common during exercise. ${ }^{1}$ Complications range from the asymptomatic increase of serum and urine parameters ${ }^{2-4}$ to the severe failure of renal function. 5

The first stage of Acute Kidney Injury (AKI) is defined as an abrupt reduction in kidney function $(<48 \mathrm{~h})$ with an absolute increase in serum creatinine $\geq 26.4 \mu \mathrm{mol} / \mathrm{L}$, a relative increase $\geq 1.5$-fold, or a reduction in urine output (AKIN criteria). ${ }^{7}$ Chronic kidney disease (CKD) is diagnosed in case of kidney damage or Glomular Filtration Rate (GFR) $<60$ $\mathrm{mL} / \mathrm{min} / 1.73 \mathrm{~m}^{2}$ for $\geq 3$ months, irrespective of its cause (KDOQI classification). ${ }^{8}$ However, accurate measurement of the GFR is complicated in sports medicine and has hardly been described. In clinical practice, serum creatinine, urine parameters, and estimates of GFR (eGFR) are used to study renal function. The guidelines ${ }^{8}$ recommend to estimate GFR using the 4-variable Modification of Diet in Renal Disease (MDRD) equation ${ }^{9}$ or, otherwise, to estimate creatinine clearance using the Cockcroft-Gault (C-G) equation. ${ }^{10}$

In sports medicine, however, serum creatinine concentrations might be influenced by skeletal muscle damage. Creatinine is a breakdown product from the muscles and depends on muscle mass ${ }^{11}$ as has also been confirmed in top level athletes. ${ }^{12}$ Banfi et al reported that for the interpretation of creatinine concentrations in athletes one should take into consideration the Body Mass Index of the athlete and the specific sport performed (training, aerobic/anaerobic metabolism, and competitive season). ${ }^{12}$ Apart from the (biased) serum creatinine, the eGFR equations require data regarding age and gender (and for C-G also body weight). ${ }^{9,10,13}$ In addition, eGFRs are developed in CKD/diseased patients, are imprecise at higher values and, consequently, cause misclassification in normals or persons with extremes in body composition. ${ }^{14,15}$ Urine collection is quite demanding during sport activities and the accuracy of the 24-h urine is therefore questionable. There is thus need for a more reliable method to measure renal function after or even during exercise.

Cystatin $C$ is a non-glycosylated $13 \mathrm{kD}$ basic protein and member of the cysteine protease inhibitors. It is constantly produced by all nucleated cells and serum concentrations correlate with GFR. ${ }^{16}$ In contrast to creatinine, cystatin C levels are less affected by factors such as age, gender and muscle mass. ${ }^{11,17,18}$ This makes cystatin $C$ a promising marker to estimate renal function during and after exercise. To the best of our knowledge, no studies have reported on cystatin C concentrations in sportsmen, whatever the sport discipline, either at rest or followed after exercise. 
In this study, cystatin C concentrations were evaluated in comparison to creatinine and creatinine-based estimates of GFR in recreational male marathon runners. Serum concentrations were obtained prior to, immediately after, and the day after the marathon.

\section{Materials and methods}

The marathon study population consisted of 70 recreational male runners (Table 1), which is part of the population studied in chapters 3 and 4 . The study was approved by the local ethical committee and all runners signed the informed consent. Serum was collected $<2 \mathrm{~h}$ pre-run and $<1 \mathrm{~h}$ post-run from the 70 runners and the day after the run serum was collected for logistic reasons from a selected group of 18 runners. The maximum temperature on the day of the marathon was $23.4^{\circ} \mathrm{C}$ with a south wind of $<14 \mathrm{~m} / \mathrm{s}$. Aliquots were stored at $-80^{\circ} \mathrm{C}$. Serum creatinine (Jaffé reaction assay, reference range 60-115 $\mu \mathrm{mol} / \mathrm{L}$, as validated in our laboratory in 31,335 polyclinical male subjects using Bhattacharya analysis) and albumin concentrations (reference range 32.0-47.0 g/L) were measured on the Synchron LX 20 (Beckman Coulter). Cystatin C (reference range 0.53-0.95 mg/L, as given in the package insert) was measured on the BN ProSpec (Siemens). eGFR was estimated using the $\mathrm{MDRD},{ }^{9}$ the $\mathrm{C}-\mathrm{G}^{10}$ adjusted for body surface area, and the Mayo Clinic Quadratic Equation (MCQE) $)^{13}$ equations, see equations 1 to 3 , respectively. Data analysis was performed using SPSS, Version 13.0. Parameters were tested using the paired-samples $t$-test

Equation 1: eGFR according to MDRD $\left(\mathrm{mL} / \mathrm{min} / 1.73 \mathrm{~m}^{2}\right)$

$=186\left(\frac{\text { creatinine }}{88.5}\right)^{-1.154} \times$ age $^{-0.203} \times$ gender

if male: gender $=1$; if female: gender $=0.742$

Equation 2: eGFR according to C-G adjusted for body surface area $\left(\mathrm{mL} / \mathrm{min} / 1.73 \mathrm{~m}^{2}\right)$

$=\frac{(140-\text { age }) \times \text { weight }}{\text { gender } \times \text { creatinine }} \sqrt{\frac{\text { length } \times \text { weight }}{36}}$

if male: gender $=0.81$; if female: gender $=0.95$; if $\mathrm{BMI}>25 \mathrm{~kg} / \mathrm{m}^{2}$ : weight $=25^{*}$ (length) ${ }^{2}$

Equation 3: eGFR according to MCQE $\left(\mathrm{mL} / \mathrm{min} / 1.73 \mathrm{~m}^{2}\right)$

$=\exp \left(1.911+\frac{5.249}{\text { creatinine } / 88.5}-\frac{2.114}{\text { (creatinine } / 88.5)^{2}}-0.00686 \times\right.$ age + gender

if male: gender $=0$; if female: gender $=-0.205$

where creatinine is in $\mu \mathrm{mol} / \mathrm{L}$, age in years, weight in kilograms, and length in meters. 
and the Wilcoxon Signed-Rank test. Parametric correlations were calculated with the Pearson's coefficient. Statistical significance was considered at $\mathrm{P}<0.05$.

\section{Results}

Pre-race cystatin $C$ and creatinine concentrations were within the reference range. As shown in Table 1 (original measurements) and Figure 1 (after correction for the effect of dehydration using the ratio of albumin concentrations from the post versus pre-run serum samples), both markers were significantly increased after running the marathon $(P<0.001)$. After running, the mean cystatin C concentration of the runners was increased by $34 \%$, while the mean creatinine concentration was increased by $53 \%$ (Table 1). Cystatin C was increased to above the upper reference limit in $46 \%$ of the 70 runners, while for creatinine this was true in $70 \%$ of the runners. After correction for the effect of dehydration, the mean cystatin C and creatinine post-run concentrations increased by 21 and 41\%, respectively (Figure 1), and concentrations were increased to above the upper reference limit in 26 and $46 \%$ of the

Table 1: Baseline characteristics of the marathon study population (mean and $95 \% \mathrm{Cl}$ )

\begin{tabular}{|c|c|c|c|c|c|}
\hline $\mathrm{n}$ & 70 males & & & & \\
\hline age, years & $47(30-68)$ & & & & \\
\hline $\mathrm{BMI}, \mathrm{kg} / \mathrm{m}^{2}$ & $23(20-26)$ & & & & \\
\hline $\begin{array}{l}\text { traınıng, number of } \\
\text { marathons completed }\end{array}$ & $8(125)$ & & & & \\
\hline running time, $\mathrm{h}$ & $3.71(2.87-4.69)$ & & & & \\
\hline & & & & pre vs & pre vs \\
\hline & & & & $\mathrm{Oh}$ & $1 \mathrm{~d}$ \\
\hline & pre & post $0 \mathrm{~h}$ & post $1 d^{b}$ & $P$ value & $\mathrm{P}$ value $^{\mathrm{b}}$ \\
\hline cystatin $\mathrm{C}, \mathrm{mg} / \mathrm{L}^{\mathrm{c}}$ & $0.71(0.56-0.95)$ & $0.95(0.63-1.45)$ & $0.73(0.60-0.93)$ & $<0.001$ & 0.032 \\
\hline creatinine, $\mu \mathrm{mol} / \mathrm{L}^{\mathrm{c}}$ & $86(65-111)$ & $132(87-264)^{d}$ & $96(68-168)$ & $<0.001$ & 0.078 \\
\hline $\mathrm{C}-\mathrm{G}, \mathrm{mL} / \mathrm{min} / 1.73 \mathrm{~m}^{2}$ & $90(64-130)$ & $61(28-93)$ & $76(44-95)$ & $<0.001$ & 0.100 \\
\hline MDRD, $\mathrm{mL} / \mathrm{min} / 1.73 \mathrm{~m}^{2}$ & $90(66-125)$ & $58(28-89)$ & $80(40-107)$ & $<0.001$ & 0.069 \\
\hline MCQE, $\mathrm{mL} / \mathrm{min} / 1.73 \mathrm{~m}^{2}$ & $114(81-138)$ & $71(27-119)$ & $88(35-106)$ & $<0.001$ & 0.105 \\
\hline albumin (g/L) & $44.0(36.0-48.2)$ & $48.2(39.4-53.0)$ & $43.2(35.9-47.3)$ & $<0.001$ & 0.495 \\
\hline
\end{tabular}




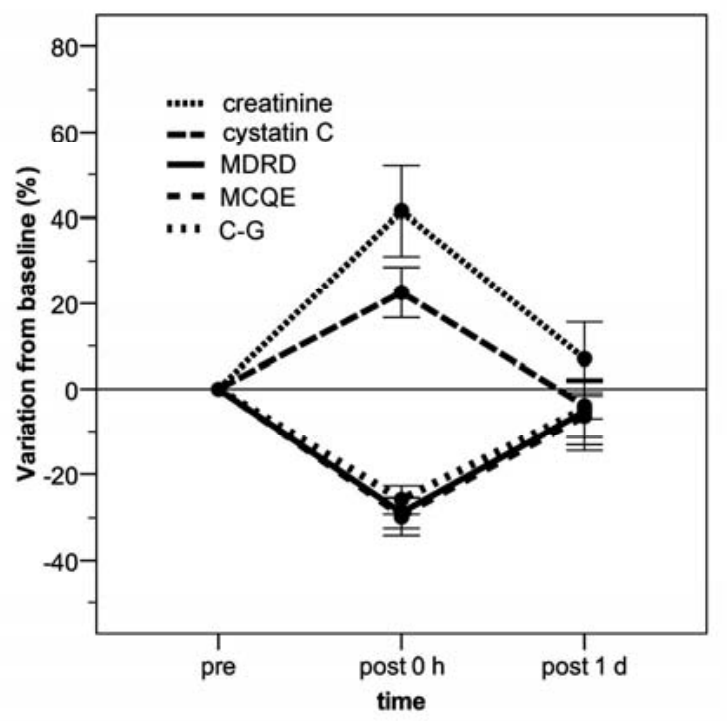

Figure 1: Variation in renal functional parameters in recreational male marathon runners. Serum measurements were performed prior (pre), immediately after (post $0 \mathrm{~h}$ ) and one day after the marathon (post 1 d). Serum concentrations were corrected for the effect of dehydration using the pre-run albumin level. Depicted are the mean $(\bullet)$ and $2 \times$ standard error of the mean (error bars).

runners, respectively. Figure 1 and Table 1 show that the renal marker concentrations returned to baseline concentrations within one day. Overall, cystatin C and creatinine concentrations were well correlated $(r=0.702)$.

Pre-race eGFR was $>60 \mathrm{~mL} / \mathrm{min} / 1.73 \mathrm{~m}^{2}$ in all the 70 runners when using the C-G equation (99\%), the MDRD and MCQE equation (100\%). After running the marathon, eGFR was $<60 \mathrm{~mL} / \mathrm{min} / 1.73 \mathrm{~m}^{2}$ in 46,55 , and $33 \%$ of the runners when using the $\mathrm{C}-\mathrm{G}$, the MDRD and the MCQE equation, respectively. For albumin corrected values this was 29,35 , and $16 \%$, respectively. All three eGFRs were highly correlated $(r>0.950, P<0.001)$. For the higher eGFR concentrations $\left(>60 \mathrm{~mL} / \mathrm{min} / 1.73 \mathrm{~m}^{2}\right)$, the MCQE equation resulted in higher values ( $\max$ deviation $+36 \mathrm{~mL} / \mathrm{min} / 1.73 \mathrm{~m}^{2}$ ) as compared to the MDRD, whereas the C-G equation resulted in lower values ( $\max$ deviation $-33 \mathrm{~mL} / \mathrm{min} / 1.73 \mathrm{~m}^{2}$ ). The eGFRs were highly correlated to 1 / creatinine $(r=0.879-0.899, P<0.001)$ and well correlated to $1 /$ cystatin $C$ $(r=0.614-0.638, P<0.001)$.

\section{Discussion}

Once serum creatinine concentrations rise above the upper reference limit, creatinine clearance has already been declined to half of normal ( $<60 \mathrm{~mL} / \mathrm{min})$, as can be interpreted from the characteristic shape of the creatinine clearance curve. ${ }^{19}$ It is thus quite alarming 
that after marathon running in half of our runners (46\%) creatinine levels were elevated to above the upper reference limit (after correction for the effect of dehydration). This was accompanied by a mean increase in creatinine concentration of $41 \%(+35 \mu \mathrm{mol} / \mathrm{L})$, indicating acute renal failure. ${ }^{7}$ Neumayr et al already suggested a temporary reduction of renal function after ultramarathon cycling, as creatinine concentrations increased by $20-33 \% .^{3,4}$ In all studies creatinine concentrations returned to baseline within one day, illustrating that exercise-induced renal impairment is temporary. ${ }^{2-4,20}$ In clinical practice estimates of GFR are used to study renal function. Recently, Lippi et al reported a decreased eGFR immediately after running a half marathon in $71 \%$ of the runners $\left(<60 \mathrm{~mL} / \mathrm{min} / 1.73 \mathrm{~m}^{2}\right.$, using the MDRD equation and after creatinine concentrations were corrected for the effect of dehydration). ${ }^{20}$ In the present study, also after dehydration correction, we found a decreased eGFR in half this percentage of the marathon runners (35\%), or when using the C-G and the MCQE equation in even fewer runners (16 and $29 \%$ of the runners, respectively). After marathon running, we calculated a $30 \%$ reduction in eGFR (Figure 1), while Neumayr et al measured a $25 \%$ reduction after ultramarathon cycling ${ }^{3}$ and Lippi et al measured a $16 \%$ reduction after running a half marathon. ${ }^{20}$ However, although the equations for eGFR are recommended in the CKD guidelines, ${ }^{8}$ they systematically underestimate renal function at high values of GFR and overestimate it at lower values of GFR in normals ${ }^{15}$ and CKD patients with normal creatinine levels. ${ }^{21}$ The AKI guidelines do not recommend evaluation of GFR, either measured or estimated. ${ }^{7}$ As exercise-induced impairment of renal function seems an example of acute renal failure, we have to be careful in conclusions concerning eGFR.

Some studies suggest that the cystatin $\mathrm{C}$ level may be affected by factors other than GFR. Cystatin C may reflect inflammation ${ }^{22}$ and is increasingly excreted in subjects with a decreased creatinine clearance. ${ }^{23}$ On the other hand, in contrast to creatinine, studies have shown that gender and muscle mass do not affect the cystatin $\mathrm{C}$ level. ${ }^{17,23}$ Furthermore, Bandaranayake et al recently showed that the within-subject variation $\left(\mathrm{CV}_{1}\right)$ and betweensubjects variation $\left(\mathrm{CV}_{\mathrm{G}}\right)$ of cystatin $\mathrm{C}$ was less than for creatinine $\left(\mathrm{CV}_{1} 4.5\right.$ and $6.1 \%$; $\mathrm{CV}_{\mathrm{G}} 13$ and $17.4 \%$, respectively). ${ }^{24}$ Next to the PENIA assay for cystatin $C$ measurements, similar results were recently obtained when using the PETIA assay (CV, 4.5 and $5.8 \%$, respectively). ${ }^{25}$ Cystatin $C$ and creatinine both had an index of individuality of $0.35(<0.6),{ }^{24}$ illustrating that the population-based reference ranges are here of limited use. ${ }^{26}$ The critical differences (including biological and analytical variation) were $12.6 \%(0.097 \mathrm{mg} / \mathrm{L})$ and $16.7 \%(13.7$ 
$\mu \mathrm{mol} / \mathrm{L})$ at the mean values of cystatin $C(0.77 \mathrm{mg} / \mathrm{L})$ and creatinine $(82 \mu \mathrm{mol} / \mathrm{L})$, respectively. ${ }^{24}$ This means that the exercise-induced elevations of cystatin $C$ and creatinine we measured in the present study are substantial (Table 1). Bandaranayake et al reported an analytical $\mathrm{CV}_{\mathrm{A}}$ of $2.5 \%$ at $0.77 \mathrm{mg} / \mathrm{L}$ and $2.3 \%$ at $64 \mu \mathrm{mol} / \mathrm{L}$ when using the $\mathrm{BN}$ II nephlometer (now Siemens) and the Synchron LX20 analyzer (as we used), respectively. ${ }^{24}$ We measured a comparable $\mathrm{CV}_{\mathrm{A}}$ for cystatin $\mathrm{C}$ on our BN ProSpec nephlometer (also Siemens), namely a $\mathrm{CV}_{\mathrm{A}}$ of $2.6 \%$ and $2.3 \%$ at $0.52 \mathrm{mg} / \mathrm{L}$ and $0.95 \mathrm{mg} / \mathrm{L}$, respectively (internal validation report). Thus, as shown in Figure 1, cystatin C elevation after marathon running (21\%) was twice as low as compared to creatinine (41\%), which might imply that the creatinine level after running was biased by skeletal muscle damage and cystatin $\mathrm{C}$ was not.

Previous studies on renal pathophysiology have shown that during exercise blood flow in the splanchic and renal circulations decreases (up to $50 \%)^{27,28}$ to redistribute the blood to the skeletal muscles, heart and lungs. ${ }^{29}$ Reduction of renal blood flow might explain the increase in renal markers observed immediately after marathon. The vasoconstriction though causes hypoxic damage to the nephron, causing an increased glomular permeability with excretion of erythrocytes and protein into the urine. ${ }^{1,27}$ Training diminishes the adverse effect of exercise on renal function. Armstrong et al studied eighty rats after $15 \mathrm{~min}$ of treadmill running and reported a $52 \%$ reduction of renal blood flow in sedentary rats and a $14 \%$ reduction in trained rats. ${ }^{30}$ This training effect might explain the discrepancies found in literature. No creatinine increase was found in 51 experienced healthy individuals after 100 $\mathrm{km}$ of running (maximal oxygen uptake $40 \pm 7 \mathrm{~mL} / \mathrm{kg} / \mathrm{min}$ and $35 \pm 6 \mathrm{~mL} / \mathrm{kg} / \mathrm{min}$ for males and females, respectively; no correction for the effect of dehydration reported). ${ }^{2}$ A slight creatinine increase of $14 \%$ was reported in 17 trained males after running a half-marathon ( $\geq 5$ years of training with maximal oxygen uptake $65 \pm 5 \mathrm{~mL} / \mathrm{kg} / \mathrm{min}$; after correction for dehydration) and a $33 \%$ increase was reported in ultra-marathon cyclists $(11,000 \pm 4,500$ trained $\mathrm{km}$ that year; no correction for dehydration reported). ${ }^{3,20}$ In the present study, we found a creatinine increase of $53 \%$ in 70 recreational trained males after marathon running (median of 8 marathons completed before; $46 \%$ after correction for the effect of dehydration). An even larger creatinine increase of $65 \%$ was found in 21 well-trained men after $70 \mathrm{~km}$ cross-country ski-race (no specification for the training status; no correction for dehydration reported). ${ }^{27}$ As illustrated above, comparison of previous studies is complicated 
because of differences in training status and sports disciplines. Future research has to reveal whether creatinine and cystatin C elevations are indeed dependent on training status.

In summary, renal investigation after extensive exercise is important to avoid injury in the long term. The present study shows preliminary data of cystatin $C$ measurements in relation to prolonged strenuous exercise. After marathon running, the mean serum cystatin C concentration was twice as low as compared to creatinine, indicating that creatinine levels indeed might be biased by skeletal muscle damage. Furthermore, equations to estimate GFR are known to be inadequate in normals and trained subjects. Therefore, especially in sports medicine, cystatin $\mathrm{C}$ seems a more reliable method to establish renal function.

\section{References}

1. Bellinghieri G, Savica V, Santoro D. Renal alterations during exercise. J Ren Nutr. 2008;18:158164.

2. Gerth J, Ott $U$, Funfstuck $R$, et al. The effects of prolonged physical exercise on renal function, electrolyte balance and muscle cell breakdown. Clin Nephrol. 2002;57:425-431.

3. Neumayr G, Pfister R, Hoertnagl H, Mitterbauer G, Prokop W, Joannidis M. Renal function and plasma volume following ultramarathon cycling. Int J Sports Med. 2005;26:2-8.

4. Neumayr G, Pfister R, Hoertnagl $\mathrm{H}$, et al. The effect of marathon cycling on renal function. Int J Sports Med. 2003;24:131-137.

5. Clarkson PM. Exertional rhabdomyolysis and acute renal failure in marathon runners. Sports Med. 2007;37:361-363.

6. Le Meur Y, Paraf F, Szelag JC, Aldigier JC, Leroux-Robert C. Acute renal failure in a marathon runner: role of glomerular bleeding in tubular injury. Am J Med. 1998;105:251-252.

7. Mehta RL, Kellum JA, Shah SV, et al. Acute Kidney Injury Network: report of an initiative to improve outcomes in acute kidney injury. Crit Care. 2007;11:R31.

8. Levey AS, Eckardt KU, Tsukamoto Y, et al. Definition and classification of chronic kidney disease: a position statement from Kidney Disease: Improving Global Outcomes (KDIGO). Kidney Int. 2005;67:2089-2100.

9. Levey AS, Bosch JP, Lewis JB, Greene T, Rogers N, Roth D. A more accurate method to estimate glomerular filtration rate from serum creatinine: a new prediction equation. Modification of Diet in Renal Disease Study Group. Ann Int Med. 1999;130:461-470.

10. Cockcroft DW, Gault MH. Prediction of creatinine clearance from serum creatinine. Nephron. 1976;16:31-41.

11. Vinge $E$, Lindergard $B$, Nilsson-Ehle $P$, Grubb A. Relationships among serum cystatin $C$, serum creatinine, lean tissue mass and glomerular filtration rate in healthy adults. Scand J Clin Lab Invest. 1999;59:587-592.

12. Banfi G, Del Fabbro M, Lippi G. Relation between serum creatinine and body mass index in elite athletes of different sport disciplines. Br J Sports Med. 2006;40:675-678; discussion 678.

13. Rule AD, Larson TS, Bergstralh EJ, Slezak JM, Jacobsen SJ, Cosio FG. Using serum creatinine to estimate glomerular filtration rate: accuracy in good health and in chronic kidney disease. Ann Int Med. 2004;141:929-937.

14. Stevens LA, Coresh J, Feldman HI, et al. Evaluation of the modification of diet in renal disease study equation in a large diverse population. J Am Soc Nephrol. 2007;18:2749-2757. 
15. Verhave JC, Fesler P, Ribstein J, du Cailar G, Mimran A. Estimation of renal function in subjects with normal serum creatinine levels: influence of age and body mass index. Am J Kidney Dis. 2005;46:233-241.

16. Tenstad O, Roald AB, Grubb A, Aukland K. Renal handling of radiolabelled human cystatin $\mathrm{C}$ in the rat. Scand J Clin Lab Invest. 1996;56:409-414.

17. Finney $H$, Newman DJ, Price CP. Adult reference ranges for serum cystatin $C$, creatinine and predicted creatinine clearance. Ann Clin Biochem. 2000;37:49-59.

18. Shlipak MG. Cystatin $C$ as a marker of glomerular filtration rate in chronic kidney disease: influence of body composition. Nat Clin Prac. 2007;3:188-189.

19. Rose BD, Post TW. In: Wonsciewicz M, McCullough K, David K, eds. Clinical physiology of acidbase and electrolyte disorders. fifth edition ed: The McGraw-Hill Companies; 2001:992.

20. Lippi G, Schena F, Salvagno GL, et al. Acute variation of estimated glomerular filtration rate following a half-marathon run. Int J Sports Med. 2008.

21. Bostom AG, Kronenberg F, Ritz E. Predictive performance of renal function equations for patients with chronic kidney disease and normal serum creatinine levels. J Am Soc Nephrol. 2002;13:21402144.

22. Keller C, Katz R, Cushman M, Fried LF, Shlipak M. Association of kidney function with inflammatory and procoagulant markers in a diverse cohort: A cross-sectional analysis from the Multi-Ethnic Study of Atherosclerosis (MESA). BMC nephrology. 2008;9:9.

23. Sjostrom $P$, Tidman $M$, Jones I. Determination of the production rate and non-renal clearance of cystatin $C$ and estimation of the glomerular filtration rate from the serum concentration of cystatin C in humans. Scand J Clin Lab Invest. 2005;65:111-124.

24. Bandaranayake N, Ankrah-Tetteh $\mathrm{T}$, Wijeratne $\mathrm{S}$, Swaminathan R. Intra-individual variation in creatinine and cystatin C. Clin Chem Lab Med. 2007;45:1237-1239.

25. Delanaye P, Cavalier E, Depas G, Chapelle JP, Krzesinski JM. New data on the intraindividual variation of cystatin C. Nephron Clin Pract. 2008;108:c246-248.

26. Fraser CG, Harris EK. Generation and application of data on biological variation in clinical chemistry. Crit Rev Clin Lab Sci. 1989;27:409-437.

27. Refsum HE, Stromme SB. Relationship between urine flow, glomerular filtration, and urine solute concentrations during prolonged heavy exercise. Scand J Clin Lab Invest. 1975;35:775-780.

28. Tidgren $B$, Hjemdahl $P$, Theodorsson $E$, Nussberger J. Renal neurohormonal and vascular responses to dynamic exercise in humans. J Appl Physiol. 1991;70:2279-2286.

29. Armstrong RB, Delp MD, Goljan EF, Laughlin MH. Distribution of blood flow in muscles of miniature swine during exercise. J Appl Physiol. 1987;62:1285-1298.

30. Armstrong RB, Laughlin $\mathrm{MH}$. Exercise blood flow patterns within and among rat muscles after training. Am J Physiol. 1984;246:H59-68. 



\section{CHAPTER 6}

Haemodialysis patients longitudinally assessed by high-sensitivity cardiac troponin $\mathrm{T}$ and commercial cardiac troponin $\mathrm{T}$ and cardiac troponin I assays

Background: Elevated cardiac troponin (cTn) concentrations predict an increased mortality in patients suffering from end-stage renal disease (ESRD). This study compares the performance of a pre-commercial high-sensitive cTnT assay (hs-cTnT) with two contemporary cTn assays in detecting cTn elevations in ESRD patients during a 6 month follow-up.

Methods: A total of 32 ESRD patients were followed for 6 months. cTn concentrations were assessed using the $4^{\text {th }}$ genenaration cTnT and hs-cTnT assay (both Roche Diagnostics) and the Architect cTnl assay (Abbott Diagnostics).

Results: During follow-up, 26 (81\%), 32 (100\%) and 9 (28\%) of the patients showed elevated cTn concentrations according to the current cTnT, the hs-cTnT, and the cTnl assays, respectively. The variation in concentrations measured within each patient had a median (IQR) magnitude of $0.03 \mu \mathrm{g} / \mathrm{L}(0.02-0.06), 0.017 \mu \mathrm{g} / \mathrm{L}(0.011-0.029)$ and $0.011 \mu \mathrm{g} / \mathrm{L}$ (<0.001-0.017), respectively. In addition, higher cTn concentrations were measured for patients who suffered from cardiac disease ( $\mathrm{P} 0.004,0.008$, and $<0.001$, respectively).

Conclusion: According to hs-cTnT assay, all of the ESRD patients had elevated cTnT concentrations at least once during the follow-up. As elevated cTn concentrations are highly prognostic of adverse events, the use of serial measurements has thus identified additional patients at risk for such events. The fact that we find CTn concentrations to be higher in patients with a history of cardiac disease is in line with this. Additional studies in ESRD patients are needed to investigate the added diagnostic and prognostic value of the very low cTnT concentrations and variations only detected by the hs-cTnT assay.

This work has been published in: Jacobs L, Van de Kerkhof J, Mingels A, Kleijnen V, Van der Sande F, Wodzig W, Kooman J, Van Dieijen-Visser M. Ann Clin Biochem 2009;46:283-90. 
Patients suffering from end-stage renal disease (ESRD) have a markedly reduced lifespan. Overall, the life expectancy of patients undergoing dialysis is about 4 times as low as for the general population. ${ }^{1}$ The main cause of death in these patients is accounted for by cardiovascular events and over $55 \%$ of patients on dialysis suffer from congestive heart failure. ${ }^{1,2}$ Considering this high incidence of cardiovascular complications, there is a need for accurate and sensitive biomarkers which can be used for diagnosis and risk stratification in ESRD patients. Over the years, the cardiac troponins (cTn) have proven to be accurate and sensitive markers for assessing ischaemic cardiac damage and predicting cardiovascular death in ESRD patients. ${ }^{3,4}$ Nonetheless, cTn concentrations can be elevated in the absence of apparent cardiac damage or clinical symptoms $s^{5,6}$ and might be influenced by a decreased renal clearance in patients with severe renal disease. ${ }^{7,8}$ As the diagnosis of acute myocardial infarction (AMI) has been defined as: a rise and/or fall of cardiac markers - preferably cTnT or cTnl - detected with at least one value above the $99^{\text {th }}$ percentile limit of the reference population and should be associated with clinical, electro-cardiographic or imaging findings, ${ }^{9,10}$ such cTn elevations can impede the diagnosis of an AMI (for instance when ESRD patients are presenting with clinical symptoms). Recent National Academy of Clinical Biochemistry (NACB) guidelines have addressed this issue and suggest that for patients with chronically elevated concentrations of cTn, changes in cTn (>20\%) 6-9 hours after the onset of clinical symptoms are indicative of an AMI. ${ }^{11}$ However, such changes in cTn concentrations might also occur in the absence of clinical symptoms. ${ }^{12,13}$ To date, little is known about the biological variation in cTn concentrations, although some studies have taken serial measurements to investigate the cTn serum concentrations over longer periods of time. $^{12-16}$

The advent of new, more sensitive cTn assays could improve the usefulness of both single and serial cTn measurements. To date, most commercial cTn assays lack a sufficient analytical performance to accurately detect cTn concentrations in healthy subjects, either because the limit of detection (LOD) of the assay is higher than the reference concentrations or because the assay imprecision, expressed as the coefficient of variation (CV) is higher than $10 \%$ at the $99^{\text {th }}$ percentile of the healthy subjects. ${ }^{17-19}$ Assays with sufficient sensitivity to determine the reference concentrations will improve the detection of "abnormal" cTn concentrations in ESRD and other patient populations. More precise assays will also be able to detect temporal changes in cTn concentrations which could not be detected to date. Such 
increasingly confident measurements will not only identify patients with abnormal cTn concentrations and variations, but could also shed light on the discrepancy between cardiac troponin T (cTnT) and cardiac troponin I (cTnl). Until recently the number of ESRD patients showing increased cTnT concentrations was about three times as high as for cTnl (53\% vs $17 \%){ }^{5}$ With the advent of new, more sensitive cTnl assays, the difference decreases, but the number of patients with cTn concentrations above the $10 \%$ CV limit of the assay is still larger for cTnT (59\%) than for Tnl (32\%). ${ }^{20}$

In this study, we investigate the performance of two recently developed cTn assays: the pre-commercial high-sensitive cTnT assay (hs-cTnT) (Roche Diagnostics, Mannheim, Germany) and the Architect i2000SR cTnl assay (cTnl) (Abbott Diagnostics, Wiesbaden, Germany) in measuring cTn concentrations in a population of haemodialysis patients. For comparison, CTnT was also measured using the current $4^{\text {th }}$ generation $\mathrm{CTnT}$ immunoassay (Roche Diagnostics). In addition, we assessed the intra-individual variation in the cTn concentrations during a 6-month follow-up.

\section{Methods}

\section{Patient population}

A cohort of 44 chronic haemodialysis patients from the Department of Internal Medicine at the University Hospital Maastricht was selected to participate in this 6-month longitudinal study. The study protocol was approved by the medical ethical review committee of the University Hospital Maastricht / Maastricht University. All patients provided written informed consent. Blood samples were collected pre-dialysis at the start of the study and subsequently every two months for a period of 6 months. During the follow-up period 12 patients were hospitalized. The reasons for hospitalization were very diverse, briefly: pneumonia, stoma operation, removal of kidney transplant, kidney transplant, malaise after chemotherapy, rectal blood loss/diarrhea, nausea, vomiting, hip replacement, kidney transplant followed by lleus, hypoglecemia/collaps, dizziness/fall, subdural hematoma. Since one of our aims was to study the occurrence of cTn variations in a stable (e.g. with no acute worsening in the patients condition) population of ESRD patients, hospitalized patients were excluded from our analysis. Collected blood samples were allowed to clot and then centrifuged: obtained serum samples were stored at $-80{ }^{\circ} \mathrm{C}$ until analysis. Four patients failed to have blood taken at one occasion. Clinical data were collected from the medical 
records in our hospital. Patients could be divided into two groups on the basis of a history of cardiovascular disease (CVD). CVD was considered present when patients had a history of myocardial infarction, had required coronary intervention like percutaneous transluminal coronary angioplasty (PTCA), coronary artery bypass grafting (CABG) or suffered from congestive cardiac failure.

\section{Laboratory methods}

cTnT was measured on the Elecsys 2010 (Roche Diagnostics, Mannheim, Germany) using the $4^{\text {th }}$ generation CTnT immunoassay with a limit of detection (LOD) of $<0.01 \mu \mathrm{g} / \mathrm{L}$ and a $10 \% \mathrm{CV}$ of $0.03 \mu \mathrm{g} / \mathrm{L}$ (according to package insert). CTnT was additionally measured using the precommercial high-sensitive cTnT (hs-cTnT) assay on the Elecsys 2010. According to the manufacturers data (Jarausch, personal communication) the $10 \%$ CV was estimated at 0.012 $\mu \mathrm{g} / \mathrm{L}$. cTnl was measured on the Architect i2000SR (Abbott Diagnostics, Wiesbaden, Germany). According to the manufacturer's data, the LOD of the assay was $0.009 \mu \mathrm{g} / \mathrm{L}$ and the $10 \% \mathrm{CV}$ concentration was $0.032 \mu \mathrm{g} / \mathrm{L}$.

Precision profiles for the hs-cTnT and the cTnl assay were determined in our laboratory by repeated $(n=20)$ measurements in 7 pooled serum samples (cTnT concentrations ranging from 0.002 to $0.019 \mu \mathrm{g} / \mathrm{L}$ and $\mathrm{cTnl}$ concentrations ranging from 0.017 to $0.088 \mu \mathrm{g} / \mathrm{L}$ ) as described in chapter 3 . The resulting $10 \%$ CV concentrations for the hs-cTnT and cTnl assays were found at 0.009 and $0.032 \mu \mathrm{g} / \mathrm{L}$, respectively. The LODs for the hs-cTnT and cTnl assays were calculated in our laboratory according to the Clinical and Laboratory Standards Institute EP17 guidelines. According to these guidelines the LOD is $\left(\operatorname{mean}_{\text {blank }}+1,645 * \mathrm{SD}_{\text {blank }}\right)$ $+\left(1,645 * S D_{\text {low concentration sample }}\right)$. The LOB, determined in cTn negative serum (supplied to us by Abbott Diagnostics) by replicate $(n=10)$ measurements revealed a LOB of $<0.001 \mu \mathrm{g} / \mathrm{L}$ for the hs-cTnT assay (mean and SD, <0.001 $\mu \mathrm{g} / \mathrm{L}$ ) and $0.006 \mu \mathrm{g} / \mathrm{L}$ for the $\mathrm{cTnl}$ assay (mean cTnl, $0.001 \mu \mathrm{g} / \mathrm{L} ; \mathrm{SD}, 0.003 \mu \mathrm{g} / \mathrm{L})$. Replicate measurements $(\mathrm{n}=20)$ with the hs-cTnT assay in a serum sample containing a mean concentration of $0.002 \mu \mathrm{g} / \mathrm{L}$ showed a SD of $0.00072 \mu \mathrm{g} / \mathrm{L}$. For the cTnl assay, a mean concentration of $0.017 \mu \mathrm{g} / \mathrm{L}$ showed a SD of $0.003 \mu \mathrm{g} / \mathrm{L}$. The resulting LOD was thus established at $0.001 \mu \mathrm{g} / \mathrm{L}$ for the hs-cTnT assay and at $0.011 \mu \mathrm{g} / \mathrm{L}$ for the cTnl assay. 


\section{Statistical analysis}

Data analyses were performed using SPSS, Version 15.0. Continuous variables are described as median and interquartile range (IQR) or as mean and standard deviation (SD). Categorical variables are described as absolute numbers and as percentages. Biovariability data was analyzed by calculating the intra-individual coefficient of variation $\left(\mathrm{CV}_{1}\right)$ and the range (minmax) of cTn concentrations measured during the follow-up. The $\mathrm{CV}_{1}$ was calculated by subtracting the analytical variation $\left(\mathrm{CV}_{\mathrm{A}}\right)$ from the total variation $\left(\mathrm{CV}_{\text {TOT }}\right)$, such that $\mathrm{CV}_{\text {TOT }}{ }^{2}$ is $C V_{1}^{2}+C_{A}^{2}$. The analytical variation was estimated by extrapolating the $\mathrm{CV}_{\mathrm{A}}$ from the precision profiles for the hs-cTnT and cTnl assays (chapter 3 ). For the $4^{\text {th }}$ generation cTnT assay the $\mathrm{CV}_{\mathrm{A}}$ was extrapolated from the precision profile in the package insert. The maximum percent change during the 6 month period for each of the patients was calculated as [(the maximum concentration measured during the 6 month period minus the minimum concentration) / minimum concentration]*100. Differences in cTn concentrations and variations between patients with and without cardiac disease were compared using the Mann-Whitney-U test. Concentrations measured below the analytical LOD were set equal to the LOD. The level of statistical significance was established at $P<0.05$.

\section{Results}

\section{Baseline measurements in the patient population}

Table 1 shows the characteristics of the 32 ESRD patients enrolled in our study. Measurements at baseline revealed median cTn concentrations (IQR) as detected by the cTnT, hs-cTnT and cTnl assays of $0.02 \mu \mathrm{g} / \mathrm{L}(<0.01-0.05), 0.053 \mu \mathrm{g} / \mathrm{L}(0.032-0.076)$ and 0.014

Table 1: Baseline characteristics of the ESRD patient population.

\begin{tabular}{ll}
\hline Characteristic & $\mathrm{n}(\%)$ \\
\hline Men & 21 \\
Women & 11 \\
Age, y (min-max) & $66(35-91)$ \\
Time on dialysis, months (min-max) & $33(1-102)$ \\
Hypertension & $28(88 \%)$ \\
Diabetes & $12(38 \%)$ \\
History of ischaemic heart disease & $10(31 \%)$ \\
History of cardiac failure & $9(28 \%)$ \\
Patient with history of cardiac disease & $17(53 \%)$ \\
\hline
\end{tabular}


Table 2: Number of patients having above cutoff cTn concentrations at baseline and at least once during the 6-month follow-up.

\begin{tabular}{llllll}
\hline Assay & & LOD & $10 \% \mathrm{CV}$ & $99^{\text {th }}$ percentile & AMl cutoff* \\
\hline \multirow{2}{*}{ cTnT } & Cutoff $(\mu \mathrm{g} / \mathrm{L})$ & $<0.01$ & 0.03 & $<0.01$ & 0.03 \\
& Baseline & $20(63 \%)$ & $12(38 \%)$ & $20(63 \%)$ & $12(38 \%)$ \\
& Follow-up & $31(97 \%)$ & $26(81 \%)$ & $31(97 \%)$ & $26(81 \%)$ \\
\multirow{4}{*}{ hs-cTnT } & Cutoff $(\mu \mathrm{g} / \mathrm{L})$ & 0.001 & 0.009 & 0.016 & 0.016 \\
& Baseline & $32(100 \%)$ & $32(100 \%)$ & $30(94 \%)$ & $30(94 \%)$ \\
& Follow-up & $32(100 \%)$ & $32(100 \%)$ & $32(100 \%)$ & $32(100 \%)$ \\
cTnl & Cutoff $(\mu \mathrm{g} / \mathrm{L})$ & 0.011 & 0.032 & 0.013 & 0.032 \\
& Baseline & $17(53 \%)$ & $6(19 \%)$ & $16(50 \%)$ & $6(19 \%)$ \\
& Follow-up & $23(72 \%)$ & $9(28 \%)$ & $22(69 \%)$ & $9(28 \%)$ \\
\hline
\end{tabular}

* According to recent NACB guidelines the $99^{\text {th }}$ percentile from a healthy reference population is the recommended cutoff concentration in AMI. However, the assay imprecision (CV) should be $\leq 10 \%$ at the 99 th percentile, otherwise the $10 \% \mathrm{CV}$ concentration is used.

$\mu \mathrm{g} / \mathrm{L}$ (0.011-0.027) respectively. Table 2 shows the number of patients having cTn concentrations above the different analytical cut-off values. At baseline 12 (38\%), 30 (94\%) and $6(19 \%)$ patients showed cTn concentrations above the designated AMI cut-off values according to the cTnT, the hs-cTnT and the cTnl assays, respectively.

\section{Serial measurements in the patient population}

Figure 1 shows the range of cTn concentrations measured during six month follow-up in each patient. We found a median (IQR) cTn concentration of $0.037 \mu \mathrm{g} / \mathrm{L}(0.017-0.074), 0.055$ $\mu \mathrm{g} / \mathrm{L}(0.033-0.079)$ and $0.014 \mu \mathrm{g} / \mathrm{L}(<0.011-0.028)$ for the $\mathrm{cTnT}$, hs-cTnT and $\mathrm{cTnl}$ assays respectively. As can be seen in Figure 1, the patients experienced large changes in cTn concentrations during the follow-up and the range of concentrations measured within each patient had a median (IQR) magnitude of $0.03 \mu \mathrm{g} / \mathrm{L}(0.02-0.06), 0.017 \mu \mathrm{g} / \mathrm{L}(0.011-0.029)$ and $0.011 \mu \mathrm{g} / \mathrm{L}(<0.001-0.017)$ according to the the cTnT, hs-cTnT and cTnl assays, respectively. This corresponded to a median within patient percent change of $150 \%$ (72-287), 44\% (27-69) and 54\% (0-114) for the cTnT, hs-cTnT and cTnl assays respectively. The total coefficient of variation $\left(\mathrm{CV}_{\text {TOт }}\right)$ was $40 \%, 16 \%$ and $20 \%$, respectively. The $\mathrm{CV}_{\mathrm{A}}$ belonging to the median concentrations measured during the follow-up (as estimated from the precision profiles) is 7\% according to the cTnT assay (median, $0.037 \mu \mathrm{g} / \mathrm{L}$ ), $5 \%$ according to the hs-cTnT assay (median, $0.055 \mu \mathrm{g} / \mathrm{L}$ ) and $15 \%$ for the $\mathrm{CTnl}$ assay (median, $0.014 \mu \mathrm{g} / \mathrm{L}$ ). The $\mathrm{CV}_{1}$ is thus 39,15 and $13 \%$ for the $\mathrm{cTnT}$, hs-cTnT and $\mathrm{cTnl}$ assays, respectively. 

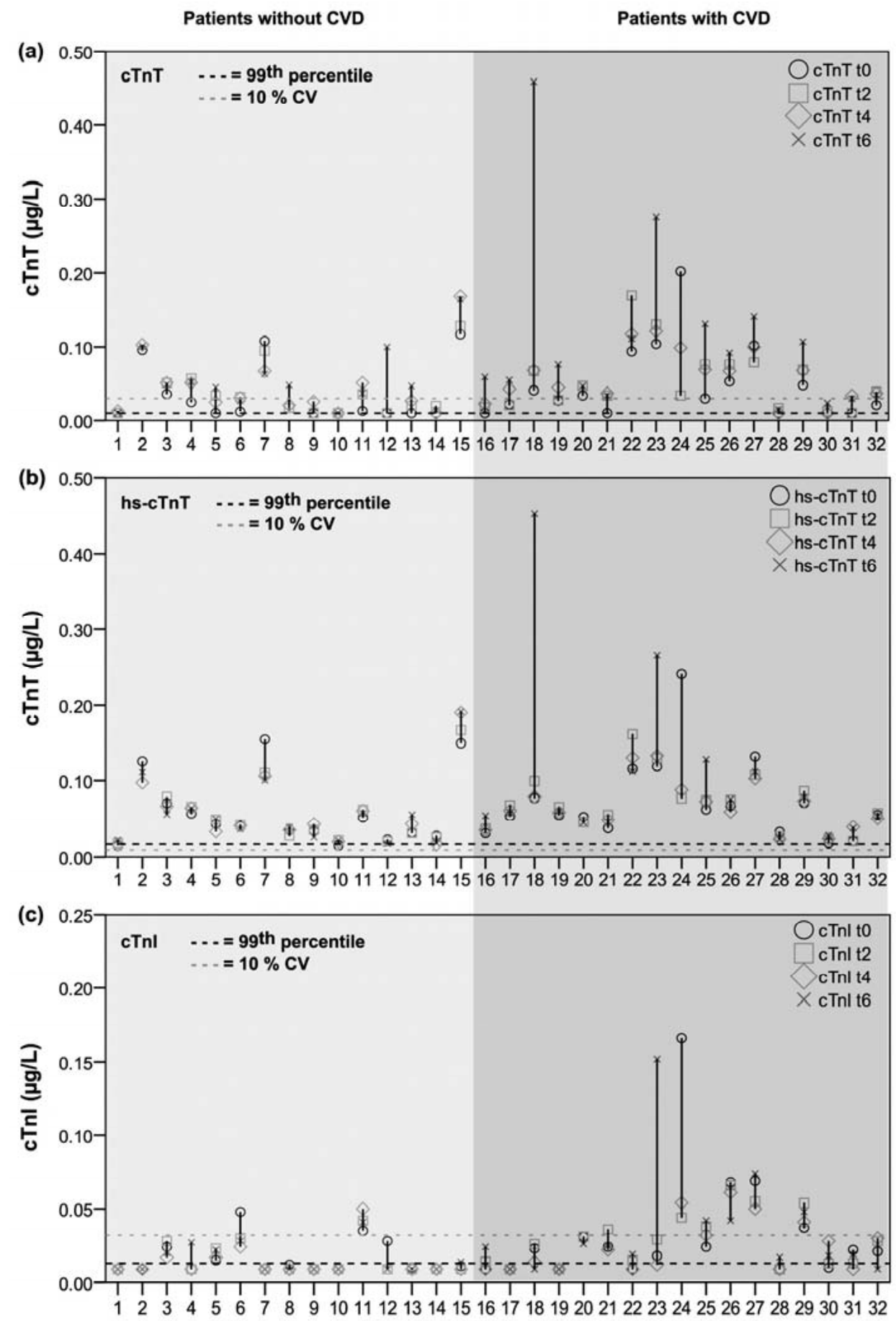

Figure 1: Range of cTn concentrations measured in 32 ESRD patients during six month follow-up. cTnT concentrations according to the (A) CTnT assay and (B) hs-cTnT assay and cTnl concentrations according to the (C) Architect cTnl assay. 
Considering the magnitude of the variation it is not surprising that the serial measurements identified additional patients that had cTn concentrations above the previously mentioned cut-off concentrations (at least once) during the 6-month period. During the follow-up we found that $26(81 \%), 32(100 \%)$ and $9(28 \%)$ patients had cTn concentrations above the AMI cut-off level according to the cTnT, hs- cTnT and cTnl assays, respectively (Table 2 ).

\section{Patients with and without a history of cardiovascular disease}

As can also be seen in Figure 1, large differences existed between the cTn concentrations and variations in patients with and without a history of CVD. Table 3 quantifies the differences in the cTn concentrations measured during the follow-up. The three assays showed significantly higher con-centrations of cTn in the patients who suffered from CVD. In addition, as might be expected, the relative number of patients having elevated concentrations of cTn was higher in the group with CVD. This difference was particularly large for the cTnl assay where only 2 out of 15 patients without CVD had cTnl concentrations above the AMI cut-off concentration, compared to 7 out of 17 in the patients with CVD. Moreover, the variations in the cTn concentrations, as assessed by the ranges of concentrations measured during the follow up, were larger in the CVD patients. Note, however, that, as shown in Table 4, the variations in cTn concentrations were in part the result of analytical rather than biological variations.

When the results were assessed for the individual patients, we found a large degree of heterogeneity in the agreement between cTnT and cTnl elevations. In some cases, as with patients 23 and 24, one can identify severely elevated concentrations of both cTnT and cTnl, which both seem to increase/decrease at the same time. On the other hand, there were patients, such as 7, 15 and 18 which showed very strong elevations (>0.1 $\mu \mathrm{g} / \mathrm{L}$ ) in cTnT (according to both cTnT assays), yet virtually no elevations in cTnl concentrations. In general, it seemed that patients with elevated concentrations of cTnl also had elevated concentrations of cTnT, but patients with elevated concentrations of cTnT did not always have elevated concentrations of cTnl. 


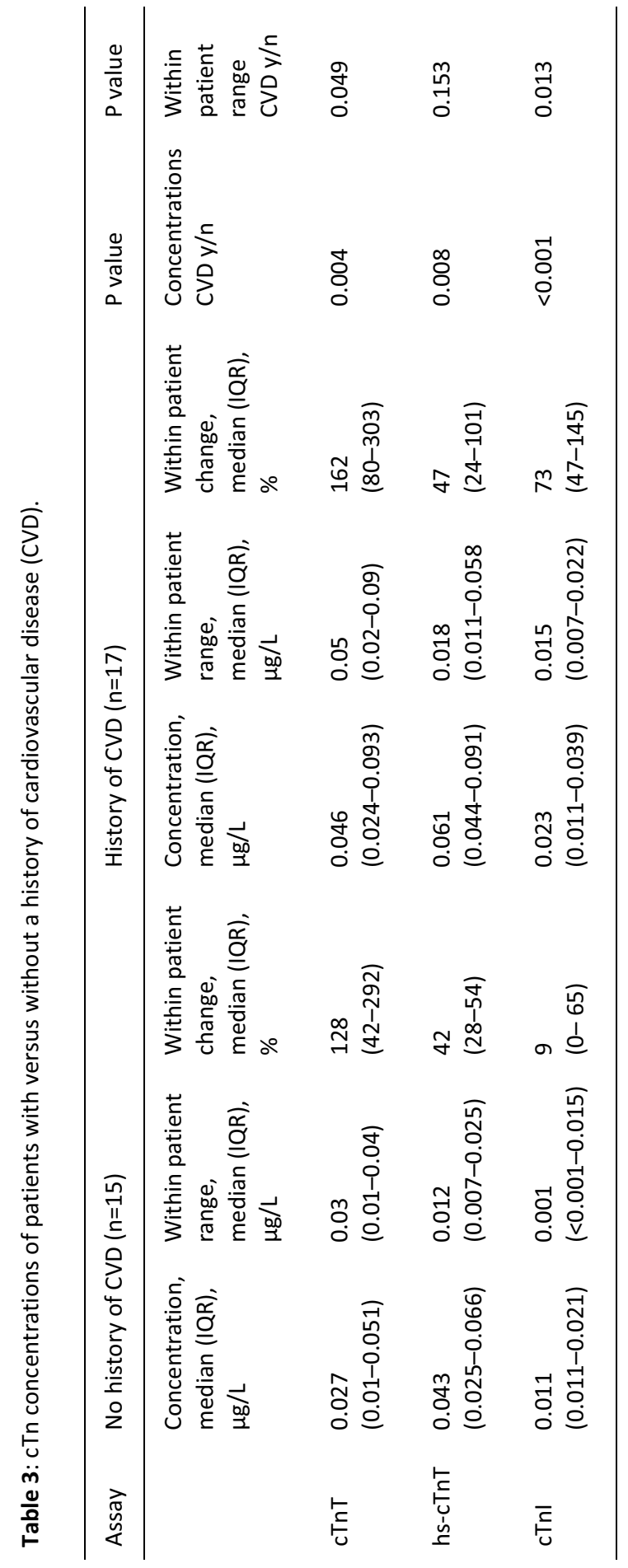


Table 4: Intra-individual coefficients of variation in patients with and without a history of CVD.

\begin{tabular}{lllllll}
\hline & \multicolumn{3}{l}{ No history of CVD $(\mathrm{n}=15)$} & \multicolumn{3}{l}{ History of CVD $(\mathrm{n}=17)$} \\
\hline Assay & $\mathrm{CV}_{\text {TOT }}$ & $\mathrm{CV}_{\mathrm{A}}$ & $\mathrm{CV}$ & $\mathrm{CV}_{\text {TOT }}$ & $\mathrm{CV}_{\mathrm{A}}$ & $\mathrm{CV}_{\text {I }}$ \\
cTnT & 35 & 10 & 34 & 47 & 6 & 47 \\
hs-cTnT & 14 & 5 & 13 & 17 & 5 & 16 \\
cTnl & n.a. & $>15 \% *$ & n.a. & 24 & 12 & 21 \\
\hline
\end{tabular}

* The coefficients of variations for the patient without CVD could not be determined accurately for the cTnl assay.

\section{Discussion}

This study describes, for the first time, the performance of a pre-commercial hs-cTnT assay in measuring cardiac troponin elevations and variations in a population of ESRD patients during a 6-month follow-up. In addition, we compared its performance to the current $4^{\text {th }}$ generation cTnT and the Architect cTnl assays.

In the past, several studies have shown the occurrence of elevated cTn concentrations in ESRD patients without apparent cardiac damage and clinical symptoms. ${ }^{21-25}$ These elevated concentrations of cTn are of cardiac origin ${ }^{26}$ and were shown to be highly predictive for a cardiovascular event. ${ }^{3,4,23}$ A meta- analysis combining results from 28 studies (3931 ESRD patients) showed that cTnT concentrations above $0.1 \mu \mathrm{g} / \mathrm{L}$ were associated with an increase in all cause mortality (relative risk: 2.64). ${ }^{3}$ Other studies have shown an increased mortality in ESRD patients with CTnT concentrations above $0.026 \mu \mathrm{g} / \mathrm{L}^{23}$ and $0.01 \mu \mathrm{g} / \mathrm{L}$. ${ }^{4}$ Due to the lack of standardization in the available assays, the prognostic value of cTnl is less conclusive and cutoff concentrations cannot be compared between assays. Nonetheless, elevated concentrations of cTnl have also been shown to be associated with an increased mortality in ESRD patients. ${ }^{4,21}$

In agreement with previous studies, ${ }^{21-25}$ we found that $12(38 \%)$ of our patients had elevated concentrations of cTnT according to the current cTnT assay and 6 (19\%) had elevated concentrations of $\mathrm{cTnl}$ according to the Archtitect cTnl assay. Using the recently developed pre-commercial hs-cTnT assay we found that the occurrence of elevated concentrations of cTnT is far greater than previously described and at baseline 30 (94\%) of the ESRD patients showed elevated concentrations of cTnT.

By following the cTn concentrations at regular points in time, we have identified an additional number of patients with elevated cTn concentrations. During the follow-up, 26 
(81\%), $32(100 \%)$ and $9(28 \%)$ of the patients showed cTn concentrations above the AMI cutoff concentrations according to the cTnT, hs-cTnT and cTnl assays respectively. As elevated concentrations of cTn are highly prognostic of adverse events in ESRD patients, the use of serial measurements has thus identified additional patients at risk for such events. The fact that we find cTn concentrations to be higher in patients with a history of cardiovascular disease seems to be in line with this.

We should note however, that due to differences in the precision with which the $99^{\text {th }}$ percentile can be determined, the AMI cut-offs for the assays are set at different concentrations. For the cTnT and cTnl assays, the 10\% CV cut-off concentrations were used, whereas for the hs-cTnT assay, the $99^{\text {th }}$ percentile cutoff was used. When we assessed the occurrence of cTn elevations above the $99^{\text {th }}$ percentile cutoff, we found that the difference between the assays was much smaller. A total of 31 (97\%) of the patients had cTnT elevations, 22 (69\%) had cTnl elevations, as compared to 32 (100\%) for the hs-cTnT assay. Considering the fact that the $4^{\text {th }}$ generation cTnT and the Architect cTnl assays were not able to detect the $99^{\text {th }}$ percentile with sufficient precision ( $C V<10 \%$ ) these findings, however, should be interpreted with caution. Nonetheless, they suggest that more sensitive cTnl measurements could reveal that the occurrence of cTnl elevations in ESRD patients is more frequent than is presently thought. This idea is supported by recent findings with sensitive cTnl assays in $\mathrm{ESRD}^{20}$ and chronic kidney disease patients, ${ }^{27}$ which find more cTnl elevations than previously described.

In general, there seems to be a high degree of heterogeneity between the patients in the amount of variation in their cTn concentrations. For instance, according to the new hscTnT assay, $8(25 \%)$ of the patients experienced changes in cTnT $>0.03 \mu \mathrm{g} / \mathrm{L}$, whereas another $8(25 \%)$ of the patients had variations $<0.01 \mu \mathrm{g} / \mathrm{L}$ during the 6 -month follow-up. Thus, as can also seen in Figure 1, the patient population consisted of a group of patients with relatively stable cTn concentrations and a group with a high degree of variations in their cTn concentrations. Further research in a larger population is needed to identify if the patients with the higher degree of variation are at greater risk for adverse events.

According to recent NACB guidelines only patients with chronically cTn elevated concentrations together with changes in cTn (>20\%) 6-9 hours after the onset of clinical symptoms are suffering from an AMI. ${ }^{11}$ Therefore, none of our patients would have been classified as having an AMI. Nonetheless, as increases in cTn represent further (subclinical) 
myocardial damage and an increased likelihood for cardiac events, they should not be ignored. It would therefore be wise to perform a detailed cardiac evaluation in patients showing large variations in cTn concentrations, even if these variations are not accompanied by clinical symptoms.

The increases in cTn, as seen in many of our patients, would, if not for the longitudinal study, have been not detected. Assessing cTn concentrations at regular points in time would therefore appear as a sensible tool to increase clinical vigilance for the presence of myocardial damage and as a means for possible intervention. This is in agreement with previous studies which provided evidence for the increased ability of serial versus single measurements to identify patients at risk for an event. ${ }^{12-16}$

In the setting of heart failure, previously undetectable concentrations of cTnT were shown to have important prognostic value. ${ }^{28}$ The use of high-sensitivity cTn assays, like the hs-cTnT assay, will enable a better differentiation between cTn concentrations in healthy and diseased patients and could improve risk stratification. Regrettably, our study was limited by a small sample size and the absence of outcomes. Therefore, additional research is needed to show if this prognostic value exists in the setting of ESRD and how patients can further benefit from serial measurements with high-sensitivity cTn assays.

\section{References}

1. National Institutes of Health; National Institute of Diabetes and Digestive and Kidney Diseases; Bethesda M. U.S. Renal Data System, USRDS 2007 Annual Data Report: Atlas of Chronic Kidney Disease and End-Stage Renal Disease in the United States. 2007:138-154.

2. U.S. Renal Data System, USRDS 2007 annual data report: atlas of Chronic Kidney Disease and End-Stage Renal Disease in the United States, National Institutes of Health, National Institute of Diabetes and Digestive and Kidney Diseases, Bethesda, MD, 2007. 2007:192-208.

3. Khan NA, Hemmelgarn BR, Tonelli M, Thompson CR, Levin A. Prognostic value of troponin T and I among asymptomatic patients with end-stage renal disease: a meta-analysis. Circulation. 2005;112:3088-3096.

4. Apple FS, Murakami MM, Pearce LA, Herzog CA. Predictive value of cardiac troponin I and T for subsequent death in end-stage renal disease. Circulation. 2002;106:2941-2945.

5. Kanderian AS, Francis GS. Cardiac troponins and chronic kidney disease. Kidney Int. 2006;69:1112-1114.

6. Lamb EJ, Webb MC, Abbas NA. The significance of serum troponin $T$ in patients with kidney disease: a review of the literature. Ann Clin Biochem. 2004;41:1-9.

7. Diris JH, Hackeng CM, Kooman JP, Pinto YM, Hermens WT, Van Dieijen-Visser MP. Impaired renal clearance explains elevated troponin $\mathrm{T}$ fragments in hemodialysis patients. Circulation. 2004;109:23-25.

8. Wiessner R, Hannemann-Pohl K, Ziebig R, et al. Impact of kidney function on plasma troponin concentrations after coronary artery bypass grafting. Nephrol Dial Transplant. 2007;23:231-238. 
9. Apple FS, Jesse RL, Newby LK, et al. National Academy of Clinical Biochemistry and IFCC committee for standardization of markers of cardiac damage laboratory medicine practice guidelines: analytical issues for biochemical markers of acute coronary syndromes. Clin Chem. 2007;53:547-551.

10. Thygesen K, Alpert JS, White HD, et al. Universal definition of myocardial infarction: Kristian Thygesen, Joseph S. Alpert and Harvey D. White on behalf of the joint ESC/ACCF/AHA/WHF task force for the redefinition of Myocardial Infarction. Eur Heart J. 2007;28:2525-2538.

11. Wu AH, Jaffe AS, Apple FS, et al. National Academy of Clinical Biochemistry laboratory medicine practice guidelines: use of cardiac troponin and B-type natriuretic peptide or N-terminal pro Btype natriuretic peptide for etiologies other than Acute Coronary Syndromes and Heart Failure. Clin Chem. 2007;53:2086-2096.

12. Roberts MA, Fernando D, Macmillan N, et al. Single and serial measurements of cardiac troponin I in asymptomatic patients on chronic hemodialysis. Clinical Nephrol. 2004;61:40-46.

13. Miller WL, Hartman KA, Burritt MF, et al. Serial biomarker measurements in ambulatory patients with chronic heart failure: the importance of change over time. Circulation. 2007;116:249-257.

14. Ooi DS, Zimmerman D, Graham J, Wells GA. Cardiac troponin T predicts long-term outcomes in hemodialysis patients. Clin Chem. 2001;47:412-417.

15. Wayand D, Baum H, Schatzle G, Scharf J, Neumeier D. Cardiac troponin T and I in end-stage renal failure. Clin Chem. 2000;46:1345-1350.

16. Han JH, Lindsell CJ, Ryan RJ, Gibler WB. Changes in cardiac troponin T measurements are associated with adverse cardiac events in patients with chronic kidney disease. Am J Emerg Med. 2005;23:468-473.

17. Panteghini M, Pagani F, Yeo KT, et al. Evaluation of imprecision for cardiac troponin assays at low-range concentrations. Clin Chem. 2004;50:327-332.

18. Giannitsis E, Katus HA. Comparison of cardiac troponin T and troponin I assays--implications of analytical and biochemical differences on clinical performance. Clin Lab. 2004;50:521-528.

19. Panteghini $M$. The new definition of myocardial infarction and the impact of troponin determination on clinical practice. Int J Cardiol. 2006;106:298-306.

20. Hickman PE, Koerbin G, Southcott E, et al. Newer cardiac troponin I assays have similar performance to troponin $\mathrm{T}$ in patients with end-stage renal disease. Ann Clin Biochem. 2007; 44:285-289.

21. Apple FS, Murakami MM, Pearce LA, Herzog CA. Multi-biomarker risk stratification of N-terminal pro-B-type natriuretic peptide, high-sensitivity C-reactive protein, and cardiac troponin $\mathrm{T}$ and $\mathrm{I}$ in End-Stage Renal Disease for all-cause death. Clin Chem. 2004;50:2233-2235.

22. Havekes B, van Manen JG, Krediet RT, Boeschoten EW, Vandenbroucke JP, Dekker FW. Serum troponin $\mathrm{T}$ concentration as a predictor of mortality in hemodialysis and peritoneal dialysis patients. Am J Kidney Dis. 2006;47:823-829.

23. Sommerer C, Beimler J, Schwenger V, et al. Cardiac biomarkers and survival in haemodialysis patients. Eur J Clin Invest. 2007;37:350-356.

24. Aviles RJ, Askari AT, Lindahl B, et al. Troponin T levels in patients with acute coronary syndromes, with or without renal dysfunction. N Engl J Med. 2002;346:2047-2052.

25. deFilippi C, Wasserman S, Rosanio $S$, et al. Cardiac troponin $T$ and C-reactive protein for predicting prognosis, coronary atherosclerosis, and cardiomyopathy in patients undergoing longterm hemodialysis. JAMA. 2003;290:353-359.

26. Fredericks S, Murray JF, Bewick M, et al. Cardiac troponin $T$ and creatine kinase MB are not increased in exterior oblique muscle of patients with renal failure. Clin Chem. 2001;47:10231030.

27. Lamb EJ, Kenny C, Abbas NA, et al. Cardiac troponin I concentration is commonly increased in nondialysis patients with CKD: experience with a sensitive assay. Am J Kidney Dis. 2007;49:507516.

28. Latini R, Masson S, Anand IS, et al. Prognostic value of very low plasma concentrations of troponin T in patients with stable chronic heart failure. Circulation. 2007;116:1242-1249. 



\section{CHAPTER 7}

\section{The extent of coronary atherosclerosis is associated with increasing circulating levels of high-sensitivity cardiac troponin T}

Objective: This study explored the relationship between coronary atherosclerotic plaque burden and quantifiable circulating levels of troponin measured with a recently introduced high sensitive cardiac troponin $\mathrm{T}$ (hs-cTnT) assay.

Methods and Results: Cardiac patients suspected of having coronary artery disease (CAD) but without acute coronary syndrome were studied. Cardiac troponin $\mathrm{T}$ levels were assessed using the fifth-generation hs-cTnT assay. All patients $(n=615)$ underwent cardiac computed tomographic angiography (CCTA). On the basis of CCTA, patients were classified as having no CAD or mild ( $<50 \%$ lesion), moderate $(50 \%$ to $70 \%$ lesion), severe $(>70 \%$ lesion), or multivessel CAD (multiple $>70 \%$ lesions). As a comparison, high-sensitivity Creactive protein levels were measured. Progressively increasing hs-cTnT levels were found in patients with mild (median, $4.5 \mathrm{ng} / \mathrm{L}$ ), moderate (median, $5.5 \mathrm{ng} / \mathrm{L}$ ), severe (median, 5.7 $\mathrm{ng} / \mathrm{L}$ ), and multivessel (median, $8.6 \mathrm{ng} / \mathrm{L}$ ) CAD compared with patients without CAD (median, $3.7 \mathrm{ng} / \mathrm{L}$ ) (all $\mathrm{P}<0.01$ ). For high-sensitivity C-reactive protein and $\mathrm{N}$-terminal proB-type natriuretic peptide, no such relationship was observed. In patients without CAD, $11 \%$ showed hs-cTnT levels in the highest quartile, compared with $62 \%$ in the multivessel disease group $(\mathrm{P}<0.05)$. Multivariance analysis identified hs-cTnT as an independent risk factor for the presence of CAD.

Conclusion: In patients without acute coronary syndrome, even mild CAD is associated with quantifiable circulating levels of hs-cTnT.

This work has been published in: Mingels A *, Laufer E*, Winkens M, Joosen I, Schellings M, Leiner T, Wildberger J, Narula J, Van Dieijen-Visser M, Hofstra L (*equal contribution). Arterioscler Thromb Vasc Biol 2010;30:1269-1275. 
The release of cardiac troponins (cTn) into the circulation occurs with cardiomyocyte injury. cTn is a preferred marker for diagnosing acute myocardial infarction (AMI) and is used as a key diagnostic tool for decision making in patients presenting with chest pain. However, the current commercially available assays do not have analytic precision for reliable detection of minor myocardial damage. ${ }^{1,2}$ The variation between measurements at the upper reference limit of a reference population, for instance, exceeds $10 \%{ }^{2}$ Furthermore, these immunoassays are unable to detect cTn in apparently healthy individuals harboring coronary artery disease (CAD). Recently, analytic improvements have been made in the lower part of the cTn measurement interval. Using the highly sensitive fifth-generation high sensitive cardiac troponin $\mathrm{T}$ (hs-cTnT) assay, we recently reported an almost gaussian distribution in a reference population $(n=479) .{ }^{3}$ For $c T n l$, a similar distribution was seen using the adapted AccuTnl assay from Beckman Coulter. ${ }^{4}$ Recent studies in patients suspected of having an acute coronary syndrome (ACS) found that ultrasensitive cTn assays substantially improve the early diagnosis of AMI. ${ }^{5,6}$

Moreover, Sabatine et al showed that transient stress test-induced ischemia is associated with increase of cTnl as detected with an ultrasensitive cTnl assay. ${ }^{7}$ The level of cTnl increase was proportionally related to the extent of ischemia as assessed by nuclear perfusion imaging.

We hypothesized that mismatch between supply and demand in the heart, and the resulting episodes of cardiac ischemia, may result in quantifiable circulating levels of cardiac troponin $T(\mathrm{cTnT})$ in patients with $C A D$, especially in patients with significant lesions. To investigate this question, we assessed the extent of coronary plaque burden on cardiac computed tomographic angiography (CCTA) and associated this with hs-cTnT levels in a group of patients suspected for having CAD but without ACS. As a comparison, we used 2 other widely used cardiac serum biomarkers, high-sensitivity C-reactive protein (hSCRP) and $\mathrm{N}$-terminal pro-B-type natriuretic peptide (NT-proBNP).

\section{Methods}

\section{Study population}

A total of 646 patients were referred from the cardiology outpatient department for CCTA because of suspected CAD. Inclusion criteria were a recent history of cardiac typical or atypical chest pain, dyspnea, or collapse; at least $1 \mathrm{~mL}$ of serum for determination of 
biomarkers; and a diagnostic CCTA-scan, defined as 7 or more interpretable coronary segments. The exclusion criterion was an hsCRP concentration $>10 \mathrm{mg} / \mathrm{L}$, indicating underlying inflammatory disease. The institutional review board and ethics committee at the Maastricht University Medical Center approved the study, and all patients gave informed consent.

\section{Risk factor assessment}

Cardiac risk factors were assessed by the referring cardiologists. Risk factors were gathered just before CCTA. Patients were classified as having diabetes if they were treated with a hypoglycemic agent or if they had a fasting plasma glucose $\geq 6.7 \mathrm{mmol} / \mathrm{L}$. Patients were classified as smokers if they had smoked in the 12 weeks before CCTA. A family history of CAD was defined as having a first degree relative with a history of myocardial infarction or sudden cardiac death before the age of 60 . We calculated the prospective cardiovascular Munster (PROCAM) risk score to estimate the 10-year risk of AMI and the Framingham risk score to estimate the 10-year risk of cardiovascular disease. ${ }^{8,9}$ The PROCAM risk score takes the following risk factors into account: age, gender, smoking status, diabetes mellitus, systolic blood pressure, myocardial infarction in first degree relatives before the age of 60, high-density lipoprotein (HDL), low-density lipoprotein (LDL), and triglycerides. The Framingham risk score takes into account: age, total cholesterol, HDL, systolic blood pressure, smoking, and diabetes mellitus.

\section{CCTA acquisition}

Patients received 5 to $20 \mathrm{mg}$ of Metoprolol intravenously to lower the heart rate to $<65$ bpm, as well as sublingual nitroglycerin spray. Heart rate and ECG were monitored during CCTA. A native scan was performed to determine the calcium score using the Agatston method. ${ }^{10}$ Subsequently, CCTA was performed using 85 to $110 \mathrm{~mL}$ of contrast agent (Xenetix 350; Guerbet), which was injected in the antecubital vein at a rate of $6.0 \mathrm{~mL} / \mathrm{s}$, directly followed by $40 \mathrm{~mL}$ of intravenous saline $(6.0 \mathrm{~mL} / \mathrm{s})$. In patients with a heart rate $<65 \mathrm{bpm}$, a prospective-gated "step and shoot" protocol ${ }^{11}$ was used. In patients with a heart rate $>65$ bpm, a retrospective-gated "helical" protocol with dose modulation ${ }^{12}$ was used to obtain the best image quality at a minimal radiation dose. CCTA was performed using a 64-slice Multi Detector Computed Tomography scanner (Brilliance 64; Philips Healthcare) with a $64 \times 0.625$ 
$\mathrm{mm}$ slice collimation, a gantry rotation time of $420 \mathrm{~ms}$, and a tube voltage of 80 to $120 \mathrm{kV}$ depending on the patient's height and weight.

\section{CCTA coronary plaque assessment}

All CCTA-scans were independently analyzed by 2 cardiologists (M.H.M.W., E.M.L.), both blinded for patient details and both experienced in interpreting more than 1,000 CCTA scans. The interobserver agreement was excellent for the Agatston score $(\kappa 0.96)$ and substantial for the CT plaque burden score ( $\kappa 0.79)$.

Figure 1: (A) Representative image of the coronary arteries when using CCTA (B) American Heart Association 16 segment coronary nomenclature diagram. ${ }^{13,14}$ Segments 1-3 are representing the proximal, mid, and distal right coronary artery (RCA), respectively. The posterior descending artery (RDP) and postero lateral (PL) branches are represented by 4 and $4 a$, respectively. The left main (LM), proximal, mid and distal left anterior descending (LAD) are represented by segment $5,6,7$, and 8 , respectively, while segment 9 and 10 represent diagonal D1 and D2. The proximal and mid circumflex (RCX) are represented by segment 11 and 13 , while segment 12 and 14 represent the first and second obtuse marginal (OM) or PL branches, respectively. The $15^{\text {th }}$ segment represents the RDP supplied by the RCX.

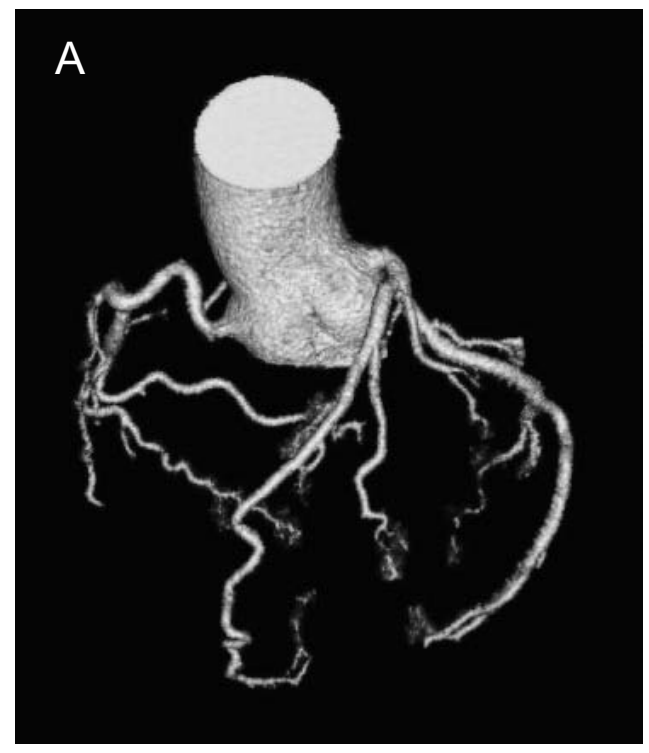

B
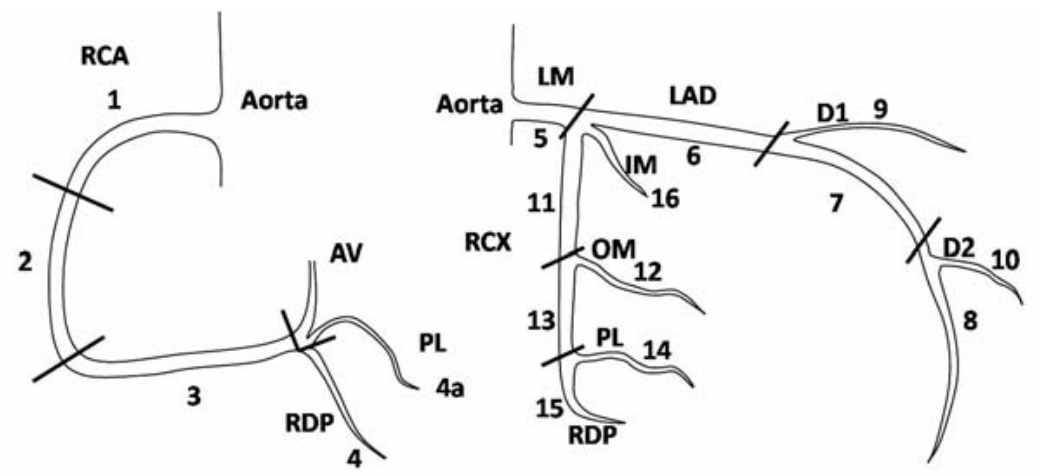
To indicate the location of coronary atherosclerosis, the 16-segment classification of the American Heart Association was used, as depicted in Figure $1 .{ }^{13}$ The coronary artery tree was assessed using the source images on the Cardiac Comprehensive Analysis software (Philips Healthcare) and Terra Recon AQNet Client reconstruction software. Coronary plaques were defined as visible structures within or adjacent to the coronary artery lumen, which could be clearly distinguished from the vessel lumen and the surrounding pericardial tissue. The degree of stenosis of atherosclerotic lesions was classified as none (no luminal stenosis), mild ( 1 or more lesions with diameter stenosis of $20 \%$ to $50 \%$ ), moderate ( 1 or more lesions with diameter stenosis of $50 \%$ to $70 \%$ ), or severe (1 or more lesions with diameter stenosis of $>70 \%)^{14}$

\section{CCTA burden scores}

- CT plaque burden score: No CAD and mild, moderate, severe, and severe multivessel CAD were distinguished. The most diseased segment determined the final score.

- Segment-based score: Segments with mild diameter stenosis scored 1 point, segments with moderate diameter stenosis scored 2 points, and segments with severe diameter stenosis scored 3 points. The total score was the sum of all points divided by the number of assessable segments.

- Plaque involvement score: Segments with no CAD scored 0 points, and segments with CAD present scored 1 point. Total score ranged from 0 to $16 .^{15}$

\section{Agatston Score}

The Agatston score, or coronary calcium score, was calculated using the calcium scoring software of Philips Healthcare, with a threshold of 130 Hounsfield units. ${ }^{10}$

\section{Biomarker measurement}

Blood samples were obtained just before CCTA, after an overnight fast. Samples were processed within 2 hours and stored at $-80^{\circ} \mathrm{C}$ until analysis. Total cholesterol, HDL, triglycerides, glucose, and creatinine concentrations were measured using the Synchron LX20 (Beckman Coulter). LDL was calculated using the Friedewald equation, except for subjects with triglycerides $>4.5 \mathrm{mmol} / \mathrm{L}$ and total cholesterol $<1.3 \mathrm{mmol} / \mathrm{L}$, in which case $\mathrm{LDL}$ was determined on the Cobas Mira Plus (Roche Diagnostics). hsCRP was measured on the BN ProSpec using the CardioPhase hsCRP assay (Siemens Diagnostics). As validated in our 
laboratory (NCCLS EP5-A guidelines), the between-runs coefficients of variation (CV) at 0.25 and $45 \mathrm{mg} / \mathrm{L}$ were 3.7 and 1.0\%, respectively. cTnT was measured on the Elecsys 2010 using the precommercial highly sensitive fifth generation cTnT assay (hs-cTnT) and the fourthgeneration cTnT assay (Roche Diagnostics). The hs-cTnT assay was validated as reported in chapter 3 with the upper reference limit $\left(99^{\text {th }}\right.$ percentile) at $0.016 \mu \mathrm{g} / \mathrm{L}$, limit of detection at

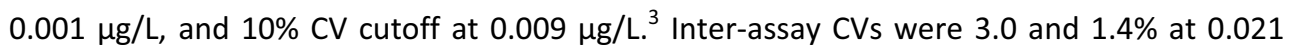
and $3.03 \mu \mathrm{g} / \mathrm{L}$, respectively. For the cTnT assay, the upper reference limit was $<0.01 \mu \mathrm{g} / \mathrm{L}$, limit of detection was $<0.01 \mu \mathrm{g} / \mathrm{L}$, and $10 \% \mathrm{CV}$ cutoff was $0.03 \mu \mathrm{g} / \mathrm{L}$ (given by manufacturer). NT-proBNP was also measured on the Elecsys 2010, with the limit of detection at $0.6 \mathrm{pmol} / \mathrm{L}$ and the inter-assay CV $6.8 \%$ at $8.78 \mathrm{pmol} / \mathrm{L}$ (given by manufacturer), and in our reference population, we measured the upper reference limit $\left(97.5^{\text {th }}\right.$ percentile) at $28 \mathrm{pmol} / \mathrm{L}$.

\section{Statistical analysis}

Data were analyzed using SPSS 15.0. To test for differences in patient characteristics, we used the Pearson $\chi^{2}$ test for discrete variables and the 1-way analysis of variance test for continuous variables, including Bonferroni correction. The PROCAM, Framingham, cardiac marker concentrations, and plaque burden scores were normalized by natural logarithm transformation. For natural log transformation of the plaque burden scores we used the score plus 1 to also include patients with a score of 0 . Gender differences were tested using the Mann-Whitney $U$ test. Correlations were calculated using Spearman's correlation coefficient and tested with the 1-sample t test. Multinomial logistic regression analysis was performed using the stepwise method including variables with $\mathrm{P}<0.05$. Receiver-operatingcharacteristic curves were plotted for the likelihood ratio of having CAD considering PROCAM, Framingham, hs-cTnT, NT-proBNP, and hsCRP. The models studied included all possible combinations of 1 to 4 of these risk factors as described by Wald and Hackshaw. ${ }^{16}$ In short, the likelihood ratio for the presence of CAD was calculated for these parameters using MATLAB R2009a (see appendix attached to this chapter). The likelihood ratio for a combination of these parameters was obtained by the product of the individual likelihood ratios. The areas under the curves (AUC) were compared 1-sided as described by Hanley and McNeil. ${ }^{17}$ For statistical calculations, biomarker concentrations less than the limit of detection were set equal to the limit of detection. The threshold for statistical significance was $\mathrm{P}<0.05$. 


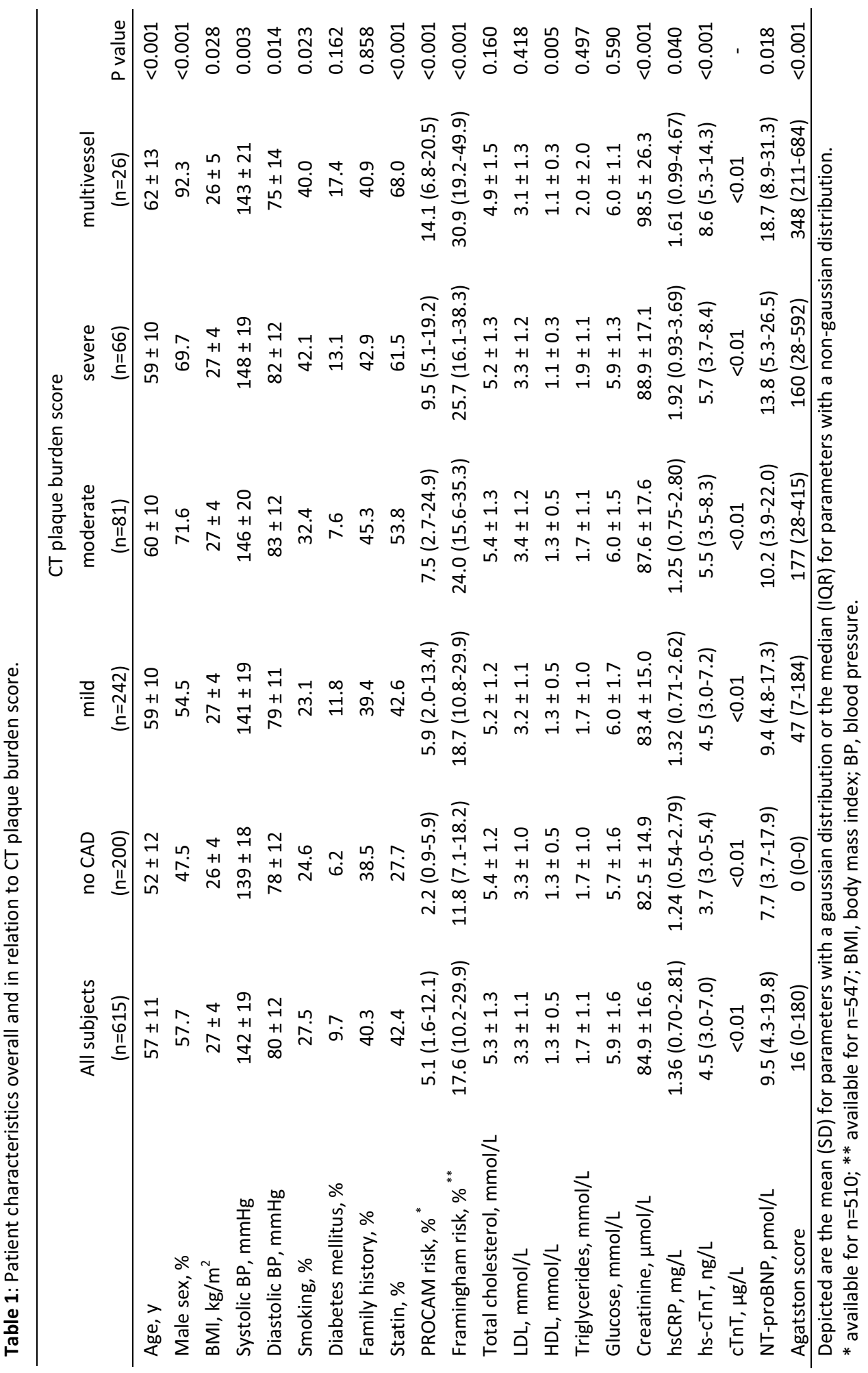




\section{Results}

Baseline characteristics of the study population are presented in Table 1. There was a positive correlation between the extent of CAD and the levels of hs-cTnT. Figure 2A shows a progressive increase of hs-cTnT in patients with mild (median, $4.5 \mathrm{ng} / \mathrm{L}$; interquartile range [IQR], <3.0 to $7.2 \mathrm{ng} / \mathrm{L}$ ), moderate (median, $5.5 \mathrm{ng} / \mathrm{L}$; IQR, 3.5 to $8.3 \mathrm{ng} / \mathrm{L}$ ), severe (median, $5.7 \mathrm{ng} / \mathrm{L}$; IQR, 3.7 to $8.4 \mathrm{ng} / \mathrm{L}$ ), and multivessel (median, $8.6 \mathrm{ng} / \mathrm{L} ; \mathrm{IQR}, 5.3$ to $14.3 \mathrm{ng} / \mathrm{L}$ ) CAD compared with patients without CAD (median, $3.7 \mathrm{ng} / \mathrm{L}$; IQR, $<3.0$ to $5.4 \mathrm{ng} / \mathrm{L}$ ) as assessed with the $C T$ plaque burden score $(P<0.01)$. For the other plaque assessment scores, similar data were observed. hs-cTnT concentrations revealed a correlation with CT plaque burden score and Agatston score $(r=0.293$ and 0.353 , respectively, both $P<0.001)$. Similar correlations were found using the involvement score and the segment-based score. Figure 2B shows gender differences in hs-cTnT concentrations, as described previously. ${ }^{3}$ Moreover, $41 \%$ of patients without CAD had hs-cTnT values in the lowest quartile, compared with $12 \%$ in the multivessel group (Figure 3). By contrast, $11 \%$ of patients without CAD showed hscTnT levels in the highest quartile, compared with $62 \%$ in the multivessel group $\left(\chi^{2}\right.$ analysis, $P<0.05)$.

hsCRP did not show a significant correlation with any of the plaque burden scores ( $r=0.074$, P 0.06 for CT plaque burden score; Figure 2C). NT-proBNP showed only modest correlation with plaque burden assessed by the different scores $(r=0.131, P<0.001$ for CT plaque burden score; Figure 2D).

Multivariance analysis (multinomial logistic regression, Table 2), using all significant risk factors from Table 1 ( $P<0.05$ ), identified gender, smoking, age, body mass index, HDL, and hs-cTnT as independent predictors for the presence of CAD. In the second and third models, in which clinical risk profiling according to the PROCAM and Framingham risk scores was used, respectively, hs-cTnT was again identified as an independent risk factor. As shown in Table 2, for a 1-unit increase in natural log-transformed hs-cTnT, the odds ratio of having a severe and severe multivessel lesion were 2.6 and 7.8, respectively $(P 0.01$ and $P<0.001$, respectively). Comparable odds ratios were obtained in the second and third models (Table 2). Overall $\chi^{2}$ of the final regression model was $133.311(P<0.001)$. The criteria for classification accuracy were satisfied, as the proportional by chance accuracy rate was below the classification accuracy rate ( $36.8 \%$ and $46.9 \%$, respectively). 

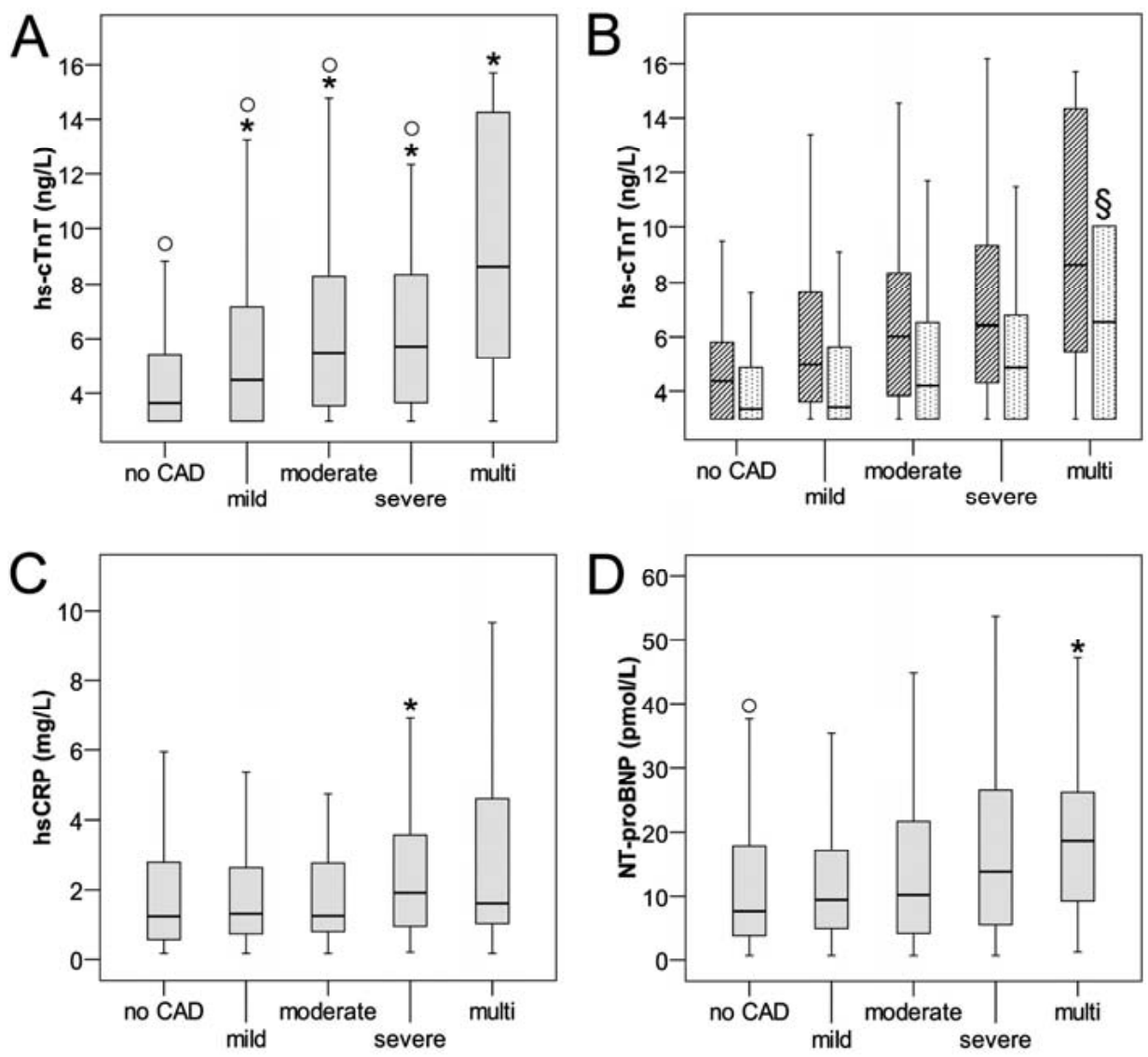

Figure 2: (A) hs-cTnT concentrations show a progressive increase with enhanced coronary plaque burden, (B) with a distinction between males (stripes) and females (dots), (C) in contrast to hsCRP and (D) NT-proBNP concentrations. For all groups, $n=20$ to 242 , except for the females in the multivessel group, with $n=2(\S)$. Indicated are the significant differences between groups after Bonferroni correction $(*$, as compared with the no-CAD group; 0 , as compared with the multivessel group, $\mathrm{P}<0.001$ in $\mathrm{A}$ except for the comparison between no-CAD and mild, $\mathrm{P}<0.05$ in $\mathrm{C}$ and $\mathrm{D}$ ).

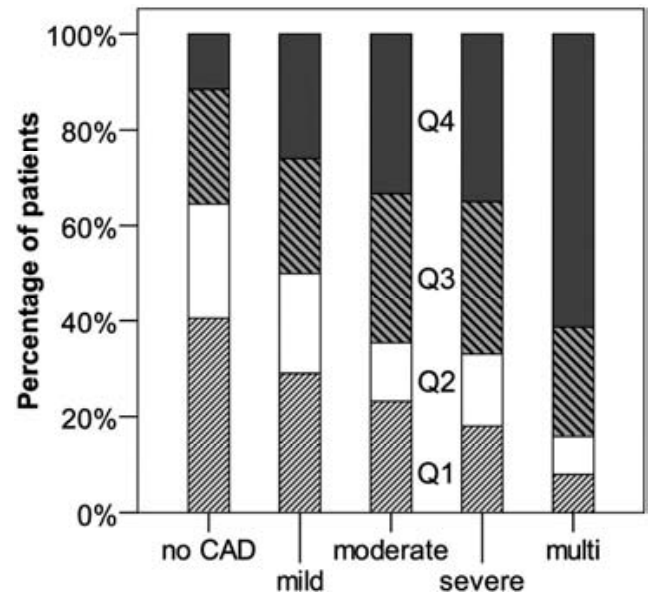

Figure 3: Distribution of hs-cTnT quartiles (Q1 to Q4) within the CT plaque burden score groups $\left(\chi^{2}\right.$ analysis, $\left.P<0.05\right)$. In patients without CAD, $41 \%$ had hs-cTnT values in the lowest quartile, compared with $12 \%$ in the multivessel group. By contrast, $11 \%$ of patients without CAD showed hs-CTnT levels in the highest quartile, compared with $62 \%$ in the multivessel group. 
Figure $4 \mathrm{~A}-\mathrm{C}$ shows that hs-cTnT was superior to hsCRP and NT-proBNP to distinguish the subjects without CAD from those with any extent of $C A D$, ranging from mild to severe multivessel CAD. Furthermore, the AUC for the presence of CAD of hs-cTnT was 0.64 (P $<0.001$ ), as plotted in Figure 5, whereas the AUCs of hsCRP and NT-proBNP did not significantly deviate from 0.5 .

A

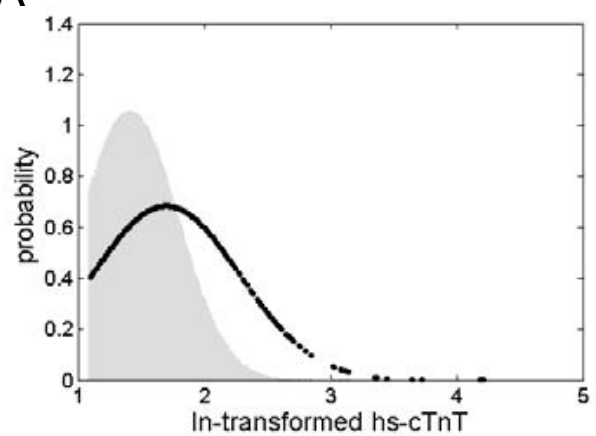

C

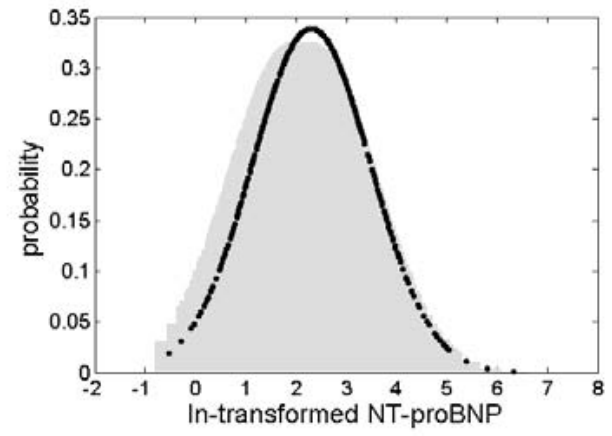

D

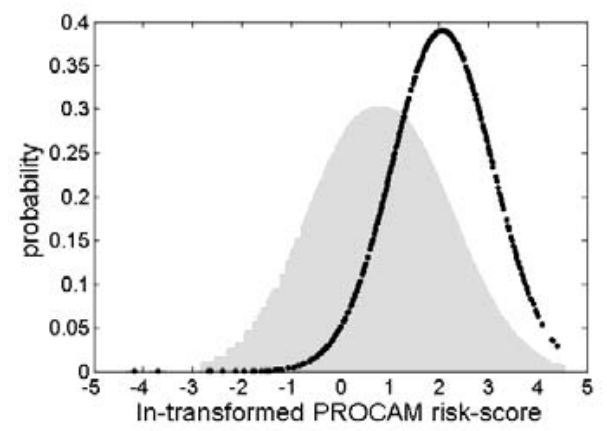

B

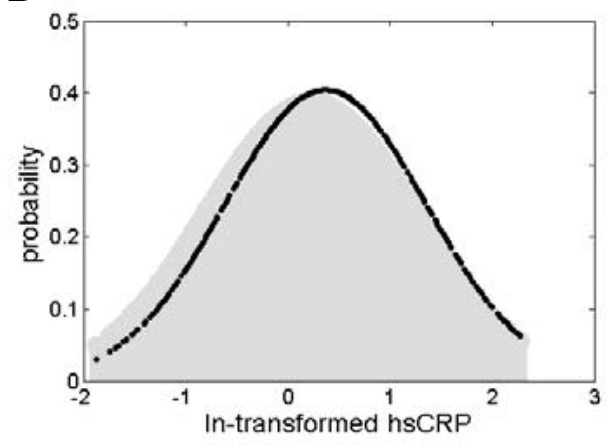

Figure 4: Probability distribution functions to distinguish the study populations without coronary plaque burden (no CAD, grey) and with any coronary plaque burden (mild to multivessel CAD, black dots) for the cardiac biomarkers (A) hs-cTnT, (B) hsCRP, (C) NT-proBNP and for clinical risk profiling when using the (D) PROCAM and (E) Framingham risk scores.

E

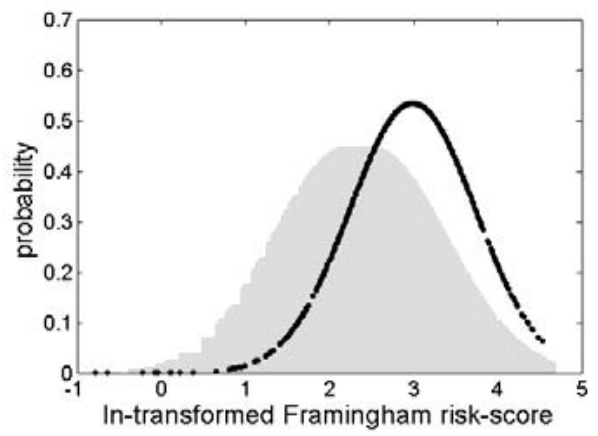


Also, clinical risk profiling using either the PROCAM or Framingham risk stratification model was not sufficient to differentiate the subjects without CAD from those with any extent of CAD, as shown in Figure 4D and E. The AUCs for the presence of CAD were 0.70 and 0.72 , respectively, using receiver-operating characteristic analysis (Figure 5). Addition of hs-cTnT to PROCAM risk profiling added significantly (P 0.046) to the AUC for the presence of CAD (AUC 0.73), which was not the case for Framingham profiling (AUC 0.72, P 0.394). For hsCRP and NTproBNP, no significant addition to the AUC for the presence of CAD was observed for either the PROCAM method (P 0.464) or the Framingham method ( 0.298 and 0.192, respectively).

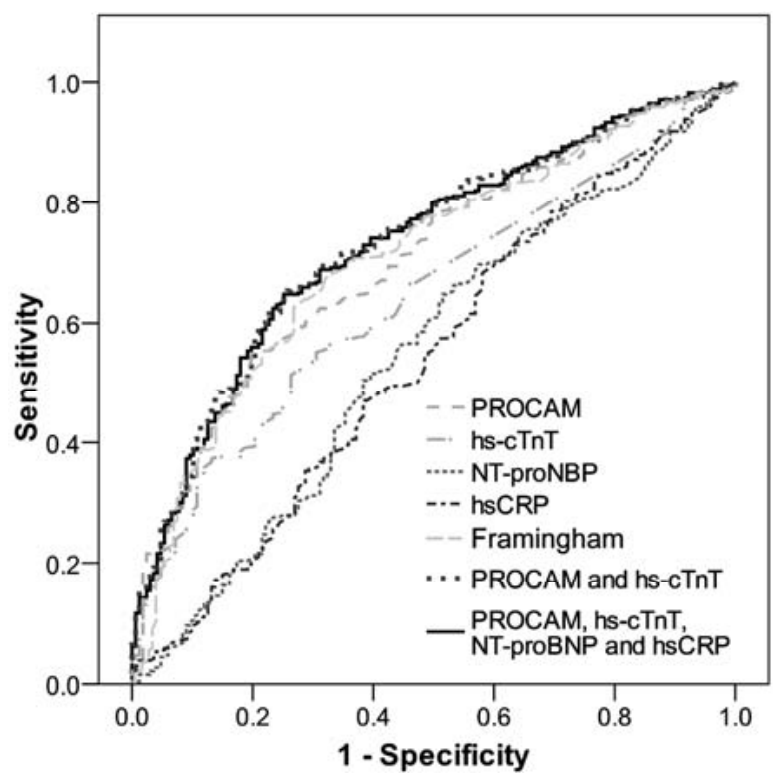

Figure 5: Receiver-operating-characteristic curve for the presence of coronary plaque burden. Addition of hs-cTnT to PROCAM risk profiling resulted in a significant increase of the AUC from 0.70 to 0.73 (P 0.046), in contrast to Framingham (AUC 0.72, P 0.394). Addition of hsCRP or NT-proBNP did not increase the AUC $(P>0.1)$.

\section{Discussion}

In the present study, we assessed hs-cTnT levels and coronary plaque burden in 615 patients suspected of having CAD but without ACS. Our findings indicate that hs-cTnT correlates well with the CT plaque burden score and that even mild coronary atherosclerosis results in quantifiable circulating levels of hs-cTnT. In addition, hs-cTnT is an independent predictor for the presence of coronary atherosclerosis. For hsCRP, no such correlation was observed, 
which is in line with studies concluding that hSCRP may only have limited value in clinical risk profiling. ${ }^{18,19}$ The fourth-generation CTnT level has shown tremendous clinical value in identification patients with acute cardiac ischemia. The detection of myocardial injury is an important step in making the clinical decision to admit patients with chest pain to the coronary care unit. Studies evaluating the clinical value of cTnT were performed in patients with unstable angina pectoris ${ }^{20,21}$ and patients who underwent coronary artery bypass grafting $^{22}$ or percutaneous coronary intervention. ${ }^{23}$ These studies unequivocally demonstrated that elevated levels of cTnT are associated with poorer prognosis and higher rates of major adverse cardiac events.

The fourth generation cTnT assay has a detection limit of $0.01 \mu \mathrm{g} / \mathrm{L}$ and is not sensitive enough to show variation in patients without cardiac ischemia. The novel, fifth-generation hs-cTnT assay has shown a gaussian variation in healthy subjects, ${ }^{3}$ and it was able to measure an increase of cTnT levels after transient ischemia. ${ }^{7}$ The ability to measure hs-cTnT variation in normal subjects prompted us to investigate the relationship between the extent of coronary plaque burden and circulating hs-cTnT levels.

A question remains as to what the meaning of circulating cTnT levels is, in patients with variable degrees of CAD who do not have ACS. Traditionally, it was thought that release of cTn is equivalent to myocardial necrosis. However, some animal studies have suggested that short episodes of ischemia may result in the release of cTnT, without demonstration of cell death. ${ }^{24}$ Recently, Sabatine et al showed that a few minutes of exercise-induced ischemia in patients is sufficient to result in the release of quantifiable levels of $\mathrm{cTnI}^{7}{ }^{7}$ It is unlikely that only minutes of ischemia would have resulted in myocardial cell death in the patients exhibiting significant ischemia. Recent work of our group demonstrated that 5-minute episodes of cardiac ischemia in a mouse model, followed by reperfusion, results in exposure of phosphatidylserine to the surface of cardiomyocytes and activation of caspase-3, both of which are indicative of apoptosis. ${ }^{25,26}$ However, no demonstration of cardiomyocyte cell death was made. In vitro studies have demonstrated that caspase-3 activation results in cleavage of cTn and subsequent release. ${ }^{27}$ Therefore, elevated hs-cTnT levels observed in patients with CAD may be the result of activation of caspase-3 within cardiac myocytes and the resulting cleavage and release of $\mathrm{cTnT}$, but they do not necessarily implicate myocardial cell death. However, even if hs-cTnT does not reflect cell death, activation of the apoptotic 
program within cardiomyocytes would still be unwanted, and as such, increased release of hs-cTnT found in patients with variable degrees of CAD is undesirable.

The question is, what triggers sufficient ischemia to result in cell stress and caspase-3 activation or even cell death? In patients with severe lesions, transient cardiac ischemia could easily result from a mismatch in supply and demand during the day, triggered by physical exercise or emotional stress. ${ }^{7}$ However, it is puzzling how mild lesions would result in elevated levels of hs-cTnT. One could argue that even mild lesions may result in ischemia and $\mathrm{cTnT}$ release during periods when the metabolic demand of the heart exceeds the supply. An alternative mechanism is suggested by the data of Rittersma et $\mathrm{al}^{28}$ who demonstrated that in $50 \%$ of the cases, organized older thrombi were visible at the site of the culprit lesion in AMI patients admitted for thrombectomy. This suggests that thrombus formation at the site of atherosclerotic lesions is not a rare event and is not necessarily linked to clinically manifest plaque rupture and vessel occlusion. Dislodgement of these thrombi in small coronary vessels could be a potential cause for microinjury. Virmani et al ${ }^{29}$ eported that $25 \%$ to $40 \%$ of $\mathrm{AMI}$ cases were caused by plaque erosion, rather than rupture, and subsequent thrombus formation. Plaque erosion may therefore be an important cause of localized thrombus formation and subsequent dislodgement.

Whatever the mechanism of the cTnT release is, the fact remains that our data show that quantifiable circulating levels of hs-cTnT occur in patients with even mild CAD. Two important questions arise from this finding. The first question is whether measurement of this variation of hs-cTnT levels and its correlation with CAD may hold diagnostic importance or predictive value. Studies have shown that coronary atherosclerosis is responsible for at least two-thirds of ACS. ${ }^{30}$ Therefore, the outcomes of our data suggest that hs-cTnT has the potential to become a serum biomarker that will improve identification of patients at risk for developing cardiac events. The second question is whether we should put mild CAD in a different perspective and treat it more aggressively, as these conditions are associated with significantly increased circulating cTnT levels. Because percutaneous intervention for mild lesions would be out of the question, pharmacological intervention aiming at regression of atherosclerotic lesions could be the way to go. Several trials have demonstrated that highdose statin therapy results in measurable regression of atherosclerotic lesions. ${ }^{31,32}$ It remains to be seen whether atherosclerotic regression would be sufficient to reduce the cellular stress indicated by circulating hs-cTnT levels. 


\section{Study limitations}

A study limitation may be the precision of assessment of coronary stenosis using CCTA. It is known that compared with conventional angiography, the accuracy of CCTA in the assessment of the extent of lesions is limited by spatial resolution constraints. ${ }^{33}$ However, a large number of patients were studied, and we used different methods for the assessment of CAD, providing more or less equivalent correlations with hs-cTnT levels. Also, we demonstrated a good interobserver agreement, with a $\kappa$ value of 0.79 . Taken together, it is likely that the plaque burden, assessed with CCTA, is an adequate reflection of the actual plaque burden in the large patient cohort presented here. Another limitation is that participants were mainly Caucasian.

\section{Conclusion}

Coronary atherosclerosis in symptomatic patients without ACS is associated with quantifiable circulating levels of hs-cTnT, even in mild CAD.

\section{References}

1. Apple FS, Jesse RL, Newby LK, et al. National Academy of Clinical Biochemistry and IFCC committee for standardization of markers of cardiac damage laboratory medicine practice guidelines: analytical issues for biochemical markers of acute coronary syndromes. Clin Chem. 2007;53:547-551.

2. Panteghini $M$, Pagani $F$, Yeo $\mathrm{KT}$, et al. Evaluation of imprecision for cardiac troponin assays at low-range concentrations. Clin Chem. 2004;50:327-332.

3. Mingels A, Jacobs L, Michielsen E, Swaanenburg J, Wodzig W, van Dieijen-Visser M. Reference population and marathon runner sera assessed by highly sensitive cardiac troponin $T$ and commercial cardiac troponin T and I assays. Clin Chem. 2009;55:101-108.

4. Kavsak PA, MacRae AR, Yerna MJ, Jaffe AS. Analytic and clinical utility of a next-generation, highly sensitive cardiac troponin I assay for early detection of myocardial injury. Clin Chem. 2009;55:573-577.

5. Reichlin T, Hochholzer W, Bassetti S, et al. Early diagnosis of myocardial infarction with sensitive cardiac troponin assays. N Engl J Med. 2009;361:858-867.

6. Keller T, Zeller T, Peetz D, et al. Sensitive troponin I assay in early diagnosis of acute myocardial infarction. N Engl J Med. 2009;361:868-877.

7. Sabatine MS, Morrow DA, de Lemos JA, Jarolim P, Braunwald E. Detection of acute changes in circulating troponin in the setting of transient stress test-induced myocardial ischaemia using an ultrasensitive assay: results from TIMI 35. Eur Heart J. 2009;30:162-169.

8. Assmann G, Cullen P, Schulte H. Simple scoring scheme for calculating the risk of acute coronary events based on the 10-year follow-up of the prospective cardiovascular Munster (PROCAM) study. Circulation. 2002;105:310-315.

9. D'Agostino RB, Sr., Vasan RS, Pencina MJ, et al. General cardiovascular risk profile for use in primary care: the Framingham Heart Study. Circulation. 2008;117:743-753. 
10. Agatston AS, Janowitz WR, Hildner FJ, Zusmer NR, Viamonte M, Jr., Detrano R. Quantification of coronary artery calcium using ultrafast computed tomography. J Am Coll Cardiol.1990;15:827832.

11. Pontone G, Andreini D, Bartorelli AL, et al. Diagnostic accuracy of coronary computed tomography angiography: a comparison between prospective and retrospective electrocardiogram triggering. J Am Coll Cardiol. 2009;54:346-355.

12. Hausleiter J, Meyer T, Hadamitzky M, et al. Radiation dose estimates from cardiac multislice computed tomography in daily practice: impact of different scanning protocols on effective dose estimates. Circulation. 2006;113:1305-1310.

13. Austen WG, Edwards JE, Frye RL, et al. A reporting system on patients evaluated for coronary artery disease. Report of the ad hoc committee for grading of Coronary Artery Disease, council on cardiovascular surgery, American Heart Association. Circulation. 1975;51:5-40.

14. Raff GL, Abidov A, Achenbach S, et al. SCCT guidelines for the interpretation and reporting of coronary computed tomographic angiography. J Cardiov Comput Tomogr. 2009;3:122-136.

15. Min JK, Shaw LJ, Devereux RB, et al. Prognostic value of multidetector coronary computed tomographic angiography for prediction of all-cause mortality. J Am Coll Cardiol. 2007;50:11611170.

16. Wald N, Hackshaw A. Tests using multiple markers. In: Wald N, Leck I, eds. Antenatal and neonatal screening. New York, N.Y.: Oxford University Press; 2000:23-57.

17. Hanley JA, McNeil BJ. A method of comparing the areas under receiver operating characteristic curves derived from the same cases. Radiology. 1983;148:839-843.

18. Wang TJ, Gona P, Larson MG, et al. Multiple biomarkers for the prediction of first major cardiovascular events and death. N Engl J Med. 2006;355:2631-2639.

19. Khera A, de Lemos JA, Peshock RM, et al. Relationship between C-reactive protein and subclinical atherosclerosis: the Dallas Heart Study. Circulation. 2006;113:38-43.

20. Antman EM, Tanasijevic MJ, Thompson B, et al. Cardiac-specific troponin I levels to predict the risk of mortality in patients with acute coronary insufficiency. New Engl J Med. 1996;335:13421349.

21. Heidenreich PA, Alloggiamento T, Melsop K, McDonald KM, Go AS, Hlatky MA. The prognostic value of troponin in patients with non-ST elevation acute coronary syndromes: a meta-analysis. $J$ Am Coll Cardiol. 2001;38:478-485.

22. Amin AP, Mukhopadhyay E, Napan S, Mamtani M, Kelly RF, Kulkarni H. Value of early cardiac troponin I to predict long-term adverse events after coronary artery bypass graft surgery in patients presenting with acute coronary syndromes. Clin Cardiol. 2009;32:386-392.

23. Prasad A, Singh M, Lerman A, Lennon RJ, Holmes DR, Jr., Rihal CS. Isolated elevation in troponin T after percutaneous coronary intervention is associated with higher long-term mortality. J Am Coll Cardiol. 2006;48:1765-1770.

24. Feng YJ, Chen C, Fallon JT, et al. Comparison of cardiac troponin I, creatine kinase-MB, and myoglobin for detection of acute ischemic myocardial injury in a swine model. Am J Clin Pathol. 1998;110:70-77.

25. Kenis H, Zandbergen HR, Hofstra L, et al. Annexin A5 uptake in ischemic myocardium: demonstration of reversible phosphatidylserine externalization and feasibility of radionuclide imaging. J Nucl Med.51:259-267.

26. Hofstra L, Liem IH, Dumont EA, et al. Visualisation of cell death in vivo in patients with acute myocardial infarction. Lancet. 2000;356:209-212.

27. Communal C, Sumandea M, de Tombe P, Narula J, Solaro RJ, Hajjar RJ. Functional consequences of caspase activation in cardiac myocytes. Proc Nati Acad Sci U S A. 2002;99:6252-6256.

28. Rittersma SZ, van der Wal AC, Koch KT, et al. Plaque instability frequently occurs days or weeks before occlusive coronary thrombosis: a pathological thrombectomy study in primary percutaneous coronary intervention. Circulation. 2005;111:1160-1165. 
29. Virmani R, Kolodgie FD, Burke AP, Farb A, Schwartz SM. Lessons from sudden coronary death: a comprehensive morphological classification scheme for atherosclerotic lesions. Arterioscler Thromb Vasc Biol. 2000;20:1262-1275.

30. Farb A, Burke AP, Tang AL, et al. Coronary plaque erosion without rupture into a lipid core. A frequent cause of coronary thrombosis in sudden coronary death. Circulation. 1996;93:13541363.

31. Nissen SE, Nicholls SJ, Sipahi I, et al. Effect of very high-intensity statin therapy on regression of coronary atherosclerosis: the ASTEROID trial. JAMA. 2006;295:1556-1565.

32. Baigent C, Keech A, Kearney PM, et al. Efficacy and safety of cholesterol-lowering treatment: prospective meta-analysis of data from 90,056 participants in 14 randomised trials of statins. Lancet. 2005;366:1267-1278.

33. Nieman $\mathrm{K}$, Oudkerk $\mathrm{M}$, Rensing $\mathrm{BJ}$, et al. Coronary angiography with multi-slice computed tomography. Lancet. 2001;357:599-603.

\section{Appendix}

\section{$\% \%$ LRhscTnT}

$\%$ Method to calculate the likelihood ratio for hscTnT in patients with plaque burden (CT score $>1$ )

$\%$ versus the patients without $(\mathrm{CT}$ score $=1)$.

$\% \%$ Import data from SPSS via Excel (manually)

$\%$ file 'all' contains all subjects $(n=615)$

$\%$ file 'plaque' contains subjects with CT score $>1$

$\%$ file 'normal' contains subjects with CT score $=1$

$\%$ with hsCRP, hs-cTnT, NTproBNP, PROCAM data, respectively, all after

$\%$ In-transformation.

$\% \%$ Method

\% Columns are ID, In hsCRP, In hs-cTnT, In NTproBNP, In PROCAM, In

$\%$ Framingham, respectively

hscTnT=all615(:,3);

hscTnT_normal=normal615(:,3);

hscTnT_plaque=plaque615(:,3);

$\%$ Gaussian distribution is described by

$\% 1 /($ standarddeviation*sqrt(2pi) $) * \exp \left(-(\mathrm{x}-\mathrm{mean})^{\wedge} 2 /\left(2 * \operatorname{standarddeviation}^{\wedge} 2\right)\right)$

$\%$ constant in Gaussian equation:

c_hscTnT_plaque $=1 /(\operatorname{std}($ hscTnT_plaque $) * \operatorname{sqrt}(2 *$ pi) $)$;

c_hscTnT_normal=1/(std(hscTnT_normal)*sqrt( $2 *$ pi));

$\%$ constant in e-power of Gaussian equation:

ce_hscTnT_plaque $\left.=-1 /(2 * \text { std(hscTnT_plaque })^{\wedge} 2\right)$;

ce_hscTnT_normal=-1/(2*std(hscTnT_normal)^2);

for $x=[1: 615]$

prob_hscTnT_plaque $(x, 1)=c \_h s c T n T \_p l a q u e * \exp (c e$ _hscTnT_plaque*(hscTnT $(x, 1)$ -

mean(hscTnT_plaque) $) *(h s c T n T(x, 1)-$ mean(hscTnT_plaque)));

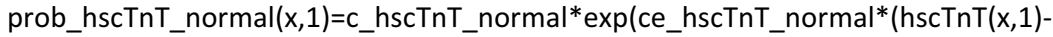

mean(hscTnT_normal))*(hscTnT(x,1)-mean(hscTnT_normal)));

LR_hscTnT $(x, 1)=$ prob_hscTnT_plaque $(x, 1)$ /prob_hscTnT_normal $(x, 1)$;

end 

High-sensitivity cardiac troponin T: risk stratification tool in patients

\section{with stable chest pain}

Background: Recent studies have demonstrated the association between increased concentrations of high-sensitivity cardiac troponin $\mathrm{T}$ (hs-cTnT) and the incidence of myocardial infarction, heart failure, and mortality. However, most prognostic studies to date focus on the value of hs-cTnT in the elderly or general population. The value of hscTnT in symptomatic patients visiting the outpatient department remains unclear. The aim of this study was to investigate the prognostic value of hs-cTnT as a biomarker in stable chest pain patients and to assess its additional value in combination with other risk stratification tools in predicting cardiac events.

Methods: We studied 1,088 patients (follow-up $2.2 \pm 0.8$ years) with stable chest pain who underwent coronary calcium scoring and coronary CT-angiography. Traditional cardiovascular risk factors and concentrations of hs-cTnT, N-terminal pro-brain-type natriuretic peptide (NT-proBNP) and high-sensitivity C-reactive protein (hsCRP) were assessed. Study endpoint was the occurrence of late revascularization, acute coronary syndrome, and cardiac mortality.

Results: Hs-cTnT was a significant predictor for the composite endpoint (highest quartile Q4 >6.7 ng/L, HR 3.55; 95\%Cl 1.88-6.70; P <0.001). Survival analysis showed that hs-cTnT had significant predictive value on top of current risk stratification tools (Chi-square change $P<0.01$ ). In patients with hs-cTnT in Q4 versus $<Q 4$, a 2- to 3-fold increase in cardiovascular risk was noticed, either when corrected for high or low Framingham risk score, coronary calcium scoring, or CT-angiography assessment (HR 3.11; 2.73; 2.47; respectively; all $\mathrm{P}<0.01$ ). This was not the case for hsCRP and NT-proBNP.

Conclusions: Hs-cTnT is a useful prognostic biomarker in patients with stable chest pain. In addition, hs-cTnT was an independent predictor for cardiac events when corrected for cardiovascular risk profiling, calcium score and CT-angiography results. 
The identification of patients at risk for acute cardiovascular events remains a challenge. One promising avenue to improve the identification of these patients is the use of serum biomarkers, which could provide a relatively easy and cost effective step in risk stratification. Several biomarkers have been evaluated with respect to their incremental diagnostic and prognostic value. ${ }^{1,2}$ However, none of these biomarkers has achieved widespread acceptance yet.

With the development of more accurate high-sensitivity cardiac troponin (hs-cTn) assays, new possibilities become available to improve risk stratification. ${ }^{3-5}$ Omland et al $^{6}$ found a significant association between increased hs-cTnT concentrations and the incidence of cardiovascular death and heart failure in patients with stable coronary artery disease (CAD). Bonaca et $\mathrm{al}^{7}$ found an association between hs-cTnl concentrations and death as well as myocardial infarction in non ST-segment elevation acute coronary syndrome patients. However, most prognostic studies to date focus on the value of hs-cTnT in the elderly or the general population. ${ }^{8-11}$ Less is known about the possible incremental value of hs-cTnT on top of existing risk stratification tools in patients with stable chest pain.

Chapter 7 describes we were the first to demonstrate the association between hs-cTnT and the extent of coronary plaque burden in stable chest pain patients, as determined by coronary computed tomographic angiography (CCTA). ${ }^{12}$ We found that even mild CAD is associated with quantifiable circulating levels of hs-cTnT, which was confirmed by others. ${ }^{13}$ CCTA is a relatively new, non-invasive imaging technique and there is considerable interest in the role of CCTA and coronary calcium scoring (CCS) in risk prediction models. ${ }^{14}$

In this study, we investigated the incremental value of hs-cTnT on top of the Framingham risk score (FRS) and the extent of CAD as assessed with CCS and CCTA, in predicting cardiac events. As a comparison, we also studied high-sensitivity C-reactive protein (hsCRP) and N-terminal pro-B-type natriuretic peptide (NT-proBNP).

\section{Methods}

\section{Study population}

We studied 1,114 patients who were referred from the cardiology outpatient department for CCTA because of suspected CAD. Part of this population was studied in chapter 7 . Included were patients with a recent history of (a)typical chest pain who gave at least one $\mathrm{mL}$ serum. Excluded were patients with missing data regarding their cardiac risk profile and 
patients with a history of percutaneous coronary intervention $(\mathrm{PCl})$ or coronary artery bypass grafting (CABG). The study was approved by the institutional review board and ethics committee at the Maastricht University. All patients gave written informed consent.

\section{Data assessment}

Cardiovascular risk factors, coronary plaque assessment using CCTA and CCS, and biomarker measurements were assessed as described in chapter 7.

\section{Follow-up}

The composite study endpoint was the occurrence of revascularization ( $\mathrm{PCl} / \mathrm{CABG}$ ) >90 days after CCTA, cardiac mortality and ACS, including myocardial infarction and unstable angina requiring hospitalization. ACS was defined as typical angina pectoris, cTnT elevation $(>0.01$ $\mu \mathrm{g} / \mathrm{L}$ ) and ST-segment elevation/depression of $\geq 1 \mathrm{~mm}$, or at least two of these characteristics together with invasive angiographic confirmation of a culprit lesion. ${ }^{15} \mathrm{We}$ censored follow-up when revascularization was performed within 90 days and after occurrence of the study endpoint. Patients were seen by their cardiologist on a regular basis, and all hospital visits, both outpatient department visits as well as emergency room visits, were recorded in the electronic patient records. Additionally, the national mortality records were checked. None of the attending clinicians had access to the results of the hs-cTnT, hsCRP and NT-proBNP measurements.

\section{Statistical analysis}

To test for differences in baseline patient characteristics, we used the Pearson $\chi^{2}$ test for discrete variables and the $t$-test for continuous variables. FRS, hsCRP, hs-cTnT, and NTproBNP concentrations, and CCS were normalized by natural logarithm transformation. For transformation of CCS we used the score plus 1 to also include patients with a score of 0 . Logistic regression and survival analysis were used to study prediction of the composite endpoint of late revascularization procedures (PCI/CABG), ACS, and cardiac mortality. For Kaplan-Meier analysis, categories of independent variables were compared using the logrank test. Cox proportional hazard regression was validated for proportionality using logminus-log and for time dependency. It was used to evaluate the additive value of the cardiac biomarkers, based on the Chi-square change (-2 log likelihood ratio) and whether biomarkers remained significant predictors. Biomarker concentrations less than the limit of detection 
were set equal to the limit of detection. The threshold for statistical significance was $P<0.05$, two-sided unless stated otherwise. All data were analyzed using SPSS Statistics 18.0 (SPSS Inc., Chicago, IL, USA).

Table 1: Baseline patient characteristics.

\begin{tabular}{|c|c|c|c|c|}
\hline \multirow[b]{2}{*}{ Variable } & \multirow[b]{2}{*}{$\begin{array}{c}\text { All participants } \\
\mathrm{n}=1,088\end{array}$} & \multicolumn{2}{|c|}{ Event* } & \multirow[b]{2}{*}{$\mathrm{P}$ value } \\
\hline & & $\begin{array}{c}\text { Non-cardiac } \\
\mathrm{n}=1,046\end{array}$ & $\begin{array}{c}\text { Cardiac } \\
\mathrm{n}=42\end{array}$ & \\
\hline Age, mean (SD), year & $56(11)$ & $56(11)$ & $59(11)$ & 0.067 \\
\hline Male sex, $\%$ & 53.8 & 53.6 & 57.1 & 0.655 \\
\hline Systolic BP, mean (SD), mmHg & $142(19)$ & $141(19)$ & $149(16)$ & 0.010 \\
\hline Smoking, \% & 26.5 & 25.6 & 50.0 & 0.001 \\
\hline Diabetes mellitus, \% & 8.4 & 8.3 & 12.5 & 0.347 \\
\hline Positive family history, $\%$ & 39.7 & 39.2 & 51.2 & 0.123 \\
\hline $\begin{array}{l}\text { Framingham risk score (FRS), } \\
\text { median (IQR), \% }\end{array}$ & $16.7(9.3-27.2)$ & $16.4(9.2-26.4)$ & $25.1(14.6-48.1)$ & $<0.001$ \\
\hline $\begin{array}{l}\text { Total cholesterol, mean (SD), } \\
\mathrm{mmol} / \mathrm{L}\end{array}$ & $5.3(1.2)$ & $5.3(1.2)$ & $5.6(1.2)$ & 0.179 \\
\hline $\mathrm{LDL}$, mean (SD), $\mathrm{mmol} / \mathrm{L}$ & $3.3(1.1)$ & $3.3(1.1)$ & $3.5(1.0)$ & 0.303 \\
\hline $\mathrm{HDL}$, mean (SD), mmol/L & $1.3(0.8)$ & $1.3(0.8)$ & $1.2(0.4)$ & 0.581 \\
\hline $\begin{array}{l}\text { Triglycerides, mean (SD), } \\
\mathrm{mmol} / \mathrm{L}\end{array}$ & $1.7(1.2)$ & $1.7(1.2)$ & $1.9(1.1)$ & 0.391 \\
\hline Glucose, mean (SD), mmol/L & $5.8(1.4)$ & $5.8(1.4)$ & $6.0(1.5)$ & 0.471 \\
\hline Creatinine, mean (SD), $\mu \mathrm{mol} / \mathrm{L}$ & $97(18)$ & $97(18)$ & $106(35)$ & 0.296 \\
\hline hsCRP, median (IQR), mg/L & $1.4(0.7-3.1)$ & $1.4(0.7-3.1)$ & $1.6(1.0-4.8)$ & 0.079 \\
\hline $\begin{array}{l}\text { hs-cTnT, 5th generation assay, } \\
\text { median (IQR), ng/L }\end{array}$ & $4.1(<3.0-6.7)$ & $4.0(<3.0-6.6)$ & $6.8(<3.0-10.3)$ & 0.015 \\
\hline $\begin{array}{l}\text { NT-proBNP, median (IQR), } \\
\text { pmol/L }\end{array}$ & $8.9(4.1-18.1)$ & $8.8(4.0-18.4)$ & $10.9(6.5-16.2)$ & 0.218 \\
\hline $\begin{array}{l}\text { Coronary calcium score (CCS), } \\
\text { median (IQR) }\end{array}$ & $7(0-122)$ & $6(0-110)$ & $252(8-644)$ & $<0.001$ \\
\hline CCTA luminal stenosis, \% & & & & $<0.001$ \\
\hline no CAD & 36.8 & 37.9 & 9.5 & \\
\hline mild CAD (20-50\%) & 38.1 & 39.0 & 16.7 & \\
\hline moderate CAD (50-70\%) & 14.5 & 14.0 & 28.6 & \\
\hline severe CAD (>70\%) & 10.6 & 9.2 & 45.2 & \\
\hline
\end{tabular}




\section{Results}

\section{Study population}

From the 1,114 patients who underwent CCS and CCTA, 18 patients had a history of coronary revascularization and in 8 patients the cardiovascular history was missing. These patients were excluded. The remaining 1,088 patients were subject of this report. Baseline characteristics of the study population are presented in Table 1.

Follow-up information was available for all patients (mean follow-up time $2.2 \pm 0.8$ years). As a result of CCTA, 50 patients underwent (early) revascularization within 90 days $(35 x \mathrm{PCl}, 15 x \mathrm{CABG})$ and these were censored at the time of revascularization. Final survival analysis included a total of 42 patients who suffered a cardiac event: 26 patients underwent (late) revascularization $>90$ days after CCTA $(20 \times \mathrm{PCl}$ and $6 \times \mathrm{CABG}), 15$ patients suffered ACS (6x AMI and 9x unstable angina requiring hospitalization), and one patient died due to heart failure. The overall cardiac event rate was $4 \%$.

Table 1 shows that patients who suffered a cardiac event consisted of significantly more smokers, had higher systolic blood pressure and FRS, higher hs-cTnT concentrations, higher CCS, and more severe lesions on CCTA.

\section{Prognostic value of hs-cTnT}

Logistic regression revealed that 1-unit increase in (In-transformed) hs-cTnT concentration resulted in a significant increase in cardiac risk ( $\mathrm{HR} 2.03,95 \% \mathrm{Cl} 1.32-3.12, \mathrm{P} 0.001$ ), in contrast to NT-proBNP (HR 1.16, 95\% Cl 0.90-1.50, P 0.256) and hsCRP (HR 1.31, 95\% Cl 0.991.74, P 0.059). Comparable results were obtained when biomarker concentrations were corrected for age and gender.

Kaplan-Meier analysis shows that hs-cTnT and NT-proBNP concentrations were both significant predictors for the occurrence of cardiac events $(P<0.001$ and 0.009 , respectively), in contrast to hsCRP (P 0.355). Moreover, Cox regression reveals that hs-cTnT was the only significant biomarker predicting for cardiac events, either when testing the biomarker concentrations as a continuous variable (Table 2: Model 1, 4, and 7, respectively) or when present in the highest quartile Q4 (Table 2: Model 2, 5, and 8, respectively). 
Table 2: Survival analysis of cardiac biomarkers for the composite endpoint of cardiac events.

\begin{tabular}{|c|c|c|c|c|c|c|}
\hline Model & Variable & $\chi^{2}$ & $P$ value & $\mathrm{HR}$ & $95 \% \mathrm{Cl}$ & $P$ value \\
\hline 1 & hs-cTnT (In-transformed) & 12.65 & $<0.001$ & 2.07 & $1.38-3.10$ & $<0.001$ \\
\hline 2 & hs-cTnT in Q4 (>6.7 ng/L) * & 17.30 & $<0.001$ & 3.55 & $1.88-6.70$ & $<0.001$ \\
\hline 3 & hs-cTnT >URL (14 ng/L) ${ }^{* \prime}+$ & 1.08 & 0.299 & 1.85 & $0.57-6.02$ & 0.307 \\
\hline 4 & NT-proBNP (In-transformed) & 1.63 & 0.202 & 1.18 & $0.92-1.52$ & 0.201 \\
\hline 5 & NT-proBNP in Q4 (>18 pmol/L) * & 0.72 & 0.396 & 0.70 & $0.31-1.60$ & 0.399 \\
\hline 6 & NT-proBNP >URL $(36 \mathrm{pmol} / \mathrm{L}){ }^{*,+}$ & 0.47 & 0.492 & 0.66 & $0.20-2.16$ & 0.495 \\
\hline 7 & hsCRP (In-transformed) & 3.39 & 0.066 & 1.29 & $0.98-1.69$ & 0.065 \\
\hline 8 & hsCRP in Q4 (>3.1 mg/L) * & 0.86 & 0.355 & 1.38 & $0.70-2.73$ & 0.357 \\
\hline 9 & $\mathrm{hsCRP}>\mathrm{URL}(3 \mathrm{mg} / \mathrm{L})^{*, \dagger}$ & 0.61 & 0.436 & 1.31 & $0.66-2.60$ & 0.437 \\
\hline
\end{tabular}

* Dichotomous variable (yes or no)

+ URL = upper reference limit (used for diagnosis)

\section{Additional value of hs-cTnT on top of FRS}

Clinical risk profiling using FRS predicted significantly for the occurrence of cardiac events (Table 1, P <0.001). This was confirmed using logistic and Cox regression for the Intransformed FRS or when FRS was categorized as follows: <5\% (low risk), 5-20\% (intermediate risk), $>20 \%$ (high risk) (all $\mathrm{P}<0.05$ ). Kaplan-Meier analysis confirmed this relation, as shown in Figure $2 \mathrm{~A}$ ( $\mathrm{P}$ 0.018). Noticeably, almost no cardiac events were observed in patients with FRS $<5 \%$.

When regarding time to event using Cox regression, hs-cTnT concentrations were significantly predictive on top of FRS (Table 3). This was true when hs-cTnT was added either to the individual parameters of the FRS (Model 1, Chi-square change 4.97, P 0.026) or to the complete FRS algorithm (Model 2, Chi-square change 4.42, P 0.035). To further illustrate, we noticed a 3-fold increase in cardiac risk in patients with hs-cTnT concentrations in Q4 as compared to $<Q 4$, independent from high or low FRS (cutoff 20\%) (Model 3, Chi-square change $10.56, \mathrm{P}$ 0.001). In patients with $\mathrm{FRS}<20 \%$, the cardiac event rate increased from $2.1 \%$ to $5.9 \%$ when hs-cTnT concentrations were in Q4 compared to $<\mathrm{Q} 4$. In patients with FRS $>20 \%$, the cardiac event rate increased from $3.6 \%$ to $10.6 \%$, respectively. This is also

Figure 2 (next page): Kaplan-Meier analysis to classify survival based on risk profiling with (A) the Framingham risk score (FRS) as mentioned in the method section of chapter 7 and (B) FRS including hs-cTnT (cutoff $20 \%$ and Q4, respectively). Survival was also classified based on the extent of coronary plaque as assessed by (C) coronary calcium scoring (CCS) and (E) coronary computed tomography angiography (CCTA). The additive value of hs-cTnT on top of these assessments is shown in (D) and (F), respectively. 
FRS

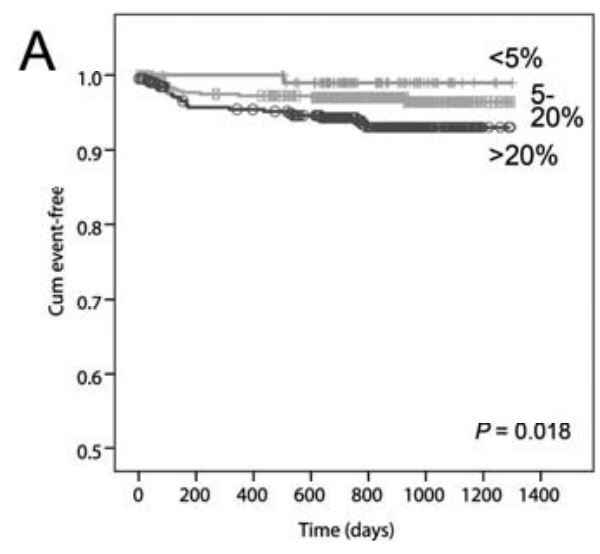

CCS

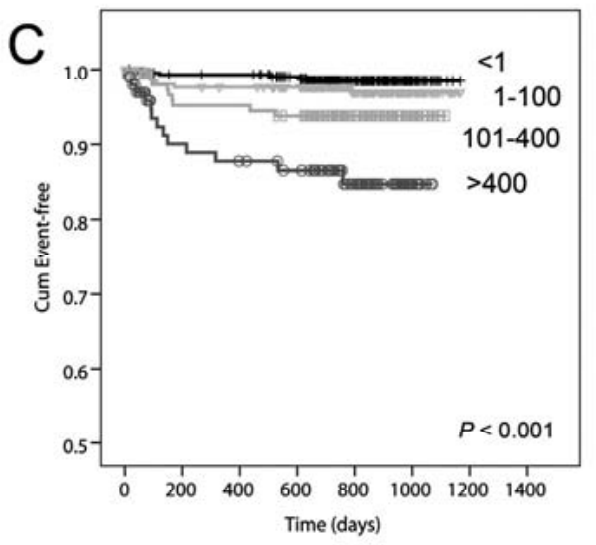

CCTA

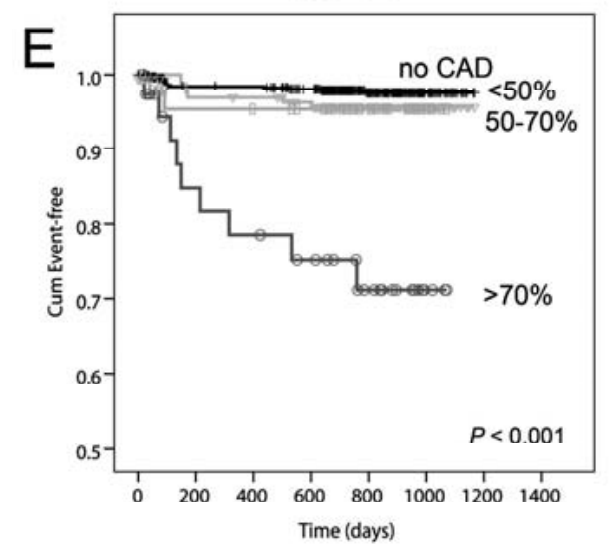

FRS and hs-cTnT

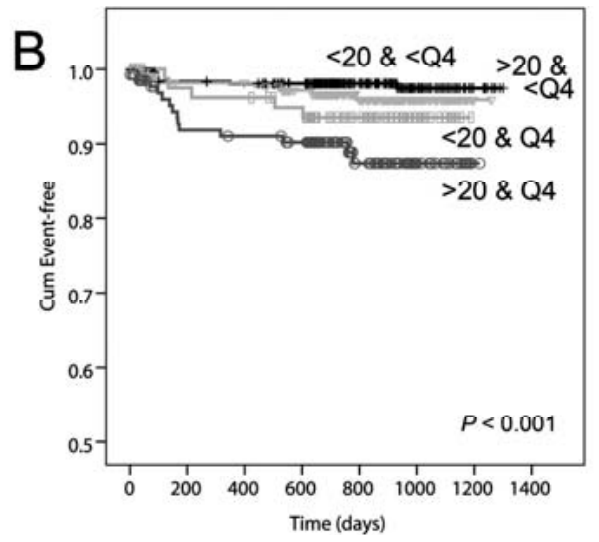

CCS and hs-cTnT

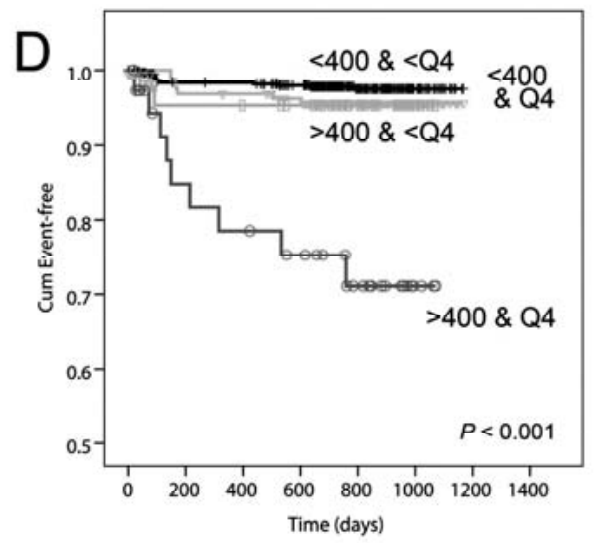

CCTA and hs-cTnT

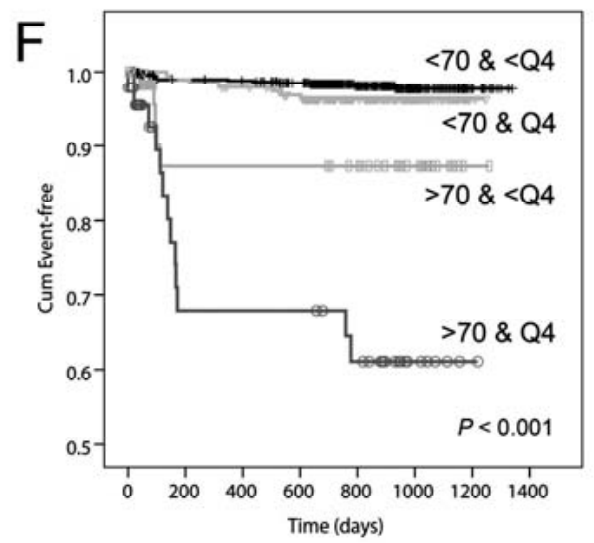


Table 3: Framingham risk profiling for the composite endpoint of cardiac events.

\begin{tabular}{|c|c|c|c|c|c|c|}
\hline & \multicolumn{3}{|c|}{ Without hs-cTnT } & \multicolumn{3}{|c|}{ With hs-cTnT } \\
\hline & $\mathrm{HR}$ & $95 \% \mathrm{Cl}$ & $P$ value & $\mathrm{HR}$ & $95 \% \mathrm{Cl}$ & $P$ value \\
\hline \multicolumn{7}{|l|}{ Model 1} \\
\hline Age & 1.03 & $1.00-1.07$ & 0.074 & 1.01 & $0.97-1.05$ & 0.536 \\
\hline Male gender * & 1.26 & $0.61-2.63$ & 0.531 & 1.00 & $0.46-2.17$ & 0.998 \\
\hline Total cholesterol & 1.11 & $0.84-1.47$ & 0.468 & 1.17 & $0.88-1.56$ & 0.272 \\
\hline HDL cholesterol & 0.92 & $0.45-1.88$ & 0.812 & 0.87 & $0.37-2.03$ & 0.743 \\
\hline Systolic blood pressure & 1.02 & $1.00-1.03$ & 0.071 & 1.02 & $1.00-1.04$ & 0.048 \\
\hline Smoking * & 3.73 & $1.83-7.60$ & $<0.001$ & 3.55 & $1.73-7.27$ & 0.001 \\
\hline Diabetes mellitus * & 1.32 & $0.44-3.94$ & 0.618 & 1.10 & $0.36-3.40$ & 0.863 \\
\hline hs-cTnT (In-transformed) & - & - & - & 1.93 & $1.12-3.35$ & 0.019 \\
\hline \multicolumn{7}{|l|}{ Model 2} \\
\hline Framingham (In-transformed) & 2.24 & $1.41-3.56$ & 0.001 & 1.94 & $1.21-3.12$ & 0.006 \\
\hline hs-cTnT (In-transformed) & - & - & - & 1.69 & $1.08-2.66$ & 0.023 \\
\hline \multicolumn{7}{|l|}{ Model 3} \\
\hline Framingham $>20 \% *$ & 2.33 & $1.19-4.55$ & 0.013 & 1.79 & $0.89-3.57$ & 0.101 \\
\hline hs-cTnT in Q4 * & - & - & - & 3.11 & $1.58-6.11$ & 0.001 \\
\hline
\end{tabular}

* Dichotomous variable (yes or no)

illustrated using Kaplan-Meier analysis in Figure 1B (P 0.001). In contrast, no significant additional value was found for NT-proBNP and hsCRP.

\section{Additional value of hs-cTnT on top of CCS and CCTA}

Kaplan-Meier analysis shows an apparent gradient of adverse survival for more severe CAD (Figure $1 \mathrm{C}$ and $1 \mathrm{E}$ ). Furthermore, hs-cTnT concentrations (median, IQR) were significantly higher in mild (4.2 ng/L, <3.0-7.3), moderate $(4.7 \mathrm{ng} / \mathrm{L},<3.0-7.3)$, and severe CAD (6.5 ng/L, 3.6-9.4) as compared to patients without CAD (3.3 ng/L, <3.0-5.3), all $P<0.001$. A similar trend was found for CCS $(P<0.001)$. These data show that increasing concentrations of hscTnT were associated with the severity of CAD, which is in line with our previous results in part of this population. ${ }^{12}$

Cox regression in Table 4 shows the additional value of hs-cTnT on top of CAD assessment with CCS and CCTA. One unit increase in hs-cTnT (In-transformed) resulted in a 
minor increase in cardiac risk (Models 1, Chi-square change 3.29 and 2.511, P 0.070 and 0.113 , respectively). Nevertheless, still a 2- to 3-fold increase in cardiac risk was noticed in patients with hs-cTnT concentrations in Q4, independent from high or low CCS (cutoff Agatston score 400) or luminal stenosis on CCTA (cutoff 70\%) (Models 2, Chi-square change 7.20 and 7.24, respectively, both P 0.007). In patients with high CCS (Agatston score $>400$, $n=85$ ), the cardiac event rates increased from $4.3 \%$ to $24 \%$ when hs-cTnT concentrations were in Q4 as compared to $<$ Q4. In patients with a CCTA lesion of $>70 \%$ luminal stenosis $(n=103)$, the cardiac event rates were $8.8 \%$ and $28 \%$ when hs-cTnT concentrations were in $<$ Q4 and Q4, respectively. This is also illustrated using Kaplan-Meier analysis in Figure 1D and $1 \mathrm{~F}$ for CCS and CCTA assessment, respectively (both P 0.001). Again, no significant additional value was found for NT-proBNP and hsCRP.

Table 4: Survival analysis of coronary plaque assessment for the composite endpoint of cardiac events.

\begin{tabular}{|c|c|c|c|c|c|c|}
\hline & \multicolumn{3}{|c|}{ Without hs-cTnT } & \multicolumn{3}{|c|}{ With hs-cTnT } \\
\hline & $\mathrm{HR}$ & $95 \% \mathrm{Cl}$ & $P$ value & $\mathrm{HR}$ & $95 \% \mathrm{Cl}$ & $P$ value \\
\hline \multicolumn{7}{|l|}{ CCS model 1} \\
\hline $\operatorname{CCS}(\text { In-transformed }+1)^{a}$ & 1.40 & $1.20-1.64$ & $<0.001$ & 1.35 & $1.14-1.58$ & $<0.001$ \\
\hline hs-cTnT (In-transformed) & - & - & - & 1.62 & $1.00-2.64$ & 0.052 \\
\hline \multicolumn{7}{|l|}{ CCS model 2} \\
\hline $\mathrm{CCS}>400^{\mathrm{b}}$ & 5.68 & $2.72-11.86$ & $<0.001$ & 4.53 & $2.13-9.64$ & $<0.001$ \\
\hline hs-cTnT in $Q 4^{b}$ & - & - & - & 2.73 & $1.32-5.62$ & 0.007 \\
\hline \multicolumn{7}{|l|}{ CCTA model 1} \\
\hline Luminal stenosis on CCTA: & & & $<0.001$ & & & $<0.001$ \\
\hline No $C A D=$ reference & 1.00 & & & 1.00 & & \\
\hline$<50 \%$ & 1.47 & $0.42-5.22$ & 0.549 & 1.36 & $0.38-4.83$ & 0.637 \\
\hline $50-70 \%$ & 7.25 & $2.27-23.11$ & 0.001 & 6.55 & $2.04-21.02$ & 0.002 \\
\hline$>70 \%$ & 23.98 & $8.10-70.96$ & $<0.001$ & 20.11 & $6.63-60.94$ & $<0.001$ \\
\hline hs-cTnT (In-transformed) & - & - & - & 1.46 & $0.94-2.26$ & 0.090 \\
\hline \multicolumn{7}{|l|}{ CCTA model 2} \\
\hline luminal stenosis on CCTA $>70 \%^{b}$ & 11.33 & $5.98-21.47$ & $<0.001$ & 9.23 & $4.79-17.82$ & $<0.001$ \\
\hline hs-cTnT in Q4 ${ }^{\mathrm{b}}$ & - & - & - & 2.47 & $1.29-4.77$ & 0.007 \\
\hline
\end{tabular}




\section{Discussion}

Our study shows that in patients with stable chest pain suspected for CAD, hs-cTnT was a significant predictor for the composite endpoint of late revascularizations, ACS and cardiac mortality. Over three times as much cardiac events were found in patients with hs-cTnT concentrations in the fourth quartile (cutoff $6.7 \mathrm{ng} / \mathrm{L}, \mathrm{HR} 3.55, \mathrm{P}<0.001$ ) as compared to patients with hs-cTnT concentrations in the lowest three quartiles. Moreover, survival analysis showed that hs-cTnT significantly contributed to the identification of a subgroup of patients with higher risk for cardiac events. When using traditional risk factors, smoking (HR 3.55, P 0.001), hs-cTnT (HR 1.93, P 0.019), and systolic blood pressure (HR 1.02, P 0.048) remained the only significant predictors. Hs-cTnT remained significantly predictive independent from FRS (HR 1.7-3.1, dependent whether variables were continuous or categorized). In addition, hs-cTnT improved classification on top of the extent of CAD as assessed with CCS and CCTA. To illustrate, a 2- to 3-fold increase in cardiac risk was noticed in patients with hs-cTnT concentrations in the highest quartile, independent from high or low CCS (cutoff Agatston score 400) or luminal stenosis on CCTA (cutoff 70\%) (HR 2.73 and 2.47 , both $P$ 0.007).

However, before widespread introduction of hs-cTn as a risk factor, it is of great importance to exclude false-positives. Reichlin et al showed that the positive predictive value of hs-cTnT in diagnosing acute myocardial infarction was only $19 \%$ (cut-off $2 \mathrm{ng} / \mathrm{L}$, limit of detection) or $50 \%$ (cut-off $14 \mathrm{ng} / \mathrm{L}, 99^{\text {th }}$ percentile), while the negative predictive value was nearly perfect $\left(99-100 \%\right.$, dependent on cutoff). ${ }^{3}$ On the other hand, the present study as well as other studies has shown the adverse outcome of elevated hs-cTn on cardiovascular events. ${ }^{6,8-10,16}$ The log-normal reference change values (hours versus weeks) in healthy individuals for a delta increase of hs-cTnT were 85 and 315\%, respectively. ${ }^{17}$ There are no results reported yet on optimal delta cutoffs for the long-term. Based on biological variation, deFilippi et al recently showed that the risk for heart failure or cardiovascular death were 1.7 and 1.8-fold, respectively, when hs-cTnT concentrations increased with $>50 \%$ over two to three years. ${ }^{9}$

Question remains what the underlying pathophysiological mechanisms of elevated hscTnT concentrations in these patients are. Korosoglou et $\mathrm{al}^{13}$ concluded that the presence of non-calcified coronary plaques may result in continuous leakage of cTn, possibly due to 
repetitive micro-embolization of atherosclerotic debris. In our study, we observed a stepwise increase in hs-cTnT concentrations with increasing atherosclerotic plaque burden which supports this explanation. Alternative explanations for cTn leakage which have been supposed are demand ischemia, myocardial ischemia (for example due to coronary vasospasm), direct myocardial damage, chronic renal insufficiency, or myocardial strain because of volume or pressure overload. ${ }^{18}$

Recently, two papers were published which feed the thought that the identification of patients at risk for a cardiovascular event may soon become easier and more accurate using hs-cTnT. ${ }^{8,9}$ Defilippi et al ${ }^{9}$ performed serial measures of hs-cTnT in community-dwelling older adults. They found a significant association between baseline hs-cTnT concentrations, changes in hs-cTnT concentrations and the development of heart failure and cardiovascular death. De Lemos et $\mathrm{al}^{8}$ found an association between increased hs-cTnT and structural heart disease, especially left ventricular hypertrophy, and subsequent risk for all-cause mortality. However, the study by deFilippi was focusing on elderly with a mean age above 70 years, while in the study of de Lemos the vast majority of the population (77\%) consisted of patients with $\mathrm{FRS}<10 \%$. These characteristics are not typical for the patients presenting at the cardiology outpatient department. Therefore, it is not clear from those studies to what extent hs-cTnT would be of incremental value in stable chest pain patients presenting at the cardiology outpatient department. Moreover, the published studies focused on left ventricular hypertrophy and heart failure, respectively. It is not inconceivable that the main cause of the elevated hs-cTnT is the presence of atherosclerosis, because it is known that the majority of patients with heart failure have underlying coronary atherosclerotic disease. ${ }^{19}$ Moreover, hypertension is an important risk factor for atherosclerosis and also the major determinant of left ventricular hypertrophy.

In previous work, we demonstrated that even mild CAD is associated with increased concentrations of hs-cTnT and we suggested that hs-cTnT may become a potential serum biomarker to improve the identification of patients at risk for developing cardiovascular events. ${ }^{12}$ From literature, it is known that the extent of CAD provides important prognostic information in both asymptomatic and symptomatic patients. Both high CCS and $\geq 50 \%$ luminal stenosis on CCTA deprive prognosis significantly. ${ }^{20}$ In this study, we show that measuring hs-cTnT provides additional value on these already strong prognostic parameters. In our opinion, these findings strengthen the hypothesis that hs-cTnT helps to identify the 
patient at risk. Clinically, there is general consensus that a severe coronary stenosis $(>70 \%$ on (CTA) may benefit from interventional procedures. However, less is known about management of patients with mild and moderate stenoses. There is increasing evidence that ACS may be predominantly caused by non-significant stenoses. ${ }^{21} \mathrm{~A}$ biomarker like hs-cTnT might improve risk stratification for cardiac events. However, due to the low event rate in our patient category, we could not prove this. Despite this, when using hs-cTnT, patients at risk for a future cardiovascular event could be better recognized in an early phase at relatively low cost. In patients with high concentrations of hs-cTnT, a more aggressive diagnostic or therapeutic approach may be beneficial to prevent cardiovascular events. These questions need to be addressed in large clinical trials.

This study has several limitations that merit comment. First, the follow-up period is relatively short and therefore we found relatively few events. Second, all patients were of European descent. It remains uncertain whether our results can be generalized to other populations. Third, we performed a single hs-cTnT measurement and it remains unclear in which manner hs-cTnT varies in time.

\section{Conclusion}

Hs-cTnT is a useful prognostic biomarker in patients with stable chest pain suspected for CAD. It appears that hs-cTnT is associated with the extent of CAD, assessed by CCS and CCTA, and that hs-cTnT is a significant predictor for a cardiac event (revascularization, ACS, and cardiac mortality). Even better performance was obtained when hs-cTnT concentrations were combined with Framingham risk profiling. Finally, though to a lesser extent, hs-cTnT also provided additive value to the assessment of CAD by computed tomography.

\section{References}

1. Kaptoge S, Di Angelantonio E, Lowe G, et al. C-reactive protein concentration and risk of coronary heart disease, stroke, and mortality: an individual participant meta-analysis. Lancet. 2010;375:132-140.

2. Wang TJ, Gona P, Larson MG, et al. Multiple biomarkers for the prediction of first major cardiovascular events and death. N Engl J Med. 2006;355:2631-2639.

3. Reichlin T, Hochholzer W, Bassetti S, et al. Early diagnosis of myocardial infarction with sensitive cardiac troponin assays. N Engl J Med. 2009;361:858-867.

4. Keller T, Zeller T, Peetz D, et al. Sensitive troponin I assay in early diagnosis of acute myocardial infarction. N Engl J Med. 2009;361:868-877. 
5. Lindahl $B$, Venge $P$, James $\mathrm{S}$. The new high-sensitivity cardiac troponin $\mathrm{T}$ assay improves risk assessment in acute coronary syndromes. Am Heart J. 2010;160:224-229.

6. Omland T, de Lemos JA, Sabatine MS, et al. A sensitive cardiac troponin $T$ assay in stable coronary artery disease. N Engl J Med. 2009;361:2538-2547.

7. Bonaca $M$, Scirica $B$, Sabatine $M$, et al. Prospective evaluation of the prognostic implications of improved assay performance with a sensitive assay for cardiac troponin I. J Am Coll Cardiol. 2010;55:2118-2124.

8. de Lemos JA, Drazner MH, Omland T, et al. Association of troponin T detected with a highly sensitive assay and cardiac structure and mortality risk in the general population. JAMA. 2010;304:2503-2512.

9. deFilippi CR, de Lemos JA, Christenson RH, et al. Association of serial measures of cardiac troponin $\mathrm{T}$ using a sensitive assay with incident heart failure and cardiovascular mortality in older adults. JAMA. 2010;304:2494-2502.

10. Otsuka T, Kawada T, Ibuki C, Seino Y. Association between high-sensitivity cardiac troponin T levels and the predicted cardiovascular risk in middle-aged men without overt cardiovascular disease. Am Heart J. 2010;159:972-978.

11. Alehagen U, Dahlstrom U, Rehfeld JF, Goetze JP. Prognostic ássessment of elderly patients with symptoms of heart failure by combining high-sensitivity troponin $\mathrm{T}$ and $\mathrm{N}$-terminal pro B-type natriuretic peptide measurements. Clin Chem. 2010;56:1718-1724.

12. Mingels AM, Laufer EM, Winkens $\mathrm{MH}$, et al. The extent of coronary atherosclerosis is associated with increasing circulating levels of high sensitive cardiac troponin T. Arterioscler Thromb Vasc Biol. 2010;30:1269-1275.

13. Korosoglou G, Lehrke S, Mueller D, et al. Determinants of troponin release in patients with stable coronary artery disease: insights from CT angiography characteristics of atherosclerotic plaque. Heart. 2011;97:823-831.

14. Detrano R, Guerci AD, Carr JJ, et al. Coronary calcium as a predictor of coronary events in four racial or ethnic groups. N Engl J Med. 2008;358:1336-1345.

15. Braunwald E, Antman EM, Beasley JW, et al. ACC/AHA 2002 guideline update for the management of patients with unstable angina and non-ST-segment elevation myocardial infarction--summary article: a report of the American College of Cardiology/American Heart Association task force on practice guidelines (Committee on the Management of Patients With Unstable Angina). J Am Coll Cardiol. 2002;40:1366-1374.

16. Kavsak PA, Wang X, Ko DT, MacRae AR, Jaffe AS. Short- and long-term risk stratification using a next-generation, high-sensitivity research cardiac troponin I (hs-cTnl) assay in an emergency department chest pain population. Clin Chem. 2009;55:1809-1815.

17. Vasile VC, Saenger AK, Kroning JM, Jaffe AS. Biological and analytical variability of a novel highsensitivity cardiac troponin T assay. Clin Chem. 2010;56:1086-1090.

18. Thygesen K, Alpert JS, White HD. Universal definition of myocardial infarction. J Am Coll Cardiol. 2007;50:2173-2195.

19. Fox KF, Cowie MR, Wood DA, et al. Coronary artery disease as the cause of incident heart failure in the population. Eur Heart J. 2001;22:228-236.

20. Hadamitzky M, Freissmuth B, Meyer T, et al. Prognostic value of coronary computed tomographic angiography for prediction of cardiac events in patients with suspected coronary artery disease. JACC Cardiovasc Imaging. 2009;2:404-411.

21. Virmani R, Burke AP, Farb A, Kolodgie FD. Pathology of the vulnerable plaque. J Am Coll Cardiol. 2006;47:C13-18. 



\section{CHAPTER 9}

\section{Time- and temperature-dependent stability of NIST standard reference material 2921 in serum and plasma}

Background: Cardiac troponin I (cTnl) immunoassays deviate more than 20-fold in results, limiting laboratory and study comparisons. Recently, well characterized cardiac troponin complex became available, being NIST standard reference material (SRM) 2921. NIST SRM 2921 was used for development of a higher-order reference assay and as model for serum based secondary reference material. However, we previously noticed instability of cTnl results for NIST SRM 2921 in plasma based pools and hypothesize this can be clarified by its susceptibility to fragmentation.

Methods: NIST SRM 2921 was spiked in cTn-negative serum and plasma pools, incubated at 4 and $37^{\circ} \mathrm{C}$, and followed for 3 days. Stability of cTnl and cTnT results was evaluated using Abbott Axsym and Roche immunoassays, respectively. Moreover, fragmentation was characterized applying the original testkit antibodies for immunoprecipitation and Western Blot detection.

Results: cTnl and cTnT assay results remained stable (>90\%) when NIST SRM 2921 based pools were stored at $4^{\circ} \mathrm{C}$. However, results reduced to $50-60 \%$ when samples were incubated for 3 days at $37^{\circ} \mathrm{C}$, except for CTnT in plasma. For cTnl, Western Blot did not reveal fragmentation. For cTnT, Western Blot showed fragmentation in serum but not in plasma, and at $37^{\circ} \mathrm{C}$ a higher extent of fragmentation was confirmed.

Conclusions: We show that NIST SRM 2921 is susceptible to time- and temperaturedependent degradation that affects immunoassay results. For cTnT this appeared in serum but not in plasma, for cTnl another modification in immunogenicity seems to happen. Future research should thus continue to search for a representative and highly defined cTnl standard. 
Standardization and harmonization purposes of cardiac troponin I (cTnl) immunoassays are still uncompleted as recently reviewed ${ }^{1-4}$ and as discussed in the latest National Academy of Clinical Biochemistry guidelines. ${ }^{5}$ The more than $20 \mathrm{cTnl}$ immunoassays that are commercially available deviate more than 20 -fold in assay outcome, which is not an issue for the highly patented CTnT assay. ${ }^{6}$ Each cTnl assay uses different antibodies, calibrators, control materials, and detection techniques, limiting laboratory and multicenter study comparison.

The International Organization for Standardization prescribes the use of a reference measurement system that consists of the following components: (1) a primary standard reference material (SRM) to calibrate a higher-order reference measurement assay; (2) that is used to assign concentrations to secondary reference material, typically with a comparable matrix as the routine samples; (3) that are subsequently used by the manufacturers to assign values to the calibrators of their assay. ${ }^{1,3,7,8}$

SRM 2921 provided by the National Institute of Standards and Technology (NIST) is cardiac troponin complex (cTnT, cTnl, and cTnC) purified from human heart tissue. It has been selected from 10 candidate $\mathrm{SRMs}^{9,10}$ and has extensively been characterized. ${ }^{11}$ Recently, the development of the higher-order reference assay was initiated, ${ }^{1,12,13}$ as well as a Western Blot method to characterize the secondary reference samples. ${ }^{14}$ Here, NIST SRM 2921 spiked in serum was used as model for serum based reference samples. We however showed time-dependent reduction of cTnl levels in NIST SRM 2921 based pools using routine immunoassays. ${ }^{15}$ We expect that this instability of cTnl can be clarified by the susceptibility of cTnl to fragmentation, ${ }^{16,17}$ which will be relevant for future applications of NIST SRM 2921.

In the present study, we characterized the time- and temperature dependent stability of NIST SRM 2921 when spiked in cTn-negative serum and plasma pools during 3 days at 4 and $37^{\circ} \mathrm{C}$. To do so, we performed Western Blot detection against $\mathrm{CTnl}$ and $\mathrm{cTnT}$ using original testkit antibodies. We applied the original Axsym cTnl (Abbott Diagnostics) and cTnT (Roche Diagnostics) capture and detector antibodies, respectively, to optimize comparability between immunoassay and Western Blot results. The incubation at $37^{\circ} \mathrm{C}$ was in the meanwhile a model for the in vivo condition. 


\section{Methods}

Mass spectrometric characterization of NIST SRM 2921

The ESI-MS system used was the 6410 Triple Quad LC/MS (Agilent). The Reversed PhaseHPLC column was the Zorbax 300SB-C18 column (Agilent, $100 \times 2.1 \mathrm{~mm}, 300 \AA$, $3.5 \mu \mathrm{m}$ ). Solvents used were ultrapure $\mathrm{H}_{2} \mathrm{O}$ with $0.1 \% \mathrm{HCOOH}$ and $\mathrm{HPLC}$ grade acetonitrile with $0.1 \%$ $\mathrm{HCOOH}$. Characteristic settings were a flow rate of $0.2 \mathrm{~mL} / \mathrm{min}$, a column temperature of $35^{\circ} \mathrm{C}$, a mass range of $\mathrm{m} / \mathrm{z} 100-1680$ and $20 \mu \mathrm{l}$ of NIST SRM 2921 solution was loaded (Hytest, certified by NIST, cTnT $36.9 \mathrm{mg} / \mathrm{L}, \mathrm{cTnl} 31.2 \mathrm{mg} / \mathrm{L}$ ). Further instrument settings were default. Gradient elution was performed from 2 to $60 \%$ acetonitrile in $30 \mathrm{~min}$. Mass spectra of the cTn were deconvoluted using MagTran (Zhang, Version 1.03).

Incubation of spiked NIST SRM 2921 in cTn-negative serum and plasma pools Serum (Venosafe) and heparin plasma (Lithium heparin, Venosafe) pools were collected from healthy controls (cTnl and $\mathrm{cTnT}<0.02$ and $<0.01 \mu \mathrm{g} / \mathrm{L}$, respectively) and pre-incubated for 12 hours either at $4^{\circ} \mathrm{C}$ or $37^{\circ} \mathrm{C}$. NIST SRM 2921 was spiked 1:1000 (v/v) in the pools in 3

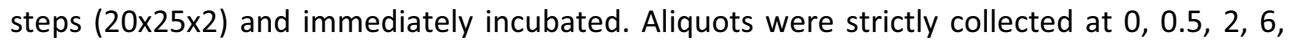
24, 48, and 72 hours. cTnl and cTnT concentrations were immediately measured as specified below, while remaining aliquots were stored at $-80^{\circ} \mathrm{C}$ until Western Blot analysis.

cTnl was measured in duplo on the Axsym analyzer (Abbott Diagnostics) using the Troponin-I ADV assay (2nd generation) with a limit of detection at $<0.02 \mu \mathrm{g} / \mathrm{L}$, measuring range $0.02-22.78 \mu \mathrm{g} / \mathrm{L}, \mathrm{CV} \leq 10 \%$ at $0.16 \mu \mathrm{g} / \mathrm{L}$, and diagnostic cut-off at $0.40 \mu \mathrm{g} / \mathrm{L}$. Since cTnl concentrations were above measuring range, samples were automatically diluted 10x using Solution 4 Line Diluent (0.1 M phosphate buffer). cTnT was measured in duplo on the Cobas 6000 analyzer (Roche Diagnostics) using the 4th generation cTnT assay with a limit of detection at $<0.01 \mu \mathrm{g} / \mathrm{L}$, measuring range $0.01-25.00 \mu \mathrm{g} / \mathrm{L}, \mathrm{CV} \leq 10 \%$ at $0.03 \mu \mathrm{g} / \mathrm{L}$, and $99^{\text {th }}$ percentile cut-off at $0.01 \mu \mathrm{g} / \mathrm{L}$. All assay characteristics were given by the manufacturer.

\section{Immunoprecipitation using cTn testkit antibodies}

Capture cTnl (epitope amino acid residue, a.a.r., 87-91 and 41-49) and cTnT (M11.7, epitope a.a.r. 136-147) antibodies were collected from the commercial Axsym Troponin-I ADV (Abbott) and $4^{\text {th }}$ generation cTnT (Roche) immunoassay, respectively, and treated as follows. For cTnl, capture antibodies were already conjugated to microparticles. For cTnT, $10 \mu \mathrm{g}$ of 
biotinylated M11.7 (1.5 mg/L) was added to $1 \mathrm{~mL}$ of magnetic beads coated with streptavidin (Invitrogen) and incubated for $90 \mathrm{~min}$ at RT. Additionally, beads were crosslinked with dimethyl pimelimidate (3x) as described previously. ${ }^{18}$ Immunoprecipitation was optimized to cTn binding $>90 \%$ (data not shown). Subsequently, $200 \mu \mathrm{L}$ of serum or heparin plasma was incubated with $50 \mu \mathrm{l}$ of beads for 1 hour at $4^{\circ} \mathrm{C}$. After being washed, the immunoprecipitate was eluted with $1 \mathrm{M}$ glycine, $\mathrm{pH} 3$ for $15 \mathrm{~min}$ at $56^{\circ} \mathrm{C}$.

\section{Western Blot using cTn testkit antibodies}

Immunoprecipitates were mixed with 4x XT Sample Buffer (Bio-Rad) and 20x Reducing Agent (Bio-Rad), heated for $5 \mathrm{~min}$ at $95^{\circ} \mathrm{C}$, and separated on a $12 \%$ Criterion XT SDS-PAGE gel (BioRad) together with the Precision Plus Protein Standard (Bio-Rad). After transfer to the nitrocellulose membrane (Bio-Rad, $0.45 \mu \mathrm{m}$ ), blots were treated using the vacuum SNAP i.d. protein detection system (Millipore) according to manufacturer instructions. Block buffer was $0.5 \%$ non-fat dry milk Blocking-Grade Blocker (Bio-Rad) in PBS, 0.1\% Tween-20 (PBST). Primary anti-cTnl solution was $1.5 \mu \mathrm{g} / \mathrm{mL}$ Troponin-I ADV (Abbott, epitope a.a.r. 24-40) diluted 1:1 with PBST, primary anti-cTnT solution was $10 \mu \mathrm{g} / \mathrm{mL}$ Roche M7 (as kindly provided by Roche Diagnostics, epitope a.a.r. 125-131), primary anti-cTnC solution was 2 $\mu \mathrm{g} / \mathrm{mL}$ (Hytest), both in PBST. Secondary antibody solution for cTnl was streptavidin-HRP (R\&D systems) 200-fold diluted, secondary antibody solution for cTnT and cTnC was 0.4 $\mu \mathrm{g} / \mathrm{mL}$ goat anti-mouse peroxidase (Dako), all in PBST. Subsequently, membranes were incubated for 5 minutes in Super Signal West Femto Substrate (Thermo Scientific) and exposure was detected using the ChemiDoc XRS scanner (Bio-Rad). Bands were quantified using Quantity One software (Bio-Rad, Version 4.6.5.).

\section{Results}

Validation of NIST SRM 2921 by Western Blot using cTn testkit antibodies

Western Blot detection against CTnT in NIST SRM 2921 estimated intact and degraded cTnT at approximately 40 and $29 \mathrm{kDa}$, respectively (Figure 1). In comparison, mass spectrometry measured MWs of 34.5 and $26.8 \mathrm{kDa}$, respectively. The relative intensities were 81 and 19\%, respectively, as based on the peak areas of the LC chromatogram.

Western Blot detection against cTnl identified 2 cTnl molecules in NIST SRM 2921 of approximately 28 and $25 \mathrm{kDa}$, with relative band intensities of 64 and 36\%, respectively. 
Deconvolution of cTnl mass spectra identified besides intact cTnl of $23.9 \mathrm{kDa}$ also degraded cTnl of 23.7 and $23.6 \mathrm{kDa}$, all coeluting in one peak and thereby limiting estimation of relative abundance.

A

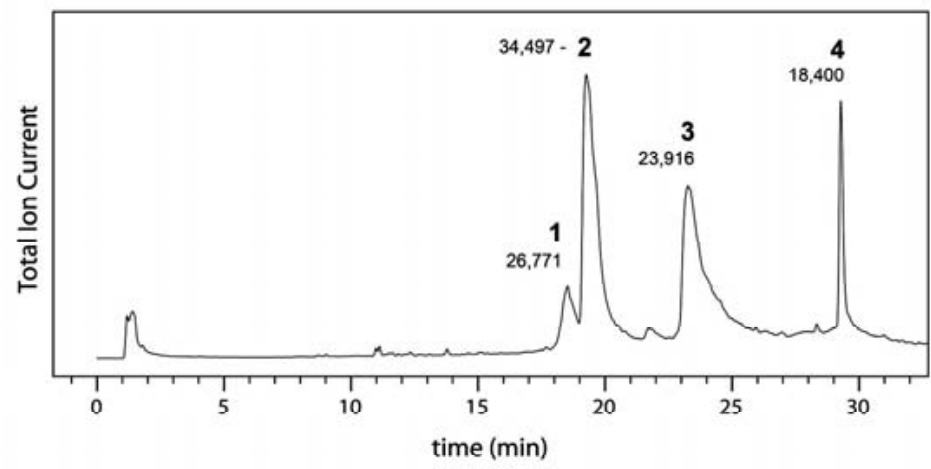

B $\quad$ CTnT WB

cTnI WB

cTnC WB

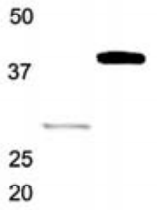

50

50

37

37

\section{5}

20

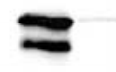

15

15

$\begin{array}{lllll}M & 1 & 2 & 3 & 4\end{array}$

$\begin{array}{lllll}M & 1 & 2 & 3 & 4\end{array}$

$\begin{array}{lllll}M & 1 & 2 & 3 & 4\end{array}$

Figure 1: Validation of NIST SRM 2921 by Western Blot using cTn testkit antibodies. Reversed PhaseHPLC separation was followed by (A) mass spectrometry or (B) fractionation and subsequent Western Blot against cTnT (Roche detector antibody), cTnl (Axsym detector antibody), and for comparison also against cTnC (Hytest). In the chromatogram are indicated the MWs (Da) as measured with LCMS. M, MW marker.

\section{Incubation study}

NIST SRM 2921 remained stable for at least 3 days when spiked in pooled cTn-negative serum or heparin plasma and stored at $4^{\circ} \mathrm{C}$, as based on the assay results of the Axsym cTnl and $\operatorname{cTnT}\left(4^{\text {th }}\right.$ gen) assays (Figure 2 and 3, top). In contrast, when stored for 3 days at $37^{\circ} \mathrm{C}$, Figure 2 shows a gradual decrease for cTnl in serum (59\%) and plasma (53\%). Figure 3 shows a reduction of $\mathrm{cTnT}$ results in serum at $37^{\circ} \mathrm{C}(59 \%)$, but not that much in plasma (87\%).

Western Blot analysis using the Axsym antibodies shows no time-dependent degradation of cTnl in NIST SRM 2921, when spiked in serum or heparin plasma, and stored 
NIST SRM 2921

spiked in serum
NIST SRM 2921

spiked in hep plasma

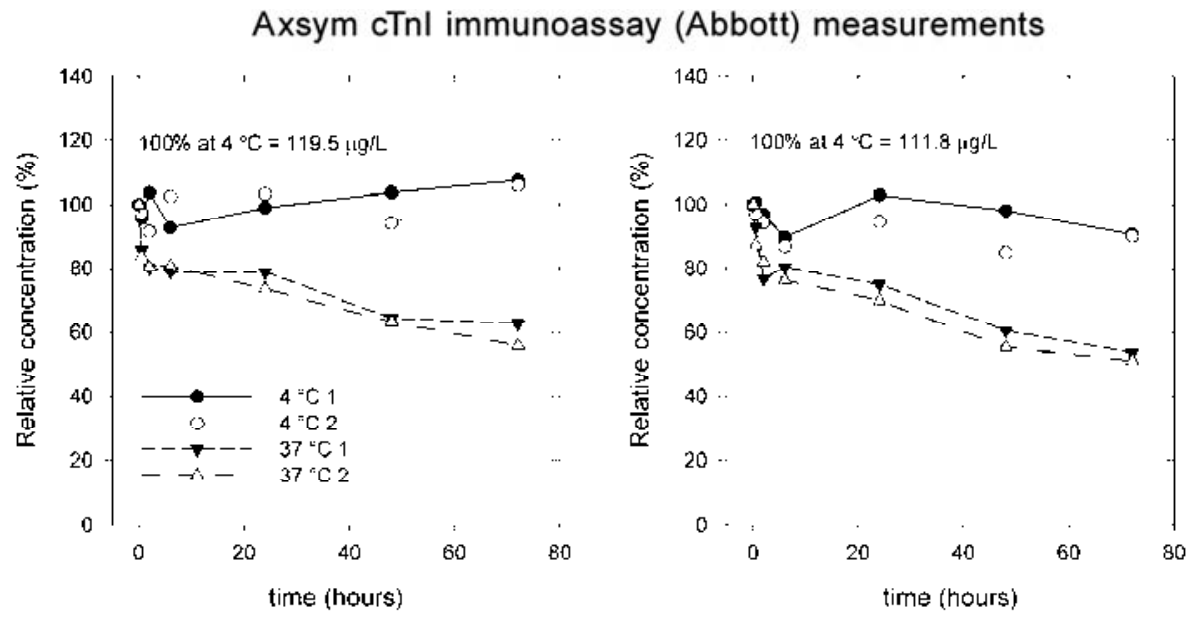

cTnl Western Blot (Axsym abs) - incubation at $4^{\circ} \mathrm{C}$
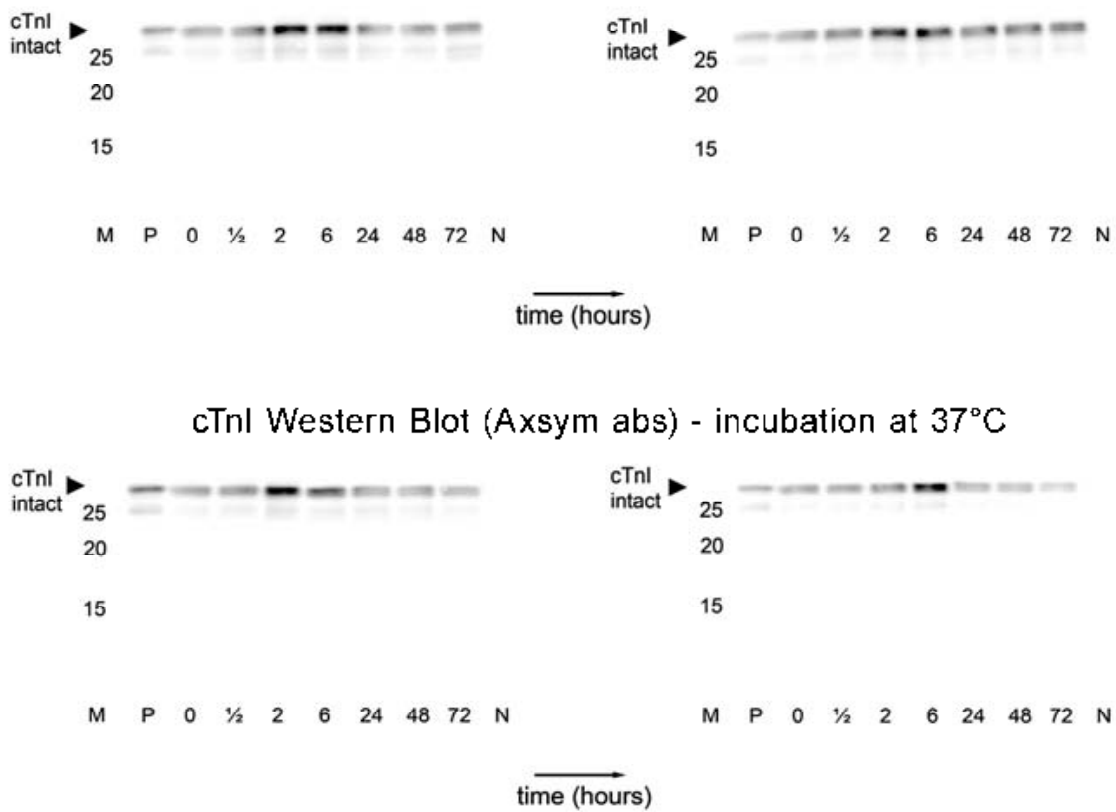

Figure 2: Stability of cTnl in NIST SRM 2921 when spiked in pooled cTn-negative serum and heparin plasma, respectively. Top: Relative concentrations (mean) compared to time zero as measured with the Axsym cTnl assay (Abbott) $(n=2)$; Bottom: Samples also underwent immunoprecipitation and Western Blot using the Axsym testkit antibodies. M, MW marker; $\mathrm{P}$, loading control NIST spiked 1:400 in SDS buffer; N, cTn-negative serum incubated for 72 hours. MW $_{\text {estimated }}$ of the bands was 28 and $25 \mathrm{kDa}$, respectively. 
NIST SRM 2921
spiked in serum

cTnT immunoassay (Roche, 4th gen) measurements

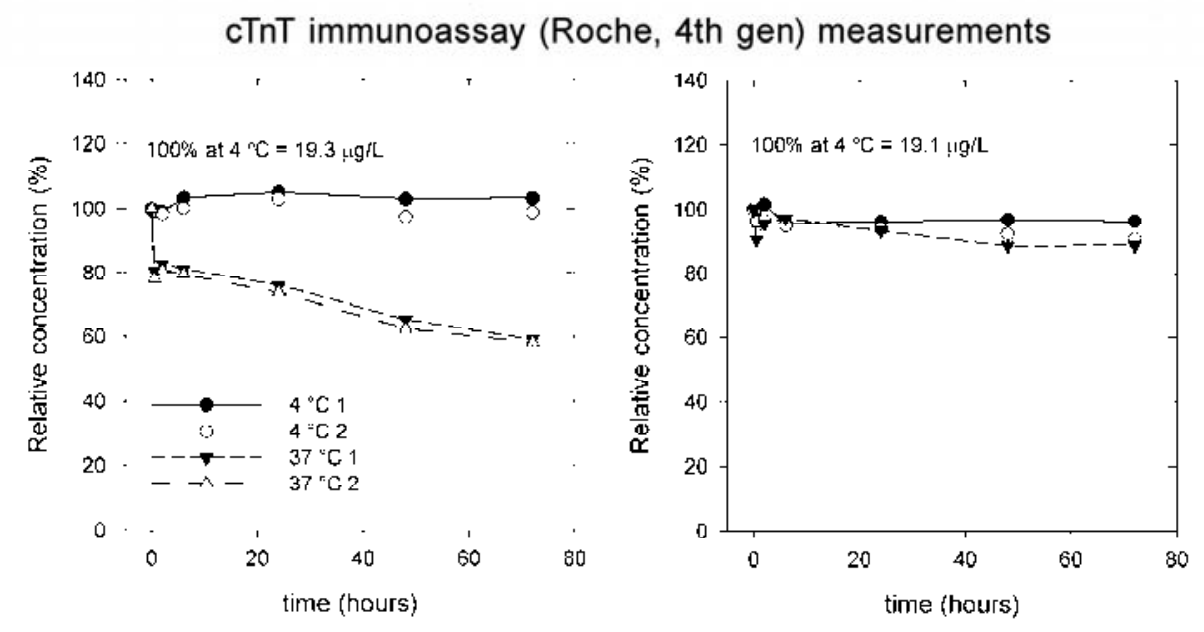

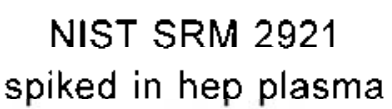

spiked in hep plasma
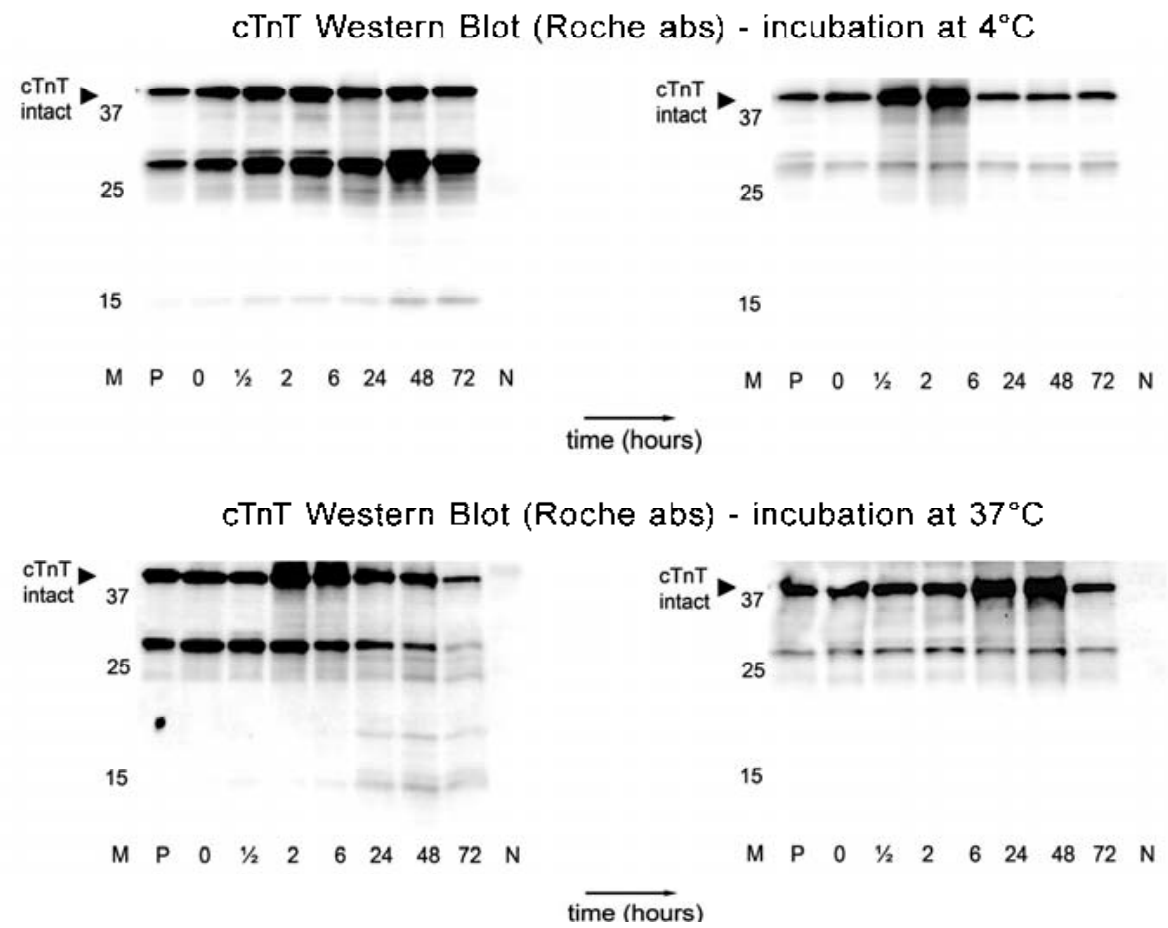

Figure 3: Stability of cTnT in NIST SRM 2921 when spiked in pooled cTn negative serum and heparin plasma, respectively. Top: Relative concentrations (mean) compared to time zero as measured with the $4^{\text {th }}$ generation cTnT assay (Roche) $(n=2)$; Bottom: Samples also underwent immunoprecipitation and Western Blot using the Roche testkit antibodies. M, MW marker; P, loading control NIST spiked 1:400 in SDS buffer; N, cTn-negative serum incubated for 72 hours. MW estimated $_{\text {of }}$ the bands was 40, 29,19 , and $16 \mathrm{kDa}$, respectively. 
at 4 or $37^{\circ} \mathrm{C}$ (Figure 2). However, Western Blot detection reveals that cTnT in NIST SRM 2921 was susceptible to fragmentation when spiked in serum and stored at $4^{\circ} \mathrm{C}$ (Figure 3). Also, the 29 and $16 \mathrm{kD}$ band showed after 3 days a 2.9- and 4.4-fold increase, respectively, compared to time zero. In heparin plasma no time-dependent degradation of cTnT was noticed, either at 4 or $37^{\circ} \mathrm{C}$ (Figure 3). When stored at $37^{\circ} \mathrm{C} \mathrm{cTnT}$ degradation in serum was noticed to an ever higher extent. Here, only $15 \%$ was present of the 40 and 29 kD band after 3 days as compared to time zero, while the 19 and $16 \mathrm{kD}$ band showed a 1.9 and 5.2-fold increase, respectively, as compared to time zero. Notice that the blots depicted in Figure 3 were overexposed, but this was required to visualize the appearance of cTnT fragments.

\section{Discussion}

In the present study, cTnl and cTnT in NIST SRM 2921 remained stable (relative concentration $>90 \%$ ) when spiked in cTn-negative pooled serum or heparin plasma at $4^{\circ} \mathrm{C}$, as based on the Axsym cTnl (Abbott) and $4^{\text {th }}$ generation cTnT (Roche) immunoassay results. When incubated at $37^{\circ} \mathrm{C}$, however, Axsym immunoassay results showed a time-dependent decline. Since no time-dependent fragmentation was detected on Western Blot using the original testkit antibodies, this needs to be clarified by another modification in cTnl immunogenicity. For cTnT, Western Blot analysis revealed time-dependent fragmentation even at $4^{\circ} \mathrm{C}$. Instability of cTnT in NIST SRM 2921 was even more obvious when incubated at $37^{\circ} \mathrm{C}$, which now went along with a decline in immunoassay results.

For cTnl in NIST SRM 2921 yet an unknown modification other than fragmentation should clarify the instability of cTnl immunoassay results. It might be expected that our observation holds for most of the available cTnl assays, since most current cTnl manufacturers chose two or three antibodies that are directed against the stable mid region of amino acid $30-110 .^{2,19}$ So, although cTnl proteolysis has been extensively described ${ }^{16,17}$ this should not affect the assay outcome of most of the cTnl immunoassays anymore. The capture $(2 \mathrm{x})$ and detector $(1 \mathrm{x})$ antibodies of the Axsym cTnl assay are indeed almost similar to the other cTnl assays, although in different combinations of capture and detector antibodies, or with two similar antibodies possibly combined with a different third cTnl antibody. 2,19

It has to be noticed, however, that the stability of cTnI in the NIST SRM 2921 based pools stored at $4^{\circ} \mathrm{C}$ (with a 1000 -fold dilution) was higher in the present Western blot study 
as compared to the previous 6171 -fold dilution (heparin plasma only). ${ }^{15}$ This discrepancy is thought to be related to the fact that we now pre-incubated the cTn-negative pools for 12 hours at $4^{\circ} \mathrm{C}$ before spiking, thereby limiting possible modification processes.

When spiked in serum, cTnT in NIST SRM 2921 appeared to be susceptible to timedependent degradation whereas in heparin plasma it remained stable. The latter can likely be clarified by the protease inactivation in plasma. Harmonization of cTnT assays is of course not an issue because of patent reasons, but when using NIST SRM 2921 for EQA-surveys it seems preferable to use plasma.

Nevertheless, it remains questionable whether highly purified cTn, like NIST SRM 2921, is representative for native samples of acute coronary syndrome (ACS) patients. We previously showed that CTnT in serum was degraded after acute myocardial infarction, ${ }^{20}$ while others showed this for $\mathrm{cTnl}^{16,17}$ Since the extent of $\mathrm{cTn}$ degradation turned out to be dependent on sample time collection after the ischemic event, this indicates that cTn degradation happens intracellularly in myocytes. These studies were critized, though, because they performed Western Blot detection with antibodies different from the ones used in the commercial testkits. ${ }^{21,22}$ Nowadays, both cTnl and cTnT assays use antibodies directed against stable mid regions. Still, the present study reveals for the first time that the original Roche antibodies detect intact cTnT as well as degraded cTnT molecules of approximately 29, 19, and $16 \mathrm{kDa}$. Moreover, we showed that (part of the) proteases targeting cTnT are still active in serum but not in heparin plasma. Apart from this, we previously reported better stability of cTnl and cTnT assay results in plasma of ACS patients than in plasma with spiked NIST SRM 2921. ${ }^{15}$ This all suggests that modification processes might already be completed for native cTn in patient blood, in contrast to the intact NIST SRM 2921 that is extracted from human heart tissue. In line with this hypothesis, harmonization of $7 \mathrm{cTnl}$ assays also turned out to be independent whether serum samples were collected before or after 48 hours post onset of ACS. ${ }^{23}$ Overall, it seems that the molecular structures of cTnT and cTnl in patients differ from the one in NIST SRM 2921 and this should be considered in the effort to harmonization and standardization of cTnl assays.

To date, standardization and harmonization of cTnl methods remains ongoing. First of all, standardization cannot be achieved as long as there is no clear definition for the cTnl measurand. ${ }^{24,25}$ NIST SRM 2921 was proposed as harmonizer, ${ }^{9,11}$ but was disappointing in calibrating cTnl immunoassays, ${ }^{10}$ and is nowadays proposed as primary reference material to 
assign values to serum based secondary reference material. ${ }^{1-4}$ To develop the whole reference measurement system, NIST SRM 2921 was also used as model for cTnl positive serum samples. ${ }^{13,14}$ In the present study, however, we show that it appears not to be stable in matrix based pools, in part because of susceptibility to fragmentation. Secondly, as discussed above, previous studies question its resemblance with native cTn in the blood circulation of patients.

For the time being, cTnl harmonization could be achieved by correcting results from a particular cTnl assay to the overall mean of cTnl assay results. This reduced the interlaboratory CV for CTnl results from $82-97 \%$ to $7-28 \% .{ }^{10}$ However, the disadvantage is that the overall mean varies continuously, depending on the cTnl methods in use in the laboratories. Therefore, based on the harmonization potential and stability ${ }^{15}$ issues, it seems preferable to use patient material for cTnl harmonization purposes, despite the fact that collection of patient material is limited, as is the reproducibility of its processing.

In conclusion, we show that the highly characterized NIST SRM 2921 when spiked into human matrices is susceptible to time- and temperature-dependent degradation that also affects immunoassay outcomes. For cTnl not fragmentation, but another modification in immunogenicity seems to occur both in serum and plasma, while cTnT fragmentation appears to happen in serum but not in plasma. Nevertheless, future research should continue to search for a representative and highly defined cTnl standard, enabling manufacturers to correctly standardize their immunoassay.

\section{Limitations}

Stability studies were performed with cTnl and $\mathrm{cTnT}$ concentrations in the upper range of physiological concentrations (cTnl $119.5 \mu \mathrm{g} / \mathrm{L}$; $\mathrm{cTnT} 19.3 \mu \mathrm{g} / \mathrm{L}$ ) to ensure detection on Western Blot, especially regarding the Roche detector antibody (M7). Also, for simplicity reasons, only the Axsym cTnl assay was considered.

\section{References}

1. Panteghini M, Bunk DM, Christenson RH, et al. Standardization of troponin I measurements: an update. Clin Chem Lab Med. 2008;46:1501-1506.

2. Panteghini M. Assay-related issues in the measurement of cardiac troponins. Clin Chim Acta. 2009;402:88-93.

3. Tate JR, Bunk DM, Christenson RH, et al. Standardisation of cardiac troponin I measurement: past and present. Pathology. 2010;42:402-408. 
4. Tate JR. Troponin revisited 2008: assay performance. Clin Chem Lab Med. 2008;46:1489-1500.

5. Apple FS, Jesse RL, Newby LK, et al. National Academy of Clinical Biochemistry and IFCC committee for standardization of markers of cardiac damage laboratory medicine practice guidelines: analytical issues for biochemical markers of acute coronary syndromes. Clin Chem. 2007;53:547-551.

6. Panteghini M, Pagani $\mathrm{F}$, Yeo $\mathrm{KT}$, et al. Evaluation of imprecision for cardiac troponin assays at low-range concentrations. Clin Chem. 2004;50:327-332.

7. Bunk DM. Reference materials and reference measurement procedures: an overview from a national metrology institute. Clin Biochem Rev. 2007;28:131-137.

8. Panteghini M. Traceability, reference systems and result comparability. Clin Biochem Rev. 2007;28:97-104.

9. Christenson RH, Duh SH, Apple FS, et al. Standardization of cardiac troponin I assays: round Robin of ten candidate reference materials. Clin Chem. 2001;47:431-437.

10. Christenson RH, Duh SH, Apple FS, et al. Toward standardization of cardiac troponin I measurements part $\mathrm{II}$ : assessing commutability of candidate reference materials and harmonization of cardiac troponin I assays. Clin Chem. 2006;52:1685-1692.

11. Bunk DM, Welch MJ. Characterization of a new certified reference material for human cardiac troponin I. Clin Chem. 2006;52:212-219.

12. (IFCC) IFoCCaLM. Working Group for Standardisation of Troponin I (WG-TNI). Available at: http://www.ifcc.org/PDF/ScientificActivities/IFCC_Troponin_Table_vDec_2010_FINAL_ng_L_28Ja n11.pdf. Accessed June 10th, 2011.

13. Noble JE, Bunk DM, Christenson RH, et al. Development of a candidate secondary reference procedure (immunoassay based measurement procedure of higher metrological order) for cardiac troponin I: I. Antibody characterization and preliminary validation. Clin Chem Lab Med. 2010;48:1603-1610.

14. He HJ, Lowenthal MS, Cole KD, Bunk D, Wang L. An immunoprecipitation coupled with fluorescent Western blot analysis for the characterization of a model secondary serum cardiac troponin I reference material. Clin Chim Acta. 2011;412:107-111.

15. Cobbaert CM, Weykamp CW, Michielsen EC, Baadenhuijsen H, van Dieijen-Visser MP. Timedependent instability of cardiac troponins in human plasma spiked with NIST reference material 2921. Clin Chem. 2008;54:2078-2079.

16. Labugger R, Organ L, Collier C, Atar D, Van Eyk JE. Extensive troponin I and T modification detected in serum from patients with acute myocardial infarction. Circulation. 2000;102:12211226 .

17. Katrukha AG, Bereznikova AV, Filatov VL, et al. Degradation of cardiac troponin I: implication for reliable immunodetection. Clin Chem. 1998;44:2433-2440.

18. Michielsen EC, Diris JH, Hackeng CM, Wodzig WK, Van Dieijen-Visser MP. Highly sensitive immunoprecipitation method for extracting and concentrating low-abundance proteins from human serum. Clin Chem. 2005;51:222-224.

19. International Federation of Clinical Chemistry and Laboratory Medicine (IFCC) Committee on the Standardization of Markers of Cardiac Damage (C-SMCD). Troponin assay analytical characteristics. Available at:

http://www.ifcc.org/PDF/ScientificActivities/IFCC_Troponin_Table_vDec_2010_FINAL_ng_L_28Ja n11.pdf. Accessed 11 June 2011.

20. Michielsen EC, Diris JH, Kleijnen VW, Wodzig WK, Van Dieijen-Visser MP. Investigation of release and degradation of cardiac troponin T in patients with acute myocardial infarction. Clin Biochem. 2007; 40:851-855.

21. Fahie-Wilson MN, Carmichael DJ, Delaney MP, Stevens PE, Hall EM, Lamb EJ. Cardiac troponin T circulates in the free, intact form in patients with kidney failure. Clin Chem. 2006;52:414-420.

22. Bates KJ, Hall EM, Fahie-Wilson MN, et al. Circulating immunoreactive cardiac troponin forms determined by gel filtration chromatography after acute myocardial infarction. Clin Chem. 2010;56:952-958. 
23. Tate JR, Heathcote $D$, Koerbin $G$, et al. The harmonization of cardiac troponin I measurement is independent of sample time collection but is dependent on the source of calibrator. Clin Chim Acta. 2002;324:13-23.

24. Panteghini M. Standardization of cardiac troponin I measurements: the way forward? Clin Chem. 2005;51:1594-1597.

25. Panteghini M. Traceability as a unique tool to improve standardization in laboratory medicine. Clin Biochem. 2009;42:236-240. 


\section{Circulating cardiac troponin $\mathrm{T}$ is degraded after acute myocardial}

\section{infarction}

Abstract: Despite cardiac troponins (cTn) are the preferred biomarkers to diagnose an acute myocardial infarction (AMI), their structures in the circulation are not correctly understood yet. We and others previously showed cTnT and cTnl degradation in patient sera but this was disputed because of antibody differences with the commercial immunoassays. Recently, it was reported by using gel filtration chromatography that cTnT in serum is predominantly intact and free and cTnl is present in complex with cTnC. However, non-denaturing separation data should always be interpreted with great care. In the present study, after extensive calibration of the above condition complemented with Western Blot detection using the commercial antibodies, we evidently proved that cTnT in AMI serum as measured with the 4th generation CTnT assay is completely degraded into smaller fragments. Furthermore, cTnl was only partly degraded and we confirmed that cTnl is mainly in complex with cTnC. The clinical impact of the present study is dependent on the validation study in a larger patient population, but might have immense consequences for CTnT assay calibration and the interpretation of clinical results, especially when disease specific modifications patterns will be identified. 
Despite the fact that cardiac troponins (cTn) are the preferred biomarkers to diagnose and monitor an acute myocardial infarction (AMI), ${ }^{1-3}$ their structural aspects in the blood circulation are not correctly understood yet. We previously showed that circulating CTnT is completely degraded in hemodialysis patients ${ }^{4}$ and in patients after AMI. ${ }^{5}$ However, these and other $\mathrm{cTnT}$ and $\mathrm{cTnl}$ degradation results ${ }^{5-9}$ were disputed because the antibodies of the commercial immunoassays were different from the ones used for Western Blot detection. ${ }^{10}$ In contrast, Fahie-Wilson et al reported that the predominant form of cTnT is intact free, unbound $\mathrm{cTnT}$ in patients with kidney failure ${ }^{11}$ and similar results were very recently found in serum of patients after AMI. ${ }^{10}$ They did not found any evidence for the presence of smaller molecular forms of cTn in the circulation. Like described previously, ${ }^{12}$ they used gel filtration chromatography (GFC) to study the non-covalent complexation of cTn in serum. However, since GFC separation takes place under non-denaturing conditions, molecular weight assignment of cTn elution profiles should not be based solely on the molecular weights of globular protein calibrators. This is especially important for elongated structures like cTnT as we discussed before. ${ }^{13,14}$

Correct understanding of the structural aspects of cTn might possibly assist in unraveling the pathophysiology of cTn release from damaged myocytes. In the past it has been hypothesized that during ischaemia cytosolic cTn are released relatively fast from myocytes in the intact form ( $<1$ day after onset of symptoms), while the slower necrotic and proteolytic degradation is required to liberate cTn bound to the contractile apparatus. ${ }^{15}$ The cytosolic pool of both cTnT and cTnl is estimated to be $5-10 \%$ of the total cTn content as based on solubility studies of myocardial tissue, ${ }^{15,16}$ though has been criticized. ${ }^{17,18}$ In comparison, under milder ischemic conditions like after prolonged exercise it has been proposed that cTn elevations could lead to the release of only intact cytosolic cTn, the so called reversible damage. ${ }^{19}$

Moreover, it would be of great clinical importance to know which molecular cTn structure(s) exactly react with the commercial cTnT and cTnl immunoassays. Degradation and other immunogenic modifications might affect the harmonization and standardization purposes of the different $\mathrm{cTnl}$ immunoassays. ${ }^{2,20}$ Furthermore, in case modification patterns are disease specific, it might even affect the interpretation of elevated cTn concentrations in routine work-up in the clinics. 
In the present pilotstudy, we investigated the molecular structures of cTn circulating in patient blood after AMI. Non-covalent complexation of cTn proteins in serum was studied using GFC as illustrated in Figure 1. The subsequent fractions were analyzed by cTnT (Roche Diagnostics) and cTnl (Axsym, Abbott Diagnostics) immunoassays and Western Blot detection with antibodies similar to the ones used in the commercial assays.

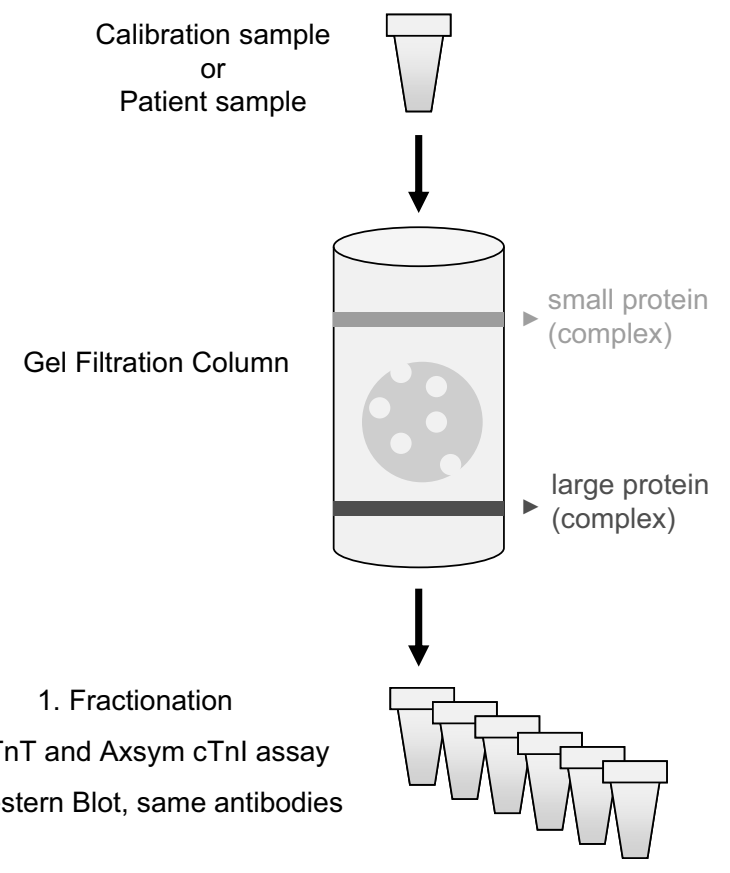

Figure 1: Schematic presentation of study design.

\section{Methods}

Samples analyzed by gel filtration chromatography

Purified human cTn complex (Hytest) and purified free cTnT, cTnl, and cTnC (all Advanced Immunochemical) were dissolved as prescribed by the manufacturer and characterized with LCMS as described in chapter 9. Subsequently, samples were diluted in running buffer to 17.5 $\mathrm{mg} / \mathrm{L}$ (theoretically). When being spiked in cTn negative pooled serum (cTnT and $\mathrm{cTnl}<0.01$ $\mu \mathrm{g} / \mathrm{L}), \mathrm{cTn}$ complex was diluted to $\mathrm{cTnT} 22.1 \mu \mathrm{g} / \mathrm{L}$ and $\mathrm{cTnl} 168.6 \mu \mathrm{g} / \mathrm{L}$, free $\mathrm{cTnT}$ was diluted to $\mathrm{CTnT} 19.9 \mu \mathrm{g} / \mathrm{L}$, and free $\mathrm{cTnl}$ was diluted to $\mathrm{cTnl} 97.2 \mu \mathrm{g} / \mathrm{L}$ (all measured). 
A series of serum samples was collected in the routine lab of an AMI patient (female, 84 years). The diagnosis at presentation at the emergency department was ST-elevated myocardial infarction with inferior and right ventricular infarctions. The patient was treated in the right coronary artery with $\mathrm{PCl}$ and 2 stents. Biomarkers measured during clinical work-up are depicted in Table 1 indicating a typical release curve for AMI.

Table 1: Release curves CK and CTnT during clinical work-up of the selected AMI patient.

\begin{tabular}{lccccccccccc}
\hline Time, days* & 0.12 & 0.34 & 0.58 & 0.90 & 1.69 & 1.91 & 2.91 & 3.93 & 4.80 & 7.57 & 8.00 \\
\hline CK, U/L & 705 & 2595 & 4042 & 3697 & 1667 & 1250 & 289 & 120 & 122 & 47 & 60 \\
CTnT, $\mu \mathrm{g} / \mathrm{L}$ & 1.53 & 9.26 & n.d. & n.d. & 23.12 & 21.07 & n.d. & n.d. & n.d. & n.d. & 5.15 \\
\hline
\end{tabular}

* Time after onset of symptoms

n.d. not determined

\section{Fractionation by gel filtration chromatography (GFC)}

Gel filtration chromatography (GFC) was performed on a HP 1100 system (Agilent) equipped with a Sephacryl-S100 column (GE Healtcare, $1.6 \times 60 \mathrm{~cm}$ ) and a diode array detector. The column was equilibrated with $0.26 \mathrm{~mol} / \mathrm{L} \mathrm{NaCl}, 2.5 \mathrm{mmol} / \mathrm{L} \mathrm{CaCl}_{2} \cdot 2 \mathrm{H} 2 \mathrm{O}, 0.02 \mathrm{~mol} / \mathrm{L}$ Tris, 6 $\mathrm{mmol} / \mathrm{L} \mathrm{NaN}_{3}$, and $1 \mathrm{~g} / \mathrm{L}$ bovine serum albumin buffer, $\mathrm{pH} 7.4^{10}$ and operated at $0.5 \mathrm{~mL} / \mathrm{min}$. The void volume $\left(\mathrm{V}_{0}\right)$ determination and calibration was performed using the Gel Filtration Calibration kit (GE Healthcare) by applying Dextran Blue (2000 kDa) and conalbumin (75.0 $\mathrm{kDa})$, ovalbumin (43.0 kDa), carbonic anhydrase (29.0 kDa), and ribonuclease (13.7 kDa) supplemented with myoglobin (Sigma, $16.9 \mathrm{kDa})$. Dextran Blue $(1 \mathrm{mg} / \mathrm{mL}$ ) and protein standards (3-4 mg/mL) were dissolved in running buffer, $0.5 \mathrm{~mL}$ was loaded on the column, and absorbance was studied at $280 \mathrm{~nm}$, all in duplo. $V_{0}$ was determined in duplo (mean for batch in Figure 3 and 4 was 39.0 and $37.3 \mathrm{~mL}$, respectively). For the serum samples, $1.0 \mathrm{~mL}$ was loaded on the column. For each sample loaded, fractions of $1.25 \mathrm{~mL}$ were collected and kept on ice until immunoassay measurements or storage at $-80^{\circ} \mathrm{C}$.

\section{Characterisation of GFC fractions by immunoassays}

cTnT was measured on the Elecsys 2010 (Roche Diagnostics) using the $4^{\text {th }}$ generation cTnT assay with the limit of detection $<0.01 \mu \mathrm{g} / \mathrm{L}$ and coefficient of variation (CV) $10 \%$ cutoff at $0.03 \mu \mathrm{g} / \mathrm{L}$. cTnl was measured on the Axsym (Abbott) using the Troponin-I ADV assay with CV $<10 \%$ from $0.27-4.00 \mu \mathrm{g} / \mathrm{L}$. NT-proBNP was also measured on the Elecsys 2010 with limit of 
detection $0.6 \mathrm{pmol} / \mathrm{L}$ and inter-assay CV $6.8 \%$ at $8.78 \mathrm{pmol} / \mathrm{L}$. Albumin was measured on the Synchron LX20 (Beckman Coulter) using the microalbumin assay with measuring range 2.0$970 \mathrm{mg} / \mathrm{L}$. All assay characteristics were given by the manufacturer.

\section{Immunoprecipitation and Western Blot detection of the GFC fractions of the AMI patient}

Catcher cTnl (epitope amino acid residue, a.a.r., 87-91 and 41-49) and cTnT (M11.7, epitope a.a.r. 136-147) antibodies were collected from the commercial Axsym Troponin-I ADV (Abbott) and $4^{\text {th }}$ generation CTnT (Roche) immunoassay, respectively. The subsequent preparation of the cTnT and cTnl antibody conjugated beads was performed as described in chapter 9. Next, 200 to $1000 \mu \mathrm{L}$ of the GFC fractions (dependent on the cTn concentration) were precipitated with $50 \mu \mathrm{L}$ of anti-cTnT or anti-cTnl coated beads for 1 hour at $4^{\circ} \mathrm{C}$. After being washed, the immunoprecipitate was eluted with $1 \mathrm{M}$ glycine, $\mathrm{pH} 3$ for $15 \mathrm{~min}$ at $56^{\circ} \mathrm{C}$ for cTnT or for $5 \mathrm{~min}$ at $95^{\circ} \mathrm{C}$ for cTnl.

Western Blot detection against cTnT, cTnl, and cTnC were performed as described in chapter 9. In short, the primary antibody solutions were $1.5 \mu \mathrm{g} / \mathrm{mL}$ Troponin-I ADV reagent 3 (Abbott, epitope a.a.r. 24-40) diluted 1:1 with 0.1\% PBS-Tween 20 (PBST), $10 \mu \mathrm{g} / \mathrm{mL}$ Roche M7 (as kindly provided by Roche Diagnostics, epitope a.a.r. 125-131) in PBST, and $2 \mu \mathrm{g} / \mathrm{mL}$ anti-cTnC (Hytest, 7B9) in PBST, respectively.

\section{Results}

Figure 2 illustrates the high purity of the commercially purified human cTn complex (A) and the free $c \operatorname{TnT}(B), c T n l(C)$, and TnC (D). Most abundant masses were assigned to intact cTnT ( $\left.\mathrm{MW}_{\text {measured }} 34.5 \mathrm{kDa}\right)$, cTnl ( $\left.\mathrm{MW}_{\text {measured }} 23.9 \mathrm{kDa}\right)$, and $\mathrm{cTnC}\left(\mathrm{MW}_{\text {measured }} 18.4 \mathrm{kDa}\right)$, as based on the expected masses (cTnT, UniProtKB ID P45379, 35.9 kDa; cTnl, UniProtKB ID P19429, 24.0 kDa; cTnC, UniProtKB ID P63316, 18.4 kDa). Similar masses were measured for the free unbound cTn, except for cTnl with $\mathrm{MW}_{\text {measured }} 23.6 \mathrm{kDa}$. Furthermore, 13 and $11 \%$ of cTnT in the cTn complex and free cTnT, respectively, were degraded to $26.8 \mathrm{kDa}$ as based on quantification of the peak area in the LCMS chromatogram (shoulder cTnT peak in Figure 2A and B).

When purified cTn complex was separated by gel filtration chromatography (GFC), as depicted in Figure 3A, the elution profiles of cTnT and cTnl overlapped (peak at 2-3 mL). On the contrary, when the free purified cTns were loaded (one after the other) cTnT and cTnI 

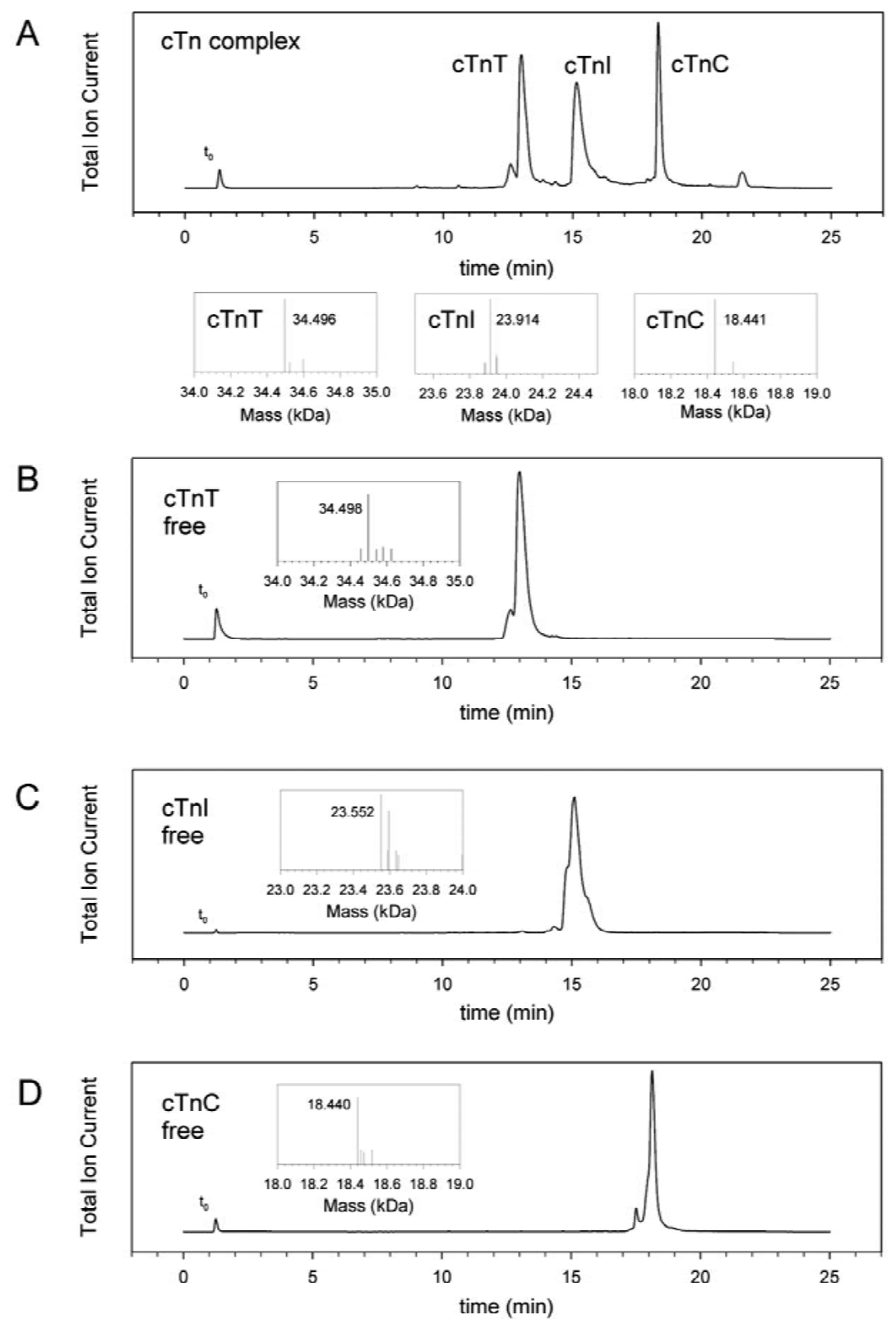

Figure 2: LCMS chromatogram of purified human cTn complex (A), free $\mathrm{CTnT}$ (B), cTnl (C), and cTnC (D) using Reversed Phase-HPLC gradient separation from $2 \%$ to $60 \%$ acetonitrile in $15 \mathrm{~min}$. The inserts show the measured masses after deconvolution of the $\mathrm{m} / \mathrm{z}$ spectra belonging to the main peaks, with labeled the most abundant measured mass. 
A

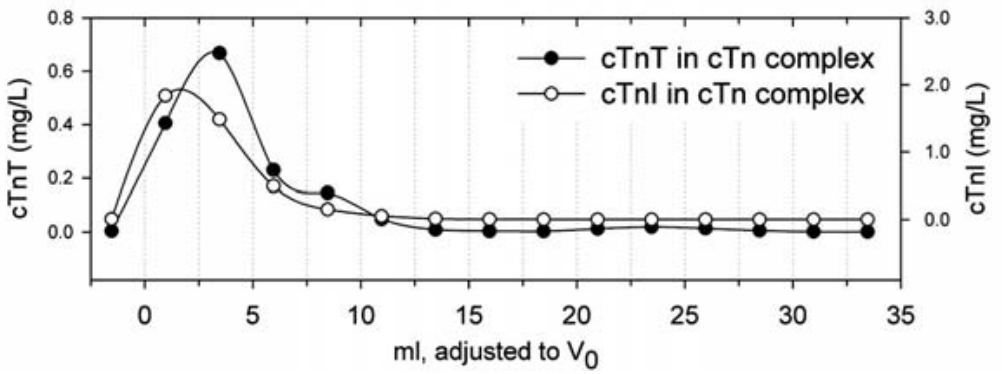

B

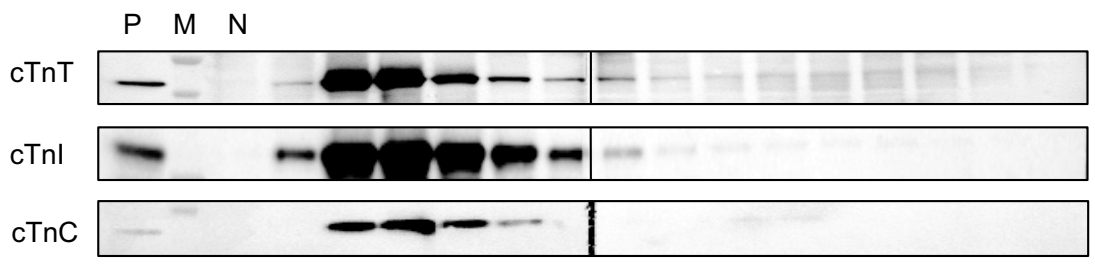

C

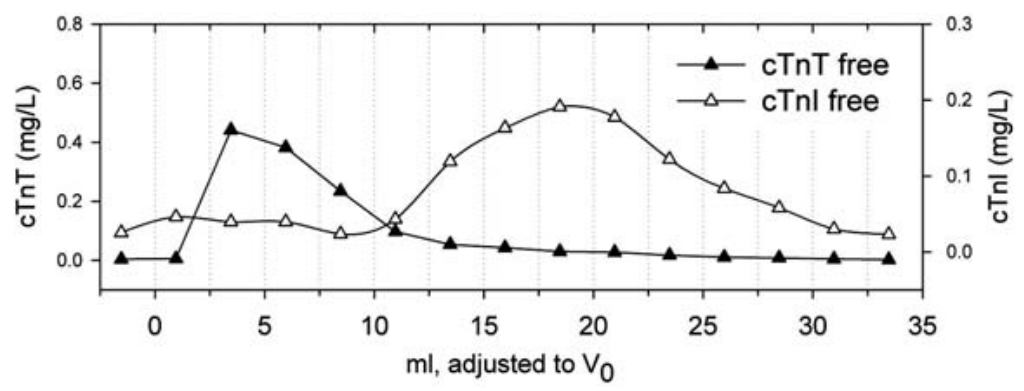

D

P $M \quad N$

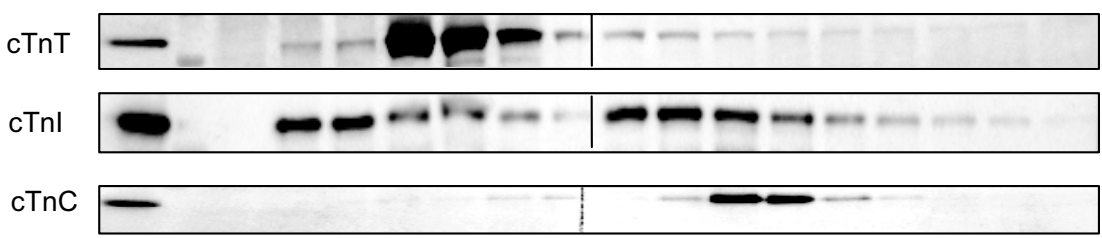

Figure 3: Human purified cTn complex (A, B) and free cTnT, cTnl, and cTnC (C, D) spiked in buffer and separated using GFC. Fractions were characterized by the $4^{\text {th }}$ generation $\mathrm{CTnT}$ and Axsym cTnl immunoassays (A, C), and Western Blot analysis (B, D) using the commercial testkit cTnT and cTnl antibodies (and $\mathrm{CTnC}$ ) as further specified in the methods section. Indicated on the blots are the positive control $\mathrm{P}, \mathrm{cTn}$ complex spiked in running buffer; the MW marker; and the negative control $\mathrm{N}$, running buffer. 
eluted around 3 and $18 \mathrm{~mL}$, respectively (Figure $3 \mathrm{C}$ ). These results were confirmed by Western Blot analysis using the detector antibodies of the commercial cTnT and Axsym-cTnI immunoassays and cTnC, as shown in Figure 3B and 3D.

Figure 4 shows that elution characteristics remained comparable when cTn was spiked in cTn negative human serum. Results were confirmed by immunoprecipitation and Western Blot detection (data not shown). Furthermore, cTnT - either in complex (peak at $3 \mathrm{~mL}$ ) or free (peak at $6 \mathrm{~mL}$ ) - eluted just before serum albumin (peak at $11 \mathrm{~mL}$ ). Free $\mathrm{cTnl}$ spiked in serum eluted around $\mathrm{V}_{0}$ and between albumin and NT-proBNP (peak at $15 \mathrm{~mL}$ ), possibly being the dimer and monomer, respectively.
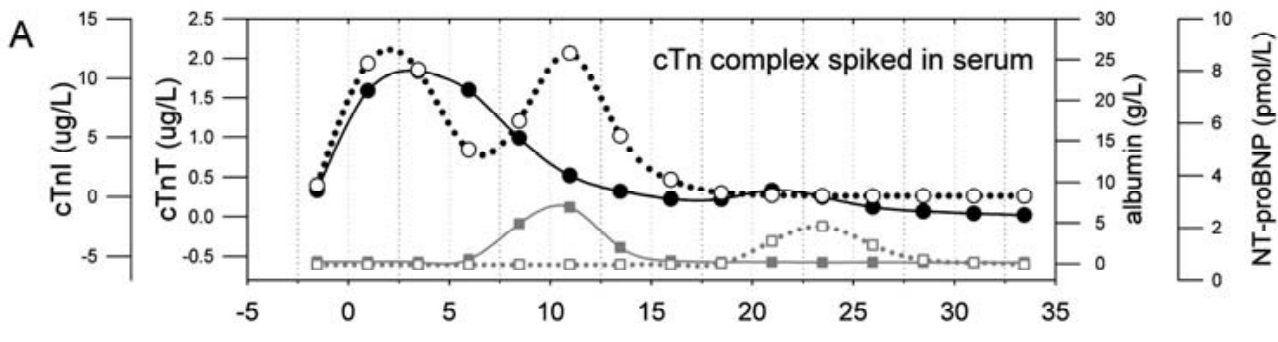

B

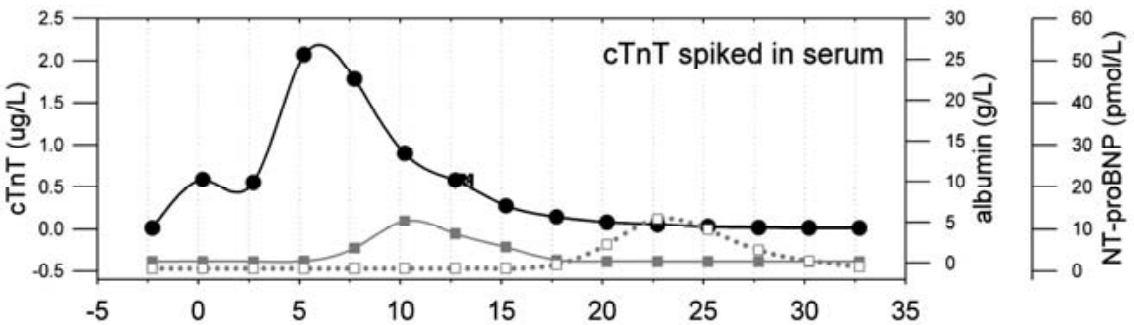

C

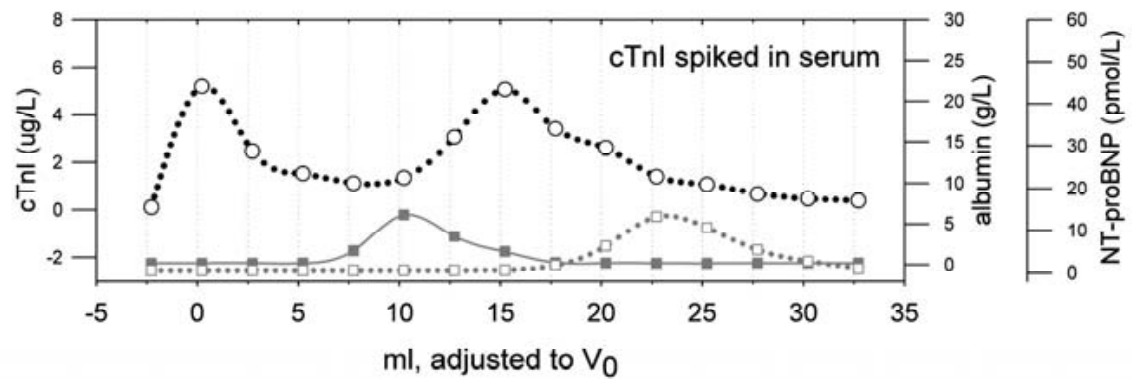

Figure 4: Human purified cTn complex (A) and free $\mathrm{CTnT}$ (B) and cTnl (C) spiked in cTn neg serum (cTnT/cTnl $<0.01 \mu \mathrm{g} / \mathrm{L}$ ) and AMI patient serum samples from 3, 14, 22, 46 hours after admission to the emergency department (D, next page) that were separated using gel filtration chromatography. Fractions were characterized by $\operatorname{cTnT}\left(-\bullet-, 4^{\text {th }}\right.$ generation) and $\operatorname{cTnl}(\cdot \circ \cdot$, Axsym) immunoassays. Internal serum markers were albumin (-m-, $68 \mathrm{kDa})$ and NT-proBNP (·-, approx $13 \mathrm{kDa})$. 
The cTnT and cTnl elution profiles of the AMI patient changed with time, dependent on the time of admission to the emergency department, as shown in Figure 4D. Moreover, as depicted in Figure 5, immunoprecipitation and Western Blot detection revealed that the first cTnT peak (5 mL) belonged to almost intact cTnT of $\mathrm{MW}_{\text {estimated }} 27 \mathrm{kDa}$ and the second cTnT peak $\left(22 \mathrm{~mL}\right.$ ) belonged to smaller cTnT degradation products of $\mathrm{MW}_{\text {estimated }} 15-17 \mathrm{kDa}$. For cTnl, as depicted in Figure 6, both intact and degraded cTnl were identified in the peak at 15 $\mathrm{mL}$ of $\mathrm{MW}_{\text {estimated }} 28,25,18$, and $15 \mathrm{kDa}$.
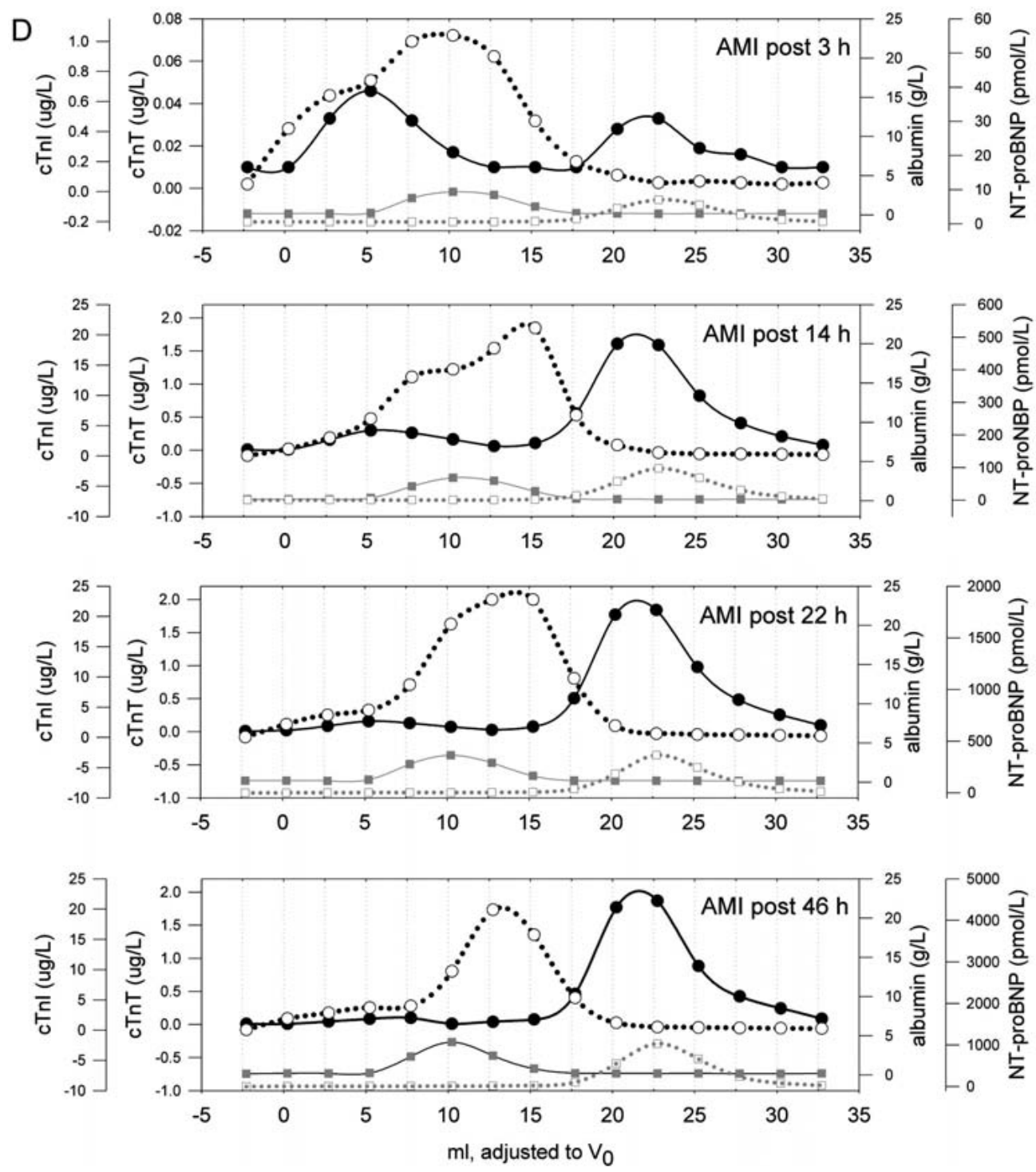
In conclusion, Figure 7 illustrates that the elution characteristics of cTn either in complex or in the free, unbound state differed from to the calibration proteins. These globular protein standards eluted in a linear relation as expected. However, all the cTn proteins, either in complex or free, deviated clearly from the calibration line, which was especially the case for free cTnT.
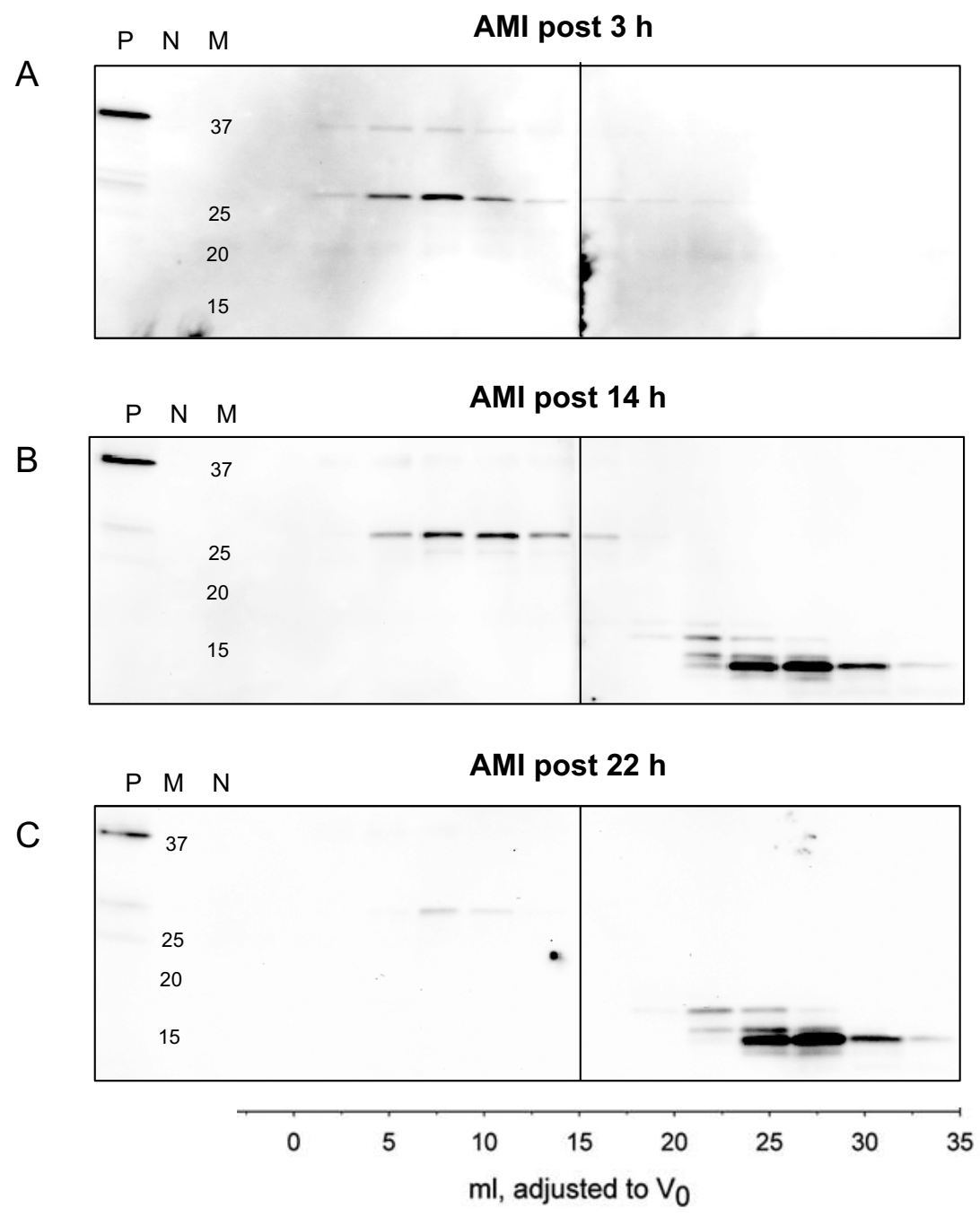

Figure 5: Western Blot analysis against CTnT of AMI patient serum samples fractionated in Figure 4D using the commercial Roche antibodies as further specified in the methods section. Considered are the samples from 3 (A), 14 (B), and 22 (C) hours after admission to the emergency department. Indicated on the blots are the positive control P, cTn complex spiked in running buffer (cTnT $1 \mu \mathrm{g} / \mathrm{L}$ ); the marker $\mathrm{M}$ with $\mathrm{MW}$ labeled $(\mathrm{kDa})$; and the negative control $\mathrm{N}$, running buffer. $\mathrm{P}$ and $\mathrm{N}$ also underwent immunoprecipitation before loaded on the gel. 


\section{Discussion}

After AMI, the circulating CTnT forms are completely degraded, as evidently shown in the present study after extensive validation but in contrast to findings of others. ${ }^{10,12}$ Concerning cTnl, we confirm the predominant form in AMI serum is most probably the binary cTnl-cTnC complex in the presence of both intact and degraded cTnl.

Investigation of the cTnT and cTnl forms in serum was performed by separation with non-denaturing technique of GFC. This enables detailed characterization of non-covalent

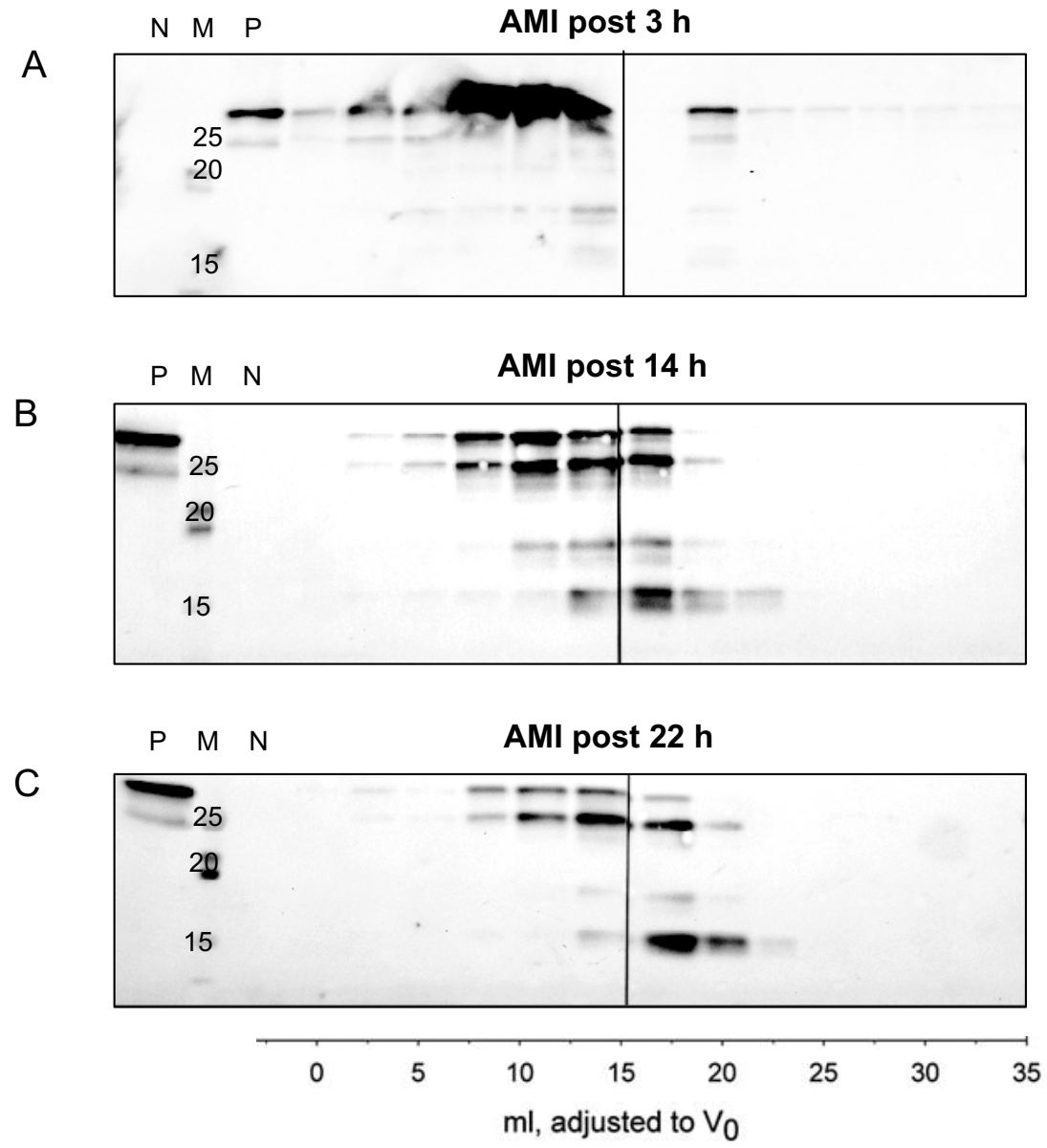

Figure 6: Western Blot analysis against cTnl of AMI patient serum samples fractionated in Figure 4D using the commercial Abbott Axsym antibodies as further specified in the methods section. Considered are the samples 3 (A), 14 (B), and 22 (C) hours after admission to the emergency department. Indicated on the blots are the positive control P, cTn complex spiked in running buffer (cTnT $1 \mu \mathrm{g} / \mathrm{L}$ ); the marker $\mathrm{M}$ with MW labeled $(\mathrm{kDa})$; and the negative control $\mathrm{N}$, running buffer. $\mathrm{P}$ and $\mathrm{N}$ also underwent immunoprecipitation before loaded on the gel. 


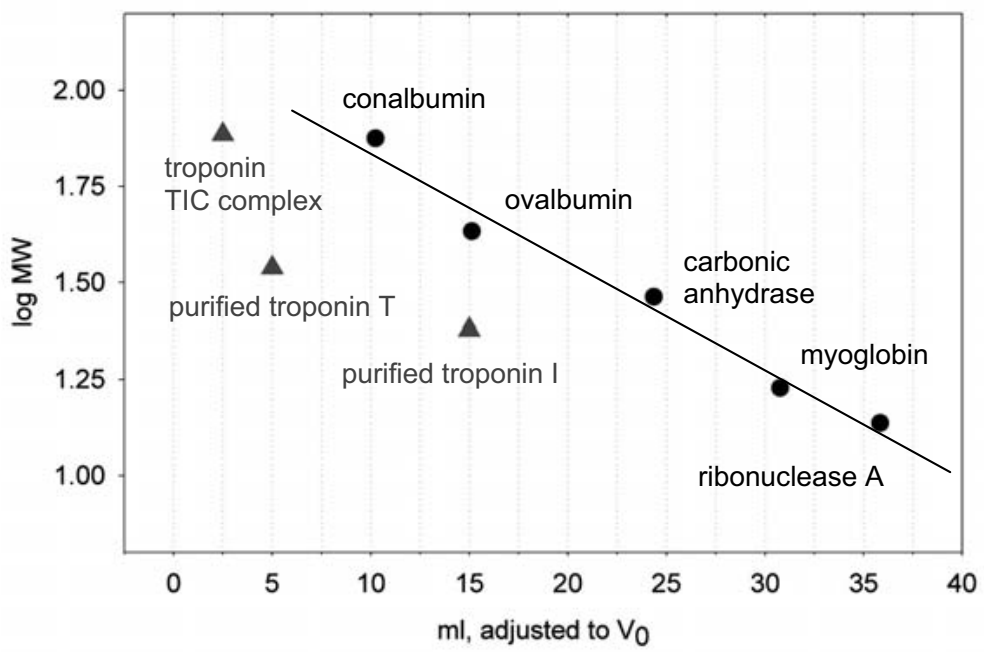

Figure 7: Calibration of the gel filtration column according to globular protein standards $(\bullet)$ as further specified in the method section. Indicated are the elution characteristics of human cTn complex, (free) cTnT, and cTnl (all $\boldsymbol{\Delta}$ ) as interpreted from Figure 4A-C. Calibration curve of the standards follows equation $y=-0.028 x+2.1175\left(R^{2} 0.9788\right)$.

complexes present in serum, but also requires extensive and careful validation. We reported cTnT and cTnI elution profiles of our AMI patient similar to the ones reported by Bates et al. ${ }^{10}$ We used the same type of gel filtration column, running buffer, and calibration proteins, except that our column was longer. However, we disagree in the assignment of the main cTnT peak that elutes after serum albumin. Bates et al assigned this CTnT peak to free, intact cTnT as based on elution profiles of the globular calibration proteins. We show that their separation conditions were unable to differentiate between CTnT in complex and in the unbound state. With Western Blot detection using the Roche antibodies, we reveal that the cTnT peak eluting after albumin should be assigned to completely degraded cTnT forms of approximately 15-17 kDa. Apart from this, both studies show the main cTnl peak coelutes with serum albumin and assign this to the binary cTn IC complex which predominance was already shown by Katrukha et al. ${ }^{21}$ In conclusion, especially for CTnT with its elongated structure $^{22}$ non-denaturing separation data should be interpreted with great care ${ }^{14}$ and our extensive validation evidently proofs cTnT in serum is completely degraded.

The cTnT and cTnl degradation patterns have been studied before, ${ }^{5-7}$ but interpretation of results has always been limited since the used antibodies differed from the ones in the commercial immunoassays. ${ }^{10}$ This could explain our discrepancy with Labugger et al, who 
reported the predominance of approximately $26 \mathrm{kDa}$ degraded cTnT in AMI serum, though they too reported the presence of mainly intact cTnl. ${ }^{6}$ To put an end to these discussions, we put a lot of effort to apply the original cTnT (Roche Diagnostics) and Axsym cTnl (Abbott Diagnostics) antibodies in our immunoprecipitation and Western Blot analyses, as kindly provided by Roche or as collected from the commercial kits.

The present study shows that the commercial cTnT assay predominantly detects CTnT fragments in AMI serum instead of intact cTnT. Since only one cTnT manufacturer is on the market, these new insights will not affect the cTnT harmonization and standardization purposes. Nevertheless, for calibration reasons it might be worthwhile to precisely know which cTnT form is predominantly present in patient serum. ${ }^{20}$ By contrast, for the more than 20 available cTnl immunoassays, research in degradation patterns has prompted the manufacturers to choose anti-cTnl antibodies directed against the stable cTnl domain at amino acid residues $30-110 .^{23,24}$ To date, results of the cTnl immunoassays still deviate up to around 3-fold and cTnl assays might thus still differ in their reactivity to degraded cTnl forms.

The circulating cTnT and cTnl forms could be specific for the time-phrase after onset of AMI symptoms, as suggested from the elution profiles in the present study and Langendorfreperfusion studies in rat hearts. ${ }^{7}$ In previous research, we already showed time-dependent degradation of cTnT in 20 AMI patients with no intact cTnT present anymore 12 hours after onset of symptoms, ${ }^{5}$ although at that time we did not use the Roche antibodies yet. In addition, Hessel et al found intact and degraded cTnT and cTnl forms in necrotic rat myocytes, ${ }^{25}$ while only intact cTnl was released in the absence of necrosis via a stretchrelated mechanism mediated via integrins. ${ }^{26}$

The release of intact cTnT and cTnl forms might thus be a sign of early or mild ischemia. Intact cTn forms would originate from the cytosolic pool of the myocytes. ${ }^{19}$ However, Jeong et al have reported cytotoxicity of nonmyofilament-associated $\mathrm{CTnT}^{18}{ }^{18}$ indicating that under healthy conditions cTnT is not present in the cytosol. Also, in comparison to intact cTnT, they found larger toxicity for the CTnT mid- en C-terminal region ${ }^{18}$ which are known for their interactions to the sarcomeres and are highly conserved among muscles types. ${ }^{27}$ It has also been shown that under stress conditions the $\mathrm{N}$-terminus is cleaved off due to increased calpain-1 and caspase- 3 activities ${ }^{28,29}$ and could be an adaptation to sustain cardiac function. ${ }^{30,31}$ This all indicates that a higher level of cell death is reached from the moment 
the $\mathrm{N}$-terminus is removed from CTnT. In relation to the present study, the first fragment that was detected after onset of AMI symptoms is thus probably N-terminal degraded cTnT (MW 25-27 kDa, a.a.r. 79/98-298). The smaller fragments detected later on after onset of symptoms could derive from the midregion, closer to the location of the epitopes of the two Roche antibodies (a.a.r. 125-147).

It would also be intriguing to find disease specific cTnT or cTnl forms. In End-Stage Renal Disease patients, we previously found degraded cTnT forms only, ranging in size from 8 to 25 kDa though without using the Roche antibodies. ${ }^{4}$ These cTnT fragments could be due to impaired renal clearance of renewed myocytes ${ }^{32,33}$ or because of myocardial ischemia. Furthermore, as shown by the group of Van der Velden, failing hearts are characterized by a lower extent of cTnl phosphorylation ${ }^{34}$ and an impaired diastolic function when cTnl is truncated at the C-terminus. ${ }^{35}$

Future research should validate whether cTnT fragmentation differs among AMI patients to investigate clinical consequences. The present study was limited to one AMI patient only. However, the obtained GFC elution profiles were similar to results obtained by Bates et $\mathrm{al}^{10}$ and, therefore, first effort was put in the extensive validation by Western Blot analysis. In addition, it remains to be elucidated whether fragmentation patterns differ in cTnT-positive patients not suffering from AMI, like with renal insufficiency or after extensive exercise.

\section{References}

1. Thygesen K, Alpert JS, White HD. Universal definition of myocardial infarction. J Am Coll Cardiol. 2007;50:2173-2195.

2. Morrow DA, Cannon CP, Jesse RL, et al. National Academy of Clinical Biochemistry laboratory medicine practice guidelines: clinical characteristics and utilization of biochemical markers in acute coronary syndromes. Circulation. 2007;115:356-375.

3. Reichlin T, Hochholzer W, Bassetti S, et al. Early diagnosis of myocardial infarction with sensitive cardiac troponin assays. N Engl J Med. 2009;361:858-867.

4. Diris JH, Hackeng CM, Kooman JP, Pinto YM, Hermens WT, Van Dieijen-Visser MP. Impaired renal clearance explains elevated troponin $\mathrm{T}$ fragments in hemodialysis patients. Circulation. 2004;109:23-25.

5. Michielsen EC, Diris JH, Kleijnen VW, Wodzig WK, Van Dieijen-Visser MP. Investigation of release and degradation of cardiac troponin T in patients with acute myocardial infarction. Clin Biochem. 2007; 40:851-855.

6. Labugger R, Organ L, Collier C, Atar D, Van Eyk JE. Extensive troponin I and T modification detected in serum from patients with acute myocardial infarction. Circulation. 2000;102:12211226. 
7. McDonough JL, Arrell DK, Van Eyk JE. Troponin I degradation and covalent complex formation accompanies myocardial ischemia/reperfusion injury. Circ Res. 1999;84:9-20.

8. Madsen $\mathrm{LH}$, Christensen $\mathrm{G}$, Lund $\mathrm{T}$, et al. Time course of degradation of cardiac troponin I in patients with acute ST-elevation myocardial infarction. The ASSENT-2 troponin substudy. Circ Res. 2006;99:1141-1147.

9. Katrukha AG, Bereznikova AV, Filatov VL, et al. Degradation of cardiac troponin I: implication for reliable immunodetection. Clin Chem. 1998;44:2433-2440.

10. Bates KJ, Hall EM, Fahie-Wilson MN, et al. Circulating immunoreactive cardiac troponin forms determined by gel filtration chromatography after acute myocardial infarction. Clin Chem. 2010;56:952-958.

11. Fahie-Wilson MN, Carmichael DJ, Delaney MP, Stevens PE, Hall EM, Lamb EJ. Cardiac troponin T circulates in the free, intact form in patients with kidney failure. Clin Chem. 2006;52:414-420.

12. Wu AH, Feng YJ, Moore R, et al. Characterization of cardiac troponin subunit release into serum after acute myocardial infarction and comparison of assays for troponin $\mathrm{T}$ and I. American Association for Clinical Chemistry subcommittee on cTnl standardization. Clin Chem. 1998;44:1198-1208.

13. Michielsen EC, Diris JH, Kleijnen VWVC, Wodzig WK, Van Dieijen-Visser MP. Interpretation of cardiac troponin $\mathrm{T}$ behaviour in size-exclusion chromatography. Clin Chem Lab Med. 2006;44:1422-1427.

14. Michielsen EC, Diris JH, Kleijnen VWVC, Wodzig WK, van Dieijen-Visser MP. Size-exclusion chromatography of circulating cardiac troponin T. Clin Chem. 2006;52:2306-2307.

15. Katus HA, Remppis A, Scheffold T, Diederich KW, Kuebler W. Intracellular compartmentation of cardiac troponin $\mathrm{T}$ and its release kinetics in patients with reperfused and nonreperfused myocardial infarction. Am J Cardiol. 1991;67:1360-1367.

16. Bleier J, Vorderwinkler KP, Falkensammer J, et al. Different intracellular compartmentations of cardiac troponins and myosin heavy chains: a causal connection to their different early release after myocardial damage. Clin Chem. 1998;44:1912-1918.

17. Thygesen $\mathrm{K}$, Mair J, Katus $\mathrm{H}$, et al. Recommendations for the use of cardiac troponin measurement in acute cardiac care. Eur Heart J. 2010;31:2197-2204.

18. Jeong EM, Wang X, Xu K, Hossain MM, Jin JP. Nonmyofilament-associated troponin T fragments induce apoptosis. Am J Physiol Heart Circ Physiol. 2009;297:H283-292.

19. Shave R, Baggish A, George K, et al. Exercise-induced cardiac troponin elevation: evidence, mechanisms, and implications. J Am Coll Cardiol. 2010;56:169-176.

20. Cobbaert CM, Weykamp CW, Michielsen EC, Baadenhuijsen H, van Dieijen-Visser MP. Timedependent instability of cardiac troponins in human plasma spiked with NIST reference material 2921. Clin Chem. 2008;54:2078-2079.

21. Katrukha AG, Bereznikova AV, Esakova TV, et al. Troponin I is released in bloodstream of patients with acute myocardial infarction not in free form but as complex. Clin Chem. 1997;43:1379-1385.

22. Flicker PF, Phillips GN, Jr., Cohen C. Troponin and its interactions with tropomyosin. An electron microscope study. J Mol Biol. 1982;162:495-501.

23. Apple FS, Jesse RL, Newby LK, et al. National Academy of Clinical Biochemistry and IFCC committee for standardization of markers of cardiac damage laboratory medicine practice guidelines: analytical issues for biochemical markers of acute coronary syndromes. Clin Chem. 2007;53:547-551.

24. Panteghini M. Assay-related issues in the measurement of cardiac troponins. Clin Chim Acta. 2009;402:88-93.

25. Hessel MH, Michielsen EC, Atsma DE, et al. Release kinetics of intact and degraded troponin I and T after irreversible cell damage. Exp Mol Pathol. 2008;85:90-95.

26. Hessel MH, Atsma DE, van der Valk EJ, Bax WH, Schalij MJ, van der Laarse A. Release of cardiac troponin I from viable cardiomyocytes is mediated by integrin stimulation. Pflugers Arch. 2008;455:979-986. 
27. Li MX, Wang X, Sykes BD. Structural based insights into the role of troponin in cardiac muscle pathophysiology. J Muscle Res Cell Motil. 2004;25:559-579.

28. Communal C, Sumandea M, de Tombe P, Narula J, Solaro RJ, Hajjar RJ. Functional consequences of caspase activation in cardiac myocytes. Proc Natil Acad Sci U S A. 2002;99:6252-6256.

29. Zhang Z, Biesiadecki BJ, Jin JP. Selective deletion of the NH2-terminal variable region of cardiac troponin $\mathrm{T}$ in ischemia reperfusion by myofibril-associated mu-calpain cleavage. Biochemistry. 2006;45:11681-11694.

30. Feng HZ, Biesiadecki BJ, Yu ZB, Hossain MM, Jin JP. Restricted N-terminal truncation of cardiac troponin $\mathrm{T}$ : A novel mechanism for functional adaptation to energetic crisis. J Physiol. 2008;283:33384-33393.

31. Sumandea MP, Vahebi S, Sumandea CA, Garcia-Cazarin ML, Staidle J, Homsher E. Impact of cardiac troponin $\mathrm{T} \mathrm{N}$-terminal deletion and phosphorylation on myofilament function. Biochemistry. 2009;48:7722-7731.

32. Bergmann O, Bhardwaj RD, Bernard S, et al. Evidence for cardiomyocyte renewal in humans. Science. 2009;324:98-102.

33. Kajstura J, Urbanek K, Perl S, et al. Cardiomyogenesis in the adult human heart. Circ Res. 2010;107:305-315.

34. Kooij V, Saes M, Jaquet K, et al. Effect of troponin I Ser23/24 phosphorylation on Ca2+-sensitivity in human myocardium depends on the phosphorylation background. J Mol Cell Cardiol. 2010;48:954-963.

35. Narolska NA, Piroddi N, Belus A, et al. Impaired diastolic function after exchange of endogenous troponin I with C-terminal truncated troponin I in human cardiac muscle. Circ Res. 2006;99:10121020. 


\section{General discussion}

Specifications of a perfect cardiac biomarker to diagnose acute myocardial infarction (AMI) are at least heart specificity, early detection after first symptoms, and a long half-life. ${ }^{1}$ The current preferred biomarkers to diagnose AMI are cardiac troponins (cTn), either cardiac troponin T (cTnT) or I (cTnl). ${ }^{2,3}$ The main advantage of cTn is its cardiac specificity. ${ }^{4}$ This is in contrast to previous markers, like lactate dehydrogenase (LDH), aspartate aminotransferase, creatine kinase, or creatine kinase muscle-brain type. Or the ones that did not even reach routine clinical practice, like myoglobin or heart-type fatty acid-binding protein, which are also present in skeletal muscles. Second advantage of cTn is the timeframe of release. After onset of symptoms cTn concentrations increase within several hours and remain elevated for approximately a week. Nevertheless, faster and better diagnosis of AMI and also prognostic applications were expected by lowering the detection limit of current cTn immunoassays.

\section{New insights due to high-sensitivity troponin assays}

\section{- Measurable troponin concentrations in healthy individuals}

Improvements have lately been achieved in lowering the detection limit of cTn immunoassays. Previously, cTn concentrations elevated after myocardial infarction to detectable levels, while cTn concentrations in a healthy control group were not detectable. When validating the new high-sensitivity cTnT (hs-cTnT) assay, as described in chapter 3, it became clear that cTnT concentrations in a reference population follow a typical gaussian like distribution in the lower measuring range. We were the first who validated the hs-cTnT assay when it was only pre-commercially available. Only Latini et al had reported on the hs- 
cTnT assay before, but they focused on the prognostic value in stable chronic heart failure patients. ${ }^{5}$ The bell-shaped cTnT distribution was later confirmed by other researchers. ${ }^{6,7}$ In chapter 3 we also validated the second generation Architect cTnl assay, but this turned out to be a less sensitive assay. Though, a bell-shaped cTnl distribution in seemingly healthy individuals was obtained when using research high-sensitivity cTnl (hs-cTnl) assays. ${ }^{8,9}$

As summarized in chapter 2, the hs-cTnT assay is nowadays the only commercially available cTn assay that measures the diagnostic cutoff concentration $\left(99^{\text {th }}\right.$ percentile of seemingly healthy individuals) with sufficient precision ( $C V<10 \%$ ) as recommended by the guidelines. ${ }^{2,3}$ The predicate of "guideline acceptance" has also been reported for research hs-cTnl assays, ${ }^{10}$ like the Singulex Erenna, ${ }^{11}$ Nanosphere VeriSens, ${ }^{12}$ and the Beckman Coulter Access assay. ${ }^{8}$ However, it remains to be elucidated whether "guideline acceptance" is required for diagnostic purposes. The clinical performance of the Architect cTnl assay to diagnosis AMI was namely not inferior to the hs-cTnT and Access hs-cTnl assay. ${ }^{13}$ On the other hand, when applying the hs-cTn assays for prognostic and screening purposes, ${ }^{14}$ it might become more important to measure with sufficient precision in the lowest concentration range. With the hs-TnT assay we were able to measure $5 \%, 98 \%$, and $14 \%$ of the cTnT concentrations with CV $<10 \%$ in our reference population (chapter 3), post-run concentrations of the marathon runners (chapter 3 and 4), and the stable chest-pain patients (chapter 7), respectively. The research Singulex Erenna assay is nowadays the only assay available - for research only - that achieves CV $<10 \%$ across most of the reference concentrations. ${ }^{10}$ Although this requirement in assay precision was to some extent arbitrarily chosen, ${ }^{2}$ further assay improvements seem essential when applying hs-cTn concentrations for prognostic purposes.

The pathophysiology of increased cTn concentrations in the blood circulation of healthy individuals is not understood yet. Previously, the heart was considered to be a post-mitotic organ in which the number of myocytes is established at birth and is lost with age or disease. Recent research, however, has shown the existence of renewal of myocytes, which will be very slow with around half of the myocytes exchanged at the age of $70,{ }^{15}$ or rather faster since another study claims replacement of the entire heart several times during life-time. ${ }^{16}$ On the other hand, survival analysis by us (chapter 8 , stable chest-pain population, 2-year follow-up) and others (general and elderly population, 6 and 12-year follow-up, respectively $)^{17,18}$ revealed adverse survival in subjects with cTn concentrations even within 
the reference range. It might thus still be true that measurable cTn concentrations in any circumstance should be avoided.

Consequently, proper selection criteria for a reference control population remain unclear. As reported in chapter 3 and reviewed in chapter 2 , we found a relatively high $99^{\text {th }}$ percentile cutoff concentration of $16 \mathrm{ng} / \mathrm{L}$ for the hs-cTnT assay. We used cardiac biomarkers to simply screen the healthiness of the reference population. Half of the validation studies (47\%) did not report their inclusion criteria. As expected, lower $\mathrm{cTnT}^{7}$ and $\mathrm{cTnl}^{19}$ upper reference limits were reported for the studies that extensively screened the subjects with a complete scale of questionnaires, ECG, (stress) echo, and biomarkers. Nevertheless, we were the first who reported a significant sex effect, and this was confirmed by others, ${ }^{6,7,20}$ while an age effect was not that obvious. Optimal diagnosis of AMI was though reported to be age dependent (cutoff, 70 years) when using the hs-cTnT or Architect cTnl assay. ${ }^{21}$ Overall, so far, the clinical impact to use cardio-healthy, sex- and age-matched control groups is not clear for diagnostic purposes of hs-cTn concentrations, but could especially be relevant for their prognostic use.

\section{- Improved diagnosis of AMI}

First clinical studies validated whether the improved hs-cTnT and hs-cTnl assays indeed accelerate the process to diagnose AMI. ${ }^{13,21,22}$ They reported perfect negative predictive values of around $100 \%$ but, this went along with low positive predictive values.

It was suggested to reduce the number of false positive diagnoses by serial sampling, as discussed in chapter 2 . The guidelines proposed a change of $20 \%$, as based on 3 times the standard deviation. ${ }^{2}$ Optimal diagnosis in evolving non-ST-elevated myocardial infarction patients was however achieved by the $99^{\text {th }}$ percentile cutoff at presentation in the emergency department with in addition a change of $>117 \%$ within 3 hours or $>243 \%$ within 6 hours. ${ }^{23}$ Secondly, first results on biological variation of $\mathrm{cTnl}^{24}$ and $\mathrm{cTnT}^{25}$ concentrations suggest that $\mathrm{cTnT}$ is more suitable for serial sampling than cTnl. To detect an increase in cTnT concentrations, log-normal concentrations should increase on the short- and long-term (4-hour and 8-weeks period, respectively) with at least $85 \%$ and $315 \%$, respectively. ${ }^{25}$

Finally, it should be reconsidered whether the $99^{\text {th }}$ percentile cutoff concentration of a healthy reference control group is the best diagnostic cutoff to diagnose AMI. One might question whether it would be better to use the $97.5^{\text {th }}$ percentile, which is less sensitive to 
outliers and is common for other biomarkers. On the other hand, the best way to validate diagnostic performance is by ROC curve analysis for each cTn immunoassay separately. ${ }^{21}$

\section{- Exercise-induced troponin elevations: how innocent are they?}

Exercise-induced cTn concentrations have occasionally been noticed after prolonged strenuous exercise but in the absence of clinical symptoms. It has been hypothesized whether these cTn elevations are caused by early or minor myocardial necrosis or by so called reversibly damaged myocytes, in which cytosolic cTn is released for instance via integrin-mediated ${ }^{26}$ or blebbing mechanisms. ${ }^{27}$

As we previously reviewed for $\mathrm{cTnT}^{28}$ and as summarized in chapter 4 for cTnl, cTn elevations were noticed with the contemporary cTn immunoassays in none to around half of the athletes immediately after prolonged strenuous exercise. This was dependent on the type of exercise, the assay, and/or the cutoff used. Echocardiographic research showed temporarily cardiac dysfunction after marathon running, ${ }^{29,30}$ but no myocardial necrosis could be confirmed using magnetic resonance imaging. ${ }^{31}$ We were the first who studied exercise-induced cTnT elevations using the hs-cTnT assay. As described in chapter 3 and 4, post-run hs-cTnT concentrations elevated above the $99^{\text {th }}$ percentile cutoff in almost all $(86 \%)$ recreational marathon runners with a 10 -fold (median) increase. In addition, pre-run concentrations were within the reference range and post-run concentrations returned to baseline 1 day after the marathon event. The exercise-induced hs-cTnT concentrations could neither be clarified by renal dysfunction because creatinine and cystatin $C$ concentrations increased with only $30 \%$ (chapter 5), nor by dehydration as comparable results were obtained after correction for dehydration (marathon runners, chapter 3 versus 4 ). This would suggest that the exercise-induced cTnT elevations are either minute or asymptomatic for myocardial injury.

We furthermore showed that post-run cTnT concentrations turned out to be dependent on running distance (chapter 4). This would suggest an association of cTnT elevations with exercise intensity or duration. ${ }^{31,32}$ We could not confirm this for runners running the same distance. However, in the marathon runners we noticed a negative association of experience on post-run cTnT concentrations (chapter 3). A training effect has been suggested by a few others ${ }^{29,33}$ and has also been proven in animal models. ${ }^{34}$ As is generally known, this might emphasize that sufficient training is protective for the heart. A so called athlete's or 
endurance-trained heart sustains long intervals of volume overloads of the left ventricular. Predominant cardiac adaptations are the increasing left and right ventricular internal diameter and the addition of new sarcomeres in-series to existing sarcomeres, which is known as eccentric hypertrophy. ${ }^{29,35,36}$ Moreover, cardiac remodelling due to training, in contrast to pathological hypertrophy, results in an increase in capillary density and a normal mitochondria-to-myofibril ratio. ${ }^{37}$ This indicates that sufficient training protects the heart from ischemia but that too extensive or prolonged exercise might result in real cardiac damage and fibrosis. ${ }^{38}$

\section{- Elevated troponin concentrations in End-Stage Renal Disease}

In End-Stage Renal Disease (ESRD) patients cTn concentrations are known to be elevated without further apparent cardiac damage or ischemia. ${ }^{39}$ It is unclear whether such chronic cTn elevations are caused by cardiac disease or by the decrease or complete absence of renal clearance. ${ }^{40}$

As described in chapter 6, in almost all ESRD patients (94\%) cTnT concentrations were elevated when using the hs-cTnT assay, compared to around half of the patients when using contemporary cTn assays. Additional patients with elevated CTn concentrations were identified by serial measurements during 6 months follow-up. Interestingly, significantly higher cTn concentrations were found in patients with a history of cardiovascular disease, with larger intra-individual variability, compared to patients without this history. These results suggest that the chronic cTn elevations are caused by a combination of coronary and renal disease.

\section{- Prognostic value of troponin in stable chest-pain subjects}

The identification of patients at coronary risk remains an ongoing challenge. Complicated are especially patients who visit the cardiology outpatient department with complaints of chestpain but with a normal ECG and a negative exercise stress test. Traditional risk factors and prediction algorithms like Framingham risk profiling turned out to be of limited use. ${ }^{41,42}$ With the development of more accurate high-sensitivity cTn assays, new possibilities seem available to improve risk stratification in patients with a possible cardiovascular risk.

Chapter 7 describes that hs-cTnT concentrations in stable chest-pain patients $(n=615)$ were associated with the extent of coronary plaque as detected with coronary computed 
tomographic angiography (CCTA). Significantly higher hs-cTnT concentrations were noticed in subjects with already mild coronary plaque lesion (diameter stenosis $<50 \%)(P<0.05)$. Such a trend was confirmed by Korosoglou et al, who in addition made the distinction between calcified, non-calcified, and remodelling plaques $(P<0.001) .{ }^{43}$ Remarkably, $97 \%$ of the hs-cTnT concentrations were within the reference range $(<16 \mathrm{ng} / \mathrm{L})$. Secondly, we showed that hs-cTnT was a significant predictor for coronary plaque, in contrast to other (cardiac) biomarkers like hsCRP and NT-proBNP. It remains puzzling, however, how cTnT is related to coronary atherosclerosis, whether CTnT is locally released due to myocardial necrosis or by mild ischemia.

The association of hs-cTnT with left ventricular hypertrophy, chronic heart failure, and cardiovascular death has been reported in elderly ${ }^{18}$ or in the general population, ${ }^{17,44}$ but these are not the typical patients visiting the cardiology outpatient department. KaplanMeier analysis in chapter 8 confirmed an adverse cardiovascular survival in stable chest pain patients with relatively higher hs-cTnT concentrations $(n=1,088$ with follow-up 2.2 years, $P$ $<0.001$ ) for the composite endpoint of late revascularization (after 90 days), ACS, and cardiac death. Comparable results were obtained when all-cause mortality was included (data not shown). To a smaller extent such a trend was also observed for NT-proBNP (P 0.009) but not for hsCRP (P 0.355). Moreover, over three times as much cardiovascular events were found in patients with hs-cTnT concentrations in the fourth quartile (HR 3.55, P<0.001), as compared to patients with hs-cTnT concentrations in the lowest three quartiles. Hs-cTnT remained significantly predictive when corrected for traditional risk factors or when risk factors were combined in the Framingham risk score (HR 1.7-3.1). Omland et al showed an even stronger additive value of hs-cTnT to traditional risk factors in patients with stable coronary artery disease $(n=3679) .{ }^{45}$ The incremental value of hs-cTnT might thus be useful for prognostic use at the cardiology outpatient department, especially since hs-cTnT is a relatively inexpensive test ${ }^{14}$ that seems more powerful than previous cardiac biomarkers. ${ }^{46}$ Further research with longer follow-up data and double blinded randomization studies are now needed to show whether and, if so, how cardiologists should adapt treatment of their outpatients based on cTn concentrations in the lower range. 


\section{Harmonisation and standardization of troponin assays}

More than $20 \mathrm{cTnl}$ immunoassays are nowadays commercially available, ${ }^{47}$ but assay results deviate up to 20 -fold. ${ }^{48}$ This is not an issue for the highly patented cTnT immunoassay (Roche Diagnostics). Panteghini emphasized the need for an internationally recognized reference measuring system. ${ }^{49,50}$ In collaboration with the National Institute of Standards and Technology (NIST), standard reference material (SRM) 2921 was selected from 10 candidates. ${ }^{51}$ NIST SRM 2921 is a highly characterized cTn TIC complex that is purified from human heart tissue. 52,53 Unfortunately, first attempts of cTnl assay harmonization were unsuccessful when using NIST SRM 2921 based pools ${ }^{53}$ and we previously observed a timedependent decline in cTnl assay results. ${ }^{55}$

In chapter 9, we showed that cTnl and cTnT assay results remained stable (recovery $>90 \%$ ) when NIST SRM 2921 was spiked in human serum and plasma pools and kept at $4^{\circ} \mathrm{C}$. However, assay results reduced to $50-60 \%$ when the pools were incubated at $37^{\circ} \mathrm{C}$, except for cTnT results in plasma (87\%). Subsequently, we applied the commercial antibodies of the $4^{\text {th }}$ generation cTnT and Axsym cTnl assay, respectively, for Western Blot analysis. For cTnl, we did not detect time-dependent cTnl fragmentation, yet another cTnl modification in immunogenicity appears to happen. For CTnT, we detected time-dependent degradation in serum but not in plasma. For the incubation at $4^{\circ} \mathrm{C}, \mathrm{cTnT}$ degradation did not affect assay results, in contrast to the higher extent of degradation found when incubated at $37^{\circ} \mathrm{C}$.

In conclusion, these limitations of NIST SRM 2921 do not support to use it for cTnl harmonization purposes. Patient material seems instead preferable, despite the fact that it is less specified and characterized. ${ }^{55}$ The susceptibility of cTnT degradation in serum but not in plasma is probably clarified by the protease inactivation in plasma. Though serum and (heparin) plasma samples showed a good correlation for cTnT results ( $r=0.995),{ }^{56}$ its impact on calibration and clinical samples might remain of importance. Nevertheless, future research should continue to search for a highly defined cTnl standard that eventually will enable manufacturers to standardize the cTnl immunoassays.

\section{Fully degraded cTnT in the blood circulation after AMI}

Despite cTn are the preferred biomarkers to diagnose and monitor $\mathrm{AMI}^{2,3}$ their structural aspects in the blood circulation are not yet correctly understood. We previously showed that 
cTnT is completely degraded in serum of hemodialysis patients ${ }^{39}$ and in patients after AMI especially after 12 hours of onset of symptoms. ${ }^{57}$ These and other cTn degradation results ${ }^{57-}$ ${ }^{61}$ were disputed because the antibodies of the commercial immunoassay were different from the Western Blots. ${ }^{62}$ By contrast, Fahie-Wilson and colleagues reported the predominant forms of cTnT being free, unbound $\mathrm{CTnT}$ both in patients after $\mathrm{AMI}^{62}$ and in patients with kidney failure. ${ }^{63}$ They used gel filtration chromatography (GFC) to study the non-covalent complexation of cTn in serum, as described before. ${ }^{64}$ However, since GFC separation takes place under non-denaturing conditions, molecular weight assignment of cTn elution profiles should not be based solely on globular protein standards. This is especially important for elongated structures like cTnT as we discussed before. ${ }^{65,66}$

In chapter 10 we extensively calibrated the Sephacryl S-100 GFC column, which was also used by Fahie-Wilson and colleagues, using human purified CTn TIC complex and free CTnT, cTnl, and cTnC. These elution profiles proof that this column is unable to separate cTnT in TIC complex from free, unbound CTnT, as measured by using the $4^{\text {th }}$ generation CTnT and Axsym cTnl assay and confirmed with Western Blot analysis using the same commercial antibodies. Next, we evidently showed that cTnT in the blood circulation after AMI is completely degraded into mainly 15-17 kDa cTnT fragments. We furthermore confirm that cTnl is predominantly present in the cTn I-C complex ${ }^{62,67}$ and, when using Axsym antibodies, only partly degraded.

The clinical impact of these new insights depends on future research. First, cTnT degradation should be validated in a larger patient population. Secondly, characterization of cTnT in plasma samples will show whether degradation happens intra- or extracellularly. Thirdly, disease specific degradation or post-translational modifications might exist. ${ }^{68,69}$ Finally, although only one manufacturer is on the market for cTnT, assay calibration and quality controls for inter- and intra-laboratory variability might improve using patient serum instead of purified cTnT spiked in serum or buffer.

\section{Directions for future research}

As can be concluded from this thesis, lowering the detection limit of cTn assays has led to the improved identification of patients at cardiovascular risk. However, the hs-cTn assays appeared to be especially useful for the "rule out" of acute coronary syndrome. It is now of great clinical relevance to minimize false-positively assigned subjects and thus to improve 
the distinction of a healthy cardiac condition from one with preliminary signs of cardiovascular disease.

In-depth future research should therefore focus on the molecular mechanism when and in what form cTn is released from damaged myocytes. The release of cTn at the cellular level was started by Hessel et $\mathrm{al}^{26,70}$ in primary rat cells and in our group in HL1 cells (Jacobs, PhD thesis, Maastricht University, 2012). Exposure of these cells to anoxia or electrical stimuli (tachypacing) revealed a simultaneous release of cTn and cytosolic LDH. This indicates that myocardial cell membranes either after ischemia or prolonged exercise are ruptured irreversibly via the necrotic cell death pathway. It has to be noticed, however, that already a significant amount of cTn was lost intracellularly before it was detected in the medium. Since this was not the case for LDH, this might suggest that intracellular breakdown of cTn was started before the onset of necrosis. More extensive research should validate the different phases of cell death (apoptosis, necroptosis, and necrosis) in the ischemia and exercise models ${ }^{71-73}$ to demonstrate in detail whether cTn release differs for the different triggers. There should also be focused on the reversibility of cell viability, to see whether cTn release takes place in the cell death pathway before or after the point-of-no-return. Ideally, it would be preferable to visualize leakage of cTn in individual myocytes using molecular imaging. ${ }^{74}$ Piper et al showed that reversible injury happens via blebbing, ${ }^{27,75}$ in which the cytosolic cell content is released via the formation of vesicles. Blebbing has indeed been shown in apoptotic cells and not in necrotic cells, ${ }^{71,75}$ but has not been related to cTn release yet.

Furthermore, certain cTn forms or fragments might be associated with particular conditions. As hypothesized in the introduction, exercise-induced cTn elevations are thought to be characterized by intact, cytosolic cTn only. We put much effort in lowering the detection limit of our Western Blot method to characterize the cTn structures released after marathon running. Unfortunately, until now, we reached a detection limit for cTnT in serum around $0.2 \mu \mathrm{g} / \mathrm{L}$. Also the identification of cTn fragments using mass spectrometry remains limited due to the complexity of blood. ${ }^{76}$ Current mass spectrometric methods that measure low-abundant proteins in blood use sophisticated nano-flow instrumentation and only focus on small parts of the protein (1-4 tryptic peptides). ${ }^{77,78}$ Finally, apart from these technical challenges, other modifications of interest might be the phosphorylation status of $\mathrm{cTnl}^{68}$ $\mathrm{cTnT}^{79}$ and other sarcomeric phosphoproteins ${ }^{80}$ in relation to calcium sensitivity and thereby cardiac contraction in general. 


\section{References}

1. Dolci A, Panteghini M. The exciting story of cardiac biomarkers: from retrospective detection to gold diagnostic standard for acute myocardial infarction and more. Clin Chim Acta. 2006;369:179187.

2. Thygesen K, Alpert JS, White HD. Universal definition of myocardial infarction. J Am Coll Cardiol. 2007;50:2173-2195.

3. Morrow DA, Cannon CP, Jesse RL, et al. National Academy of Clinical Biochemistry laboratory medicine practice guidelines: clinical characteristics and utilization of biochemical markers in acute coronary syndromes. Circulation. 2007;115:356-375.

4. Hochholzer W, Morrow DA, Giugliano RP. Novel biomarkers in cardiovascular disease: update 2010. Am Heart J. 2010;160:583-594.

5. Latini R, Masson S, Anand IS, et al. Prognostic value of very low plasma concentrations of troponin T in patients with stable chronic heart failure. Circulation. 2007;116:1242-1249.

6. Giannitsis E, Kurz K, Hallermayer K, Jarausch J, Jaffe AS, Katus HA. Analytical validation of a highsensitivity cardiac troponin T assay. Clin Chem. 2010;56:254-261.

7. Koerbin G, Tate JR, Hickman PE. Analytical characteristics of the Roche highly sensitive troponin $T$ assay and its application to a cardio-healthy population. Ann Clin Biochem. 2010:1-5.

8. Kavsak PA, MacRae AR, Yerna MJ, Jaffe AS. Analytic and clinical utility of a next-generation, highly sensitive cardiac troponin I assay for early detection of myocardial injury. Clin Chem. 2009;55:573-577.

9. Wu AHB, Fukushima N, Puskas R, Todd J, Goix P. Development and preliminary clinical validation of a high sensitivity assay for cardiac troponin using a capillary flow (single molecule) fluorescence detector. Clin Chem. 2006;52:2157-2159.

10. Apple FS. A new season for cardiac troponin assays: it's time to keep a scorecard. Clin Chem. 2009;55:1303-1306.

11. Apple FS, Simpson PA, Murakami MM. Defining the serum 99th percentile in a normal reference population measured by a high-sensitivity cardiac troponin I assay. Clin Biochem. 2010;43:10341036.

12. Wilson SR, Sabatine MS, Braunwald E, Sloan S, Murphy SA, Morrow DA. Detection of myocardial injury in patients with unstable angina using a novel nanoparticle cardiac troponin I assay: observations from the PROTECT-TIMI 30 Trial. Am Heart J. 2009;158:386-391.

13. Reichlin T, Hochholzer W, Bassetti S, et al. Early diagnosis of myocardial infarction with sensitive cardiac troponin assays. N Engl J Med. 2009;361:858-867.

14. Apple FS. High-sensitivity cardiac troponin for screening large populations of healthy people: is there risk? Clin Chem. 2011;54:537-539.

15. Bergmann O, Bhardwaj RD, Bernard S, et al. Evidence for cardiomyocyte renewal in humans. Science. 2009;324:98-102.

16. Kajstura J, Urbanek K, Perl S, et al. Cardiomyogenesis in the adult human heart. Circ Res. 2010;107:305-315.

17. de Lemos JA, Drazner MH, Omland T, et al. Association of troponin T detected with a highly sensitive assay and cardiac structure and mortality risk in the general population. JAMA. 2010;304:2503-2512.

18. deFilippi CR, de Lemos JA, Christenson RH, et al. Association of serial measures of cardiac troponin T using a sensitive assay with incident heart failure and cardiovascular mortality in older adults. JAMA.304:2494-2502.

19. Tate JR, Ferguson W, Bais R, Kostner K, Marwick T, Carter A. The determination of the 99th centile level for troponin assays in an Australian reference population. Ann Clin Biochem. 2008;45:275-288.

20. Saenger AK, Beyrau R, Braun S, et al. Multicenter analytical evaluation of a high-sensitivity troponin T assay. Clin Chim Acta. 2011;412:748-754. 
21. Reiter $M$, Twerenbold $R$, Reichlin $T$, et al. Early diagnosis of acute myocardial infarction in the elderly using more sensitive cardiac troponin assays. Eur Heart J. 2011;32:1379-1388.

22. Keller T, Zeller T, Peetz D, et al. Sensitive troponin I assay in early diagnosis of acute myocardial infarction. N Engl J Med. 2009;361:868-877.

23. Giannitsis E, Becker M, Kurz K, Hess G, Zdunek D, Katus HA. High-sensitivity cardiac troponin T for early prediction of evolving non-ST-segment elevation myocardial infarction in patients with suspected acute coronary syndrome and negative troponin results on admission. Clin Chem. 2010;56:642-650.

24. Wu AH, Lu QA, Todd J, Moecks J, Wians F. Short- and long-term biological variation in cardiac troponin I measured with a high-sensitivity assay: implications for clinical practice. Clin Chem. 2009;55:52-58.

25. Vasile VC, Saenger AK, Kroning JM, Jaffe AS. Biological and analytical variability of a novel highsensitivity cardiac troponin T assay. Clin Chem. 2010;56:1086-1090.

26. Hessel MH, Atsma DE, van der Valk EJ, Bax WH, Schalij MJ, van der Laarse A. Release of cardiac troponin I from viable cardiomyocytes is mediated by integrin stimulation. Pflugers Arch. 2008;455:979-986.

27. Hickman PE, Potter JM, Aroney C, et al. Cardiac troponin may be released by ischemia alone, without necrosis. Clin Chim Acta. 2010;411:318-323.

28. Michielsen EC, Wodzig WK, Van Dieijen-Visser MP. Cardiac troponin T release after prolonged strenuous exercise - a review. Sports Med. 2008;38:425-435.

29. Neilan TG, Januzzi JL, Lee-Lewandrowski E, et al. Myocardial injury and ventricular dysfunction related to training levels among nonelite participants in the Boston marathon. Circulation. 2006;114:2325-2333.

30. Neilan TG, Yoerger DM, Douglas PS, et al. Persistent and reversible cardiac dysfunction among amateur marathon runners. Eur Heart J. 2006;27:1079-1084.

31. Jassal DS, Moffat D, Krahn J, et al. Cardiac injury markers in non-elite marathon runners. Int J Sports Med. 2009;30:75-79.

32. Scharhag J, Shave R, George K, Whyte G, Kindermann W. "Exercise-induced increases in cardiac troponins in endurance athletes: a matter of exercise duration and intensity?". Clin Res Cardiol. 2008;97:62-63; author reply 61.

33. Fortescue EB, Shin AY, Greenes DS, et al. Cardiac troponin increases among runners in the Boston Marathon. Ann Emerg Med. 2007;49:137-143, 143 e131.

34. Chen Y, Serfass RC, Mackey-Bojack SM, Kelly KL, Titus JL, Apple FS. Cardiac troponin T alterations in myocardium and serum of rats after stressful, prolonged intense exercise. J Appl Physiol. 2000;88:1749-1755.

35. Scharf M, Brem MH, Wilhelm M, Schoepf UJ, Uder M, Lell MM. Atrial and ventricular functional and structural adaptations of the heart in elite triathletes assessed with cardiac MR imaging. Radiology. 2010;257:71-79.

36. Pluim BM, Zwinderman AH, van der Laarse A, van der Wall EE. The athlete's heart. A metaanalysis of cardiac structure and function. Circulation. 2000;101:336-344.

37. Anversa P, Levicky V, Beghi C, McDonald SL, Kikkawa Y. Morphometry of exercise-induced right ventricular hypertrophy in the rat. Circ Res. 1983;52:57-64.

38. Benito B, Gay-Jordi G, Serrano-Mollar A, et al. Cardiac arrhythmogenic remodeling in a rat model of long-term intensive exercise training. Circulation. 2011;123:13-22.

39. Diris JH, Hackeng CM, Kooman JP, Pinto YM, Hermens WT, Van Dieijen-Visser MP. Impaired renal clearance explains elevated troponin $\mathrm{T}$ fragments in hemodialysis pPatients. Circulation. 2004;109:23-25.

40. Lamb EJ, Kenny C, Abbas NA, et al. Cardiac Troponin I Concentration Is Commonly Increased in Nondialysis Patients With CKD: Experience With a Sensitive Assay. Am J Kidney Dis. 2007;49:507516.

41. D'Agostino RB, Sr., Vasan RS, Pencina MJ, et al. General cardiovascular risk profile for use in primary care: the Framingham Heart Study. Circulation. 2008;117:743-753. 
42. Pencina MJ, D'Agostino RB, Sr., D'Agostino RB, Jr., Vasan RS. Evaluating the added predictive ability of a new marker: from area under the ROC curve to reclassification and beyond. Stat Med. 2008;27:157-172; discussion 207-112.

43. Korosoglou G, Lehrke S, Mueller D, et al. Determinants of troponin release in patients with stable coronary artery disease: insights from CT angiography characteristics of atherosclerotic plaque. Heart. 2011;97:823-831.

44. Saunders JT, Nambi V, de Lemos JA, et al. Cardiac troponin T measured by a highly sensitive assay predicts coronary heart disease, heart failure, and mortality in the atherosclerosis risk in communities study. Circulation. 2011;123:1367-1376.

45. Omland T, de Lemos JA, Sabatine MS, et al. A sensitive cardiac troponin T assay in stable coronary artery disease. N Engl J Med. 2009;361:2538-2547.

46. Wang TJ, Gona P, Larson MG, et al. Multiple biomarkers for the prediction of first major cardiovascular events and death. N Engl J Med. 2006;355:2631-2639.

47. International Federation of Clinical Chemistry and Laboratory Medicine (IFCC) Committee on the Standardization of Markers of Cardiac Damage (C-SMCD). Troponin assay analytical characteristics 2009, September 12th. Available at:

http://www.ifcc.org/pdf/scientificactivities/committees/c-smcd/ctn_assay_table_v091209.pdf. Accessed June, 11th, 2011.

48. Panteghini M, Pagani F, Yeo KT, et al. Evaluation of imprecision for cardiac troponin assays at low-range concentrations. Clin Chem. 2004;50:327-332.

49. Panteghini M. Assay-related issues in the measurement of cardiac troponins. Clin Chim Acta. 2009;402:88-93.

50. Panteghini M, Bunk DM, Christenson RH, et al. Standardization of troponin I measurements: an update. Clin Chem Lab Med. 2008;46:1501-1506.

51. Christenson RH, Duh SH, Apple FS, et al. Standardization of cardiac troponin I assays: round Robin of ten candidate reference materials. Clin Chem. 2001;47:431-437.

52. Bunk DM, Welch MJ. Characterization of a new certified reference material for human cardiac troponin I. Clin Chem. 2006;52:212-219.

53. Christenson RH, Duh SH, Apple FS, et al. Toward standardization of cardiac troponin I measurements part II: assessing commutability of candidate reference materials and harmonization of cardiac troponin I assays. Clin Chem. 2006;52:1685-1692.

54. Noble JE, Bunk DM, Christenson RH, et al. Development of a candidate secondary reference procedure (immunoassay based measurement procedure of higher metrological order) for cardiac troponin I: I. Antibody characterization and preliminary validation. Clin Chem Lab Med. 2010;48:1603-1610.

55. Cobbaert CM, Weykamp CW, Michielsen EC, Baadenhuijsen H, van Dieijen-Visser MP. Timedependent instability of cardiac troponins in human plasma spiked with NIST reference material 2921. Clin Chem. 2008;54:2078-2079.

56. Hermsen D, Apple F, Garcia-Beltran L, et al. Results from a multicenter evaluation of the 4th generation Elecsys Troponin T assay. Clin Lab. 2007;53:1-9.

57. Michielsen EC, Diris JH, Kleijnen VW, Wodzig WK, Van Dieijen-Visser MP. Investigation of release and degradation of cardiac troponin T in patients with acute myocardial infarction. Clin Biochem. 2007; 40:851-855.

58. Labugger R, Organ L, Collier C, Atar D, Van Eyk JE. Extensive troponin I and T modification detected in serum from patients with acute myocardial infarction. Circulation. 2000;102:12211226.

59. McDonough JL, Arrell DK, Van Eyk JE. Troponin I degradation and covalent complex formation accompanies myocardial ischemia/reperfusion injury. Circ Res. 1999;84:9-20.

60. Madsen LH, Christensen G, Lund T, et al. Time course of degradation of cardiac troponin I in patients with acute ST-elevation myocardial infarction. The ASSENT-2 troponin substudy. Circ Res. 2006;99:1141-1147. 
61. Katrukha AG, Bereznikova AV, Filatov VL, et al. Degradation of cardiac troponin I: implication for reliable immunodetection. Clin Chem. 1998;44:2433-2440.

62. Bates KJ, Hall EM, Fahie-Wilson MN, et al. Circulating immunoreactive cardiac troponin forms determined by gel filtration chromatography after acute myocardial infarction. Clin Chem. 2010;56:952-958.

63. Fahie-Wilson MN, Carmichael DJ, Delaney MP, Stevens PE, Hall EM, Lamb EJ. Cardiac troponin T circulates in the free, intact form in patients with kidney failure. Clin Chem. 2006;52:414-420.

64. Wu AH, Feng YJ, Moore R, et al. Characterization of cardiac troponin subunit release into serum after acute myocardial infarction and comparison of assays for troponin $\mathrm{T}$ and I. American Association for Clinical Chemistry subcommittee on cTnl standardization. Clin Chem. 1998;44:1198-1208.

65. Michielsen EC, Diris JH, Kleijnen VWVC, Wodzig WK, Van Dieijen-Visser MP. Interpretation of cardiac troponin $\mathrm{T}$ behaviour in size-exclusion chromatography. Clin Chem Lab Med. 2006;44:1422-1427.

66. Michielsen EC, Diris JH, Kleijnen VWVC, Wodzig WK, van Dieijen-Visser MP. Size-exclusion chromatography of circulating cardiac troponin T. Clin Chem. 2006;52:2306-2307.

67. Katrukha AG, Bereznikova AV, Esakova TV, et al. Troponin I is released in bloodstream of patients with acute myocardial infarction not in free form but as complex. Clin Chem. 1997;43:1379-1385.

68. Kooij V, Saes M, Jaquet K, et al. Effect of troponin I Ser23/24 phosphorylation on Ca2+-sensitivity in human myocardium depends on the phosphorylation background. J Mol Cell Cardiol. 2010;48:954-963.

69. Narolska NA, Piroddi N, Belus A, et al. Impaired diastolic function after exchange of endogenous troponin I with C-terminal truncated troponin I in human cardiac muscle. Circ Res. 2006;99:10121020.

70. Hessel MH, Michielsen EC, Atsma DE, et al. Release kinetics of intact and degraded troponin I and T after irreversible cell damage. Exp Mol Pathol. 2008;85:90-95.

71. Kung G, Konstantinidis K, Kitsis RN. Programmed necrosis, not apoptosis, in the heart. Circ Res. 2011;108:1017-1036.

72. Laufer EM, Reutelingsperger CP, Narula J, Hofstra L. Annexin A5: an imaging biomarker of cardiovascular risk. Basic Res Cardiol. 2008;103:95-104.

73. Vandenabeele $P$, Galluzzi L, Vanden Berghe $T$, Kroemer G. Molecular mechanisms of necroptosis: an ordered cellular explosion. Nat Rev Mol Cell Biol. 2010;11:700-714.

74. Dumont EA, Reutelingsperger CP, Smits JF, et al. Real-time imaging of apoptotic cell-membrane changes at the single-cell level in the beating murine heart. Nat Med. 2001;7:1352-1355.

75. Piper HM, Hutter JF, Spieckermann PG. Relation between enzyme release and metabolic changes in reversible anoxic injury of myocardial cells. Life Sci. 1984;35:127-134.

76. Service RF. Proteomics. Proteomics ponders prime time. Science. 2008;321:1758-1761.

77. Keshishian $\mathrm{H}$, Addona $\mathrm{T}$, Burgess $\mathrm{M}$, et al. Quantification of cardiovascular biomarkers in patient plasma by targeted mass spectrometry and stable isotope dilution. Mol Cell Proteomics. 2009;8:2339-2349.

78. Addona TA, Abbatiello SE, Schilling B, et al. Multi-site assessment of the precision and reproducibility of multiple reaction monitoring-based measurements of proteins in plasma. Nat Biotechnol. 2009;27:633-641.

79. Dubois E, Richard V, Mulder P, et al. Decreased serine207 phosphorylation of troponin T as a biomarker for left ventricular remodelling after myocardial infarction. Eur Heart J. 2011;32:115123.

80. Cuello F, Bardswell SC, Haworth RS, et al. Novel role for p90 ribosomal S6 kinase in the regulation of cardiac myofilament phosphorylation. J Biol Chem. 2011;286:5300-5310. 



\section{Samenvatting}

Hart- en vaatziekten zijn de belangrijkste oorzaak van overlijden wereldwijd. Het grootste aandeel wordt veroorzaakt door ischemische ziekten, zoals een acuut myocard infarct (AMI). Eigenschappen van de ideale biomerker om AMI te diagnostiseren zijn specificiteit voor hartschade, een vroege detectie na het ontstaan van de eerste symptomen en een lange halfwaarde tijd. Op dit moment voldoen de cardiale troponines (cTn), cardiale troponine T (cTnT) of I (cTnl), het meest aan deze criteria. De troponines zijn eiwitten die een regulerende functie hebben in het contractiemechanisme van het hart. Volgens de meest recente internationale richtlijnen kan de diagnose $\mathrm{AMI}$ gesteld worden wanneer sprake is van een stijging of daling van cTn concentratie met tenminste één waarde boven de $99^{\text {ste }}$ percentiel van een referentie/controle groep, samen met andere klinische bevindingen en beeldvorming.

De huidige cTn immunoassays zijn echter niet (of met onvoldoende precisie) in staat om cTn concentraties te detecteren in de bloedcirculatie van gezonde personen en de $99^{\text {ste }}$ percentiel concentratie als afkapwaarde kan daarom niet behoorlijk bepaald worden. Bovendien zijn er sterke verschillen in cTnl resultaten tussen verschillende laboratoria en klinische studies. Er zijn namelijk meer dan $20 \mathrm{cTnl}$ assays commercieel verkrijgbaar die tot wel 20 maal kunnen variëren in uitslagen, dit in tegenstelling tot de cTnT assay waar nog altijd patent op zit. Tenslotte zijn er tegenstrijdige resultaten beschreven betreffende de structuur van cTn in de bloedcirculatie. In dit proefschrift trachten we de analytische beperkingen van de huidige cTn metingen te overwinnen.

\section{- Meetbare troponine concentraties bij gezonde personen}

Zeer recentelijk zijn er verbeteringen bereikt in het lage meetbereik van de cTn assays. Dit heeft geleid tot de zogenaamde hoog-sensitieve (hs) cTn immunoassays zoals bediscussieerd in hoofdstuk 2. Wij hebben als eerste gepubliceerd over toepassing van de hs-cTnT assay in gezonde personen. In hoofdstuk 3 hebben we laten zien dat cTnT concentraties in de bloedcirculatie van deze gezonde referentiepopulatie een typisch gaussische verdeling heeft met een $99^{\text {e }}$ percentiel afkapwaarde van $16 \mathrm{ng} / \mathrm{L}$. We ontdekten een verschil in concentratie tussen mannen en vrouwen, terwijl een relatie met leeftijd minder duidelijk was. Waarom cTn bij gezonde personen in bloed kan worden aangetoond is nog onduidelijk. Voorheen 
werd verondersteld dat myocyten vanaf geboorte bestaan en dat veroudering en ziekten leiden tot verlies van myocyten. Recent onderzoek heeft echter aangetoond dat aanmaak van nieuwe myocyten wel mogelijk is.

Desalniettemin, de hs-cTnT assay was de enige commercieel verkrijgbare cTn assay die de diagnostische afkapwaarde kon meten met de aanbevolen precisie (variatie coefficient $<10 \%)$, zoals besproken in hoofdstuk 2 en 3 . Het blijft vooralsnog onduidelijk of deze richtlijn in precisie noodzakelijk is voor diagnostische doeleinden. Voor prognostische doeleinden zou het echter veel belangrijker kunnen zijn om het hele referentiegebied te meten met optimale precisie en om geslachts- en leeftijdsafhankelijke afkapwaarden toe te passen.

\section{- Nieuwe inzichten in het lage meetbereik van troponine}

Met de huidige cTn assays werden af en toe cTn concentraties gemeten bij personen zonder duidelijke klinische aanwijzingen voor een AMI. Dit zou mogelijk kunnen duiden op het feit dat cTn kan vrijkomen uit beschadigde myocyten zonder dat necrose van de hartspiercel is opgetreden. Doordat wij als een van de eersten beschikten over de hs-cTnT assay waren wij in de gelegenheid om verschillende populaties met een cardiaal risico te bestuderen, met cTnT concentraties in het lage meetbereik.

Inspannings-geinduceerde verhoging van cTn concentraties zijn nu en dan gemeten na langdurige inspanning maar in de afwezigheid van klinische symptomen. Zoals bediscussieerd in hoofdstuk 4 was dit ook afhankelijk van het type inspanning, de gebruikte assay, en de daarbij gekozen afkapwaarde. In hoofdstuk 3 en 4 laten we zien dat cTnT concentraties na het lopen van een marathon waren gestegen in nagenoeg alle lopers (86\%) en één dag na de loop weer zakten. Deze inspannings-geinduceerde verhoging van cTn konden we niet verklaren door uitdroging (hoofdstuk 3 versus 4) of door een verminderde renale klaring (hoofdstuk 5). We vonden een positieve associatie met de gelopen afstand (hoofdstuk 4) en een negatieve associatie met training (hoofdstuk 3). Dit alles suggereert dat cTn verhoging door inspanning symptomatisch is voor cardiale schade en dat met voldoende training het hart hiertegen wordt beschermd.

Daarnaast blijft het onduidelijk waarom patiënten met terminale nierinsufficiëntie een chronisch verhoogde cTn concentratie vertonen, of dit komt door cardiale ziekte of door verminderde of zelfs afwezige renale klaring. Hoofdstuk 6 beschrijft dat cTnT concentraties waren verhoogd tot boven de $99^{\text {ste }}$ percentiel afkapwaarde in nagenoeg al deze patiënten 
(94\%). Opvallend was dat de patiënten met een historie van cardiovasculaire ziekte significant hogere CTnT concentraties vertoonden met een hogere intra-individuele variabiliteit in vergelijking tot de patiënten zonder deze historie. Dit doet vermoeden dat de chronische cTn verhoging wordt veroorzaakt door een combinatie van zowel coronair als renaal lijden.

De identificatie van patiënten met coronair lijden blijft een grote uitdaging. Traditionele risicofactoren, predicitiemodellen, en biomerkers worden tot nu toe beperkt toegepast. In hoofdstuk 7 hebben we patiënten bestudeerd met stabiele klachten van pijn-op-de-borst. We vonden een significante associatie tussen cTnT concentraties in de circulatie en de mate van atherosclerose in de coronaire arteriën zoals gedetecteerd met computed tomografie. Een dergelijke associatie vonden we niet voor de biomerkers NT-proBNP en hsCRP. Onderzoek naar de overlevingsduur in hoofdstuk 8 bevestigde inderdaad dat cTnT was geassocieerd met het krijgen van een cardiaal event (revascularisatie, acuut coronair syndroom, of cardiaal overlijden). We vonden meer dan drie maal zoveel cardiale events in patiënten met een hs-cTnT concentratie in het vierde kwartiel (>6.7 ng/L), ook wanneer gecorrigeerd voor tradiotionele riscicofactoren. In mindere mate vonden we zelfs een verbeterde classificatie bovenop de detectie van coronaire plaque met computed tomografie.

Alles te samen ondersteunen de resultaten in dit proefschrift de hypothese dat elke meetbare cTn concentratie moet worden geassocieerd met cardiaal lijden, dat te allen tijde vermeden dient te worden.

\section{- Harmonisatie en standaardisatie van troponine assays}

Harmonisatie- en standaardisatiepogingen van de verschillende cTnl assays laten nog zeer te wensen over, ook met gebruik van het gezuiverde en goed gekarakteriseerde standaard referentiemateriaal NIST SRM 2921. In hoofdstuk 9 laten we haar instabiliteit zien na standaard additie in serum en heparineplasma, wat beperkingen geeft in de harmonisatie van $\mathrm{cTnl}$ assays. Op dit moment lijkt cTn-positief patiëntenmateriaal de voorkeur te hebben als harmonisator, ondanks dat dit moeilijk te verkrijgen is en minder goed is gespecificeerd en gekarakteriseerd. 


\section{- Volledig gedegradeerde troponine $\mathrm{T}$ in de bloedcirculatie}

Tegenstrijdige resultaten zijn beschreven over de structuur van cTn in de bloedcirculatie. Wij laten in hoofdstuk 10 duidelijk zien dat CTnT na een AMI volledig is gedegradeerd in serum. Daarnaast bevestigen we dat cTnl met name voorkomt in het cTn I-C complex en slechts gedeeltelijk is gedegradeerd. Klinische consequenties zijn afhankelijk van een validatie studie in een grotere AMI populatie en of er eventueel ziekte afhankelijke fragmenten of fragmentpatronen geidentificeerd kunnen worden.

\section{- Richtingen voor toekomstig onderzoek}

Het is van groot klinisch belang om fout-positieve toekenning van patiënten met cardiaal lijden te minimaliseren. Toekomstig onderzoek moet zich daarom richten op het nog beter onderscheid kunnen maken tussen een gezonde myocyte en een myocyte met de eerste tekenen van cardiovasculair lijden. Dit kan bereikt worden door bijvoorbeeld het moleculaire mechanisme, wanneer en in welke vorm cTn vrijkomt uit beschadigde myocyten, verder uit te diepen of door een nog betere of complementaire cardiale biomerker te ontdekken. 


\section{Summary}

Cardiac and/or vascular disease is the leading cause of death worldwide. The highest incidence accounts for ischemic diseases, like an acute myocardial infarction (AMI). Specifications of a perfect biomarker to diagnose AMI are heart specificity, early detection after first symptoms, and a long half-life. The current preferred biomarkers are cardiac troponins (cTn), either cardiac troponin $\mathrm{T}(\mathrm{cTnT})$ or I (cTnl), being regulatory proteins of the cardiac contractile apparatus. As recently redefined by the international guidelines, $\mathrm{AMI}$ is diagnosed with the detection of a rise and/or fall of cTn with at least one value exceeding the $99^{\text {th }}$ percentile of a reference control group, together with clinical and imaging findings.

Up to now, however, the contemporary cTn immunoassays were unable to detect cTn concentrations in the blood circulation of healthy individuals (or with insufficient precision) and the $99^{\text {th }}$ percentile cutoff concentration could thus not be properly determined. In addition, comparison of cTnl results among different laboratories and clinical studies remained limited since more than $20 \mathrm{cTnl}$ assays are commercially available, in contrast to the highly patented cTnT assay, that deviate up to 20-fold in assay result. Finally, conflicting results have been reported on the structural aspects of cTn in the blood circulation. In this thesis, we attempt to overcome these analytical limitations in the cTn measurements.

\section{- Measurable troponin concentrations in healthy individuals}

Improvements in the lower cTn measuring range have lately been achieved, resulting in the so called high-sensitivity (hs) cTn immunoassays as reviewed in chapter 2. By using the hscTnT assay, as described in chapter 3, we were the first who showed that CTnT concentrations in the blood circulation of a healthy reference population follow a typical gaussian distribution and we reported the $99^{\text {th }}$ percentile cutoff at $16 \mathrm{ng} / \mathrm{L}$. We found a significant difference between sexes, while an age effect was not that obvious. The reason for the presence of cTn concentrations in healthy individuals remains unclear. It was previously considered that the number of myocytes is established at birth and is lost with age or disease, though recent research has shown the existence of (slow) renewal of myocytes. Nevertheless, the hs-cTnT assay was the only commercially available cTn assay that measured the diagnostic cutoff concentration with sufficient precision according to the guidelines, as can be concluded from chapter 2 and 3. It remains to be elucidated, however, 
whether the predicate "guideline acceptance" is required for diagnostic purposes. For prognostic and screening purposes, it might become more important to measure with optimal precision across the complete reference range and to apply sex- and age-specific cutoff concentrations.

\section{- New insights in the lower troponin measuring range}

With the contemporary assays, measurable cTn concentrations have occasionally been noticed without the clear evidence of AMI. This raises the possibility that cTn can be released from damaged myocytes but without typical myocardial necrosis. The availability of the hs-cTnT assay enabled us to investigate several populations at (low) coronary risk in more detail.

Exercise-induced cTn concentrations have occasionally been noticed after prolonged strenuous exercise but in the absence of clinical symptoms. This turned out to be dependent on the type of exercise, the assay, or the cutoff used. As described in chapter 3 and 4, after marathon running, post-run cTnT concentrations elevated to above the $99^{\text {th }}$ percentile cutoff in almost all runners (86\%) and returned to baseline one day after the run. The exerciseinduced cTnT concentrations could neither be clarified by a diminished renal function (chapter 5), nor by dehydration (chapter 3 versus 4). We furthermore found a positive association to running distance (chapter 4) and a negative association to experience (chapter 3). Overall, this indicates that exercise-induced cTnT elevations are symptomatic for minor myocardial injury and that sufficient training protects the heart from real cardiac damage.

In addition, it remains unclear whether chronic cTn elevations in patients with End-Stage Renal Disease are caused by cardiac disease or by the decrease or absence of renal clearance. Chapter 6 describes that CTnT concentrations were above the $99^{\text {th }}$ percentile cutoff in almost all patients (94\%). Interestingly, in the patients with a history of cardiovascular disease, significantly higher cTnT concentrations were found with higher intra-individual variability compared to patients without this history. This might suggest that the chronic cTn elevations are caused by a combination of coronary and renal disease.

The identification of patients at coronary risk remains an ongoing challenge. Traditional risk factors, prediction models, and biomarkers turned out to be of limited use so far. In chapter 7 , we investigated patients with stable chest-pain. We found a significant association between circulating cTnT concentrations and the extent of coronary atherosclerotic plaque 
as assessed with coronary computed tomography. Such an association we did not find for NT-proBNP and hsCRP. Survival analysis in chapter 8 indeed confirmed that CTnT was associated with the occurrence of a cardiac event (revascularization, acute coronary syndrome, or cardiac death). We found more than three as much cardiac events in patients with hs-cTnT concentrations in the fourth quartile $(>6.7 \mathrm{ng} / \mathrm{L})$, also when hs-cTnT was corrected for traditional risk factors. To a lesser extent, improved risk classification was even obtained on top of coronary plaque assessment.

Overall, the results shown in this thesis support the hypothesis that any measurable cTn concentration is associated with cardiac injury that should be avoided at any time.

\section{- Harmonization and standardization of troponin assays}

Harmonization and standardization efforts for cTnl assays have been of limited success when using the purified and highly characterized standard reference material NIST SRM 2921. In chapter 9, we showed its instability when spiked in serum and heparin plasma, and its limited ability in harmonization of cTnl results. For now, cTn-positive patient material seems preferable, despite the fact that it is difficult to obtain and less specified and characterized.

\section{- Fully degraded troponin $\mathrm{T}$ in the blood circulation}

Conflicting results have been reported on the structural aspects of cTnT in the blood circulation. We evidently show in chapter 10 that cTnT after AMI is completely degraded in serum. Furthermore, we confirm that cTnl is predominantly present in the cTn I-C complex and only partly degraded. Clinical consequences are dependent on the validation in a larger AMI population and whether disease specific modification or modification-patterns exist.

\section{- Directions for future research}

It is of great clinical relevance to minimize false-positively assigned subjects at coronary risk. Future in-depth research should therefore focus on improving the distinction between a healthy myocyte and preliminary signs of cardiovascular disease. This could possibly be achieved by unraveling the molecular mechanism when and in what form cTn is released from myocytes, or by identifying an even better or complementary cardiac biomarker. 



\section{Dankwoord / Acknowledgment}

Hier en nu is het moment gekomen om terug te blikken op een speciale periode uit mijn leven waarin ik mij heb kunnen ontplooien tot zelfstandig onderzoeker. Met veel enthousiasme heb ik gewerkt aan het onderzoek dat in dit proefschrift beschreven staat (en aan datgene dat in het labjournaal is blijven steken). Ja, ik kijk er met heel veel genoegen op terug, wat vooral te wijten is aan de combinatie van de toegepaste wetenschap die klinische chemie is en de mensen die mij daarbij gesteund hebben.

Geachte professor Van Dieijen, allerbeste Marja, jij bent een bijzonder inspirerend persoon op zowel wetenschappelijk, zakelijk als sociaal vlak. Ik ben dan ook zeer verheugd dat ik nog vier jaar voor je mag werken tijdens mijn opleiding tot klinisch chemicus. Dr. Will Wodzig, beste Will, jij ook hartelijk dank voor je begeleiding tijdens mijn onderzoek en je vaak nuttige tips op het gebied van blotten.

Special thanks to professor dr. Hugo Katus. It is a great honour to me that you, the founder of cardiac troponin $\mathrm{T}$ as cardiac marker, are willing to be part of my assessment committee. Also special thanks to dr. Paul Collinson, another great expert in the field of cardiac biomarkers. Professor dr. Luc van Loon, professor dr. Hans-Peter Brunner-La Rocca en professor dr. Chris Reutelingsperger, ook jullie hartelijk bedankt dat jullie onderdeel zijn van mijn beoordelingscommissie. De combinatie van jullie expertises geeft een goede weerspiegeling van de vragen die in dit proefschrift aan de orde komen, en wellicht dat we in de toekomst de krachten kunnen bundelen om nog beter inzicht te krijgen in de afgifte van troponine.

Tijdens mijn promotieonderzoek heb ik de eer gehad om met verschillende personen te mogen samenwerken. Dit geldt in de eerste plaats voor de afdeling cardiologie van ons ziekenhuis. Professor dr. Leo Hofstra, jouw enorme bevlogenheid en enthousiasme zijn aanstekelijk, en jij bent hèt voorbeeld hoe je dit kunt overbrengen op anderen. Ward, Ivo, en Mathijs, bedankt voor de zeer intensieve samenwerking die heeft geleid tot mooie hoofdstukken. We zijn heel complementair geweest aan elkaar. Bovendien heb ik door jullie mijn praktisch inzicht in de kliniek sterk kunnen verbeteren. Bijzonder dank ook voor de fijne medewerking van alle deelnemers en de organisatie van HAPPY, het health check programma van ons ziekenhuis, van de Maas Marathon, het hardloopevenement Maastrichts Mooiste en van alle participerende patiënten. Professor dr. Joachim Wildberger, 
dr. Bjorn Winkens en dr. Christa Cobbaert, bedankt voor de zeer fijne samenwerking. Bedankt ook dr. Maarten Raaijmakers van het klinisch chemisch lab uit het Atrium Medisch Centrum voor het aanleveren van troponine restreagentia. Ten slotte wil ik ook professor $\mathrm{dr}$. Bert Meijer en ing. Joost van Dongen van de Technische Universiteit Eindhoven bedanken dat ik gebruik heb mogen maken van jullie analytisch lab en expertise. Helaas wilden de troponines niet goed 'vliegen' en had ik maar weinig materiaal tot mijn beschikking. Toch hoop ik dat we ooit nog een samenwerking mogen hebben die wel tot mooie resultaten leidt.

Beste staf van het lab klinische chemie in Maastricht, beste Paul, Otto, Bart, Judith en Douwe, jullie kritische blik tijdens het refereren, de Journal Club, of zelfs tijdens een onschuldig kopje koffie was ontzettend belangrijk voor de voortgang van dit onderzoek. Beste assistenten, beste Steven en Lenneke, ik verheug mij op de komende periode dat ik jullie team mag versterken! Dank ook aan de 'oude' assistenten van ons lab, Jart, Snjezana, en Maurice en veel dank ook aan Etienne, van wie ik het onderzoek heb voortgezet.

De dagelijkse sfeer op het lab was altijd zeer prettig en bovenal ook heel gezellig. Dat kwam in de eerste plaats door jou, Leo. Je bent een kleurrijk persoon, met jou valt altijd iets te beleven en te lachen. Blijf dat vooral zo houden :) Ook veel dank voor de fijne tijd aan de andere onderzoekers, aan Bianca, Eline en Lieke. Ik wens jullie heel veel succes toe met het afronden van jullie eigen promotieonderzoek en jullie verdere loopbaan. Eline, ik hoop dat we samen nog mooi onderzoek voor elkaar krijgen! De afgelopen jaren heb ik ook twee masterstudenten mogen begeleiden. Wim en Tom, ik hoop dat jullie veel hebben opgestoken van de tijd bij ons op het lab en nu nog enthousiaster zijn geworden van het vak klinische chemie.

Heel veel dank verder aan de hoofdanalisten Huub, Serva en Loe en zeker weten ook aan álle andere analisten die het lab klinische chemie (letterlijk van lab A tot Z) rijk is. Jullie behulpzaamheid en de fijne sfeer maken van elke dag een feest. Jullie namen passen helaas niet op deze pagina, jullie zijn ook met zo velen!! Bijzonder dank wel nog aan chemie 3 en 6 , waar heel wat validatie-experimenten zijn uitgevoerd voordat de blotjes in hoofdstuk 9 en 10 verwezenlijkt konden worden. En ook aan Vincent, jij was onmisbaar door het vele labwerk dat je me uit handen hebt genomen. Dit alles was ook onmogelijk geweest zonder de ondersteuning van de gLi, ICT, secretariaat en administratie. Charles, jouw handigheid was vaak onmisbaar. Alaaf voor Jan, Harry, Richard, Lucie, Mariëlle en all-rounder Maurice. 
Mijn leven heeft zich altijd rijk omringd door veel lieve vrienden en een grote familie. Het zou werkelijk een onmogelijke taak zijn om al deze namen hier op te sommen. Soms lijkt het misschien alsof ik jullie een beetje vergeten ben. Maar, já, ik wil graag met jullie blijven dansen, muziek maken, lachen, soms huilen en samen het leven beleven.

Papa en mama, ik ben vereerd met de bijzondere opvoeding die jullie mij gegeven hebben. Veel van jullie idealen hebben mij gevormd tot de persoon die ik vandaag de dag ben. Jo en Riet, ik waardeer het enorm dat jullie mij zo warm hebben opgenomen in jullie familie. Marjanka en Omayra, zonder jullie zusjes zou mijn leven niet compleet zijn en het was dan ook logisch om jullie beiden als mijn paranimfen te vragen. Ruben en David, jullie zijn een geweldige aanvulling op onze familie.

Lieve Tim, jouw brede schouders geven mij letterlijk en figuurlijk de steun die ik nodig heb en ik hoop dat dat voor eeuwig zo mag blijven. 


\section{Curriculum vitae}

Alma Mingels was born on November $14^{\text {th }}, 1981$ in Veldhoven, the Netherlands. She finished her secondary education (atheneum) in 2000 at the S.G. Sophianum in Gulpen. In the same year, she started the study of Biomedical Engineering at the Eindhoven University of Technology. Her graduation research project was performed at the Laboratory of Macromolecular and Organic Chemistry under supervision of prof. dr. Bert (E.W.) Meijer, dr. Maarten Merkx, and ing. Joost van Dongen. She investigated (modified) protein structures using liquid chromatography and mass spectrometry. During her Master, she also did an internship at the University of Delaware, United States of America, in the group of prof. Kristi Kiick. Subsequently, in 2007 she started as a PhD student at the department of Clinical Chemistry of the Maastricht University Medical Center under supervision of prof. dr. Marja van Dieijen-Visser and dr. Will Wodzig. This was in close collaboration with the Cardiovascular Research Institute Maastricht (CARIM) at the Maastricht University, where she completed several additional courses in statistics and cardiovascular diseases. The most important results are described in this thesis and have been presented in part at (inter)national congresses like the IFCC WordLab 2011 in Berlin. Chapter 7 was awarded with an abstract prize in 2010, handed out by the Dutch Society of Clinical Chemistry (NVKC). She will continue her work at the department of Clinical Chemistry in Maastricht, where as of December 2011 she started her residency in Clinical Chemistry. 


\section{List of publications}

Mingels $A^{*}$, Laufer $E^{*}$, Winkens $M$, Joosen I, Schellings M, Leiner T, Wildberger J, Narula J, Van Dieijen-Visser $M$, Hofstra $L$ (*equal contribution). The extent of coronary atherosclerosis is associated with increasing circulating levels of high sensitive cardiac troponin $\mathrm{T}$. Arterioscler Thromb Vasc Biol 2010; 30:1269-1275. IF 7.2

Mingels A, Jacobs L, Michielsen E, Swaanenburg J, Wodzig W, Van Dieijen-Visser M. Reference population and marathon runner sera assessed by highly sensitive cardiac troponin T and commercial cardiac troponin T and I assays. Clin Chem 2009;55:101-108. IF 6.3

Jacobs L*, Van de Kerkhof J*, Mingels A, Kleijnen V, Mazairac A, Van der Sande F, Wodzig W, Konings C, Leunissen K, Van Dieijen-Visser M, Kooman J (*equal contribution). Inflammation, overhydration and cardiac biomarkers in haemodialysis patients: a longitudinal study. Nephrol Dial Transplant 2010;25:243-248. IF 3.3

Mingels A, Jacobs L, Kleijnen V, Laufer E, Winkens B, Hofstra L, Wodzig W, Van Dieijen-Visser $M$. Cardiac troponin T elevations, using highly sensitive assay, in recreational running depend on running distance. Clin Res Cardiol 2010;99:385-391. IF 3.0

Mingels A, Van Dongen J, Merkx M. Mapping preferred sites for fluorescent labeling by combining fluorescence and MS analysis of tryptic CNA35 protein digests. J Chrom B 2008;863:293-297. IF 2.8

Jacobs L, Mingels A, Wodzig W, Van Dieijen-Visser M, Kooman J. Renal dysfunction, hemodialysis, and the NT-proBNP/BNP ratio. Am J Clin Pathol 2010;1343:516-517. IF 2.5

Jacobs L, Van de Kerkhof J, Mingels A, Kleijnen V, Van der Sande F, Wodzig W, Kooman J, Van Dieijen-Visser M. Haemodialysis patients longitudinally assessed by highly sensitive cardiac troponin $\mathrm{T}$ and commercial cardiac troponin $\mathrm{T}$ and cardiac troponin I assays. Ann Clin Biochem 2009;46:283-90. IF 1.8

Mingels A, Jacobs L, Kleijnen V, Wodzig W, Van Dieijen-Visser M. Cystatin C, a marker for renal function after exercise. Int J Sports Med 2009;30:668-671. IF 1.6

Jacobs L, Mingels A, Van Dieijen-Visser M. Cardiac Biomarkers in End-stage Renal Disease. Renal Diseases Book 3. 2011. M. Sahay (Ed.) ISBN 979-953-307-705-4, Intech. Accepted for publication.

Mingels A, Jacobs L, Michielsen E, Swaanenburg J, Wodzig W, Van Dieijen-Visser M. Cardiac and renal markers: reference population versus marathon runners. Ned Tijdschr Klin Chem Labgeneesk 2008;33:188-190.

Jacobs L, Van de Kerkhof J, Mingels A, Kleijnen V, Van der Sande F, Wodzig W, Kooman J, Van Dieijen-Visser M. Cardiac biomarkers in dialysis patients: variations during a six month follow up. Ned Tijdschr Klin Chem Labgeneesk 2008;33:176-178. 
Cardinaels E, Mingels A, Jacobs L, Meex S, Bekers O, Van Dieijen-Visser M. A comprehensive review of upper reference limits reported for (high-)sensitivity cardiac troponin assays: the challenges that lie ahead. Clin Chem Lab Med, under review.

Mingels $A^{*}$, Joosen $I^{*}$, Versteylen $M$, Laufer $E$, Winkens $M$, Wildberger J, Van Dieijen-Visser $M$, Hofstra L (*equal contribution). High-sensitivity cardiac troponin $\mathrm{T}$ : risk stratification tool in patients with stable chest-pain. Submitted.

Mingels A, Cobbaert C, Smit N, Van den Hof W, Van Dieijen-Visser M. Time- and temperature-dependent stability of NIST standard reference material 2921 in serum and plasma. Submitted. 